\title{
THE OVER 50s IN A CHANGING IRELAND Economic Circumstances, Health and Well-Being
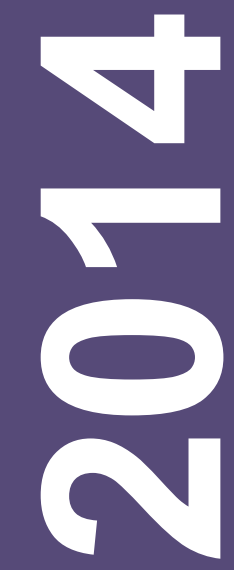
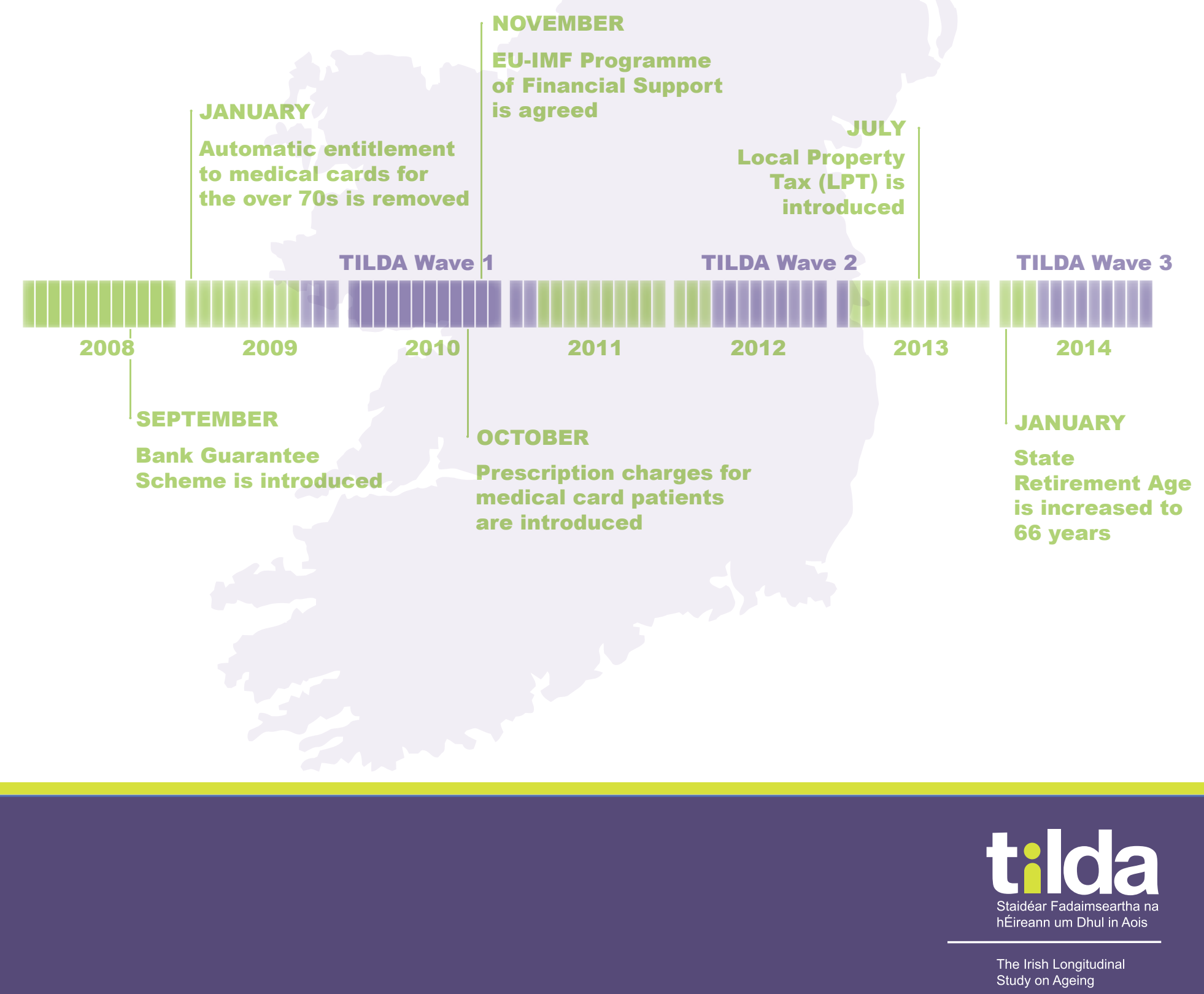
The 


\section{The Over 50s in a Changing Ireland}

\section{Economic Circumstances, Health and Well-Being}

\section{Editors:}

Anne Nolan, Claire O’Regan, Cara Dooley, Doireann Wallace, Ann Hever, Hilary Cronin, Eibhlin Hudson and Rose Anne Kenny

\section{Contributors:}

Orna Donoghue ${ }^{1}$, Cara Dooley ${ }^{1}$, Joanne Feeney ${ }^{1}$, Ciarán Finucane ${ }^{1}$, Eibhlin Hudson ${ }^{1}$, Rose Anne Kenny ${ }^{1}$, Siobhan Leahy ${ }^{1}$, Cathal McCrory ${ }^{1}$, Christine McGarrigle ${ }^{1}$, Sheena McHugh ${ }^{2}$, Patrick Moore ${ }^{1}$, Irene Mosca ${ }^{1}$, Catriona Murphy',

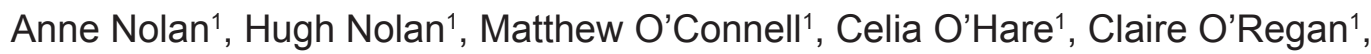
Vincent O'Sullivan ${ }^{1}$ 
Copyright @The Irish Longitudinal Study on Ageing 2014

The Irish Longitudinal Study on Ageing

Chemistry Extension Building

Trinity College Dublin

Dublin 2

Republic of Ireland

Tel: +35318964120

Email: tilda@tcd.ie

Website: www.tilda.ie

ISBN: 978-1-907894-07-7 


\section{Acknowledgements}

The authors would like to thank the funders of TILDA: Irish Life, the Atlantic Philanthropies and the Department of Health, which is providing funding on behalf of the State. The views expressed in this report are not necessarily those of the Department of Health, and responsibility for any errors or omissions rests with the authors alone.

The authors are extremely grateful to the members of the TILDA Scientific Advisory Board, Oversight Board, Steering Committee and Executive Committee, who provide invaluable advice on the design, implementation and strategic objectives of TILDA. Past and current members of these groups are listed on the TILDA website at http://www.tcd.ie/tilda/ organisation/.

A large number of individuals were involved in the preparation of this report. The fieldwork for wave 2 was conducted by Ipsos MORI, who co-ordinated a large team of dedicated interviewers. Particular thanks to TILDA team members Deirdre O'Connor, Jacinta O'Grady and Pauline Walsh for their work in preparing the final report for publication.

Finally, and most importantly, we would like to thank our valued participants, $86 \%$ of whom agreed to participate in wave 2. Without their time and effort neither this report nor the resource for future research offered by TILDA would be possible. 



\section{Contents}

Key Findings

1. Introduction 5

Rose Anne Kenny and Anne Nolan

2. The Economic Well-Being of Over 50s and their Children. 25

Eibhlin Hudson, Irene Mosca and Vincent O'Sullivan

3. Changes in Physical and Behavioural Health in Older Irish Adults

Ciarán Finucane, Joanne Feeney, Hugh Nolan, Claire O'Regan

4. Obesity and Health Outcomes in Older Irish Adults. 85

Siobhan Leahy, Orna Donoghue, Matthew O'Connell, Celia O'Hare and Hugh Nolan

5. Health and Social Care Utilisation

Catriona Murphy, Patrick Moore, Sheena McHugh, Hugh Nolan

6. What Factors are Associated with Change in Older People's

Quality of Life?

Cathal McCrory, Siobhan Leahy and Christine McGarrigle

7. Methodology

Cara Dooley 


\section{List of Tables}

\section{Introduction}

\section{Table 1.1:}

Wave 2 interview types.

\section{The Economic Well-Being of Over 50s and their Children}

\section{Table 2.1:}

Proportion holding different types of assets and debt

Table 2.2:

Median value of assets for those holding the assets (in $€ k$ ).

Table 2.3:

Proportion of total wealth held in each type of asset

Table 2.4:

Median value of weekly gross ncome by source (in €)

Table 2.5:

Proportion in receipt of different sources of income....

Table 2.6:

Proportion of total weekly gross income from different sources

Table 2.7:

Labour market status at wave 2 by age and sex. 42

Table 2.8:

Changes in labour market status between wave 1 and wave 2

Table 2.9:

Main reason for retirement.

\section{Changes in Physical and Behavioural Health in Older Irish Adults}

Table 3.1:

Changes in falls prevalence between wave 1 and wave 2

Table 3.2:

Changes in smoking behaviour between wave 1 and wave 2 
Table 3.3:

Changes in problematic alcohol use between wave 1 and wave 2 .

65

Table 3.4:

Changes in physical activity levels between wave 1 and wave 2 ....... 66

\section{Appendix 3A: Tables on Changes in Physical and Behavioural Health in Older Irish Adults}

Table 3.A1a:

Prevalence of cardiovascular conditions at wave 2 by age 69

Table 3.A1b:

Two-year incidence of cardiovascular conditions by age 70

Table 3.A2:

Prevalence of cardiovascular conditions by sex, and two-year incidence of cardiovascular conditions by sex

Table 3.A3a:

Prevalence of chronic conditions (non-cardiovascular) at wave 2 by age 72

Table 3.A3b:

Two-year incidence of chronic conditions (non-cardiovascular) 73

Table 3.A4a:

Prevalence of falls, recurrent falls, and injurious falls by age and sex at wave 2 74

Table 3.A4b:

Prevalence of falls, recurrent falls, and injurious falls by age and sex at wave 1 75

Table 3.A5:

Prevalence of negative health behaviours by age. 76

Table 3.A6:

Prevalence of negative health behaviours by sex..... 77

Table 3.A7a:

Changes in problematic alcohol use between wave 1 and wave 2 by age 78

Table 3.A7b:

Changes in problematic alcohol use between wave 1 and wave 2 by sex. 79

Table 3.A8:

Changes in physical activity between waves by age 80

Table 3.A9:

Changes in physical activity between waves by sex 81 


\section{Obesity and Health Outcomes in Older Irish Adults}

Table 4.1:

World Health Organisation body mass index classifications

Table 4.2:

WHO waist circumference classifications.

Table 4.3:

Changes in ADL and IADL disability between wave 1 and wave 2

Table 4.4a:

Depression at wave 2 by wave 1 waist circumference classification

Table 4.4b:

Depression at wave 2 by wave 1 body mass index classification

Table 4.5a:

Anxiety at wave 2 by wave 1 waist circumference classification

Table 4.5b:

Anxiety at wave 2 by wave 1 body mass index classification.

\section{Appendix 4A: Tables on Obesity and Health Outcomes in Older Irish Adults}

Table 4.A1:

Prevalence of normal, overweight and obesity at wave 1 by age and sex 109

Table 4.A2:

Prevalence of normal, increased and substantially increased waist circumference at wave 1 by age and sex

Table 4.A3:

Prevalence of cardiovascular disease at wave 2 by wave 1 body mass index classification and sex

Table 4.A4:

Prevalence of cardiovascular disease risk factors at wave 2 by wave 1 body mass index classification and sex

Table 4.A5:

Proportion reporting new ADL and IADL disabilities at wave 2 by wave 1 body mass index category and sex

Table 4.A6:

Prevalence of major depressive disorder at wave 2 by wave 1 body mass index classification and sex. 


\section{Table 4.A7:}

Prevalence of generalised anxiety disorder at wave 2 by wave 1 waist circumference classification and age

Table 4.A8:

Prevalence of generalised anxiety disorder at wave 2 by wave 1 body mass index classification and age

\section{Table 4.A9:}

Prevalence of generalised anxiety disorder at wave 2 by wave 1 body mass index classification and sex

Table 4.A10:

Physical activity levels at wave 2 by wave 1 waist circumference classification and age 118

Table 4.A11:

Physical activity levels at wave 2 by wave 1 body mass index classification and sex 119

\section{Table 4.A12:}

Smoking behaviour at wave 2 by wave 1 body mass index classification and sex..... 120

Table 4.A13:

Alcohol consumption at wave 2 by wave 1 body mass index classification and sex. 121

Table 4.A14:

Proportion reporting reduction in alcohol use by wave 1 body mass index classification and sex

\section{Health and Social Care Utilisation}

\section{Table 5.1:}

Health care entitlement status at wave 1 by age.

Table 5.2:

Health care entitlement status at wave 2 by age

Table 5.3:

Changes in health care entitlement status between wave 1 and wave 2

Table 5.4:

Proportion utilising primary and secondary care services by age and health care entitlement status

\section{Table 5.5:}

Proportion utilising primary and secondary prevention services by age and health care entitlement status 
Table 5.6:

Proportion utilising community-based state care services

Table 5.7:

Prevalence of $A D L$ and IADL disability by age and sex.

Table 5.8:

Proportion utilising home help, personal care and meals services by age, sex, health care entitlement status and disability status

Table 5.9:

Changes in medication use between wave 1 and wave 2 .....

Table 5.10:

Top five most commonly used medications, medication classes and food supplements

Table 5.11:

Generic share of Atorvastatin at wave 2 by wave 1 use and medical card status. 142

Table 5.12:

Proportion of deceased and survivors utilising primary and secondary care services

at wave 2

Table 5.13:

Proportion of deceased and survivors utilising home help, personal care and meals services at wave 2

\section{Appendix 5A: Tables on Health and Social Care Utilisation}

\section{Table 5.A1:}

Intensity of GP service utilisation at wave 2

Table 5.A2:

Proportion utilising community-based state care services at wave 2 by health care

entitlement status

Table 5.A3:

Prevalence of $A D L$ and IADL disability by an expanded age category.

Table 5.A4:

Medication use in wave 2 by highest educational attainment

Table 5.A5:

Medication use in wave 2 by self-rated health

Table 5.A6:

Medication use in wave 2 by physical activity levels 


\section{What Factors are Associated with Change in Older People's Quality of LIfe?}

Table 6.1:

Scale composition and sample items on the CASP-19 quality of life measure 157

Table 6.2:

Mean CASP-19 quality of life score at wave 2 and mean change in quality of life by sex 160

Table 6.3:

Mean CASP-19 quality of life score at wave 2 and mean change in quality at life score by age........

Table 6.4:

Mean CASP-19 quality of life score at wave 2 by transitions in marital status 161

Table 6.5:

Mean CASP-19 quality of life score at wave 2 by transitions in employment status 163

Table 6.6:

Mean CASP-19 quality of life score at wave 2 by social participation 173

Table 6.7:

Changes in social participation between wave 1 and wave 2 174

Table 6.8:

Mean CASP-19 quality of life score at wave 2 by transitions in social participation 174

Table 6.9:

Mean change in CASP-19 quality of life score by transitions in social participation 174

Table 6.10:

Mean CASP-19 quality of life score at wave 2 by caring status 178

\section{Methodology}

\section{Table 7.1:}

Wave 2 response rates by age and sex 190

Table 7.2:

Wave 1 study engagement by wave 2 participation and age 190

Table 7.3:

Self Completion Questionnaire response rates by age and sex 191

Table 7.4:

Reasons for non-response 192 


\section{List of Figures}

\section{Introduction}

Figure 1.1:

TILDA Data Collection

Figure 1.2:

Unemployment Rate (\%) and Net Migration (thousands), 2008-2013

Figure 1.3:

Overall Consumer Prices (CPI) and House Prices, 2008-2013

(December 2011=100).

Figure 1.4:

Selected Policy Changes, 2008-2013.

13

\section{The Economic Well-Being of Over 50s and their Children}

Figure 2.1:

Median value of total household gross assets by age (in $€ k$ )......

Figure 2.2:

Median value of total household gross assets by highest educational

attainment (in $€ k$ )

30

Figure 2.3:

The distribution of total household gross assets 30

Figure 2.4:

Median value of total household net assets by age (in $€ k$ )

Figure 2.5:

Median value of total household net assets by highest educational

attainment (in $€ k$ )

Figure 2.6:

Median value of weekly gross income by age (in $€$ ).

Figure 2.7:

Median value of weekly gross income by highest educational attainment (in €)......

Figure 2.8:

The distribution of weekly gross income 


\section{Figure 2.9:}

Proportion with labour income in wave 2 by age......

Figure 2.10:

Proportion with pension income by age

Figure 2.11:

Proportion with social insurance/allowance income by age 39

Figure 2.12:

Proportion with social insurance/allowance income as sole source or no income by highest educational attainment

Figure 2.13:

New retirees by age and highest educational attainment. 44

Figure 2.14:

Children's place of residence at wave 2 by children's place of residence at wave 1 46

Figure 2.15:

Children's labour market status at wave 2 by children's migration status 48

Figure 2.16:

Children's labour market status at wave 2 by children's internal migration status 49

\section{Changes in Physical and Behavioural Health in Older Irish Adults}

Figure 3.1:

Distribution of self-rated health 54

Figure 3.2:

Changes in self-rated health between wave 1 and wave 2 55

Figure 3.3:

Prevalence of cardiovascular conditions.... 56

Figure 3.4:

Two-year incidence of cardiovascular conditions 57

Figure 3.5:

Prevalence of chronic conditions (non-cardiovascular)

Figure 3.6:

Two-year incidence of chronic conditions (non-cardiovascular) 59

Figure 3.7:

Prevalence of falls, recurrent falls and injurious falls 61 
Figure 3.8:

Prevalence of falls, recurrent falls and injurious falls at wave 2 by age

Figure 3.9:

Prevalence of negative health behaviours

\section{Appendix 3B: Figures on Changes in Physical and Behavioural Health in Older Irish Adults}

Figure 3.B1a:

Prevalence of smoking in wave 2 by age (5-year age groups)

Figure 3.B1b:

Prevalence of problematic alcohol use in wave 2 by age (5-year age groups)

\section{Obesity and Health Outcomes in Older Irish Adults}

\section{Figure 4.1:}

Distribution of body mass index at wave 1

Figure 4.2:

Distribution of body mass index at wave 1 by age and sex

Figure 4.3:

Distribution of waist circumference at wave 1

Figure 4.4:

Distribution of waist circumference at wave 1 by age and sex.

Figure 4.5:

Prevalence of cardiovascular disease at wave 2 by wave 1 waist circumference classification and sex

Figure 4.6:

Prevalence of cardiovascular disease risk factors at wave 2 by wave 1 waist circumference classification and sex

Figure 4.7:

Proportion reporting new ADL and IADL disabilities at wave 2 by wave 1 waist circumference classification and sex

Figure 4.8:

Depression at wave 2 by wave 1 waist circumference classification and sex.......

Figure 4.9:

Anxiety at wave 2 by wave 1 waist circumference classification and sex 
Figure 4.10:

Physical activity levels at wave 2 by wave 1 waist circumference classification

and sex......

Figure 4.11:

Smoking behaviour at wave 2 by wave 1 waist circumference classification and sex 101

Figure 4.12:

Frequency of alcohol consumption at wave 2 by wave 1 waist circumference classification and sex

Figure 4.13:

Proportion reporting reduction in alcohol use by wave 1 waist circumference

classification and sex 102

\section{Health and Social Care Utilisation}

Figure 5.1:

Mean number of medications (excluding food supplements) used in wave 2 by age 140

\section{Appendix 5B: Figures on Health and Social Care Utilisation}

Figure 5.B1:

Medication use in wave 2 by age and sex. 152

\section{What Factors are Associated with Change in Older People's Quality of Llfe?}

Figure 6.1:

Mean CASP-19 quality of life score at wave 2 by age

Figure 6.2:

Mean scores on the control, autonomy, self-realisation and pleasure subscales of the

CASP-19 quality of life measure at wave 2 by age 159

Figure 6.3:

Mean change in CASP-19 quality of life score by transitions in marital status. 162

Figure 6.4:

Mean change in the CASP-19 quality of life score by transitions in employment status 
Figure 6.5:

Mean CASP-19 quality of life score at wave 2 by the number of ADLs.

Figure 6.6:

Mean CASP-19 quality of life score at wave 2 by transitions in ADL status

Figure 6.7:

Mean change in CASP-19 quality of life score by transitions in ADL status 167

Figure 6.8:

Mean CASP-19 quality of life score at wave 2 by transitions in depression status 168

Figure 6.9:

Mean change in CASP-19 quality of life score by transitions in depression status 169

Figure 6.10:

Distribution of Berkman-Syme Social Network Index of social connection at wave 2 by age 170

Figure 6.11:

Mean CASP-19 quality of life score at wave 2 by Berkman-Syme Social Network Index and age

Figure 6.12:

Percentage engaging in intimate social relationships by age. 172

Figure 6.13:

Percentage engaging in formal organisational involvement outside of work 2 by age 172

Figure 6.14:

Mean CASP-19 quality of life score by frequency of volunteering and sex.....

Figure 6.15:

Mean change in CASP-19 quality of life score by transitions in volunteering frequency 176

Figure 6.16:

Proportion providing care to parents and children at wave 2 177

Figure 6.17:

Mean change in CASP-19 quality of life score by caring status at wave 2 (parents) 178

Figure 6.18:

Mean change in CASP-19 quality of life score by caring status at wave 2 (children) 179

Figure 6.19:

Mean change in CASP-19 quality of life score by caring status at wave 2 (grandchildren) 179 


\section{Key Findings}

\section{Chapter 2: The Economic Circumstances of the Over 50s and their Children}

- The gross income levels of the TILDA participants remained the same between wave 1 and wave 2 despite a shift away from labour income sources towards retirement income sources.

- Wealth has fallen between wave 1 and wave 2 and this is largely due to reductions in property values.

- Of those who were employed in wave $1,13 \%$ had retired by wave 2 .

- Of these new retirees, a higher percentage of those with higher levels of education had retired before the state pension age (SPA).

- Eligibility for the state pension is the main reason for retirement for new retirees.

- $5 \%$ of the adult children of TILDA participants who were living in Ireland in wave 1 had emigrated by wave 2 .

- Employment levels amongst the adult children of TILDA participants are highest among those who have emigrated or were already living abroad at wave 1.

- Unemployment among children at wave 2 is highest among those who have returned to Ireland from abroad, have returned to live with their parents or were already living with their parents at wave 1.

\section{Chapter 3: Changes in Physical and Behavioural Health in Older Irish Adults}

- The proportion of the older population who report that their health is 'excellent' or 'very good' has increased from $41 \%$ in wave 1 to $44 \%$ in wave 2 .

- Hypertension and diabetes are the most prevalent cardiovascular conditions in older Irish adults, affecting $37 \%$ and $9 \%$ of older Irish adults respectively. The prevalence of most cardiovascular conditions has remained stable since wave 1 except for angina, 
which has decreased, and atrial fibrillation, which has increased.

- Arthritis now affects $51 \%$ of those aged 75 and over, while the two-year incidence of arthritis among this age group is $10 \%$.

- Arthritis, osteoporosis and cataracts have the highest two-year incidence rates (i.e., new cases among those previously undiagnosed) of non-cardiovascular chronic conditions, with rates of $7.6 \%, 5.6 \%$ and $5.7 \%$ respectively.

- Approximately $19 \%$ of men, $25 \%$ of women and $30 \%$ of individuals aged 75 and over have fallen in the last year. Almost $10 \%$ of the over 50 s population have had an injurious fall (i.e., requiring medical treatment) in the last year.

- $16 \%$ of smokers at wave 1 had quit by wave 2 . A notable decrease in smoking occurs after the age of 65 years.

- The overall prevalence of problematic alcohol use has increased between wave 1 and wave 2 and is significantly higher in men $(21.7 \%)$ than in women (11\%). There is a drop in problematic alcohol use after the age of 65 years.

- The proportion of adults reporting low levels of physical activity increases with age, with $51.6 \%$ of over 75 s reporting low levels of physical activity at wave 2 .

\section{Chapter 4: Obesity and Health Outcomes in the Older Population}

- $35 \%$ of older Irish adults are classified as obese according to their body mass index; a further $44 \%$ are overweight.

- According to World Health Organisation criteria, $53 \%$ of older Irish adults are at a substantially increased risk of metabolic and cardiovascular disease based on their waist circumference.

- Obesity at wave 1 is strongly associated with cardiovascular disease at wave 2. Both men and women who were obese at wave 1 have a significantly higher prevalence of diabetes at wave 2 , while obese men have a significantly higher prevalence of heart attacks, and obese women have a significantly higher prevalence of angina.

- Increased waist circumference at wave 1 is associated with the development of disability, particularly among women.

- A significantly higher proportion of men who were obese at wave 1 had reduced their alcohol intake by wave 2 (in comparison with men who were of normal weight at wave 1). 


\section{Chapter 5: Health and Social Care Utilisation by the Over 50s}

- The proportion of TILDA participants with a medical card or GP visit card increased overall between wave 1 and wave 2 (from $52 \%$ to $57 \%$ ), but declined in those aged $70+$ years.

- Between wave 1 and wave 2, private health insurance cover declined in those under 65 years and increased in those aged over 65 years.

- In wave 2, $21.1 \%$ of participants aged $80+$ years old had attended an Emergency Department (ED) at least once in the previous year (the corresponding figure for wave 1 was $15.1 \%)$.

- Utilisation of community health and social care services by the older population remains low.

- The uptake of prostate cancer screening services in men and breast cancer screening services women is high but the uptake of flu vaccination is low, particularly for those who do not have a medical or GP visit card.

- Polypharmacy (i.e., taking five or more medications) has increased from $21 \%$ at wave 1 to $26 \%$ at wave 2 .

- Participants who had died between wave 1 and wave 2 had higher levels of secondary care service utilisation (ED visits and hospital admissions) than survivors.

\section{Chapter 6: What Factors are Associated with Change in Older People's Quality of Life?}

- Self-reported quality of life peaks around 65-67 years, and declines rapidly after the age of 80 .

- Between wave 1 and wave 2 of TILDA, overall quality of life declined for all age groups, but the decline was greatest for those aged $75+$ years.

- Those who were married at both waves have a higher quality of life than those who remain never married, divorced/separated, or widowed between waves.

- Those who reported that they no longer suffer from a disability in relation to activities of daily living (e.g., dressing, eating, bathing) have a significantly higher quality of life than those reporting a disability in both wave 1 and wave 2 .

- TILDA participants whose depressive symptoms had remitted between wave 1 and 
wave 2 experienced a significant improvement in quality of life.

- Based on their social networks (i.e., marital status, close ties with family and friends and membership of voluntary and religious organisations), $27 \%$ of men and $22 \%$ of women in TILDA are classed as 'most socially integrated', and these proportions have only changed slightly between wave 1 and wave 2 of the study.

- Participants with strong social networks, who engage in various types of active social relationships and who volunteer regularly have a higher quality of life than those who are less socially active.

- Overall, 35\% of TILDA participants look after their grandchildren for at least one hour a week, and those who care for their grandchildren have a higher quality of life than those who do not. 


\section{Introduction}

Rose Anne Kenny and Anne Nolan

\section{Contents}

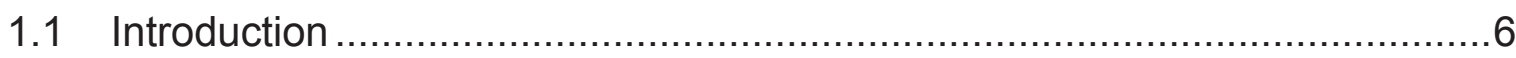

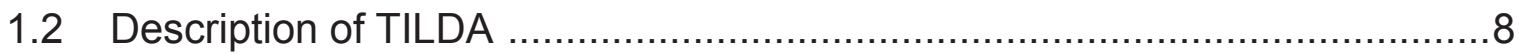

1.3 Macroeconomic and Policy Context ................................................ 10

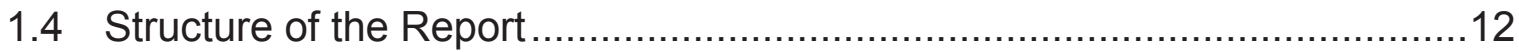

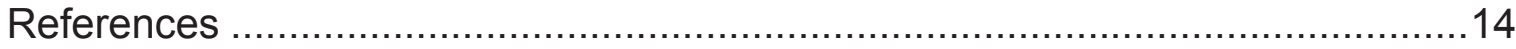

Appendix 1: TILDA Reports and Publications ............................................ 15 


\section{Introduction}

\subsection{Introduction}

In 2011, we published our first summary report 'Fifty Plus in Ireland 2011: First Results from the Irish Longitudinal Study on Ageing' (1). In that report, we described the lives of the over 50s population in Ireland using data from the first wave of The Irish Longitudinal Study on Ageing (TILDA), carried out between October 2009 and February 2011. A wide variety of information on the lives of the over 50 s in Ireland was presented, covering areas such as marital status, migration history, incomes, wealth, employment status, physical and behavioural health, mental health and cognitive function, health and social care utilisation, social engagement and quality of life. The report painted a picture of a diverse over $50 \mathrm{~s}$ population, with marked differences in many domains of life between young old and older old, and between different socio-economic groups. There were also some differences between men and women, in particular with respect to health and pensions coverage. Older people were found to enjoy a high quality of life and to make important contributions to their families and communities. Childhood circumstances were found to exert strong influences on later life outcomes. A key finding was the large discrepancy between subjective and objective indicators of health, with substantial rates of undiagnosed illness observed for many health conditions (e.g., hypertension).

In this, our second summary report, we use information from the second wave of data collection for TILDA, which lasted from April 2012 to January 2013, to document how the lives of the over 50 s in Ireland have changed over the intervening period. As described in greater detail below, the period since TILDA began at the end of 2009 has been one of considerable social and economic change, both as a result of, and in response to, the most severe financial and economic crisis in the State since the second world war (2). The purpose of this report is to document how the lives of the over 50s in Ireland have changed over this period, with a particular focus on economic circumstances, physical and behavioural health, health and social care utilisation and quality of life. Other domains of life such as mental health and migration are not discussed directly in this report but will be subject to more in-depth analysis in forthcoming reports from the TILDA research team. 
The population of Ireland is ageing. By 2046, approximately $21 \%$ of the Irish population will be aged 65 years or older, and approximately $7 \%$ will be aged 80 years or older (the corresponding figures for 2011 were $11.6 \%$ and $2.8 \%$ respectively). ${ }^{1} \mathrm{~A}$ growing older population will require innovative policy approaches to enable healthier, happier and economically solvent extended life spans. The EU has set a target for its member states to increase healthy life years by two years by the year 2020. In recognition of the importance of good quality data as an input into the design, monitoring and evaluation of such strategies, many countries have established longitudinal studies on ageing. TILDA is modelled closely on 'sister' studies such as the US Health and Retirement Survey (HRS) and the English Longitudinal Study on Ageing (ELSA). Just as these longitudinal datasets inform policies and strategies in relation to healthy ageing in the UK and US, TILDA continues to provide information for evidence-based policy in Ireland.

As described in the wave 1 report (1), the specific aims of TILDA are to:

- Provide comprehensive, internationally comparable baseline data on older people in Ireland, leading to improvements in policy and planning;

- Provide new insights into the causal pathways underlying the ageing process;

- Add to the prominence of ageing as an issue of public interest and allow the voice of older people to be heard more clearly, by effectively disseminating results to various audiences;

- Lead to further extensive analysis by academic researchers both in Ireland and abroad, helping to create an enhanced infrastructure for ageing research in Ireland and to attract international scholars and funding, by making its anonymised dataset openly available.

In common with other longitudinal studies of ageing, TILDA is a multidisciplinary study with three principal domains: health, economics and social circumstances. It is now well established that these domains interact with each other to determine the process of ageing, and to fully understand one, researchers and policy makers must better understand these complex interactions. The TILDA research environment encourages such cross-disciplinary exploration of the data.

In addition to the wave 1 and wave 2 summary reports, the TILDA team have published widely in academic journals. They have also produced a number of more in-depth 'topic'

1. Authors' calculations from CSO Database (www.cso.ie/px/pxeirestat/) [last accessed 16 December 2013]. 
reports based on the wave 1 data. To date, these reports have focussed on issues such as caring responsibilities, health care utilisation and polypharmacy. The full list of TILDA publications is detailed in Appendix 1.

TILDA is also to the forefront of new research into the ageing process, into disorders which dominate disability and research into pension, health care and social care reforms. This work is creating inward investment into 'ageing' in Ireland and new employment opportunities. TILDA has thus become an invaluable infrastructure in the Irish research and development landscape. To further facilitate research on ageing in Ireland and elsewhere, the anonymised data from wave 1 has been archived at the Irish Social Science Data Archive at University College Dublin (UCD) (and the anonymised data from wave 2 will follow shortly). In addition, the data are also being prepared for deposit at the National Archive of Computerized Data on Ageing (NACDA) at the University of Michigan, which will facilitate international research using TILDA. In 2013, the Journal of the American Geriatrics Society published a special supplement on the TILDA study with a view to assisting researchers in the interpretation of the TILDA data, and to encourage widespread use of the TILDA data, both nationally and internationally (3-8). ${ }^{2}$

\subsection{Description of TILDA}

TILDA is a population-based, representative, longitudinal study of 8,504 communitydwelling adults in Ireland aged 50 and older and their partners. The sample was derived from a clustered random sample of all households in the Republic of Ireland. Surveyors called on selected addresses to ascertain whether occupants were eligible for study inclusion, i.e., aged 50 years or older and free from dementia. Eligible participants (and their partners or spouses of any age) were invited to take part in the survey every two years, initially for a ten year period. The response rate at wave 1 was $62 \%$ (4).

The response rate at wave 2 was $86 \%$. Of the 7,610 participants interviewed in wave 2, 78 were carried out by proxy (i.e., when participants were incapable of responding in person to the survey questions) (see Table 1.1). The average age at wave 1 was 63 and two years later, at wave 2, was 65 years. Chapter 7 in this report contains further details on the methodologies used in this report.

2. The papers described the TILDA study, methods of data collection (including the health assessment), established normative values of cognitive and physical function in older adults, compared TILDA data on health outcomes with that from the ELSA and the HRS, and described quality of life among older Irish adults. 


\begin{tabular}{l|c|}
\hline Wave 2 Interview Type & Number \\
\hline Self & 7353 \\
\hline Proxy & 80 \\
\hline End of life & 155 \\
\hline Institutional & 22 \\
\hline Total & 7610 \\
\hline
\end{tabular}

As illustrated in Figure 1.1, the data for wave 1 were collected in three steps:

1. A computer-assisted personal interview (CAPI), conducted by a trained interviewer;

2. A self-completion questionnaire (SCQ) for the collection of more sensitive information;

3. A physical and cognitive health assessment, conducted by trained research nurses in dedicated health assessment centres in Dublin or Cork or in the participant's home.

Further details on the TILDA data collection process are described elsewhere $(4,5,9)$. In wave 2, steps 1 and 2 were repeated, while in wave 3 (to be collected in 2014), the physical and cognitive health assessment will be repeated. The data collected by TILDA have replicated core health, social and economic data from the other principal European and US studies thus enabling important cross-country comparisons and harmonisation across studies. However, TILDA has further capitalised on a unique opportunity to incorporate a battery of objective measures of physical and cognitive health in addition to self-reported status aided by the involvement of health care professionals from the leading third-level institutions in Ireland. As noted, the detailed physical and cognitive health assessment is only carried at on alternate waves, i.e., waves 1 and 3 . Therefore, in wave 2 , additional objective tests of mental health, cognitive function, locomotion and muscle strength were included as part of the CAPI interview process to ensure that measures of physical and cognitive function are captured at each wave and facilitate comparisons with other studies. 
Figure 1.1: TILDA Data Collection

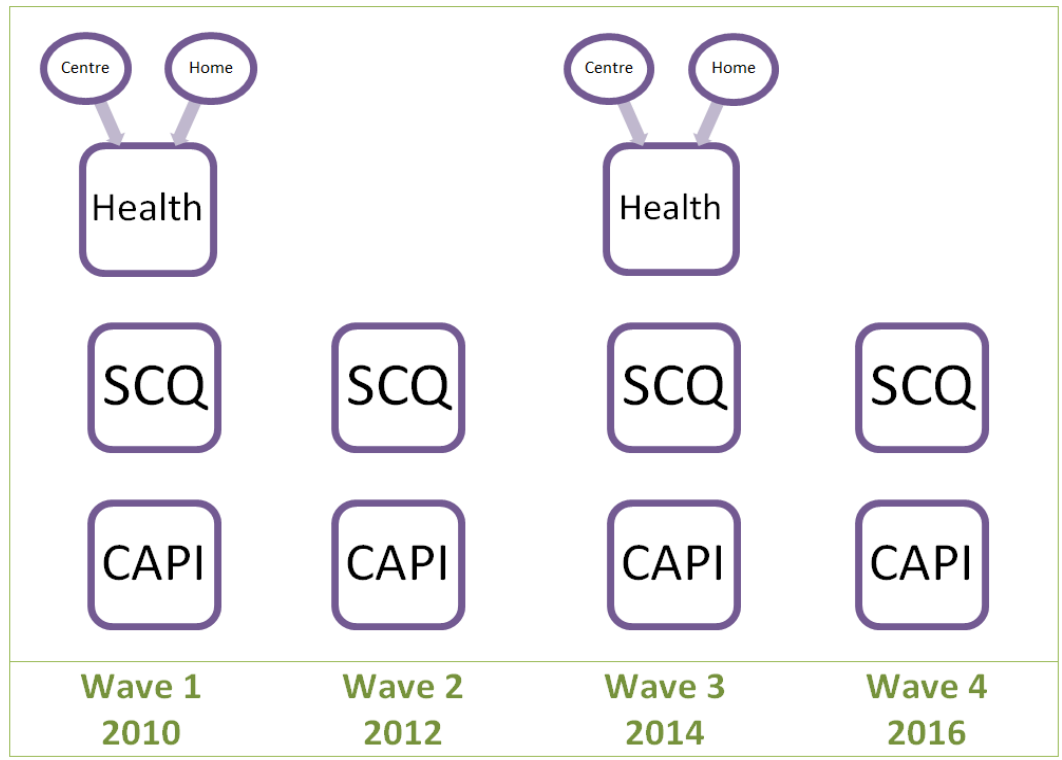

\subsection{Macroeconomic and Policy Context}

As noted, in this report, we document how the lives of the over 50s in Ireland have changed over the period between wave 1 and wave 2 of TILDA (i.e., 2009-2013). This was a period of considerable social and economic change in Ireland. The Irish economy officially entered recession in 2008 (10), and so the economic downturn was already wellestablished by the time TILDA began interviewing participants for the first time in October 2009. The current economic recession in Ireland is the worst since the second world war (2), both in its severity and its duration. While the Irish economy continues to perform poorly, in recent months there have been some positive signs emerging (11).

Unfortunately, the economy showed little sign of improvement in the period between waves 1 and 2 of TILDA. Unemployment and net emigration continued to increase between 2009 and 2013 (see Figure 1.2). Unemployment is now approximately 14 per cent. The current rate of net emigration of approximately 30,000 is comparable with levels last observed in the late 1980s (when the population was considerably smaller). Consumer prices have remained relatively stable over the period, although house prices have continued their sharp decline, albeit with some recent signs of stabilisation (see Figure 1.3). Of particular interest to the older population who may be more reliant on income from savings are trends in interest rates, which have been falling since 2008 and are now approximately $1 \% .^{3}$

3. ECB marginal interest rate; see CSO Database (www.cso.ie/px/pxeirestat/) [last accessed 16 December 2013]. 
Figure 1.2: Unemployment Rate (\%) and Net Migration (thousands), 2008-2013

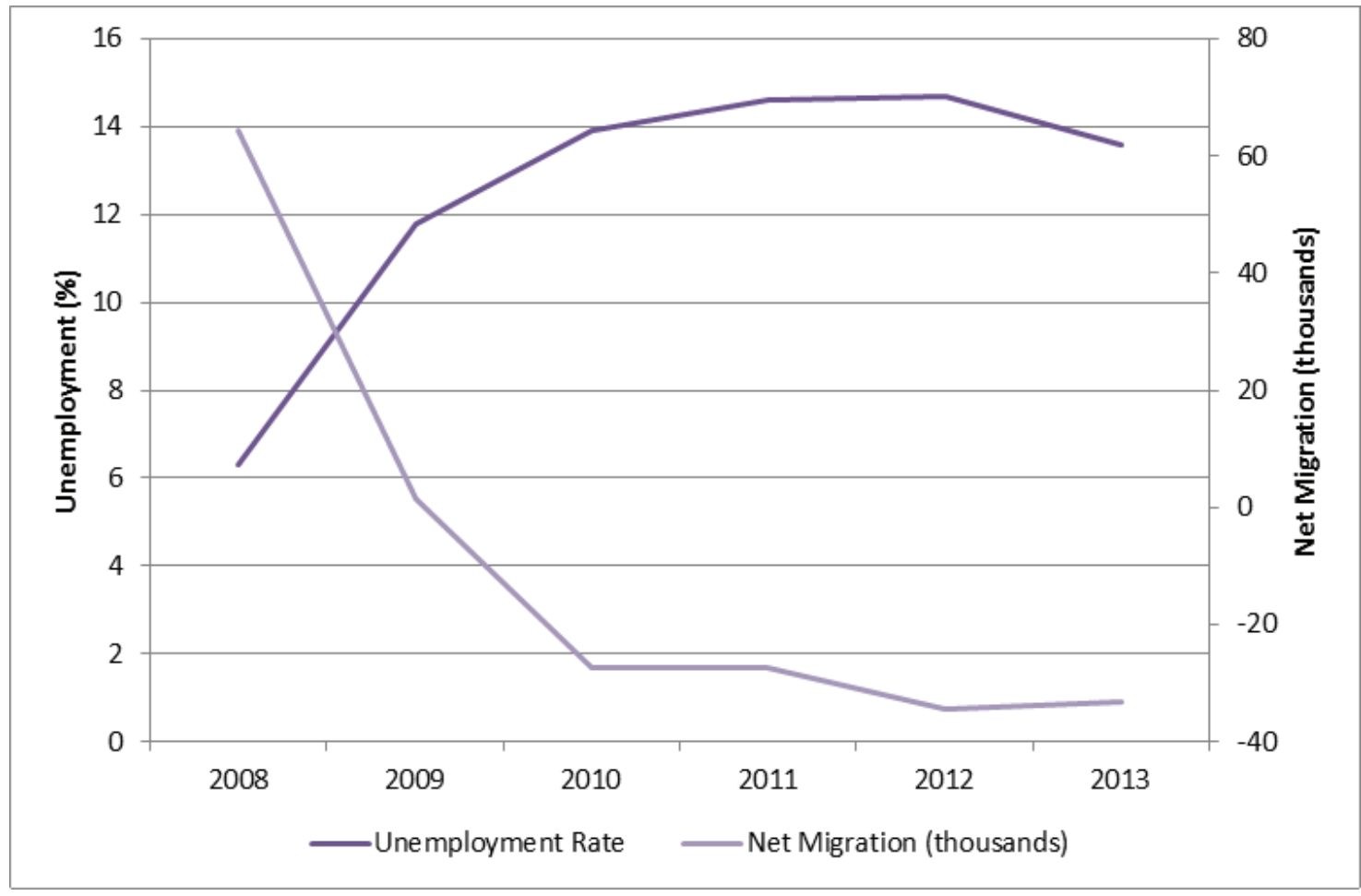

Sources: (11); CSO Database (www.cso.ie/px/pxeirestat/) [last accessed 7 December 2013]

Figure 1.3: Overall Consumer Prices (CPI) and House Prices, 2008-2013 (December 2011=100)

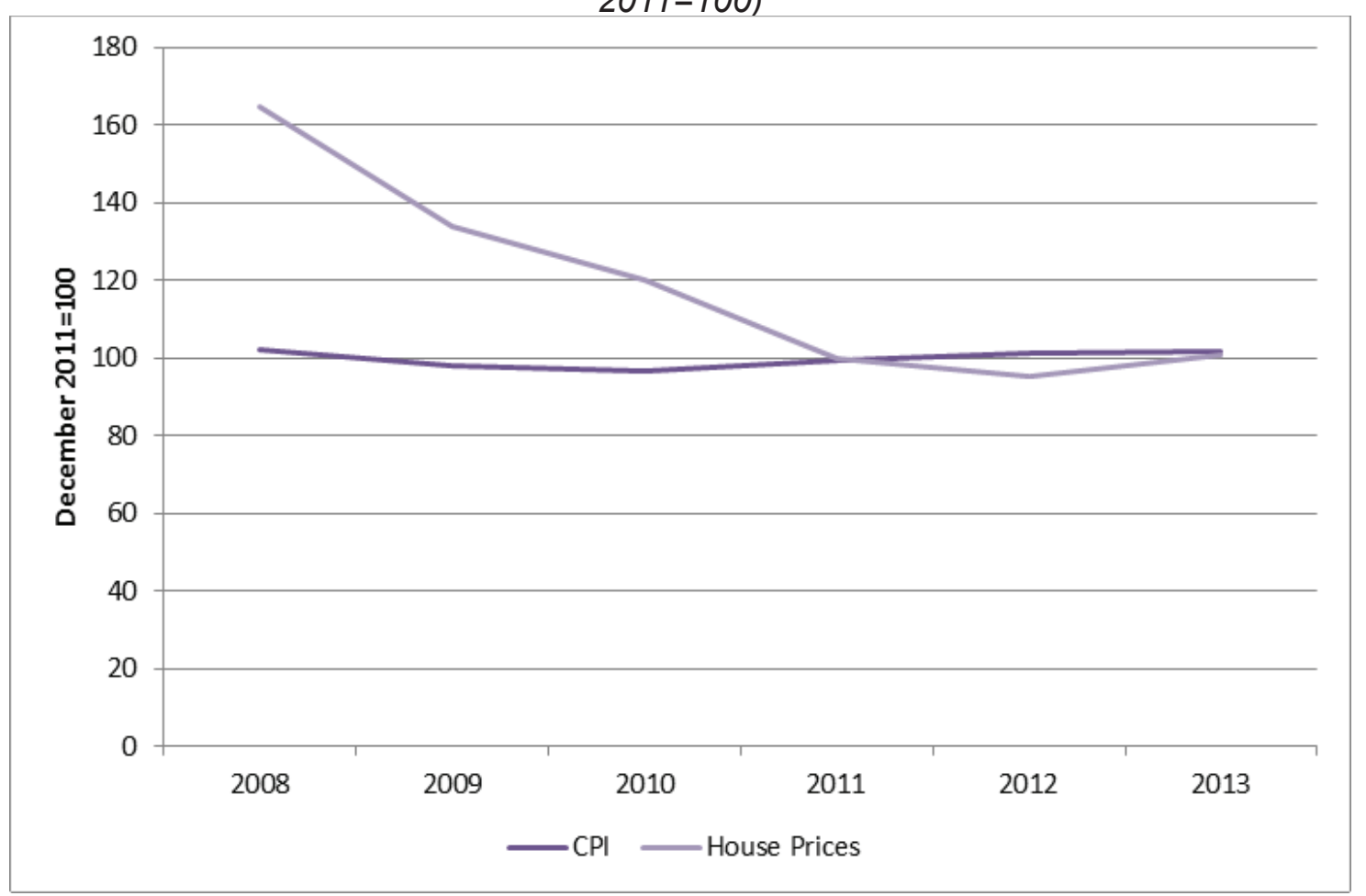

Source: CSO Database (www.cso.ie/px/pxeirestat/) [last accessed 7 December 2013] 
In November 2010, the Government accepted an EU-IMF Programme of Financial Support worth €85bn for the period 2010-2013, after a period in which Government borrowing costs had become unsustainable. This introduced a period of strict oversight of Irish economic policy, with the continuation of previous public spending cuts and taxation increases. The full extent of the policy changes introduced in each of the seven 'austerity' budgets are illustrated in Figure 1.4. Many of these policy changes are directly relevant for the over 50 s population, in particular the changes announced in relation to pensions and public healthcare entitlements.

While the state pension has remained at the same rate since January 2009 , automatic entitlement to a medical card for all over 70 s was removed in January 2009. A prescription charge per item of $0.50 \mathrm{c}$ was introduced in October 2010 (towards the end of wave 1 of TILDA), and has been subsequently increased twice (to $€ 1.50$ from January 2013 and to $€ 2.50$ from December 2013). Hospital and prescription charges for private (i.e., nonmedical card) patients have been increased, the latter on four occasions since January 2009. Other significant policy developments of relevance to the older population include the announcement of the increase in the State Pension Age (SPA) in March 2010, with the first phase (i.e., the increase in the SPA from 65 years to 66 years) taking effect from January 2014. Between wave 1 and wave 2 of TILDA, a number of taxation changes with respect to pensions were introduced, such as the reduction in the threshold for the taxation of pension lump sum payments in December 2010. Since the end of wave 2 of TILDA in early 2013 , income thresholds for medical cards for the over 70 s have been reduced, and certain social benefits have been cut (e.g., the household benefits package) or abolished entirely (e.g., the bereavement grant).

\subsection{Structure of the Report}

We begin in Chapter 2 by examining how the economic circumstances of TILDA participants and their children have changed between wave 1 and wave 2 . Chapter 3 focuses on changes in physical and behavioural health, while Chapter 4 focuses on the issue of obesity and its association with various health outcomes. Chapter 5 analyses patterns of public healthcare eligibility and health and social care utilisation between waves 1 and 2 of TILDA. It also examines the characteristics and experiences of those who died between waves. Chapter 6 focuses on quality of life, its determinants and its relationship to changes in circumstances (e.g., marital status, employment, disability) between waves. Finally, chapter 7 provides further details on the methodologies used throughout this report. As noted in Chapter 7, the analyses in this report are essentially descriptive. More detailed analysis of the issues in this report using multivariable statistical analysis 


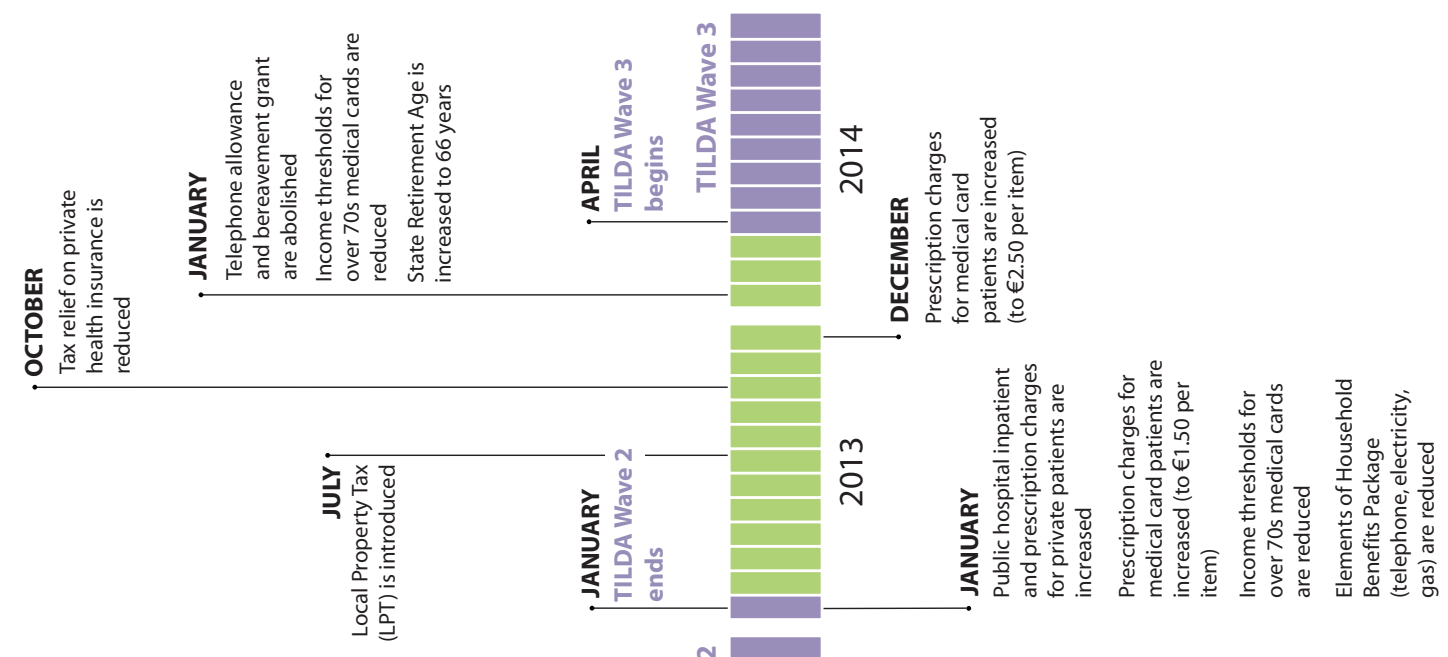

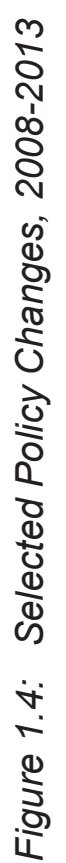

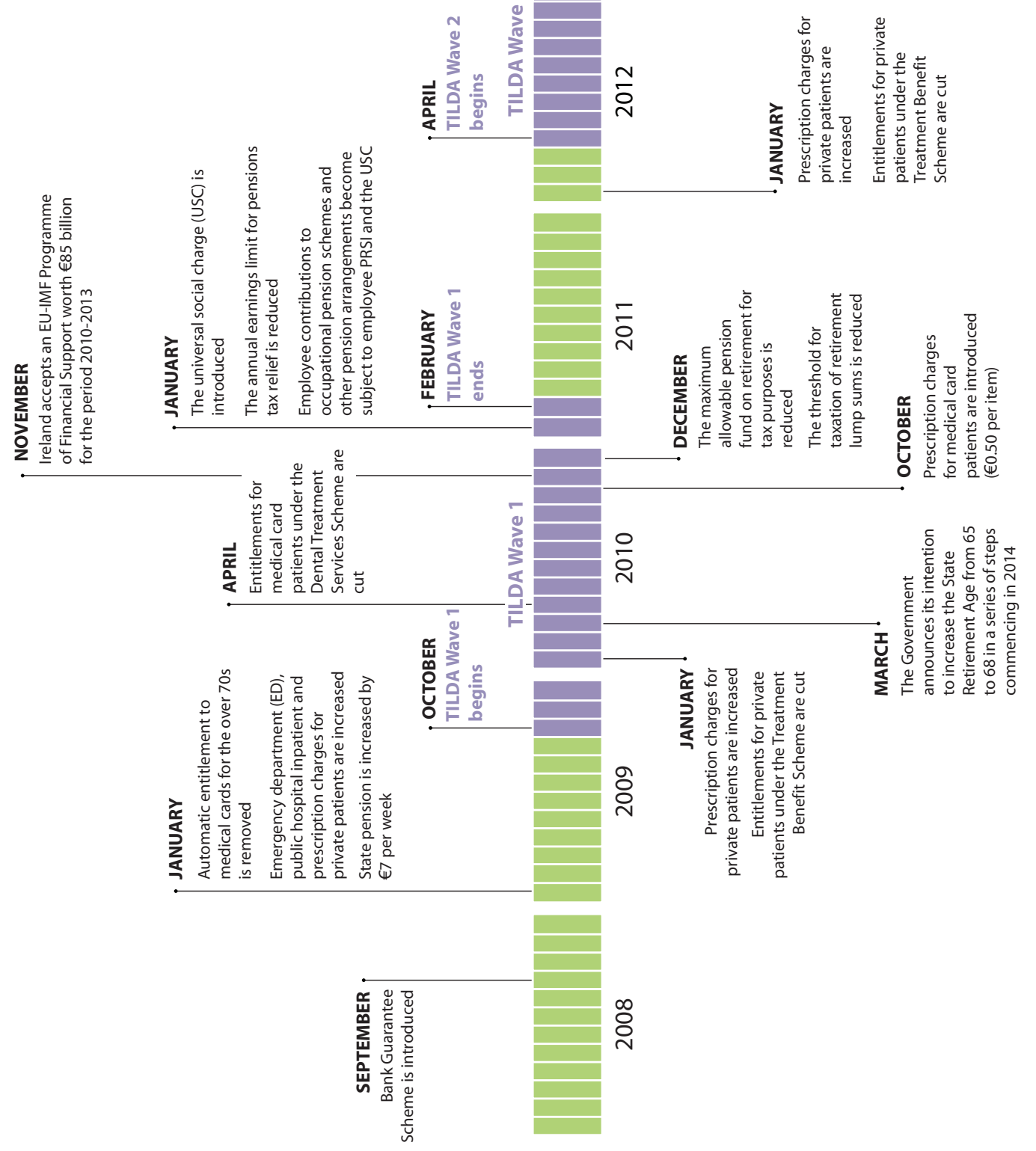


techniques is currently being undertaken by the TILDA research team and will be published on an on-going basis throughout 2014. Each chapter begins with a set of key findings.

\section{References}

1. Barrett A, Savva G, Timonen V, Kenny R. Fifty Plus in Ireland 2011. First results from the Irish Longitudinal Study on Ageing (TILDA). Dublin: The Irish Longitudinal Study on Ageing; 2011.

2. FitzGerald J, Kearney I, Bergin A, Conefrey T, Duffy D, Timoney K, et al. Medium-Term Review 2013-2020. Dublin: Economic and Social Research Institute; 2013.

3. Kenny RA. An Introduction to The Irish Longitudinal Study on Ageing. Journal of the American Geriatrics Society. 2013;61:S263-S4.

4. Whelan BJ, Savva GM. Design and Methodology of The Irish Longitudinal Study on Ageing. Journal of the American Geriatrics Society. 2013;61:S265-S8.

5. Cronin H, O'Regan C, Finucane C, Kearney P, Kenny RA. Health and Aging: Development of The Irish Longitudinal Study on Ageing Health Assessment. Journal of the American Geriatrics Society. 2013;61:S269-S78.

6. Kenny RA, Coen RF, Frewen J, Donoghue OA, Cronin H, Savva GM. Normative Values of Cognitive and Physical Function in Older Adults: Findings from The Irish Longitudinal Study on Ageing. Journal of the American Geriatrics Society. 2013;61:S279-S90.

7. Savva GM, Maty SC, Setti A, Feeney J. Cognitive and Physical Health of the Older Populations of England, the United States, and Ireland: International Comparability of The Irish Longitudinal Study on Ageing. Journal of the American Geriatrics Society. 2013;61:S291-S8.

8. Layte R, Sexton E, Savva G. Quality of Life in Older Age: Evidence from an Irish Cohort Study. Journal of the American Geriatrics Society. 2013;61:S299-S305.

9. Kenny R, Whelan B, Cronin H, Kamiya Y, Kearney P, O'Regan C, et al. The Design of the Irish Longitudinal Study on Ageing. Dublin: Trinity College Dublin; 2010.

10. Barrett A, Kearney I, O’Brien M. Quarterly Economic Commentary, Summer 2008. Dublin: Economic and Social Research Institute; 2008.

11. Duffy D, FitzGerald J, Timoney K, Byrne D. Quarterly Economic Commentary, Autumn 2013. Dublin: Economic and Social Research Institute; 2013. 


\section{Appendix 1: TILDA Reports and Publications}

\section{TILDA Reports}

1. "Profile of the Sandwich Generation and Intergenerational Transfers in Ireland" by Christine McGarrigle \& Rose Anne Kenny. 2013.

2. "Patterns and Determinants of Health Care Utilisation in Ireland" by Aoife McNamara, Charles Normand \& Brendan Whelan.

3. "Polypharmacy in Adults Over 50 in Ireland: Opportunities for Cost Saving and Improved Healthcare” by Kathryn Richardson*, Patrick Moore*, Jure Peklar, Rose Galvin, Kathleen Bennett \& Rose Anne Kenny. *joint first authors.

4. "Supplementary Pensions and the Income of Ireland's Retirees" by Sanna Nivakoski and Alan Barrett

5. "Profile of Community-Dwelling Older People with Disability and their Caregivers in Ireland" by Yumiko Kamiya, Catriona Murphy, George Savva and Virpi Timonen.

6. "Fifty Plus in Ireland 2011. First results from The Irish Longitudinal Study on Ageing." Edited by Alan Barrett, George Savva, Virpi Timonen and Rose Anne Kenny.

7. “TILDA Design Report 2010". Rose Anne Kenny, Brendan Whelan, Hilary Cronin et al.

\section{Peer-Reviewed Journal Articles}

\section{3}

1. Barrett A and Mosca I. (2013). Increasing the State Pension Age, the Recession and Expected Retirement Ages. Economic and Social Review. 44(4): 447-472.

2. Barrett A and Mosca I. (2013). Early-life Causes and Later-life Consequences of Migration: Evidence from Older Irish Adults. Journal of Population Ageing. 6(1-2): 2945.

3. Barrett A and Mosca I. (2013). Social Isolation, Loneliness and Return Migration: Evidence from Older Irish Adults. Journal of Ethnic and Migration Studies. 39(10): 1659-1677.

4. Barrett A and Mosca I. (2013). The Psychic Costs of Migration: Evidence from Irish Return Migrants. Journal of Population Economics. 26(2): 483-506.

5. Cronin H, O'Regan C, Kearney P, Finucane C, Kenny RA. (2013). Health and Ageing: 
Development of the TILDA Health Assessment. Journal of the American Geriatrics Society. 61(s2): S269-278.

6. Donoghue OA, Ryan H, Duggan E, Finucane C, Savva GM, Cronin H, Loughman J, Kenny RA. (2013). Relationship between fear of falling and mobility varies with visual function among older adults. Geriatrics and Gerontology International [Epub ahead of print: doi: 10.1111/ggi.12174.]

7. Donoghue OA, Cronin H, Savva GM, O'Regan C, \& Kenny RA. (2013). Effects of fear of falling and activity restriction on normal and dual task walking in community dwelling older adults. Gait \& posture. 38: 120-124.

8. Feeney J, Finucane C, Savva GM, Cronin H, Beatty S, Nolan JM, Kenny RA. (2013). Low macular pigment optical density is associated with lower cognitive performance in a large, population-based sample of older adults. Neurobiology of Aging. 34(11): 2449-56.

9. Feeney J, Kamiya Y, Robertson IH, \& Kenny RA. (2013). Cognitive Function Is Preserved in Older Adults With a Reported History of Childhood Sexual Abuse. Journal of traumatic stress. 26(6), 735-743.

10. Frewen J, Finucane C, Cronin H, Rice C, Kearney PM, Harbison J, Kenny R A. (2013). Factors that influence awareness and treatment of atrial fibrillation in older adults. QJM, 106(5), 415-424.

11. Frewen J, Finucane C, Savva G, Boyle G, Kenny RA. (2013). Cognitive function is associated with impaired heart rate variability in ageing adults: the Irish longitudinal study on ageing wave one results. Clinical Autonomic Research. 23(6):313-23.

12. J Frewen, C Finucane, G Savva, G Boyle, RA Kenny. Orthostatic Hypotension is Associated with Cognitive Performance only in Middle Aged and Older Adults with Supine Hypertension. Neurobiology of Ageing. [In Press].

13. Kamiya Y, Doyle M, Henretta JC, Timonen V. (2013). Depressive symptoms among older adults: The impact of early and later life circumstances and marital status. Aging and Mental Health. 17(3): 349-357.

14. Kamiya Y, Doyle M, Henretta JC, Timonen V. (2013). Early-Life Circumstances and Later-Life Loneliness in Ireland. The Gerontologist, gnt097.

15. Kenny RA, Coen RF, Frewen J, Cronin H, Donoghue OA, Savva GM. (2013). Normative values of cognitive and physical function in the older population: Findings from The Irish Longitudinal Study on Ageing. Journal of the American 
Geriatrics Society. 61(s2): S279-90.

16. Kenny RA. (2013). An Introduction to the Irish Longitudinal Study on Ageing. Journal of the American Geriatrics Society. 61(s2): S263-64.

17. Killane I, Donoghue OA, Savva GM, Cronin H, Kenny RA, Reilly RB. (2013). Variance between walking speed and neuropsychological test scores during three gait tasks across the Irish longitudinal study on aging (TILDA) dataset. Conference Proceedings IEEE Engineering in Medicine and Biology Society: 6921-6924.

18. Layte R, Sexton E, Savva G. (2013). Quality of Life in Older Age: Evidence from an Irish Cohort Study. Journal of the American Geriatrics Society. 61(s2): S299-305.

19. McGarrigle CA, Cronin H, Kenny RA. (2013). The impact of being the intermediate caring generation and intergenerational transfers on self-reported health of women in Ireland. International journal of public health, 1-8.

20. Mosca I, Ní Bhuachalla B, Kenny RA. (2013). Explaining significant differences in subjective and objective measures of cardiovascular health: evidence for the socioeconomic gradient in a population-based study. BMC Cardiovascualar Disorders. 13(64).

21. Mosca I. (2013). Body Mass Index, Waist Circumference and Employment: Evidence from Older Irish Adults. Economics and Human Biology. 11(4): 522-533.

22. O'Halloran AM, Kenny, RA, King-Kallimanis BL. (2013). The latent factors of depression from the short forms of the CES-D are consistent, reliable and valid in community-living older adults. European Geriatric Medicine. [In press].

23. O'Halloran AM, Finucane C, Savva GM, Robertson IH, Kenny RA. (2013). Sustained Attention and Frailty in the Older Adult Population. Journals of Gerontology Series B: Psychological Sciences and Social Sciences.

24. O’Regan C, Kearney PM, Cronin H, Savva GM, Lawlor BA, \& Kenny R. (2013). Oscillometric measure of blood pressure detects association between orthostatic hypotension and depression in population based study of older adults. BMC psychiatry, 13(1), 266.

25. O'Regan C, Kearney PM, Savva GM, Cronin H, Kenny RA. (2013). Age and sex differences in prevalence and clinical correlates of depression: first results from the Irish Longitudinal Study on Ageing. International Journal of Geriatric Psychiatry.

26. Peklar J, Henman MC, Richardson K, Kos M, Kenny RA. (2013). Food supplement 
use in the community dwelling population aged 50 and over in the Republic of Ireland. Complementary Therapies in Medicine. 21(4): 333-41.

27. Richardson K, Kenny RA, Peklar J, Bennett K. (2013). Agreement between patient interview data on prescription medication use and pharmacy records in the over 50 s varied by therapeutic group and reporting of indicated health conditions. Journal of Clinical Epidemiology. 66(11): 1308-1316.

28. Robertson DA, Savva GM, Kenny RA. (2013). Frailty and cognitive impairment-A review of the evidence and causal mechanisms. Ageing Research Reviews. 12(4):840851.

29. Romero-Ortuno R, O'Connell MD, Finucane C, Soraghan C, Fan CW, Kenny RA. (2013). Insights into the clinical management of the syndrome of supine hypertension-orthostatic hypotension (SH-OH): the Irish Longitudinal Study on Ageing (TILDA). BMC geriatrics. 13(1), 73 .

30. Savva GM, Donoghue OA, Horgan F, O'Regan C, Cronin H, Kenny RA. (2013). Using Timed Up-and-Go to Identify Frail Members of the Older Population. Journals of Gerontology Series A: Biological Sciences and Medical Sciences. 68(4): 441-446.

31. Savva GM, Maty SC, Setti A, Feeney J. (2013). Cognitive and Physical Health of the Older Populations of England, the United States, and Ireland: International Comparability of The Irish Longitudinal Study on Ageing. Journal of the American Geriatrics Society. 61 (s2): S291-98.

32. Sexton E, King-Kallimanis BL, Conroy R, Hickey A. (2013). Psychometric evaluation of the CASP-19 quality of life scale in an older Irish cohort. Quality of Life Research, 1-11.

33. Whelan BJ and Savva GM. (2013). Design and Methodology of the TILDA Study. Journal of the American Geriatrics Society. 61(s2): S265-68.

\section{2}

1. Donoghue OA, Horgan NF, Savva GM, Cronin H, O'Regan C, Kenny RA. (2012). Association Between Timed Up-and-Go and Memory, Executive Function, and Processing Speed. Journal of the American Geriatrics Society. 60(9):1681-6.

2. Fan CW, Savva GM, Finucane C, Cronin H, O'Regan C, Kenny RA. (2012). The Irish Longitudinal Study on Ageing. Factors affecting continuous beat-to-beat orthostatic blood pressure response in community-dwelling older adults. Blood Pressure Monitor. 17(4):160-3. 
3. Gallagher D, O'Regan C, Savva GM, Cronin H, Lawlor BA, Kenny RA. (2012). Depression, anxiety and cardiovascular disease: Which symptoms are associated with increased risk in community dwelling older adults? Journal of Affective Disorders. 142(1-3): 132-8.

4. Nolan JM, Feeney J, Kenny RA, Cronin H, O'Regan C, Savva GM, Loughman J, Finucane C, Connolly E, Meagher K, Beatty S. (2012). Education is positively associated with macular pigment: the Irish Longitudinal Study on Ageing (TILDA). Investigative Ophthalmology and Visual Science. 53(12): 7855-7861.

\section{1}

1. Kearney PM, Cronin H, O'Regan C, Kamiya Y, Savva GM, Whelan B, Kenny RA. (2011). Cohort Profile: the Irish Longitudinal Study on Ageing. International Journal of Epidemiology. 40(4):877-84.

2. Kearney PM, Cronin H, O'Regan C, Kamiya Y, Whelan BJ, Kenny RA. (2011). Comparison of centre and home-based health assessments: early experience from the Irish Longitudinal Study on Ageing (TILDA). Age and Ageing. 40(1):85-90.

\section{0}

1. Nolan JM, Kenny R, O'Regan C, Cronin H, Loughman J, Connolly EE, Kearney P, Loane E, Beatty S. 2010. Macular pigment optical density in an ageing Irish population: The Irish Longitudinal Study on Ageing. Ophthalmic Research. 44(2):131-9.

\section{Articles under review}

1. Barrett A, Kamiya Y, O' Sullivan V. (2013). "Childhood Sexual Abuse and Later-Life Economic Consequences" [revising for Journal of Socio-Economics].

2. Barrett A, \& Vincent O' Sullivan. (2013) A Note on Living Standards and Subjective Well-being of Older Irish People Before and During the Economic Crisis." SHARE Discussion Paper.

3. Frewen J, Savva G, Finucane C, Boyle G, Kenny RA. (2013).Cognitive Performance in Orthostatic Hypotension: Findings from a Nationally Representative Sample. Journal of American Geriatric Society.

4. Mosca I, Kenny RA. (2013). Differences in prevalence of diagnosed, measured and undiagnosed hypertension: the case of Ireland and the US. 
5. O' Sullivan V and O' Connell B. (2013). The Effect of Water Fluoridation on the Dentition and Bone Health of Older People in Ireland.

6. O' Sullivan V, Nolan B, Barrett A. (2013). "Income and Wealth in The Irish Longitudinal Study on Ageing." IZA Discussion Paper 7393. [revising for Economic and Social Review].

7. O'Regan C, Cronin H, Finucane C, Kenny R,Kearney PM. (2013). Antidepressants Strongly Influence the Relationship between Depression and Heart Rate Variability: Findings from the Irish Longitudinal Study on Ageing. [revising for Psychological Medicine].

\section{Articles in submission}

1. McCrory C, Dooley C, Layte R, \& Kenny RA. The lasting legacy of childhood adversity for disease risk in later life.

2. McCrory C, Finucane C, Frewen J, O'Hare C, Kenny RA, \& Kearney P. Social disadvantage and social isolation are associated with a higher resting heart rate in men: results from The Irish Longitudinal Study on Ageing (TILDA).

\section{Articles in preparation}

1. Barrett A, Mosca I and Whelan BJ. (Lack of) Pension Knowledge. IZA Discussion Paper 7596. [In Preparation].

2. Beatty S, Akuffo KO, Kenny RA, Feeney J, Cronin H, Dooley C, Stack J, Peto T, Moran $\mathrm{R}$, Nolan JM. Prevalence of age-related macular degeneration in the Republic of Ireland: The Irish Longitudinal Study on Ageing. [In Preparation].

3. Carmody M, Nolan H, Kenny R, Finucane C. Combining the Active Stand Test and Pattern Recognition Methods to Predict Vasovagal Syncope [In Preparation]

4. Coen RF, Robertson DA, Kenny RA, King-Kallimanis BL. Dimensions of the Montreal Cognitive Assessment (MoCA) in a representative sample of Irish community dwelling older adults. [In Preparation].

5. Duggan E, Kenny RA, Donoghue O, Savva G, Cronin H, Finucane C. Contrast sensitivity but not visual acuity is associated with gait in older adults. Journal of American Geriatrics, TILDA. [In Preparation].

6. Dupan S, O Connell M, Kenny R, Finucane C. A Novel Measure of Neural and Mechanical Baroreflex Sensitivity: Understanding Its Relationship to Active Stand 
Responses in Older Adults [In Preparation]

7. Feeney $\mathrm{J}$ et al. Stressful life events are associated with impaired blood pressure recovery after standing in a sample of community dwelling older adults. [In Preparation].

8. Finucane C, Donoghue O, Fan CW, O'Connell MDL, Jansen S, Soraghan C, Savva G, Kenny RA. Does Impaired Orthostatic BP control predict Syncope and Falls in older adults. [In Preparation].

9. Finucane C, O'Connell MDL, Fan CW, Soraghan C, Savva G, Kenny RA. The Spectrum of Orthostatic Blood Pressure Control in Older Community Dwelling Adults. [In Preparation].

10. Finucane C, Savva G, Soraghan C, Kenny RA. Capturing the Patterns of BP Responses to Active Standing in a Population Sample: A Pattern Recognition Approach. [In Preparation].

11. Flood S, O'Hare C, O' Sullivan V. The association between weather and depressive symptoms in older Irish adults. [In Preparation].

12. Hudson E, Barrett A. Peer groups, employment status and depressive symptoms among older adults in Ireland [In Preparation].

13. Jansen S, Frewen J, Finucane C, De Rooij SE, Van Der Velde N, Kenny RA. AF is associated with falls and syncope in a general population cohort. [In Preparation].

14. Killane I, Donoghue OA, Savva GM, Cronin H, Kenny RA, Reilly RB. What Gait Task is Appropriate to Assess Community Dwelling Older Adults? Investigation over the Executive Function Spectrum. [In Preparation].

15. Killane I, Donoghue OA, Savva GM, Cronin H, Kenny RA, Reilly RB. Interpreting Dual Walking Task Data in Clinical Environments: Relative Contribution of Speed of Processing, Short Term Memory and Sustained Attention with Task on Gait Speed. [In Preparation].

16. King-Kallimanis BL, Jensen R, Kenny RA. Investigating Differences in Quality of Life Across Age, Aging Perceptions and Frailty. [In Preparation].

17. King-Kallimanis BL, Kenny RA \& Savva G. Testing Alternative Models of Frailty in the Irish Longitudinal Study of Ageing. [In Preparation].

18. Leahy S, Kenny RA. Obesity is associated with poorer sustained attention in middleage. [In Preparation]. 
19. Leahy S, O' Connell MDL, Kenny RA. Obesity, grip strength and functional ability in older adults. [In Preparation, abstract accepted for ICFSR 2014]

20. McCrory C, Gallagher D, Kenny RA. Control orientation as mediator of the social gradient in depression. [In Preparation].

21. McCrory C, Layte R, Kenny RA. Social gradients and slippery slopes: what have cohort studies contributed to our understanding of the relationship between socio-economic status and health? [In Preparation].

22. McDaid O, Kelly A, Normand C, Smith S M. Cross-sectional analysis of prevalence and patterns of multimorbidity in a community-dwelling Irish cohort. [In Preparation].

23. McDaid O, Kelly A, Smith S M, Normand C. Multimorbidity and healthcare utilisation in a cross sectional study of the community dwelling Irish population aged 50 years and over. [In Preparation].

24. McDaid O, Smith S M, Normand C, Kelly A. Factors associated with multimorbidity in a cross sectional study of the community dwelling Irish population aged 50 years and over. [In Preparation].

25. Morrow J, O Connell M, Kenny R, Finucane C. Identifying the Spectrum of CO and TPR Responses in Older Adults Using Clustering Methods [In Preparation].

26. Mosca I, Barrett A. The Impact of Adult Child Emigration on the Mental Health of Older Parents. [In Preparation].

27. Mosca I, Kenny RA. Investigating Cross-nationals Differences in Prevalence of Diagnosed, Measured and Undiagnosed Hypertension: the Case of Ireland and the US. [In Preparation].

28. Murphy C, Kearney PM, Shelley E, Fahey T, Kenny RA. Hypertension prevalence and awareness in an older Irish cohort. [In Preparation].

29. Murphy C, Whelan BJ, Normand C. Formal home care utilisation by older adults in Ireland: Findings from the Irish Longitudinal Study on Ageing [In Preparation].

30. Nolan H, Finucane C et al. Automated Sleep Segmentation of Accelerometer Recordings in Epidemiological Studies. [In Preparation].

31. Nolan H, Finucane $\mathrm{C}$ et al. Normative Values of Heart Rate Variability and Blood Pressure Variability in the Irish Population. [In Preparation].

32. O'Connell MDL, Savva GM, Fan CW \& Kenny RA. Orthostatic Hypotension, Orthostatic Intolerance and Frailty: The Irish Longitudinal Study on Ageing (TILDA). [In 
Preparation].

33. O'Connell MDL, Savva GM, Finucane C, Romero-Ortuno R, Fan CW, Soraghan C, Cronin H \& Kenny RA. Impairments in Hemodynamic Responses to Orthostasis Associated with Frailty in Older Adults: The Irish Longitudinal Study on Ageing (TILDA). [In Preparation].

34. Peklar J, Henman MC, Kos M, Richardson K, Kenny RA. Concurrent use of drug and food supplements in a community-dwelling population aged 50 years and more: potential benefits and risks. [In Preparation].

35. Peklar J, O'Halloran AM, Maidment I, Henman MC, Kenny RA, Kos M. Sedative load and the frailty syndrome among community-dwelling population aged $\geq 65$ years. [In Preparation].

36. Robertson D A, Savva GM, Coen RF, Kenny RA. Cognitive Function in the Pre-Frailty and Frailty Syndromes. [In Preparation].

37. Robertson D A, Savva GM, Kallimanis BK, Kenny RA. The Influence of Negative Perceptions of Ageing on Walking Speed: A Self-Fulfilling Prophecy. [In Preparation].

38. Romero-Ortuno R, O'Connell MDL, Finucane C, Fan CW, Dooley C \& Kenny RA. Higher Orthostatic Heart Rate Predicts Mortality in the Irish Longitudinal Study on Ageing. [In Preparation].

39. Salter-Townshend M, King-Kallimanis BL, Feeney J, Kenny RA. Network analysis of the Irish Longitudinal Study on Ageing Cognitive Battery. [In Preparation].

40. Sheehan KJ, O'Connell MDL \& Kenny RA. Central Adiposity is an Independent Predictor for the Development of Frailty in Community Dwelling Older Adults. [In Preparation].

41. Soraghan C, Kenny RA, Fan CW, Savva G, Finucane C. A Signal Processing Framework for large scale analysis of active stand responses. [In Preparation].

\section{Other publications}

1. Barrett, A and Mosca, I. 2013. Learning more about the causes and consequences of migration through the Experiences of Ireland's older people. ESRI Research Bulletin.

2. Barrett, A and Kamiya, Y. 2012. Childhood Sexual Abuse and Later-Life Economic Consequences. IZA Discussion Paper 6332.

3. O'Sullivan, V. The Long Term Health Effects of Education. ESRI Working Paper 429. 


\section{The Economic Well-Being of Over 50 s and their Children}

\section{Eibhlin Hudson, Irene Mosca and Vincent O'Sullivan}

\section{Contents}

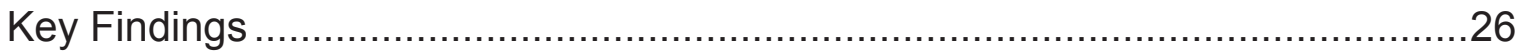

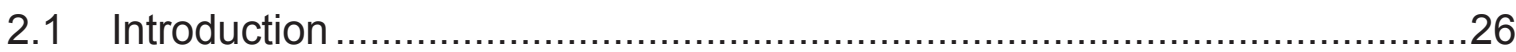

2.2 A comparison of income and wealth between wave 1 and wave $2 \ldots \ldots \ldots . . .27$

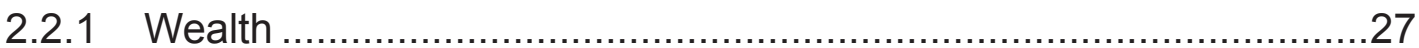

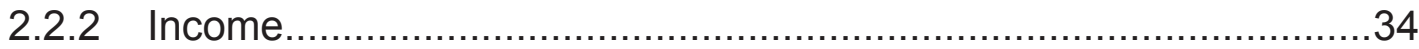

2.3 Employment and retirement............................................................ 41

2.3.1 Principal labour market status ............................................. 41

2.3.2 Changes in labour market status...........................................42

2.4 Migration and labour market outcomes of TILDA participants' adult

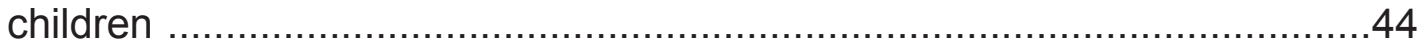

2.4.1 Adult children of TILDA participants: what do we know? ...............45

2.4.2 Adult children's internal and international migration ......................46

2.4.3 Adult children's migration patterns and labour market outcomes.....47 


\section{2 \\ The Economic Well-Being of Over 50 s and their Children}

\section{Key Findings}

- The gross income levels of the TILDA participants remained the same between wave 1 and wave 2 despite a shift away from labour income sources towards retirement income sources.

- Wealth has fallen between wave 1 and wave 2 and this is largely due to reductions in property values.

- Of those who were employed in wave $1,13 \%$ had retired by wave 2 .

- Of these new retirees, a higher percentage of those with higher levels of education had retired before the state pension age (SPA).

- Eligibility for the state pension is the main reason for retirement for new retirees.

- $5 \%$ of the adult children of TILDA participants who were living in Ireland in wave 1 had emigrated by wave 2 .

- Employment levels amongst the adult children of TILDA participants are highest among those who have emigrated or were already living abroad at wave 1.

- Unemployment among children at wave 2 is highest among those who have returned to Ireland from abroad, have returned to live with their parents or were already living with their parents at wave 1

\subsection{Introduction}

In this chapter the economic circumstances of participants and their children is examined from a number of perspectives. Firstly, changes in the income and wealth of participants between wave 1 and 2 of TILDA are examined, as are the sources of income and wealth. Secondly, changes in labour market status between waves are examined. Although labour market status, income and wealth might not have changed for many participants, they are likely to have changed for some, particularly for those who were approaching retirement age at wave 1. 
Thirdly, as youth migration patterns to and from Ireland have changed substantially in recent years, the participants' children's internal and international migration patterns between wave 1 and wave 2 are investigated. Specifically, the relationship between children's migration patterns and labour market outcomes is examined.

\subsection{A comparison of income and wealth between wave 1 and wave 2}

In this section, changes in the income and wealth of the TILDA participants between wave 1 and wave 2 are discussed. In the analysis below, one will see that the wealth of older people has fallen and this is largely due to continuing reductions in property values. The analysis also shows that the gross income levels of the TILDA participants remained the same despite a shift away from labour income sources towards retirement income sources.

\subsubsection{Wealth}

In this sub-section which discusses wealth, the sample used is a subset of the total TILDA sample. Firstly, only participants who responded to both waves and who were over the age of 50 in wave $1(n=6,984)$ are used in the analysis in this sub-section. Secondly, a large number of participants chose not to respond to certain questions relating to their wealth or responded that they did not know the value of certain items. A further 3,284 observations are dropped from the analysis for this reason (i.e., the participants did not know, or refused to provide information about at least one component of their wealth). Three quarters of these missing values that were dropped were due to non-response to wealth questions in wave 1 . The improved rate of complete cases in wave 2 was due to changes in the modes of response offered to the participants in wave 2. In wave 2 of TILDA, participants who did not give exact answers to the wealth questions were offered banded answers as a response. The final working sample for the analysis in this sub-section consists of 3,700 participants.

In both waves of TILDA the financial respondent within each household is asked whether or not they hold, and their own valuations of: owner occupied residential property; savings on deposit; financial assets; cars; other residential property; other types of assets such as farmland and businesses. The value of total household gross assets can be derived from aggregating the values of these assets. The value of total household net assets is obtained by subtracting non-mortgage debt and mortgage debt from total household gross assets. 
Table 2.1: Proportion holding different types of assets and debt

\begin{tabular}{|l|c|c|c|c|}
\hline & \multicolumn{2}{|c|}{ wave 1} & \multicolumn{2}{c}{ wave 2} \\
\hline Owner Occupied Housing & $\%$ & $(95 \% \mathrm{Cl})$ & $\%$ & $(95 \% \mathrm{Cl})$ \\
\hline Savings on Deposit & 88.2 & $(86.4,89.9)$ & 85 & $(83.2,86.8)$ \\
\hline Financial Assets & 64 & $(61,66.9)$ & 76 & $(73.6,78.4)$ \\
\hline Cars & 29.5 & $(27.2,31.9)$ & 24.8 & $(22.6,26.9)$ \\
\hline Other Assets & 77.8 & $(75.6,79.9)$ & 78.7 & $(76.7,80.8)$ \\
\hline Non-Owner Occupied Housing & 20 & $(17.8,22.1)$ & 19.4 & $(17.4,21.5)$ \\
\hline Mortgage Debt & 11.9 & $(10.4,13.3)$ & 12.3 & $(10.9,13.7)$ \\
\hline Non-Mortgage Debt & 26.4 & $(24.2,28.6)$ & 26.3 & $(24.2,28.3)$ \\
\hline Any Assets & 12.1 & $(10.7,13.6)$ & 11.1 & $(9.8,12.4)$ \\
\hline
\end{tabular}

In Table 2.1 one can see that the proportion owning cars, non-owner occupied housing and other types of assets such as business assets has remained broadly the same between waves. The proportion owning their own home has fallen slightly (from $88 \%$ in wave 1 to $85 \%$ in wave 2), but is still of a similar magnitude. However there has been an increase in the percentage with savings on deposit by about twelve percentage points to about $76 \%$. This rise in people having savings was not fully offset by the reduction in the proportion of the sample who hold financial assets (from approximately $30 \%$ in wave 1 to $25 \%$ in wave 2). The increase in the number of participants with savings, and indeed the reduction in those holding riskier financial assets, could be interpreted as a precautionary reaction in a time of uncertain economic conditions. Overall there has been a slight increase in the proportion with any wealth from about $93 \%$ in wave 1 to about $96 \%$ in wave 2 .

From Table 2.2 it can be seen that the median value of total household gross assets has fallen from around $€ 271,000$ in wave 1 to $€ 229,000$ in wave 2. In Figure 2.1 one can see that the 65-74 age group had the biggest losses in absolute terms and in relative terms. One can see from Figure 2.2 that when categorising individuals by highest educational group, all groups experienced losses and that the losses were around 10-15\% for each educational group.

From Figure 2.1 and 2.2 it is evident that the slopes of the gradients of wealth against age 
and education are preserved between waves. The data in Figure 2.3 present the entire distribution of wealth in both waves of TILDA. For both waves, about a fifth of the over 50 s have less than $€ 100,000$ in wealth, and about two thirds have wealth of less than $€ 350,000$. For both waves, around $6 \%$ have wealth in excess of $€ 1,000,000$.

Table 2.2: Median value of assets for those holding the assets (in $€ k$ )

\begin{tabular}{|c|c|c|c|c|}
\hline & \multicolumn{2}{|c|}{ wave 1} & \multicolumn{2}{|c|}{ wave 2} \\
\hline & Median & (95\% Cl) & Median & (95\% Cl) \\
\hline Owner Occupied Housing & 230 & $(223,237)$ & 180 & $(173,187)$ \\
\hline Savings on Deposits & 20 & $(19,21)$ & 20 & $(19,21)$ \\
\hline Financial Assets & 20 & $(18,22)$ & 20 & $(17,23)$ \\
\hline Cars & 5 & $(5,5)$ & 5 & $(5,5)$ \\
\hline Other Assets & 100 & $(80,120)$ & 150 & $(133,167)$ \\
\hline Non-Owner Occupied Housing & 200 & $(180,220)$ & 150 & $(136,164)$ \\
\hline Gross Assets & 271 & $(261,281)$ & 229 & $(219,239)$ \\
\hline Mortgage Debt & 56 & $(50,62)$ & 54 & $(48,60)$ \\
\hline Non-Mortgage Debt & 9 & $(8,10)$ & 8 & $(7,8)$ \\
\hline Net Assets & 255 & $(244,266)$ & 213 & $(203,223)$ \\
\hline
\end{tabular}

Figure 2.1: Median value of total household gross assets by age (in $€$ )

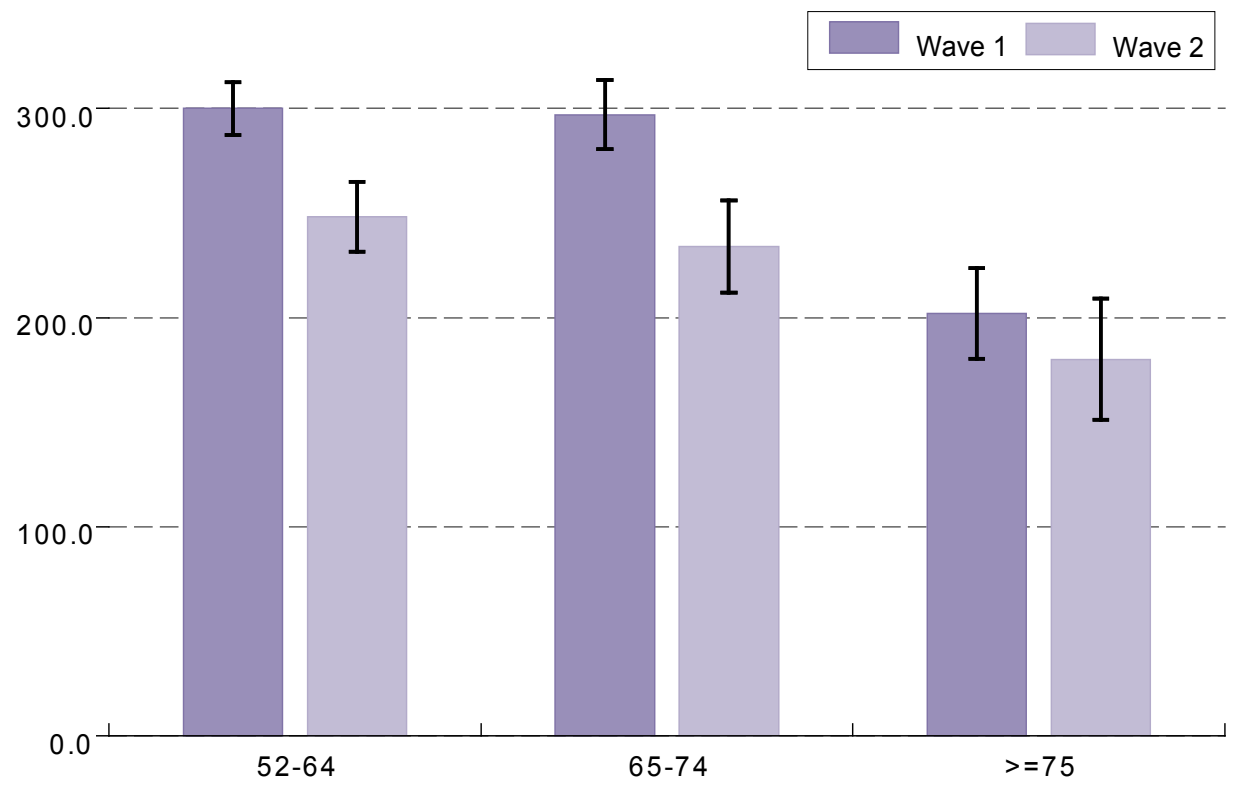

Note. $\mathrm{N}=3700 ;$ Missing obs $=1219$; Error bars correspond to $95 \%$ confidence intervals 
Figure 2.2: Median value of total household gross assets by highest educational attainment (in €k)

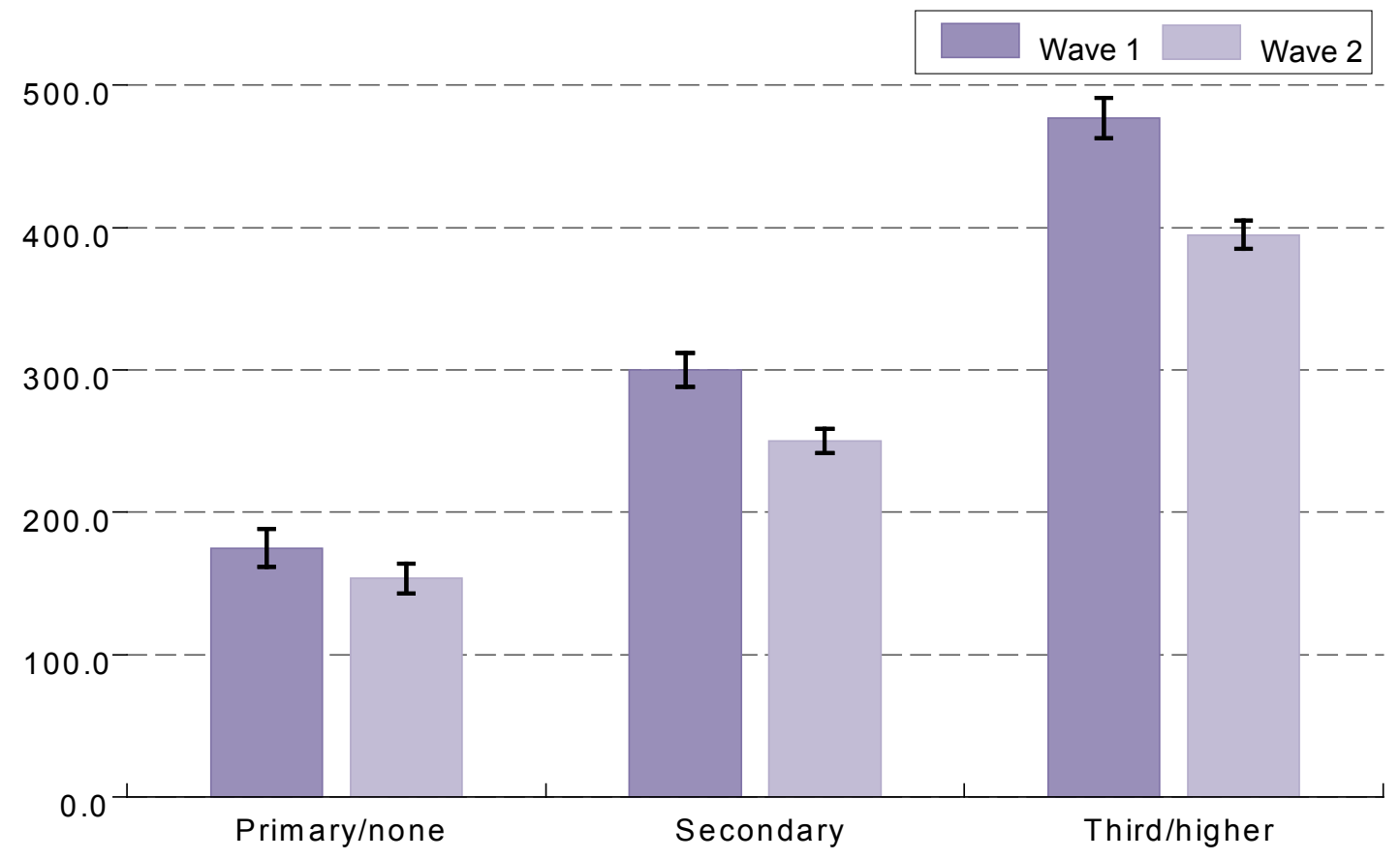

Note. $\mathrm{N}=3699 ;$ Missing obs $=1220$; Error bars correspond to $95 \%$ confidence intervals

Figure 2.3: The distribution of total household gross assets

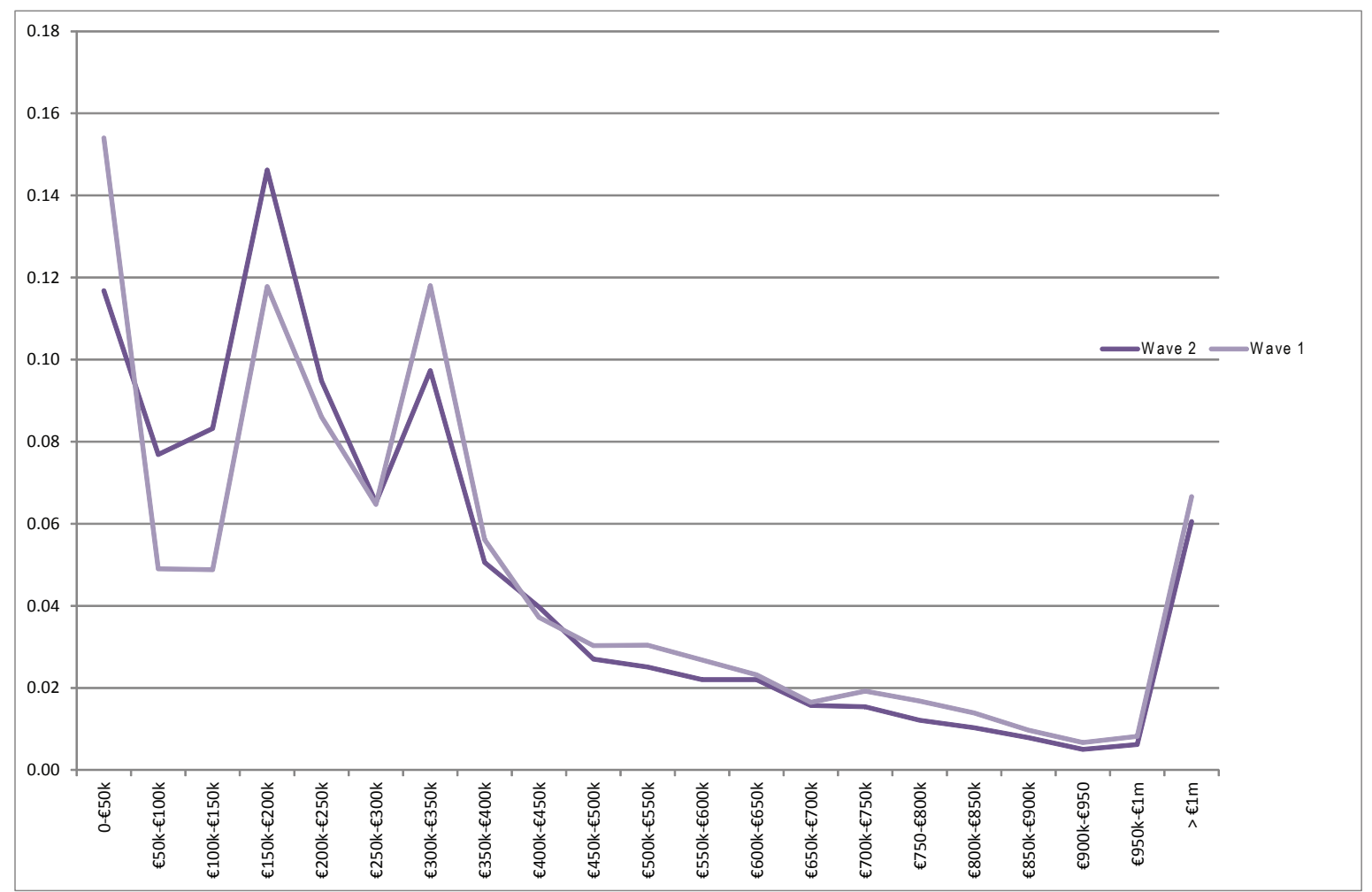


The Gini coefficient is a standard measure of inequality used throughout the world. A Gini coefficient of zero represents perfect equality in a society while a Gini coefficient of one represents a perfectly unequal society. The estimated Gini coefficients for total household gross assets were found to be roughly similar for each wave at a value of around 0.53 . Due to the paucity of both Irish and international wealth data it is hard to put the estimated wealth Gini coefficients into context. However, wealth Gini coefficients ranging from 0.547 to 0.808 have been estimated for all ages in certain OECD countries using data from the late 1990s to the early 2000s (1). Thus the Gini coefficient for the wealth of older Irish people appears to be on the lower range of wealth inequality internationally.

Table 2.3 shows the average composition of the total asset portfolio of the over 50 s. There were two statistically significant changes in the asset portfolio. Firstly, owner-occupied housing wealth as a percentage of total wealth fell from about $71 \%$ to about $67 \%$ between waves. Secondly, savings on deposit as a percentage of total wealth rose from just under $10 \%$ in wave 1 to just under $13 \%$ in wave 2 . All of the other components more or less maintained their share of overall wealth between wave 1 and wave 2 .

Table 2.3: Proportion of total wealth held in each type of asset

\begin{tabular}{|c|c|c|c|c|}
\hline & \multicolumn{2}{|c|}{ wave 1} & \multicolumn{2}{|c|}{ wave 2} \\
\hline & $\%$ & $(95 \% \mathrm{Cl})$ & $\%$ & $(95 \% \mathrm{Cl})$ \\
\hline Owner Occupied Housing & 71.1 & $(69.7,72.5)$ & 67.1 & $(65.7,68.5)$ \\
\hline Savings on Deposits & 9.8 & $(9,10.6)$ & 12.7 & $(11.8,13.5)$ \\
\hline Financial Assets & 3.8 & $(3.3,4.3)$ & 3.5 & $(2.9,4)$ \\
\hline Cars & 4.1 & $(3.6,4.7)$ & 4.9 & $(4.3,5.5)$ \\
\hline Other Assets & 7.3 & $(6.3,8.2)$ & 8.3 & $(7.4,9.3)$ \\
\hline $\begin{array}{l}\text { Non-Owner Occupied } \\
\text { Housing }\end{array}$ & 3.9 & $(3.4,4.4)$ & 3.6 & $(3.1,4)$ \\
\hline Total & 100 & & 100 & \\
\hline
\end{tabular}

In Table 2.2 it can be seen that median valuations of owner-occupied housing wealth fell from around $€ 230,000$ in wave 1 to $€ 180,000$ in wave 2 . Given that approximately $85 \%$ of participants own their home (see Table 2.1) and that owner-occupied housing wealth makes up about two thirds of overall gross wealth in wave 2 (see Table 2.3), changes in housing values have big effects on overall total wealth. 
Staying with property assets, one can see from Table 2.1 that about $12 \%$ of households own non-owner occupied housing and this has remained constant between waves. The median value of these second and subsequent homes has fallen greatly from $€ 200,000$ in wave 1 to $€ 150,000$ in wave 2 (see Table 2.2).

In Table 2.1 it can be seen that the percentage of those with savings on deposit has risen from $64 \%$ in wave 1 to $76 \%$ in wave 2 . The median level of savings for those who hold savings remained at about $€ 20,000$ between waves (see Table 2.2). The percentage holding financial assets other than savings on deposit has fallen from about $30 \%$ in wave 1 to about $25 \%$ in wave 2 (see Table 2.1). These assets include life insurance (current cash value), mutual funds, bonds or shares. The value of these financial assets for those who hold them is approximately $€ 20,000$ in both waves of TILDA (see Table 2.2).

In Table 2.1 one can see that the percentage of households holding other types of assets such as business assets and farmland has remained at about $20 \%$ between waves. About $50 \%$ of these other types of assets are concentrated in the hands of those who are selfemployed (including farmers) and their partners. In Table 2.2 it can be seen that the value of these assets rose from a median $€ 100,000$ in wave 1 to a median of $€ 150,000$ in wave 2.

Figure 2.4: Median value of total household net assets by age (in $€ k$ )

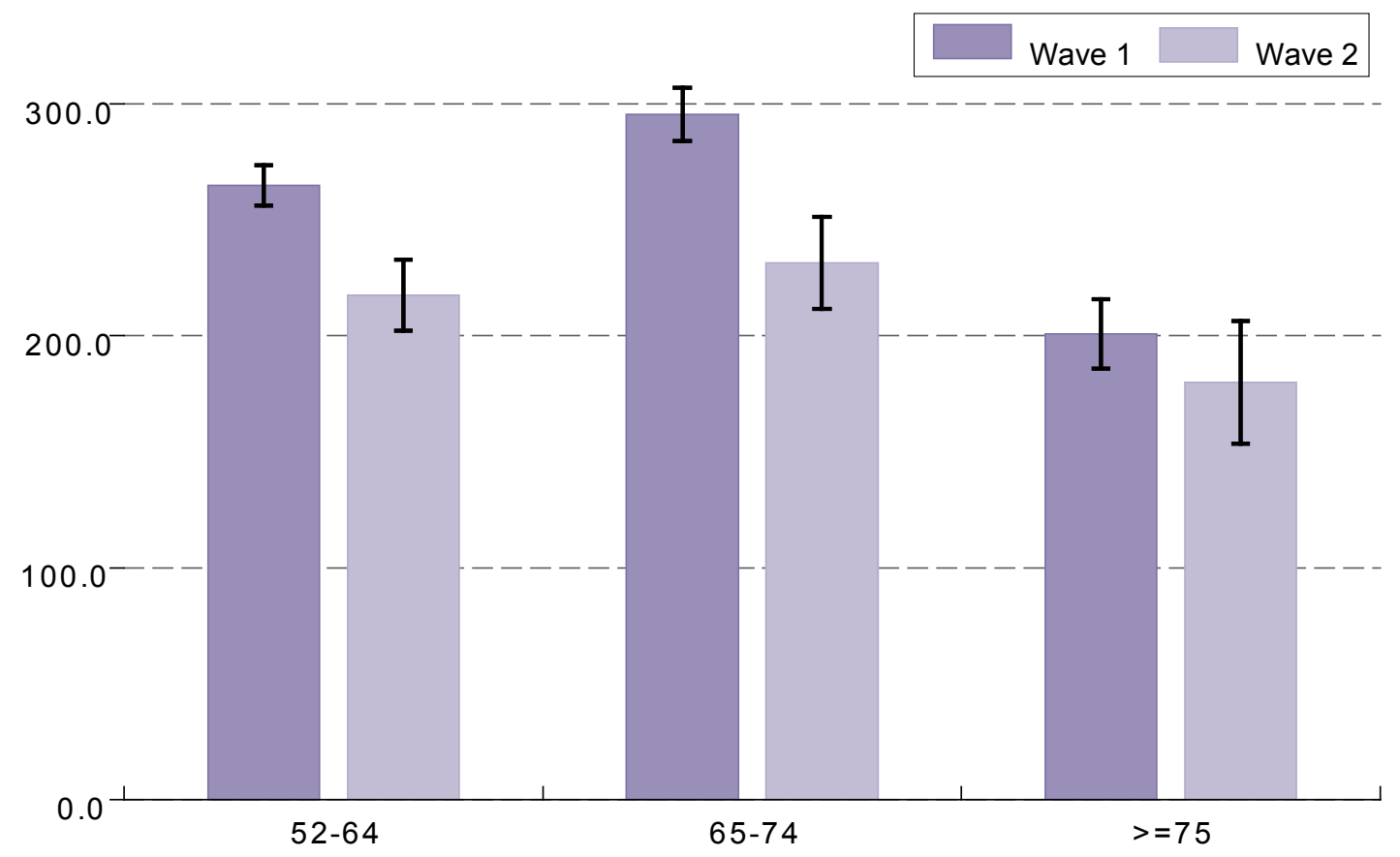

Note. $N=3700 ;$ Missing obs $=1219 ;$ Error bars correspond to $95 \%$ confidence intervals 
In Table 2.1 one can see that the percentage of those with non-mortgage debt (around $26 \%$ ) and mortgage debt (around $11-12 \%$ ) has not changed significantly between waves. Table 2.2 shows that the median amount of outstanding non-mortgage debt has fallen slightly from $€ 9,000$ in wave 1 to $€ 8,000$ in wave 2 . The median amount of remaining mortgage debt has also fallen slightly from $€ 56,000$ in wave 1 to $€ 54,000$ in wave 2 .

Finally from Table 2.2, it is evident that total net assets have fallen from $€ 255,000$ in wave 1 to $€ 213,000$ in wave 2. In Figure 2.4 and Figure 2.5 one can see that falls in net assets affected all age groups and education groups, similar to the findings above in relation to gross assets levels.

Figure 2.5: Median value of total household net assets by highest educational attainment (in $€ k$ )

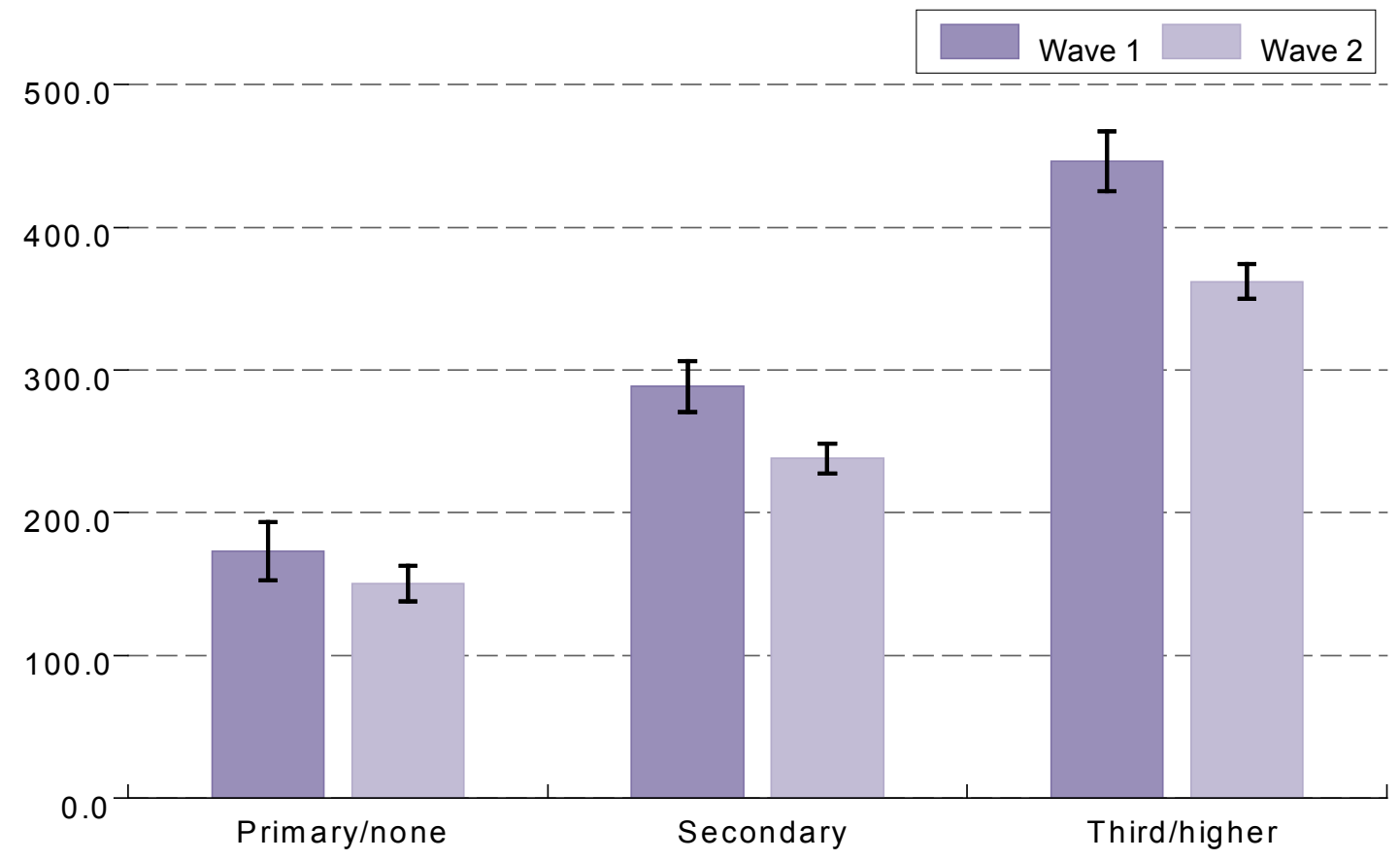

Note. $N=3699 ;$ Missing obs = 1220; Error bars correspond to $95 \%$ confidence intervals

While the types of assets held by participants have not changed drastically, the value of these assets has fallen. Owner-occupied housing is the largest component of overall wealth, and therefore falls in property values drive much of the decrease in wealth between waves. By relying on self-reported values of assets, the true level of wealth is being measured with error. Furthermore, the degree and direction of measurement error may differ according to different demographic characteristics. For example, those participants with adult children who bought property in the last number of years may 
have a better assessment of what their own property is worth. Additionally there could be differences in the accuracy of people's assessment of their wealth over the course of the two waves of TILDA. According to the Daft Report 2013 Q2, the rate of decline in asking prices for houses nationally during the first wave of TILDA was about $1.6 \%$ from month to month. However, this appears to have slowed down to less than $1 \%$ per month during the period in which wave 2 of TILDA was collected (2). With house prices stabilising during the collection of wave 2 and a greater number of transactions on the market, participants may have been better able to value their properties.

\subsubsection{Income}

In both waves of TILDA, all eligible participants within each household are asked about their overall level of income and the different sources of income. In this sub-section, the sources of income are categorised as labour income (from employment or selfemployment); occupational or private pension income; and social insurance and social allowance income. In this analysis, social insurance and social allowance income includes the contributory and non-contributory old age pensions. Asset income is not considered as there was a change in wave 2 in the way in which participants were asked about their savings on deposit. This is unlikely to affect our calculations as asset income only makes up around $5 \%$ of total gross income in wave 1 . Throughout this sub-section, only gross individual-level income is reported and all amounts are expressed in terms of weekly income.

In this sub-section, which analyses changes in income, only participants who responded to both waves and who were over the age of 50 in wave $1(n=6,984)$ are examined. A further 1,161 observations are dropped as the participants did not know or refused to provide information on at least one component of their income. This leaves a working sample of 5,823 .

As shown in the first row of Table 2.4, weekly median gross income at an individual level was around $€ 240$ in each wave. Stratifying by the age of the participant at wave 2, it can be seen in Figure 2.6 that median income is down slightly for those aged 52-64 from just over $€ 325$ per week in wave 1 to just under $€ 300$ per week in wave 2 , but slightly up for those aged 65-74 from just over $€ 230$ per week in wave 1 to just under $€ 238$ per week in wave 2 (but the increase for those aged 65-74 years is not statistically significant). Median income for those aged 75 and over increased from €233 per week in wave 1 to $€ 239$ per week in wave 2 but the difference between waves is statistically insignificant. 
Table 2.4: Median value of weekly gross ncome by source (in €)

\begin{tabular}{|l|c|c|cr|}
\hline & \multicolumn{2}{|c|}{ wave 1} & \multicolumn{3}{c|}{ wave 2} \\
& Median & $(95 \%$ CI) & Median & $(95 \%$ CI) \\
\hline All Income* & 240 & $(234,245)$ & 240 & $(234,246)$ \\
\hline Pension Income** & 250 & $(222,278)$ & 267 & $(242,291)$ \\
\hline Social Insurance/Allowance Income ** & 219 & $(217,220)$ & 225 & $(224,227)$ \\
\hline Labour Income** $^{* *}$ & 500 & $(478,522)$ & 500 & $(478,522)$ \\
\hline
\end{tabular}

*all observations **non-zero observations

Figure 2.6: Median value of weekly gross income by age (in €)

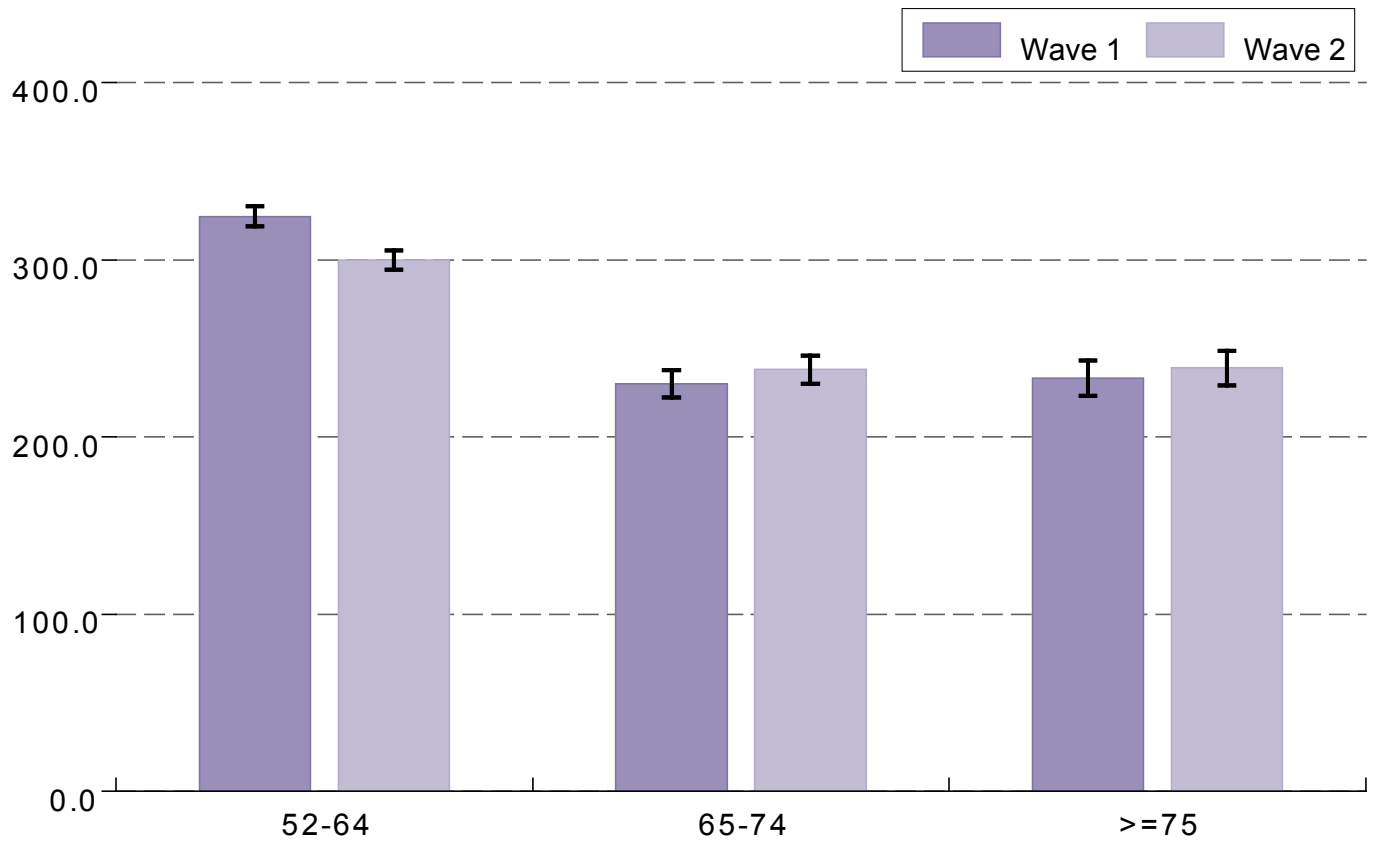

Note. $N=5823$; Missing obs $=0$; Error bars correspond to $95 \%$ confidence intervals

Median incomes fell from $€ 593$ per week in wave 1 to $€ 550$ per week in wave 2 for those with third level education or higher (see Figure 2.7). However graduates still have median incomes that are over twice the size of those whose highest level of education is primary education (€230 in wave 2). 
Figure 2.7: Median value of weekly gross income by highest educational attainment (in €)

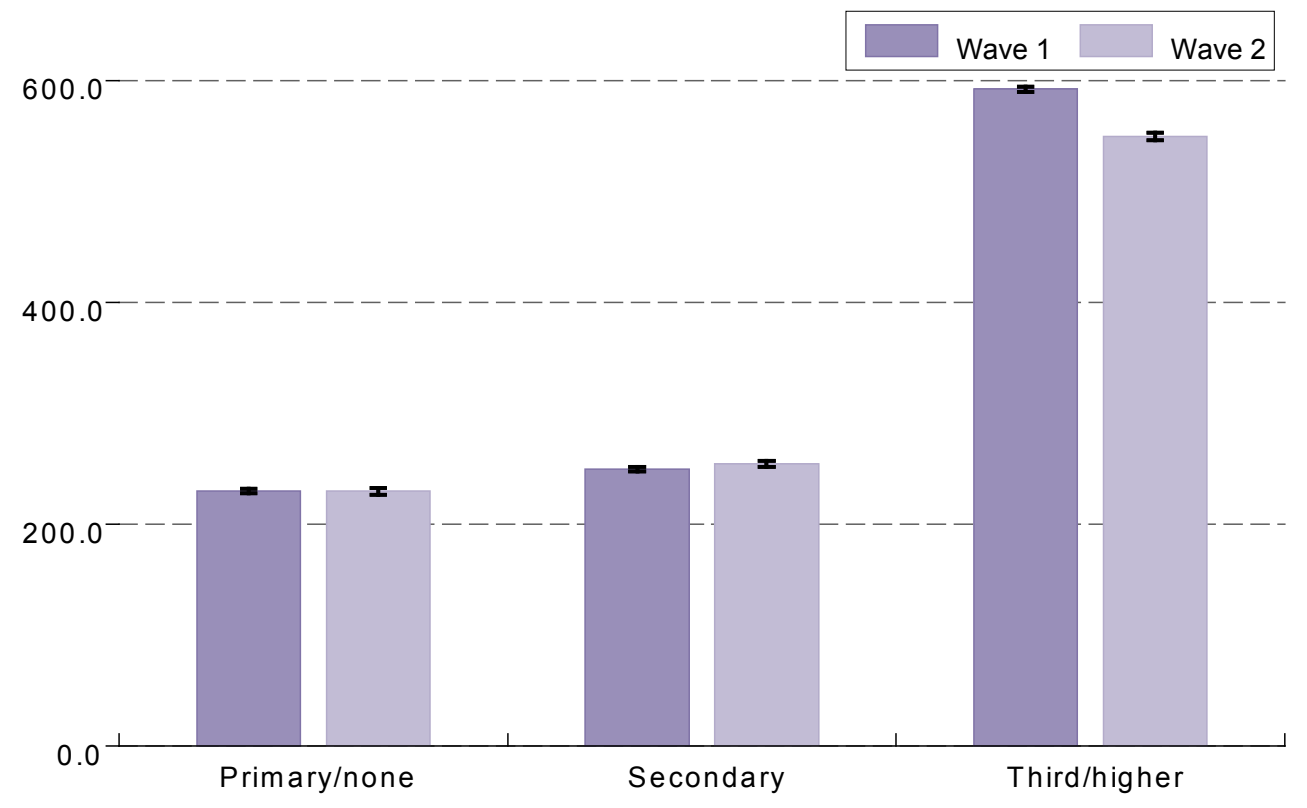

Note. $\mathrm{N}=5822$; Missing obs $=1$; Error bars correspond to $95 \%$ confidence intervals

In Figure 2.8 the entire gross weekly income distribution for both waves of TILDA is presented. The distributions nearly completely overlap. The mass of distribution around the $€ 200-€ 300$ per week category represent those on fixed social insurance/allowance income. For both waves of TILDA around $12 \%$ of individuals have gross incomes of over $€ 1,000$ per week.

In the last three rows of Table 2.4 the levels of income from the three different sources, conditional on having any income from that source, are shown. The data illustrate that the levels of income from the different sources have remained more or less the same between waves, with the exception of income from social insurance/allowances which increased significantly from $€ 219$ per week in wave 1 to $€ 225$ per week in wave 2 . The most striking finding is that there has been switching away from some sources and towards other sources of income. In Table 2.5 one can see how the percentage of those in receipt of different sources of income has changed between waves. The percentage of those in receipt of labour income has fallen from about $35 \%$ in wave 1 to about $29 \%$ in wave 2. There have been corresponding increases of about four percentage points in the percentage of those receiving pension (private or occupational) income or social insurance/allowance income ${ }^{1}$. In each wave about $11 \%$ of participants state that they do not have their own source of income from labour, pensions, social insurance or social

1. The overwhelming majority of those receiving non-state pensions do so from occupational schemes rather than from private pensions. 
allowances.

Figure 2.8: The distribution of weekly gross income

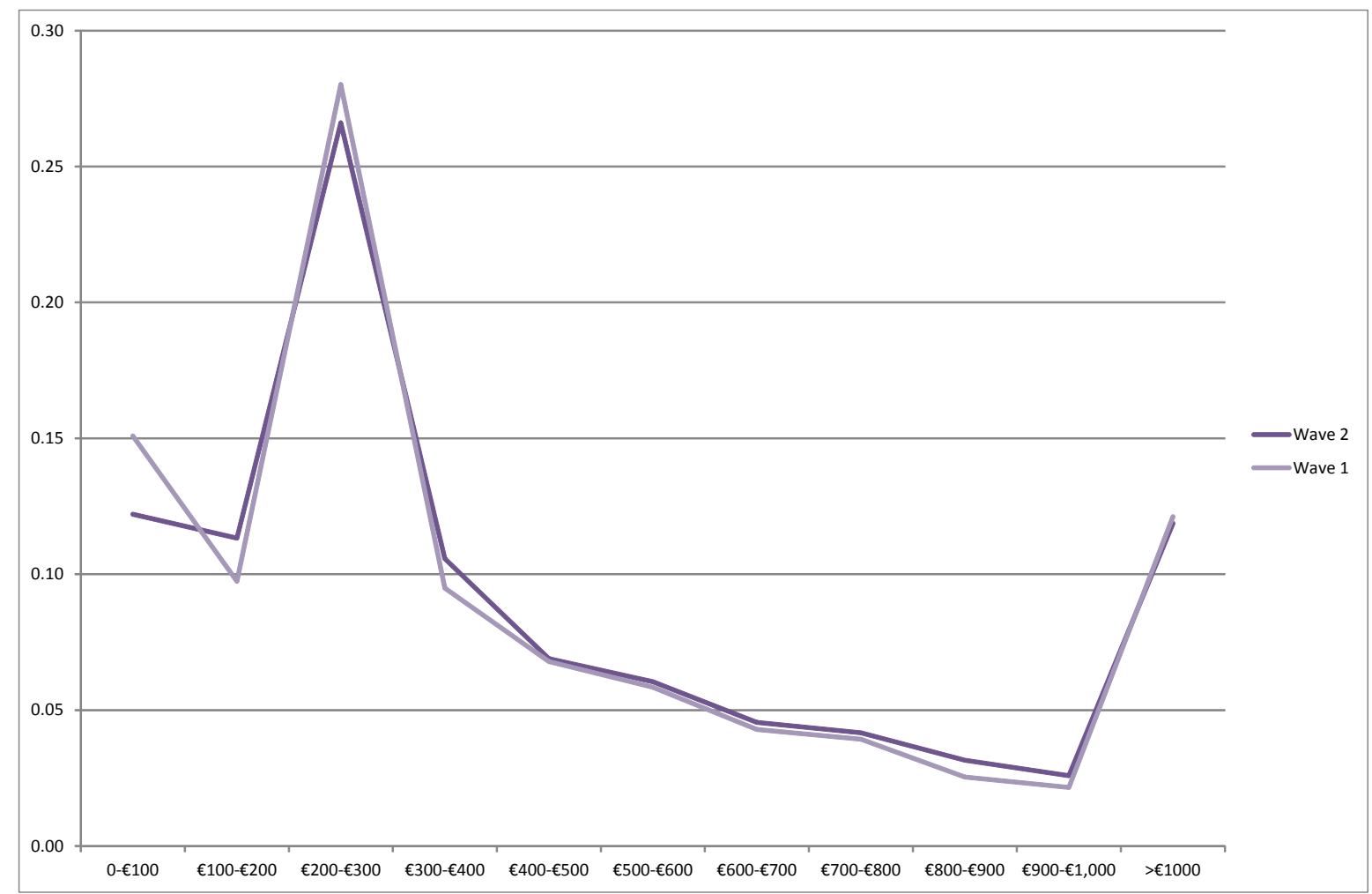

Table 2.5: Proportion in receipt of different sources of income

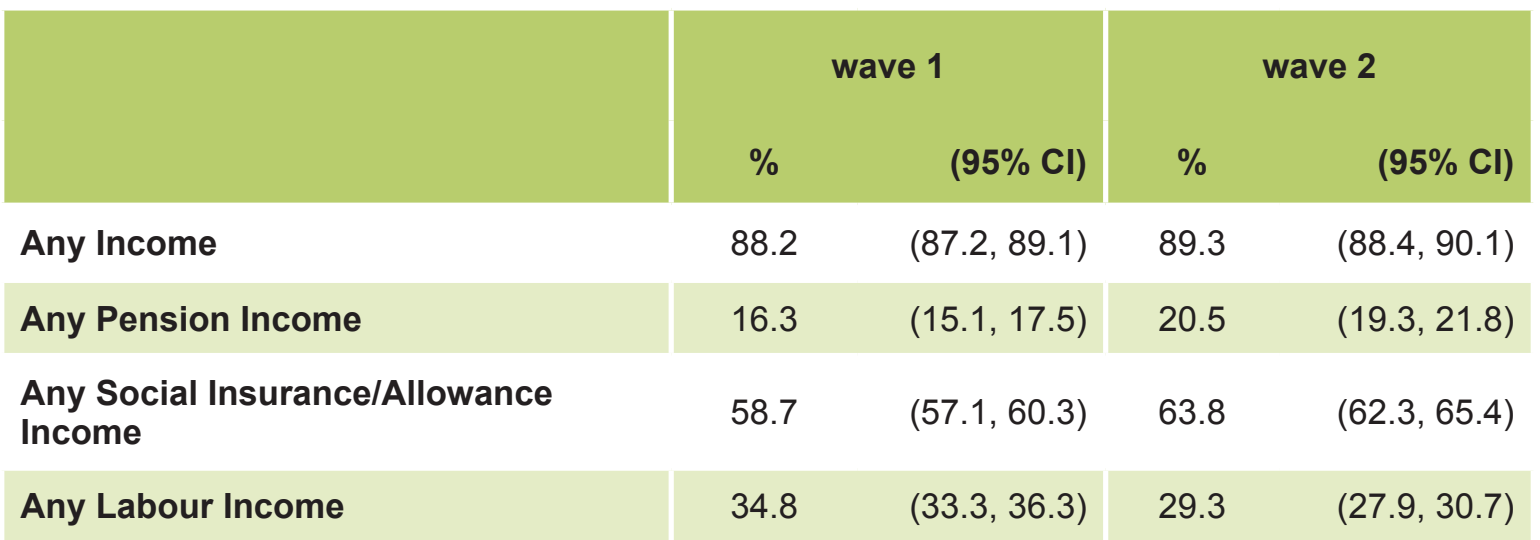

*all observations **non-zero observations

In relation to the fall in those receiving any labour income in Figure 2.9, it can be seen that there is a fall in the percentage receiving labour income amongst those aged 65-74 (from about $17 \%$ in wave 1 to just above 10\% in wave 2). This is a reflection of those who reached the state pension age (SPA) between waves. However there is also a fall in the percentage earning labour income amongst those aged $52-64$ from about $55 \%$ in wave 1 
to about $48 \%$ in wave 2 . Only about $5 \%$ of those aged 75 and over in both waves have any labour income.

Figure 2.9: Proportion with labour income in wave 2 by age

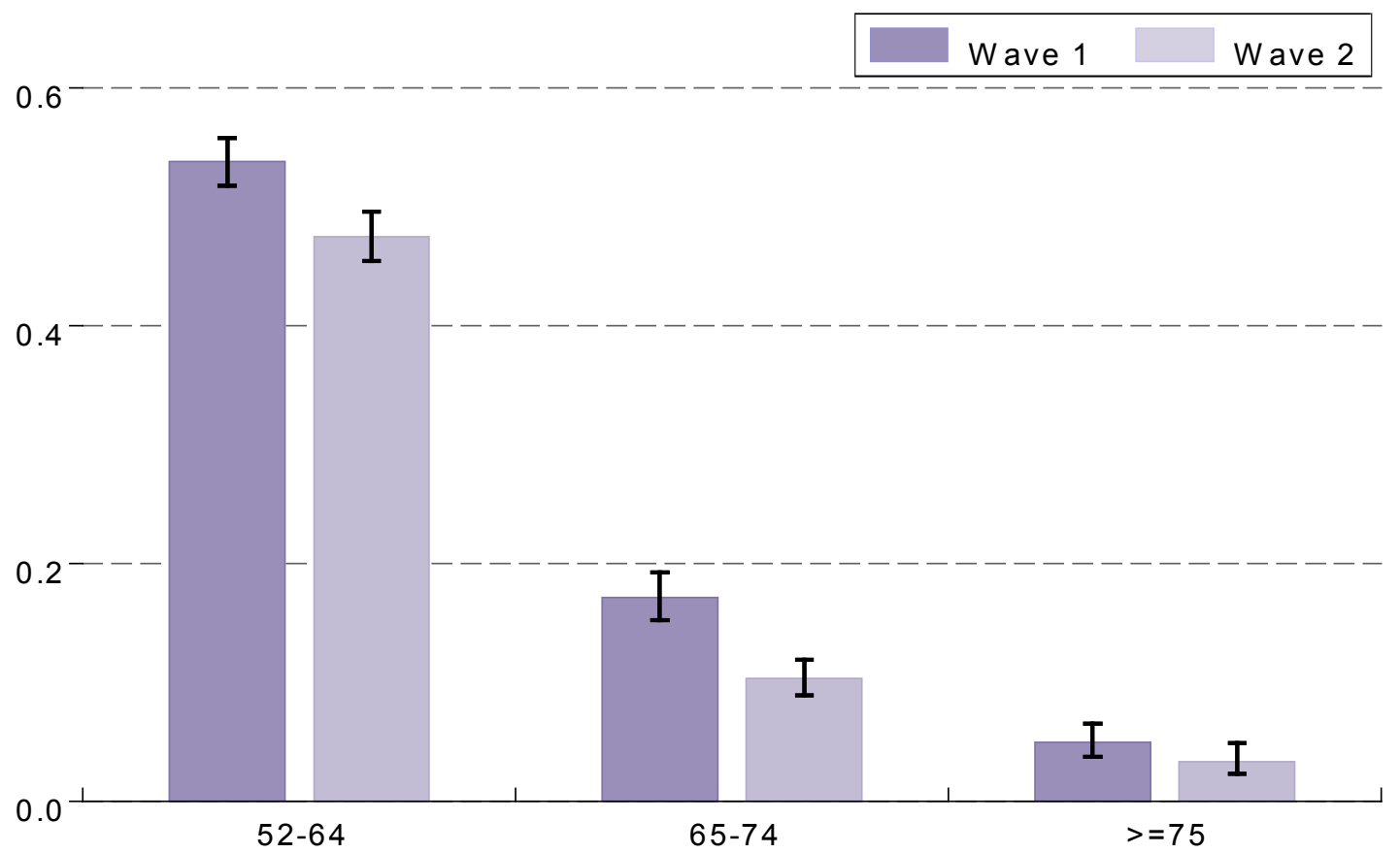

Note. $\mathrm{N}=5823$; Missing obs $=0$; Error bars correspond to $95 \%$ confidence intervals

From Figure 2.10 it is evident that most of the increase in those with income from occupational or private pensions can be attributed to those in the 65-74 age group (where the proportion in that age group with occupational or private pension income increased from about $28 \%$ in wave 1 to about $34 \%$ in wave 2). The percentage aged 75 and over who receive pension income rose from just under $25 \%$ in wave 1 to just over $28 \%$ in wave 2 but this rise was not statistically significant. There was also an increase from $8 \%$ to about $13 \%$ in the percentage of the youngest age group (aged 52-64 years) receiving pension income between wave 1 and wave 2 .

It can be seen from Figure 2.11 that nearly all of the increase in social insurance/allowance as a source of income can be attributed to participants aged between 65 and 74 years. The percentage of this age group in receipt of social insurance/allowance income rose from about $74 \%$ in wave 1 to about $87 \%$ in wave 2 . The percentage of those aged 75 and older in receipt of social insurance/allowance income remained constant at about $91 \%$ between waves. The percentage of those aged 64 and younger receiving social insurance/ allowance income rose marginally from $38 \%$ in wave 1 to about $41 \%$ in wave 2 , but this increase was not statistically significant. 
Figure 2.10: Proportion with pension income by age
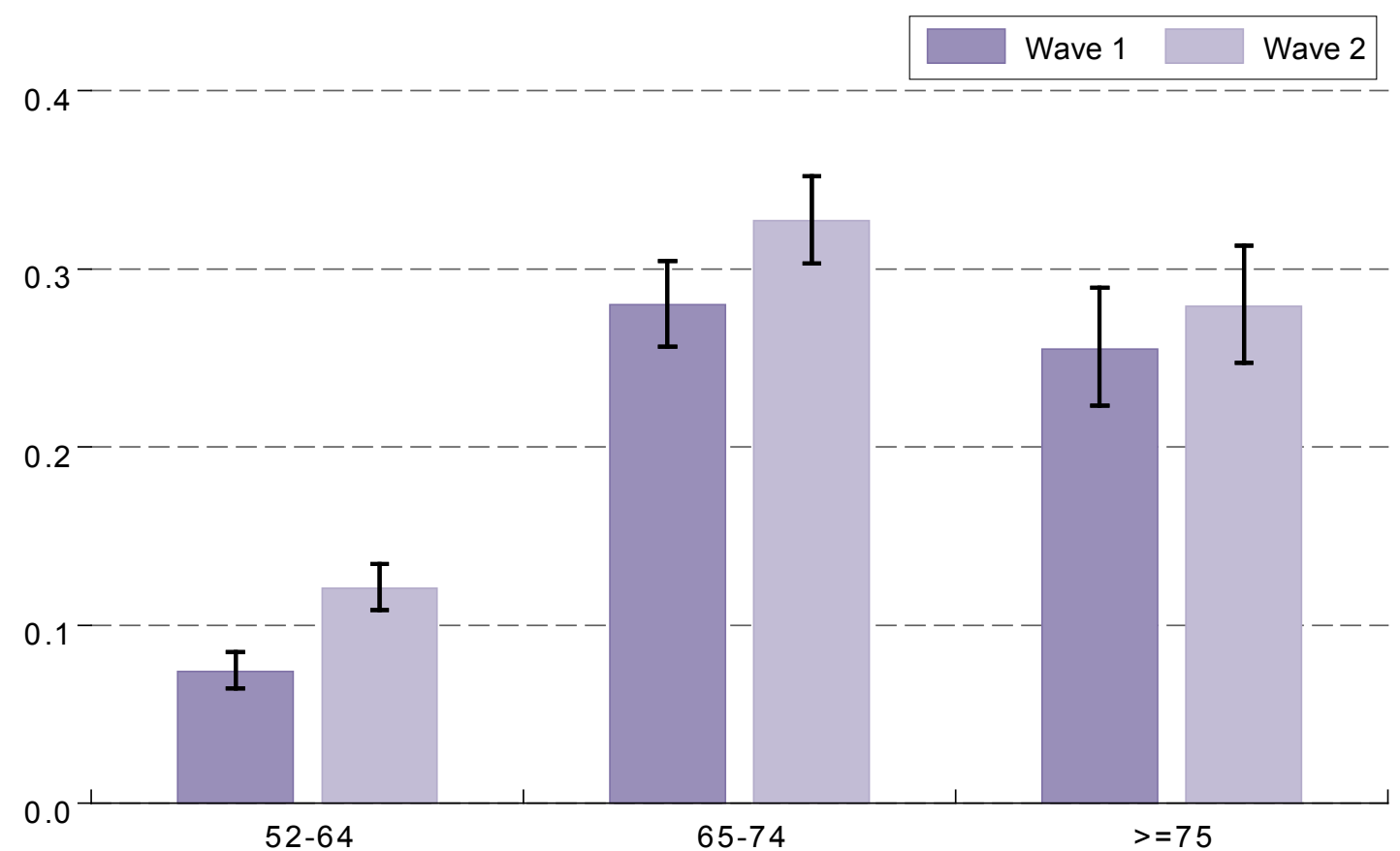

Note. $\mathrm{N}=5823$; Missing obs $=0$; Error bars correspond to $95 \%$ confidence intervals

Figure 2.11: Proportion with social insurance/allowance income by age

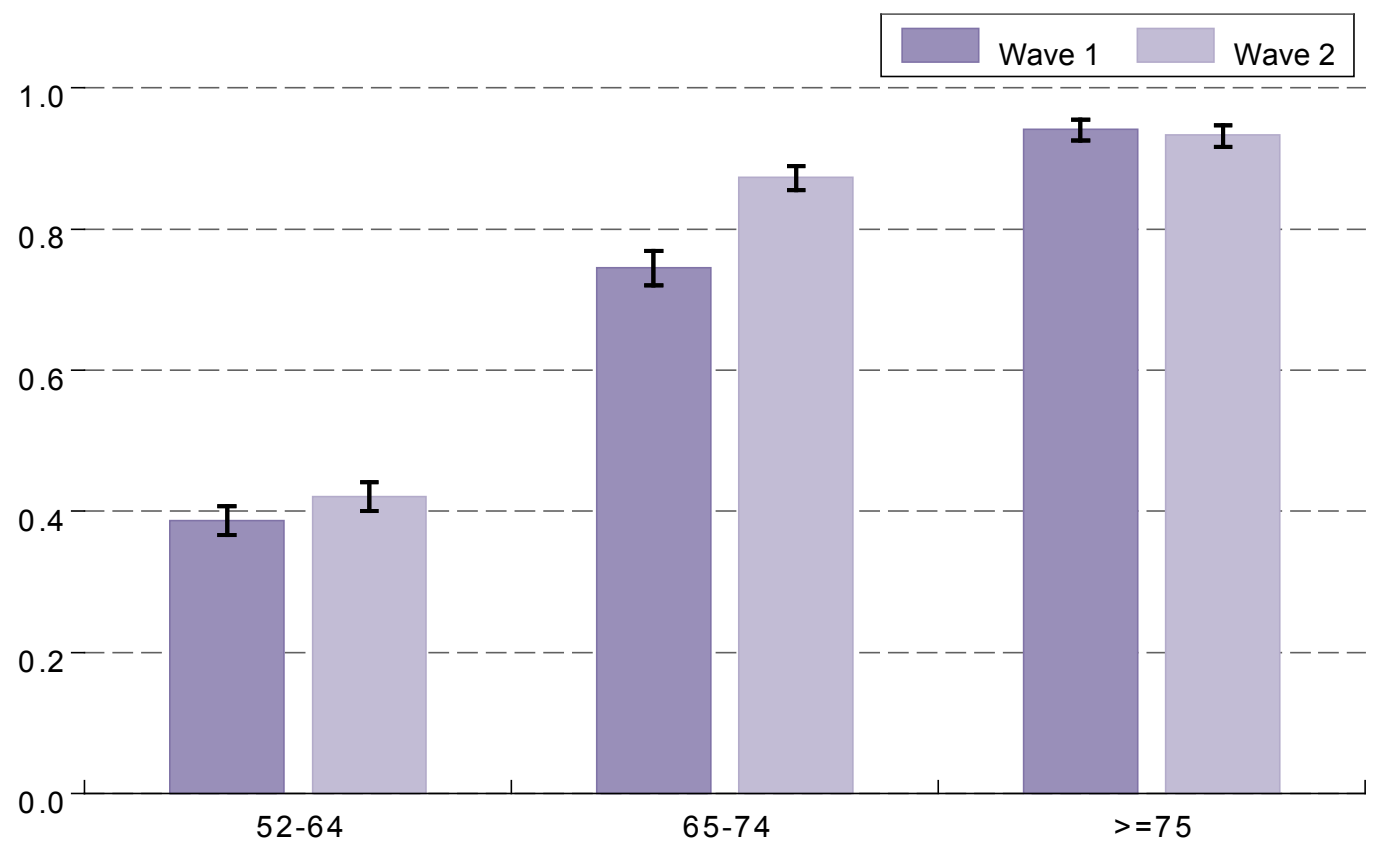

Note. $\mathrm{N}=5823$; Missing obs $=0$; Error bars correspond to $95 \%$ confidence intervals 
Figure 2.12: Proportion with social insurance/allowance income as sole source or no income by highest educational attainment

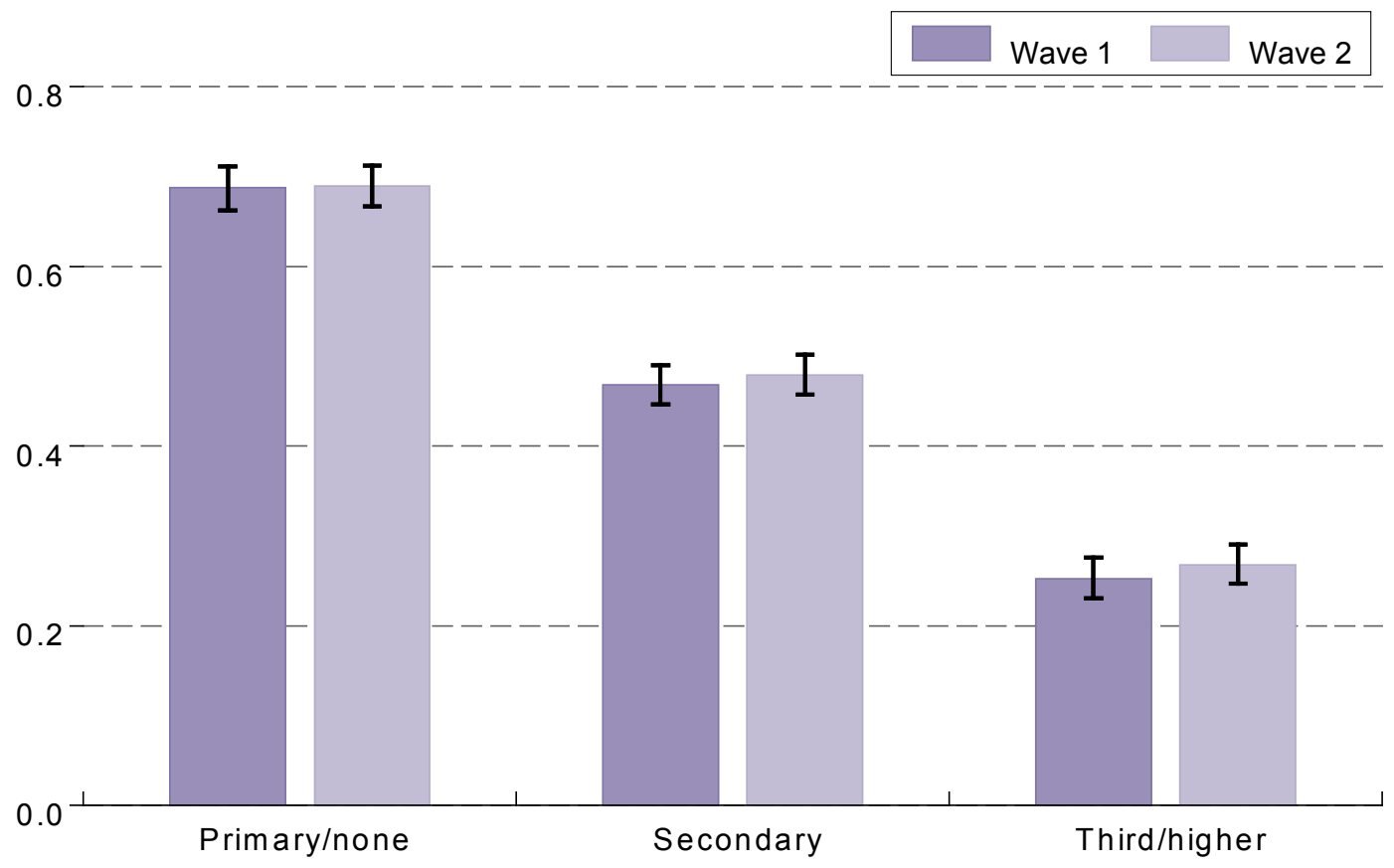

Note. $\mathrm{N}=5822$; Missing obs $=1$; Error bars correspond to $95 \%$ confidence intervals

About half of people in both waves are dependent on social insurance/allowance for their income or have no source of income of their own. Figure 2.12 shows that about two thirds of those with primary education as their highest level of education have no source of income or depend on social insurance/allowance as their only source, but this applies to only around a quarter of those with third level education or higher degrees.

Finally, Table 2.6 shows the share of total gross income accounted by the different sources. The percentage of total income from occupational or private pensions has increased by about three percentage points to just over $13 \%$ of total income. The proportion of total gross weekly income accounted for by social insurance/allowance income has risen from $55 \%$ in wave 1 to just under $59 \%$ in wave 2 . Conversely labour income as a source of total income has fallen by about 6-7 percentage points to just over $28 \%$ of total income in wave 2 . These changes in the sources of income are all statistically significant. This reinforces the move away from labour as a source of income towards pension and social insurance/allowance income sources that was shown in previous tables and figures. 
Table 2.6: Proportion of total weekly gross income from different sources

\begin{tabular}{|l|c|c|c|c|}
\hline & \multicolumn{2}{|c|}{ wave 1 } & \multicolumn{2}{c|}{ wave 2 } \\
& $\%$ & $(95 \%$ CI) & $\%$ & $(95 \%$ CI) \\
\hline Pension Income & 10.2 & $(9.3,11)$ & 13.1 & $(12.1,14)$ \\
\hline Social Insurance/Allowance Income & 55 & $(53.4,56.7)$ & 58.6 & $(57,60.2)$ \\
\hline Labour Income & 34.8 & $(33.2,36.4)$ & 28.3 & $(26.8,29.8)$ \\
\hline Total & 100.0 & & 100.0 & \\
\hline
\end{tabular}

\subsection{Employment and retirement}

As people age, many people consider or experience a change in labour market status. The impact of labour market status on the lives of older people is important both at an individual and societal level. A detailed overview of the labour force participation of participants was provided in the summary report based on data collected in the first wave of the study (3). This overview is built upon in this section by examining changes in labour market status between waves. In particular, transitions from employment to retirement are examined as are the characteristics of these new retirees both above and below the state pension age (SPA).The sample employed refers to participants who participated in both waves of the study and who provided information on labour force status at each wave $(n=7,285)$.

\subsubsection{Principal labour market status}

In each wave, participants are asked to report the status that best describes their current labour market situation from the following options: retired; employed; self-employed; unemployed; permanently sick or disabled; looking after home or family; in education or training; and other. It should be noted that these are self-reports and that participants are asked to choose the response that 'best' describes their current situation. Participants can only select one status. For example, a participant that is both retired and looking after their home or family chooses which of these categories best describes their current situation.

For ease of exposition, employed and self-employed participants are grouped together. Those in education or training are grouped with those classified as 'other' due to the small number of participants in this category. The distribution of labour market status is examined with respect to age and education. Overall a lower proportion of women are employed compared to men. Unsurprisingly, the proportion of both men and women above the current SPA of 65 years in employment is lower than those aged below the SPA. For 
example, in wave 2 , approximately $61 \%$ of men aged under 65 are employed compared to $13 \%$ of men over 65 (see Table 2.7 ).

Table 2.7: Labour market status at wave 2 by age and sex

\begin{tabular}{|c|c|c|c|c|c|c|c|c|c|c|c|c|c|c|}
\hline \multirow[b]{2}{*}{ Female } & $\%$ & Retired & \multicolumn{2}{|c|}{ Employed } & \multicolumn{2}{|c|}{ Unemployed } & \multicolumn{2}{|c|}{$\begin{array}{c}\text { Sick/ } \\
\text { Disabled }\end{array}$} & \multicolumn{2}{|c|}{$\begin{array}{l}\text { Looking after } \\
\text { home/family }\end{array}$} & \multicolumn{2}{|r|}{ Other } & Total & $\begin{array}{c}\text { Number } \\
\text { in } \\
\text { sample }\end{array}$ \\
\hline & & & & & & & & & & & & & & \\
\hline Under 65 & 13 & $(11-14)$ & 47 & $(44-49)$ & 4 & $(3-5)$ & 6 & $(5-7)$ & 29 & $(26-31)$ & 2 & $(1-2)$ & 100 & 2255 \\
\hline 65 and over & 56 & (53-58) & 6 & $(5-7)$ & 0 & $(0-1)$ & 4 & $(3-5)$ & 33 & $(30-36)$ & 1 & $(1-2)$ & 100 & 1799 \\
\hline Total & 34 & $(32-36)$ & 27 & $(25-28)$ & 2 & $(2-3)$ & 5 & $(4-6)$ & 31 & $(29-33)$ & 1 & $(1-2)$ & 100 & 4054 \\
\hline \multicolumn{15}{|l|}{ Male } \\
\hline Under 65 & 15 & $(14-17)$ & 61 & $(58-63)$ & 14 & $(12-16)$ & 8 & $(7-10)$ & 1 & $(0-1)$ & 2 & $(1-2)$ & 100 & 1638 \\
\hline 65 and over & 84 & $(81-85)$ & 13 & $(12-15)$ & 1 & $(0-1)$ & 1 & $(1-2)$ & 0 & $(0-1)$ & 1 & $(0-1)$ & 100 & 1593 \\
\hline Total & 46 & $(44-48)$ & 39 & $(37-41)$ & 8 & $(7-9)$ & 5 & $(4-6)$ & 1 & $(0-1)$ & 1 & $(1-2)$ & 100 & 3231 \\
\hline \multicolumn{15}{|l|}{ Total } \\
\hline Under 65 & 14 & $(13-15)$ & 54 & $(52-56)$ & 9 & $(8-10)$ & 7 & $(6-8)$ & 15 & $(13-16)$ & 2 & $(1-2)$ & 100 & 3893 \\
\hline 65 and over & 68 & $(66-70)$ & 9 & $(8-10)$ & 0 & $(0-1)$ & 3 & $(2-3)$ & 18 & $(17-20)$ & 1 & $(1-1)$ & 100 & 3392 \\
\hline Total & 40 & $(38-41)$ & 33 & $(31-34)$ & 5 & $(4-6)$ & 5 & $(4-6)$ & 16 & $(15-17)$ & 1 & $(1-2)$ & 100 & 7285 \\
\hline
\end{tabular}

\subsubsection{Changes in labour market status}

As participants were asked about their labour market status in both waves, transitions between labour market states can be examined. Table 2.8 shows the labour market status of participants in wave 2 by their labour market status in wave 1. As the time between waves was relatively short most participants have not changed labour market status, particularly those who were employed or retired at wave 1. Disaggregating the patterns in Table 2.8 by sex is not appropriate as the numbers for some transitions are very small.

Overall, $13 \%$ of those who were employed at wave 1 had retired by wave 2, while $79 \%$ remain in employment in wave 2 . Of those who were retired in wave $1,83 \%$ remain retired in wave $2,3 \%$ are back in employment, $1 \%$ report that they are unemployed at wave $2,3 \%$ are sick or disabled and $9 \%$ are now looking after home or family.

Changes in labour market status are more common for those that were not employed or retired at wave 1. For example, of those who were permanently sick or disabled in wave 1 , 
although $47 \%$ remain sick or disabled at wave 2, $24 \%$ retired, $4 \%$ are in employment, $6 \%$ are unemployed and $17 \%$ look after their home or family. Of those who were unemployed in wave $1,49 \%$ remain unemployed at wave $2,14 \%$ now classify themselves as retired, $19 \%$ regained employment, $7 \%$ are now permanently sick or disabled and $8 \%$ report that looking after their home or family is their principal labour market status.

One of the more interesting labour market transitions is that from employment to retirement. As noted, $13 \%$ of those who were employed at wave 1 moved into retirement by wave 2. Of these 354 people who retired, over half were over the SPA (approximately $53 \%$ ). A higher proportion of those with higher levels of education retired before the SPA than in the groups with lower levels of education (see Figure 2.13). As the employed were more likely to have higher levels of education it is not surprising that high education is a characteristic of these early retirees.

Participants were also asked their main reason for retiring. Pension eligibility was the main reason for retirement for most participants. For $21 \%$ of those with either primary or no education, ill-health was their main reason for retirement, in comparison with just $4 \%$ of those with a third level or higher education. 'To enjoy life' was the main reason for retirement for $12 \%$ and $11 \%$ of those with primary and secondary education respectively. For $23 \%$ of those with tertiary education, 'to enjoy life' was the main reason for retirement (see Table 2.9).

Table 2.8: Changes in labour market status between wave 1 and wave 2

\begin{tabular}{|c|c|c|c|c|c|c|c|c|c|c|c|c|c|c|}
\hline \multirow[b]{2}{*}{ Retired (W1) } & \multicolumn{2}{|c|}{$\begin{array}{l}\text { Retired (W2) } \\
\% \quad(95 \% \mathrm{Cl})\end{array}$} & \multicolumn{2}{|c|}{$\begin{array}{l}\text { Employed (W2) } \\
\% \quad(95 \% \mathrm{Cl})\end{array}$} & \multicolumn{2}{|c|}{$\begin{array}{l}\text { Unemployed (W2) } \\
\% \quad(95 \% \mathrm{Cl})\end{array}$} & \multicolumn{2}{|c|}{$\begin{array}{l}\text { Sick/Disabled (W2) } \\
\% \quad(95 \% \mathrm{CI})\end{array}$} & \multicolumn{2}{|c|}{$\begin{array}{l}\text { Looking after home/ } \\
\text { family (W2) }\end{array}$} & \multicolumn{2}{|c|}{$\begin{array}{c}\text { Other (W2) } \\
\% \quad(95 \% \mathrm{Cl})\end{array}$} & \multirow{2}{*}{$\begin{array}{l}\text { Total } \\
100\end{array}$} & \multirow{2}{*}{$\begin{array}{l}\begin{array}{c}\text { Number in } \\
\text { sample }\end{array} \\
2555\end{array}$} \\
\hline & 83 & $(82-85)$ & 3 & $(2-4)$ & 1 & $(0-1)$ & 3 & $(2-4)$ & 9 & $(8-11)$ & 1 & $(1-1)$ & & \\
\hline Employed (W1) & 13 & $(12-14)$ & 79 & $(77-80)$ & 3 & $(3-4)$ & 1 & $(1-2)$ & 2 & $(2-3)$ & 1 & $(1-2)$ & 100 & 2774 \\
\hline Unemployed (W1) & 14 & $(11-18)$ & 19 & $(15-24)$ & 49 & $(44-55)$ & 7 & $(5-10)$ & 8 & $(6-12)$ & 3 & $(2-6)$ & 100 & 355 \\
\hline Sick/Disabled (W1) & 24 & $(20-29)$ & 4 & $(2-7)$ & 6 & $(4-9)$ & 47 & $(42-53)$ & 17 & $(13-22)$ & 2 & $(1-4)$ & 100 & 328 \\
\hline $\begin{array}{l}\text { Looking after home/ } \\
\text { family (W1) }\end{array}$ & 22 & $(19-26)$ & 7 & $(5-9)$ & 2 & $(1-3)$ & 3 & $(2-4)$ & 65 & $(62-68)$ & 1 & $(1-2)$ & 100 & 1130 \\
\hline Other (W1) & 28 & $(21-37)$ & 23 & $(16-31)$ & 8 & $(4-14)$ & 9 & $(5-17)$ & 22 & $(15-31)$ & 10 & $(6-16)$ & 100 & 141 \\
\hline Total & 40 & $(38-41)$ & 33 & $(31-34)$ & 5 & $(4-6)$ & 5 & $(4-6)$ & 16 & $(15-17)$ & 1 & $(1-2)$ & 100 & 7283 \\
\hline
\end{tabular}

Note. $\mathrm{Cl}=$ confidence interval; Missing observations $=14.05 \%$ 
Figure 2.13: New retirees by age and highest educational attainment

\section{Under 65 65 and over}

Female

Male

$1.0^{-}$
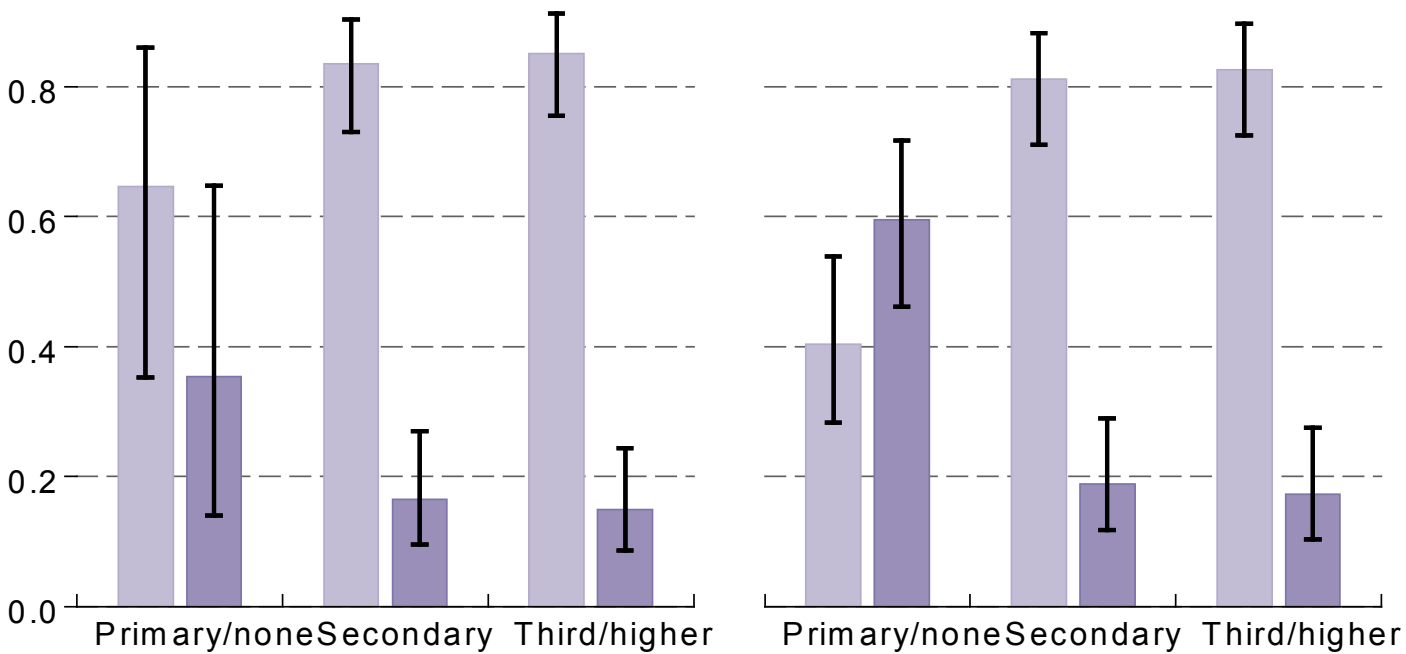

Note. $\mathrm{N}=354$; Missing obs $=0$; Error bars correspond to $95 \%$ confidence intervals

While these results may suggest a divide between wanting to retire and needing to retire among those with different education levels, the differences between education groups in the proportion reporting 'to enjoy life' as their main reason for retirement are not statistically significant.

Table 2.9: Main reason for retirement

\begin{tabular}{|c|c|c|c|c|c|c|c|c|c|c|c|c|}
\hline \multirow[b]{3}{*}{ Primary/none } & \multirow{2}{*}{\multicolumn{2}{|c|}{$\begin{array}{l}\text { Eligible for } \\
\text { SPA } \\
\% \quad(95 \% \mathrm{CI})\end{array}$}} & \multicolumn{2}{|c|}{$\begin{array}{l}\text { Eligible for } \\
\text { occupational } \\
\text { pension }\end{array}$} & \multicolumn{2}{|c|}{ III health } & \multicolumn{2}{|c|}{$\begin{array}{l}\text { To enjoy } \\
\text { life }\end{array}$} & \multicolumn{2}{|c|}{ Other } & \multirow[t]{2}{*}{ Total } & \multirow[t]{2}{*}{$\begin{array}{l}\text { Number } \\
\text { in sample }\end{array}$} \\
\hline & & & $\%$ & $95 \% \mathrm{Cl})$ & $\%$ & $(95 \% \mathrm{Cl})$ & $\%$ & $(95 \% \mathrm{Cl})$ & $\%$ & $(95 \% \mathrm{Cl})$ & & \\
\hline & 33 & $(25-42)$ & 2 & $(1-7)$ & 21 & $(14-30)$ & 12 & $(7-20)$ & 31 & $(23-40)$ & 100 & 122 \\
\hline Secondary & 37 & $(29-47)$ & 12 & $(7-19)$ & 10 & $(6-17)$ & 11 & $(6-18)$ & 30 & $(23-39)$ & 100 & 115 \\
\hline Third/higher & 23 & $(13-36)$ & 19 & $(11-33)$ & 4 & $(1-12)$ & 23 & $(13-36)$ & 31 & $(21-44)$ & 100 & 60 \\
\hline Total & 34 & $(28-39)$ & 8 & $(5-12)$ & 15 & $(11-20)$ & 13 & $(9-17)$ & 31 & $(25-37)$ & 100 & 297 \\
\hline
\end{tabular}




\subsection{Migration and labour market outcomes of TILDA participants' adult children}

It is well known that the Irish economy has changed significantly in the last decade; after sustaining a strong economic growth, Ireland has been hit by a severe recession. Coupled with drastic changes in the economy, migration patterns to and from Ireland have changed substantially (see also Chapter 1 ). Ireland has shifted, once again, from a country with positive net migration to a country with negative net migration. For example, the Central Statistics Office (CSO) estimates that in 2007 the number of immigrants exceeded the number of emigrants by around 105,000 (4). By 2012, the pattern had reversed with an estimated negative net migration of around 34,400 . The majority of individuals who left Ireland in 2012 were younger adults aged between 15 and 44 (4).

The adult children of TILDA participants are among those who have recently left the country or have recently returned to Ireland. In both the first and second wave of TILDA, information on children is collected through an extensive battery of questions on the number and characteristics of participants' children. As a result of this, TILDA data can be used in a novel way to investigate children's characteristics and to examine whether, and the extent to which, children's conditions have changed between the two waves. Perhaps more importantly, by collecting data on both children and parents, TILDA data can be used to investigate how changes in children's outcomes affect parents' outcomes.

In this section, children's internal and international migration patterns between wave 1 and wave 2 are first investigated. Next, the relationship between children's migration patterns and labour market outcomes is examined. This section differs from the rest of this chapter and from the rest of this report because it focuses on younger Irish adults and not on the older Irish population.

\subsubsection{Adult children of TILDA participants: what do we know?}

TILDA participants are asked a number of questions about their children. The same questions are asked at wave 1 and wave 2 . For each living child, the following information is collected: age, marital status, place of residence, educational attainment and labour market status.

The analysis of this section is based on children for whom complete information on place of residence and labour market status is provided at wave 1 and wave 2 . Children who have died between the two waves and children of new participants are excluded. The 
analysis is restricted to adult children aged 21 to 44 years. This is done to ensure that the children on which the analysis is based are a relatively homogenous group. The analysis is based on 10,496 children.

\subsubsection{Adult children's internal and international migration}

Of the 10,496 children of TILDA participants on which the analysis is based, $14.4 \%$ were living with their parents at wave 1,68.2\% were living in Ireland but not with their parents and the remaining $17.4 \%$ were living abroad. Because information on children's place of residence is collected also at wave 2, children's internal and international migration between the two waves can be examined. One can see from Figure 2.14 that although most children have not moved between the two survey waves, a non-negligible proportion of children have migrated internally, emigrated or returned to Ireland. These findings are in line with the CSO figures discussed above.

Figure 2.14: Children's place of residence at wave 2 by children's place of residence at wave 1

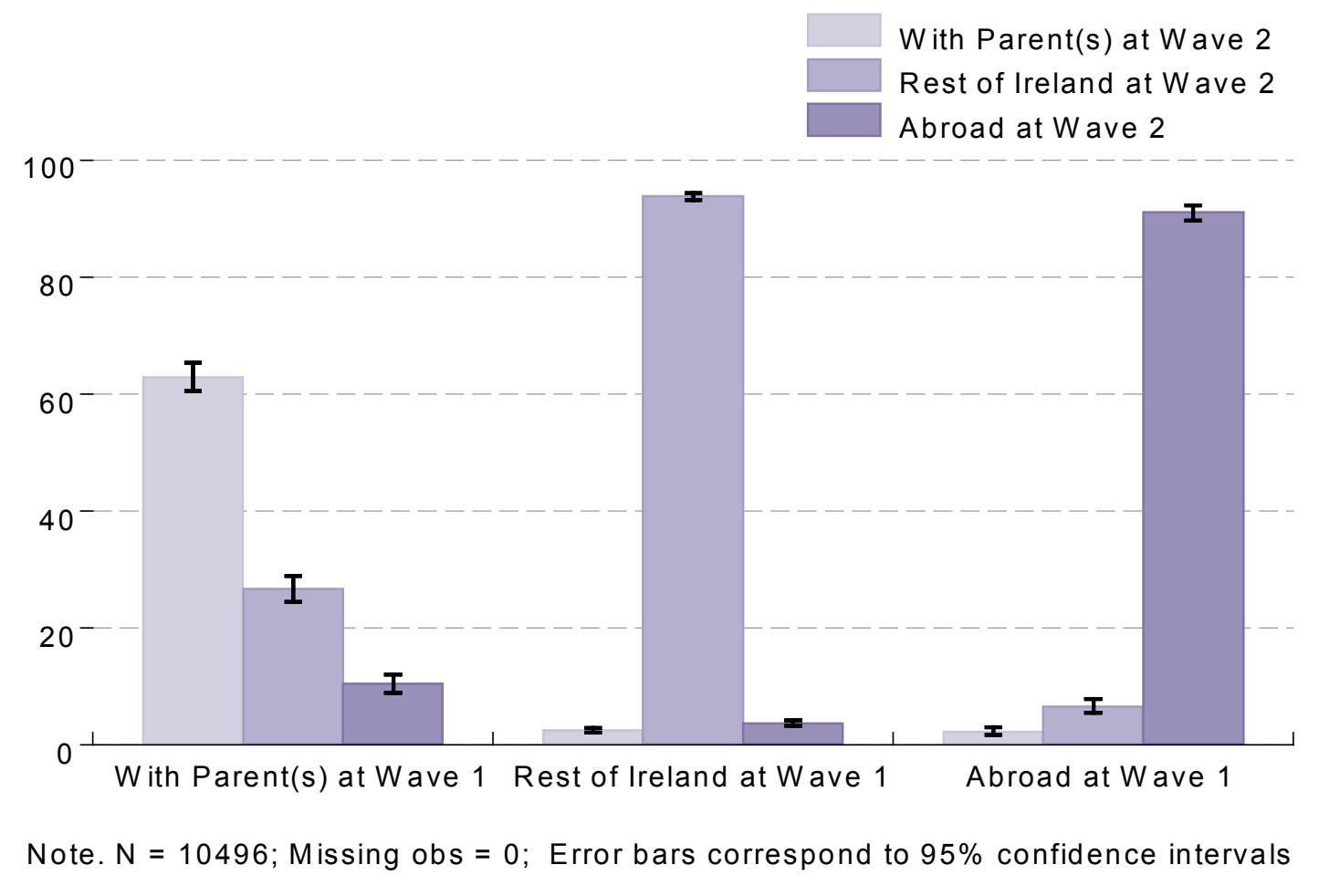

Figure 2.14 shows that, of the children living with their parents at wave 1, 62.9\% are still living with their parents at wave $2 ; 26.6 \%$ are living in the rest of Ireland and $10.4 \%$ have emigrated. Place of residence has not changed for the vast majority of children living in Ireland but not with their parents. However, $2.5 \%$ of these children have returned home to 
live with their parents and $3.7 \%$ have emigrated. Combining these figures together, around $5 \%$ of children living in Ireland at wave 1 emigrated between the two survey waves. Finally, around $90 \%$ of those living abroad at wave 1 are still living abroad. Of the remaining $10 \%$, $6.6 \%$ have returned to Ireland (but not to live with their parents) and $2.3 \%$ are now living with their parents.

\subsubsection{Adult children's migration patterns and labour market outcomes}

The relationship between children's migration patterns and labour market outcomes at wave 2 is now investigated.

Focusing first on migration patterns, children are assigned to four categories: 1) 'Ireland Stayers': living in Ireland at both waves; 2) 'Abroad Stayers': living abroad at both waves; 3) 'Emigrants': living in Ireland at wave 1 and abroad at wave 2; and 4) 'Return Migrants': living abroad at wave 1 and in Ireland at wave 2. Almost 8 in 10 children $(78.7 \%)$ are 'Ireland Stayers'. Of the remaining children, 15.8\% are 'Abroad Stayers', 4\% are 'Emigrants'2 and $1.5 \%$ are 'Return Migrants'.

Turning then to labour market outcomes at wave 2, children are assigned to three categories: 1) employed (full-time and part-time employed, self-employed and on maternity/paternity leave); unemployed; and inactive (in education, retired, permanently sick or disabled, looking after home or family or other). More than three quarters of children $(77.7 \%)$ are employed, $10 \%$ are unemployed and $12.3 \%$ are inactive.

Figure 2.15 shows that there is a clear relationship between children's migration patterns and labour market outcomes. Figure 2.15 shows that economic wellbeing, expressed here in terms of favourable labour market outcomes, is greatest for children living abroad at both wave 1 and wave 2 ('Abroad Stayers'). A total of $88.3 \%$ of children belonging to this category are in employment and $2.7 \%$ are unemployed at wave 2 . In contrast, around $72.2 \%$ of children who have returned to Ireland are in employment and $18.5 \%$ are unemployed at wave 2 . A total of $82.9 \%$ of children who have emigrated are employed at wave 2. This compares to $75.4 \%$ of children who have stayed in Ireland. Around $7 \%$ of children who have emigrated are unemployed at wave 2 . This compares to $11.4 \%$ of children who are still in Ireland.

2. As noted above, $5 \%$ of children who were living in Ireland at wave 1 had emigrated by wave 2 . The different result here refers to the use of a different denominator, i.e., all children (living both in Ireland and abroad). 
Figure 2.15 illustrated international migration and ignored internal migration: children living with parents or in the rest of Ireland at both waves were assigned to the same category, 'Ireland Stayers'. The relationship between children's internal migration and labour market outcomes is explored in Figure 2.16. For this purpose, children living in Ireland at both waves are assigned to four categories: 1) 'Home Stayers': living with parents at both waves; 2) 'Rest of Ireland Stayers': living in Ireland but not with parents at both waves; 3) 'Home Leavers': living with parents at wave 1 and in the rest of Ireland at wave 2; and 4) 'Home Returners': living in Ireland but not with parents at wave 1 and with parents at wave 2. Children living abroad at wave 1 and/or wave 2 are excluded from this analysis.

Figure 2.15 showed that unemployment is highest among those who have returned to Ireland after living abroad ('Return Migrants'). Figure 2.16 shows that, similarly, unemployment is highest among returners, defined here as children returning to live with their parents. Around $27 \%$ of children in this category are unemployed at wave 2 . This is significantly above the rates of $9.6 \%$ for 'Rest of Ireland Stayers' and $12.4 \%$ for 'Home Leavers'. Similarly, employment is lowest among children who are still at home or have returned home $(60.7 \%$ and $62.9 \%$, respectively) and highest among those who are still living in the rest of Ireland or who have left home ( $77.6 \%$ and $80.2 \%$, respectively).

Figure 2.15: Children's labour market status at wave 2 by children's migration status

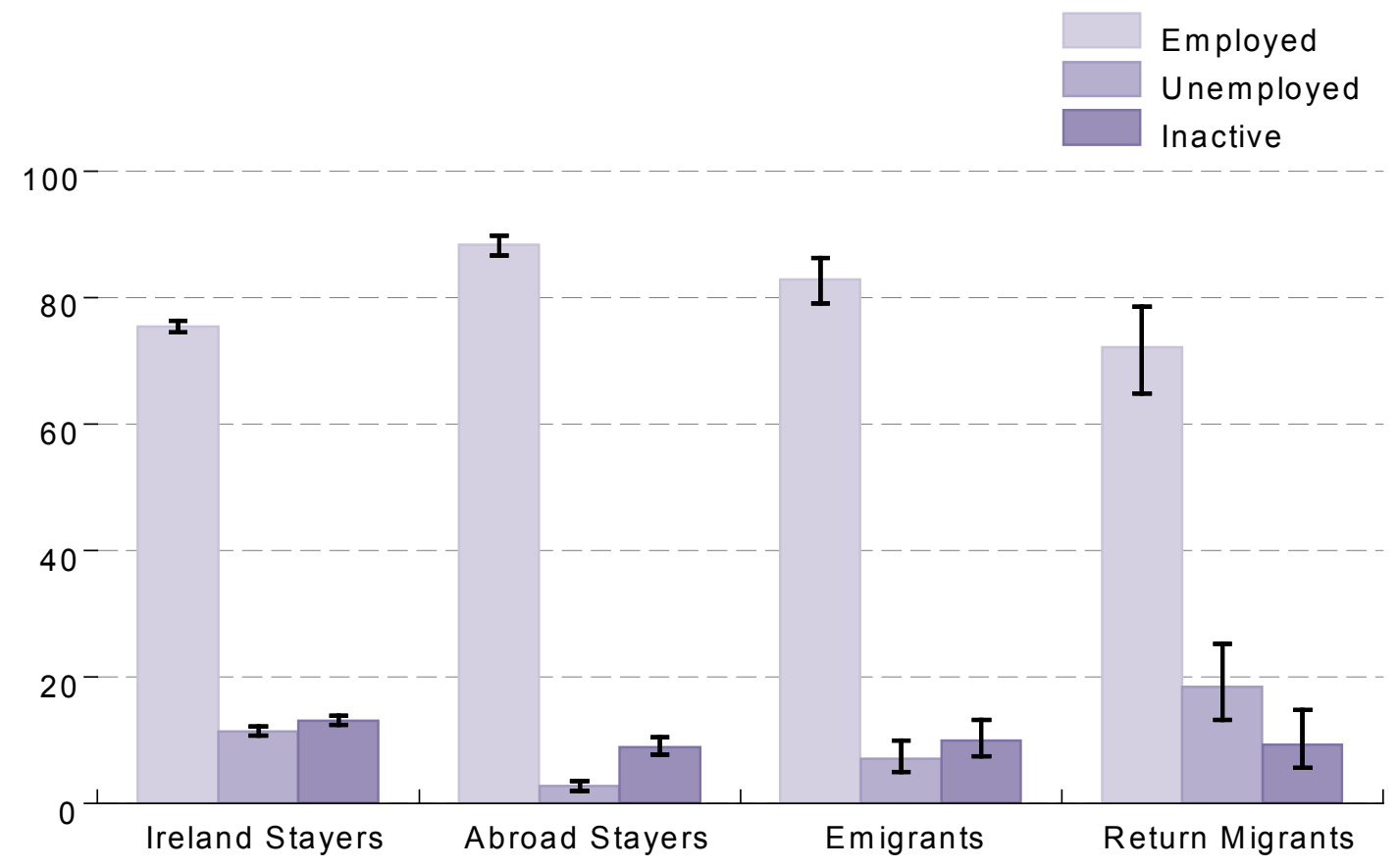

Note. $N=10496 ;$ Missing obs $=0 ;$ Error bars correspond to $95 \%$ confidence intervals 
Figure 2.16: Children's labour market status at wave 2 by children's internal migration status

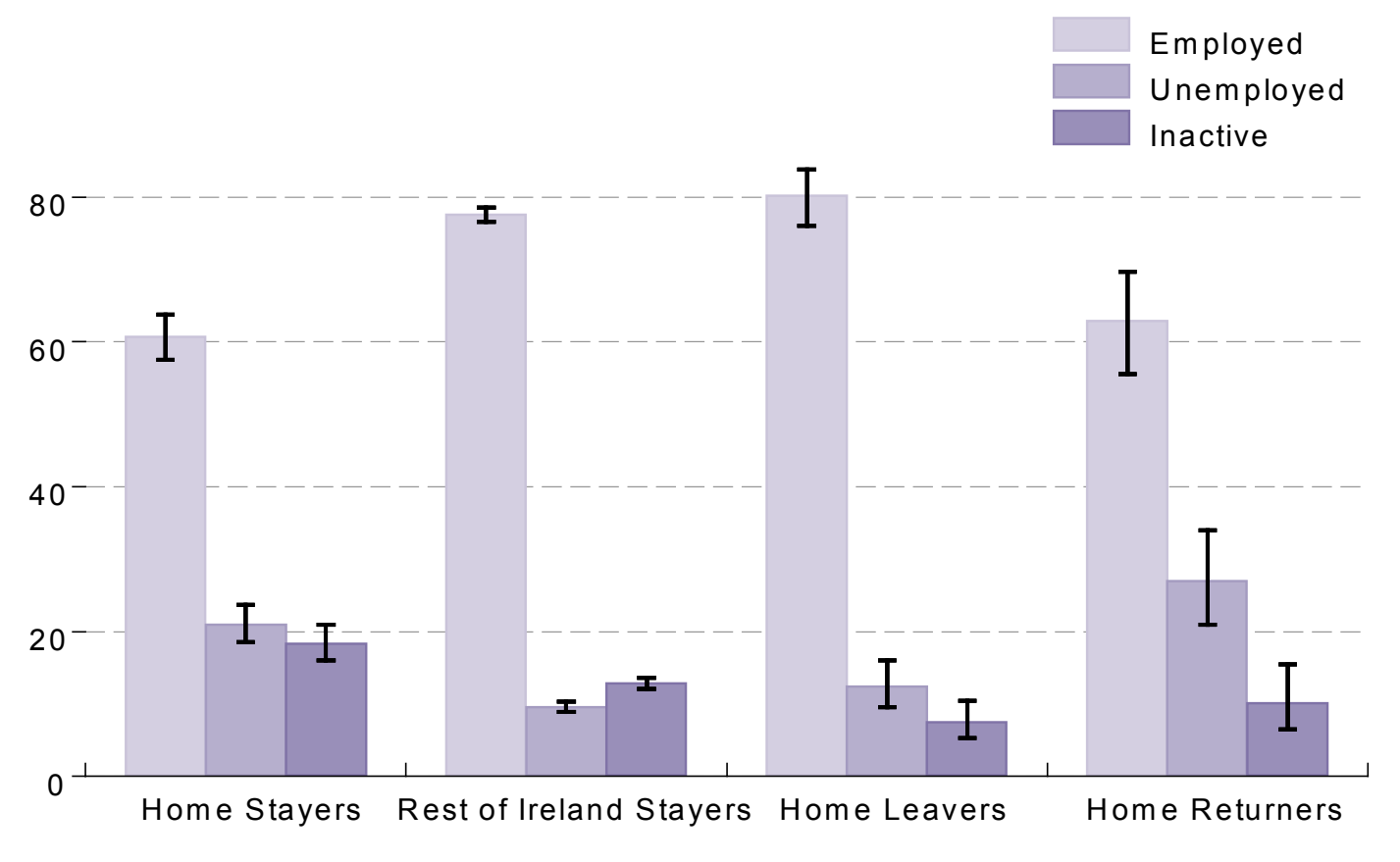

Note. $N=8252 ;$ Missing obs $=2244 ;$ Error bars correspond to $95 \%$ confidence intervals

\subsection{Conclusion}

In this chapter the economic circumstances of older people and their children were examined from a number of perspectives. Firstly, changes in income and wealth were examined. Despite a shift away from labour income sources towards retirement income sources, the gross income levels of the TILDA participants remained relatively unchanged since the last wave of data was collected. However, primarily as a result of falls in property values, the participants' wealth levels have fallen.

In terms of employment, overall labour market status has remained largely stable between waves for those who were employed or retired. However, $13 \%$ of those who were employed in wave 1 had retired by wave 2. According to participants, pension eligibility is their main reason for retirement. As the SPA increased to 66 years from January 2014, and is set to further increase over the next few years, it will be interesting to observe whether people remain in employment for longer as a result.

Turning to the participants' adult children, approximately $5 \%$ of adult children who were living in Ireland at wave 1 had emigrated by wave 2. A clear relationship between children's internal and international migration patterns and labour market outcomes was 
found. Employment levels amongst the adult children of TILDA participants are highest among those who have emigrated or were already living abroad at wave 1. Unemployment among children at wave 2 is highest among those who have returned to Ireland from abroad, have returned to live with their parents or were already living with their parents at wave 1.

\section{References}

1. Davies J. Wealth and Income Inequality. In: Nolan B, Salverda W, Smeeding T, editors. Oxford Handbook of Economic Inequality. Oxford: Oxford University Press; 2009.

2. Daft.ie. The Daft.ie House Price Report. http://www.daft.ie/report/daft-house-report-Q22013.pdf?v=1 (accessed 3 December 2013).

3. Barrett A, Savva G, Timonen V, Kenny R. Fifty Plus in Ireland 2011. First results from the Irish Longitudinal Study on Ageing (TILDA). Dublin: The Irish Longitudinal Study on Ageing; 2011.

4. CSO. Population and Migration Estimates April 2013. Dublin: CSO; 2013. 


\section{Changes in Physical and Behavioural Health in Older Irish Adults}

Ciarán Finucane, Joanne Feeney, Hugh Nolan, Claire O'Regan

\section{Contents}

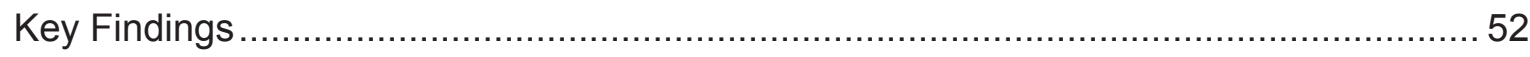

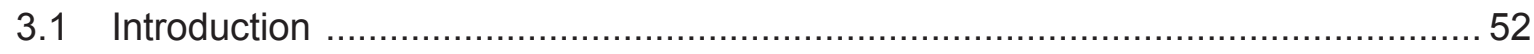

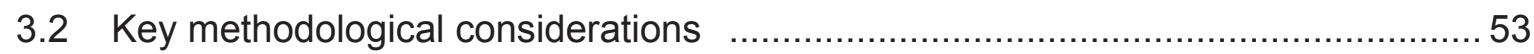

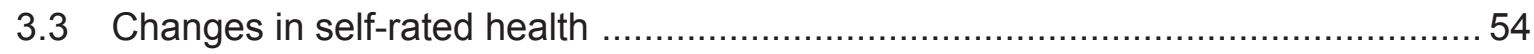

3.4 Prevalence and incidence of cardiovascular conditions ..................................... 55

3.4.1 Changes in prevalence of cardiovascular conditions ............................... 56

3.4.2 Two-year incidence of cardiovascular conditions ................................ 57

3.5 Prevalence and incidence of chronic conditions (non-cardiovascular) .................... 57

3.5.1 Changes in prevalence of chronic conditions (non-cardiovascular) ............ 58

3.5.2 Two-year incidence of chronic conditions (non-cardiovascular)................. 59

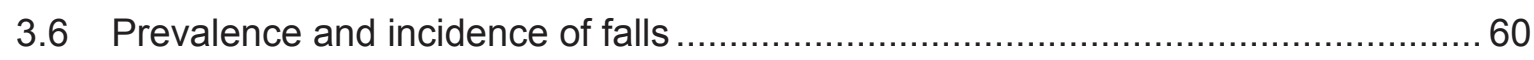

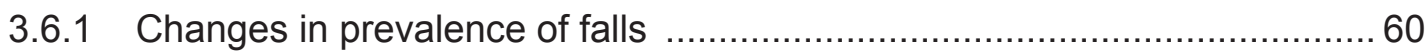

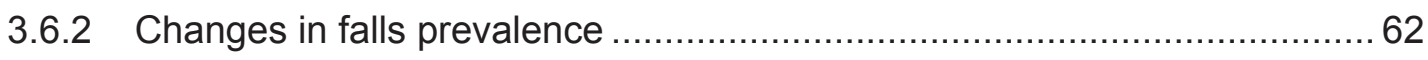

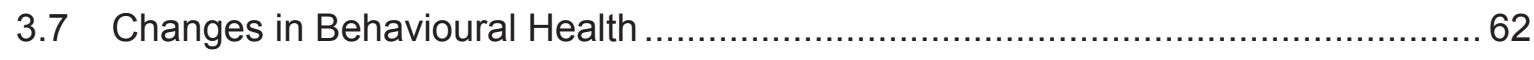

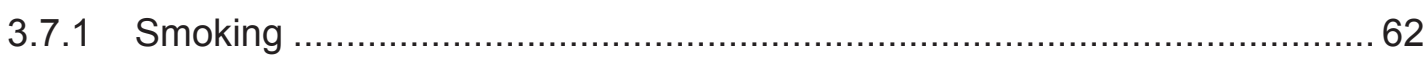

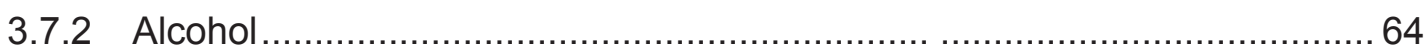

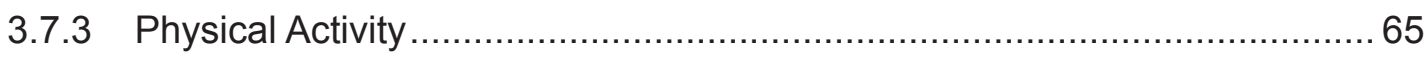

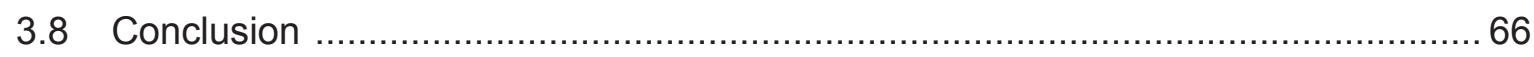

Appendix 3A: Tables on Changes in Physical and Behavioural Health in Older Irish

Adults

Appendix 3B: Figures on Changes in Physical and Behavioural Health in Older Irish

Adults

Appendix 3C: The CAGE Screening Questionnaire Tool.

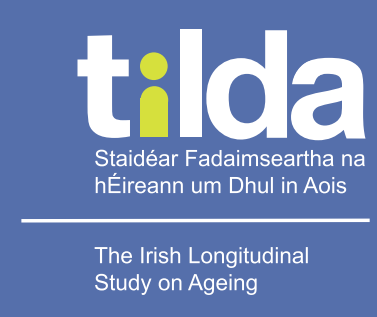




\section{Changes in Physical and Behavioural Health in Older Irish Adults}

\section{Key Findings}

- The proportion of the older population who report that their health is 'excellent' or 'very good' has increased from $41 \%$ in wave 1 to $44 \%$ in wave 2 .

- Hypertension and diabetes are the most prevalent cardiovascular conditions in older Irish adults, affecting $37 \%$ and $9 \%$ of older Irish adults respectively. The prevalence of most cardiovascular conditions has remained stable since wave 1 except for angina, which has decreased, and atrial fibrillation, which has increased.

- Arthritis now affects $51 \%$ of those aged 75 and over, while the two-year incidence of arthritis among this age group is $10 \%$.

- Arthritis, osteoporosis and cataracts have the highest two-year incidence rates (i.e., new cases among those previously undiagnosed) of non-cardiovascular chronic conditions, with rates of $7.6 \%, 5.6 \%$ and $5.7 \%$ respectively.

- Approximately $19 \%$ of men, $25 \%$ of women and $30 \%$ of individuals aged 75 and over have fallen in the last year. Almost $10 \%$ of the over 50 s population have had an injurious fall (i.e., requiring medical treatment) in the last year.

- $16 \%$ of smokers at wave 1 had quit by wave 2 . A notable decrease in smoking occurs after the age of 65 years.

- The overall prevalence of problematic alcohol use has increased between wave 1 and wave 2 and is significantly higher in men $(21.7 \%)$ than in women (11\%). There is a drop in problematic alcohol use after the age of 65 years.

- The proportion of adults reporting low levels of physical activity increases with age, with $51.6 \%$ of over 75 s reporting low levels of physical activity at wave 2 .

\subsection{Introduction}

The importance of the opportunities and challenges associated with ageing (1) have been acknowledged by the objectives set forth in Ireland's recent health reform policy document, 
Healthy Ireland - A Framework for Improved Health and Well-being 2013-2025 (2) and more recently in the National Positive Ageing Strategy(3). Pertinent goals set out in these documents include: to increase the proportion of people who are healthy at all stages of life; to reduce health inequalities; to support people as they age to maintain, improve or manage their physical, mental health and well-being; and to use an evidence-based approach to better inform policy responses to population ageing.

By design, the data collected in TILDA can inform and help achieve these objectives. TILDA collates information on mortality rates, health conditions, perceptions, behaviours and health inequalities that have important public health significance (4). In the summary report on wave 1 of TILDA, Cronin et al. (5) reported the high prevalence of cardiovascular and non-cardiovascular disorders in the older Irish population alongside behavioural health patterns.

As a natural extension to this earlier work, this chapter presents data on the changes in physical and behavioural health which have occurred in the period between wave 1 and wave 2 . We report on changes in self-rated health followed by prevalence and incidence data on the burden of chronic conditions (cardiovascular and non-cardiovascular) and their risk factors. Finally, we present changes in behavioural health of the over 50s population and update current information on the prevalence of falls in Ireland - one of the giants of geriatric medicine.

\subsection{Key methodological considerations}

To facilitate an accurate comparison of wave 1 and wave 2 data only adults aged 52 and over are included in the sample for the current analysis. Analysis of incidence is restricted to those participants who took part in both wave 1 and wave 2 only. Two-year incidence rates are calculated as the number of individuals who newly report a health condition at wave 2 expressed as a proportion of those individuals who were free of this condition in wave 1 (paired sample). Incidence rates are reweighted using appropriate attrition weights. It is likely that using a paired sample will introduce a survivor bias; however attrition weights have been introduced to correct for this (see Chapter 7 for further details).

Both prevalence and incidence data are reported stratified by age and sex. Age at wave 1 is used when reporting incidence rates and variables of change between wave 1 and wave 2 , while age at wave 1 and age at wave 2 are used for prevalence analyses based on wave 1 or wave 2 data respectively. 


\subsection{Changes in self-rated health}

Self-rated health is a well-known marker of an individual's health status and is a strong predictor of life expectancy and morbidity levels (6). Self-rated health was measured by a single question whereby participants were asked to rate their health using one of five categories ranging from excellent to poor.

Figure 3.1: Distribution of self-rated health

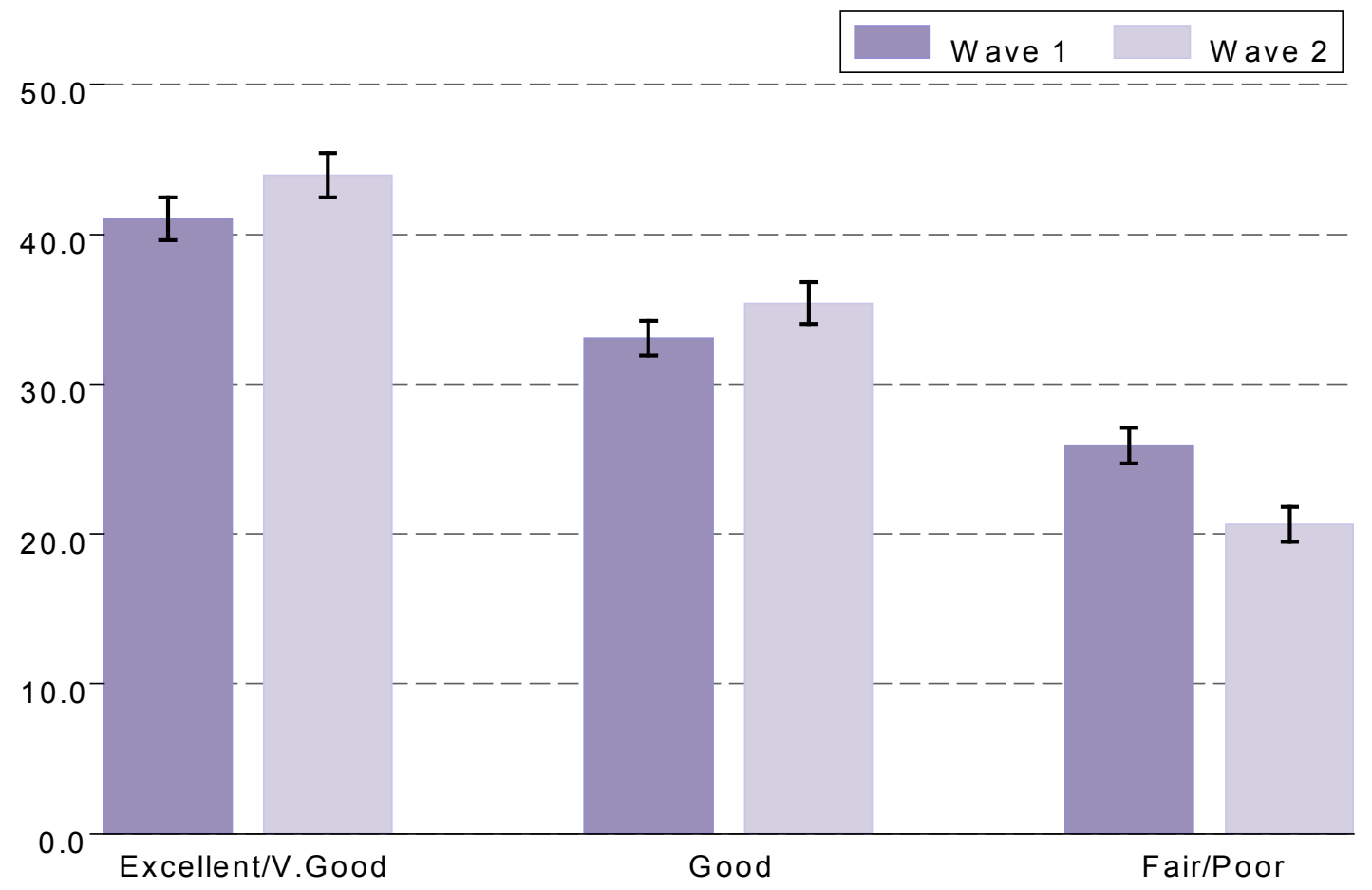

In wave 2, 44\% of older adults reported that their health was excellent or very good and $21 \%$ reported that their health was fair or poor. These figures are broadly comparable to those reported for the full adult (i.e., 18+ years) Irish population, albeit using slightly different response categories (very good, good, fair, bad and very bad), and using data for 2010. Using the same data, it has been found that estimates of self-rated health in Ireland are consistently above those reported in other EU-27 countries (7). Our results suggest a more optimistic perception of health currently, since compared to 2010 the number of people reporting excellent or very good health has increased by 3 percentage points and the proportion reporting fair or poor health has reduced by 5 percentage points (see Figure 3.1).

Figure 3.2 shows transitions in self-rated health status over time. A clear pattern exists 
across all age groups whereby the majority of adults who reported excellent or very good health in wave 1 continue to report high levels in wave 2 . Reporting of fair or poor health is less consistent across waves; approximately $45 \%$ of adults who reported fair or poor health in wave 1 transition to excellent, very good or good self-rated health by wave 2 . This pattern is broadly similar across all age groups; however a greater percentage of individuals in the oldest age group transition between self-rated health categories between wave 1 and wave 2 .

Figure 3.2: Changes in self-rated health between wave 1 and wave 2

W2 Exc./V. Good W2 Good W2 Fair/Poor
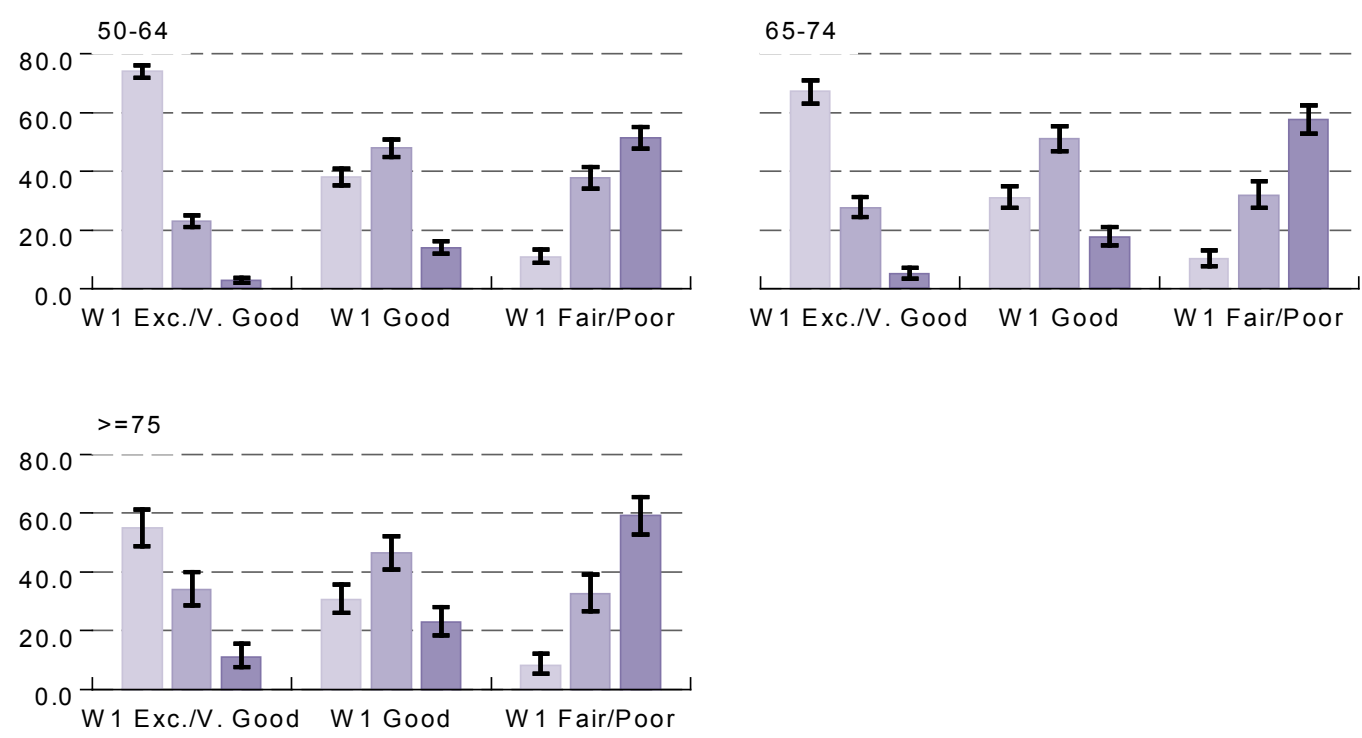

Note. $N=6915$; Missing obs $=1$; Error bars correspond to $95 \%$ confidence intervals

\subsection{Prevalence and incidence of cardiovascular conditions}

Cardiovascular disease (CVD) remains the leading cause of death in Ireland despite the significant (67\%) drop of age-standardised death rates over the last 30 years (8). This downward trend in CVD mortality has been attributed to a decrease in the prevalence of important risk factors for CVD and improvement in treatments available (9). With this substantial decrease in mortality from CVD since the 1980s some people are now living longer with a higher burden of morbidity. This was evident from the data collected at wave 1 of the study (5) and has major implications for planning and delivery of effective health services. 
Here we provide an update on the prevalence and incidence of key cardiovascular conditions from wave 1 . As a health assessment was not carried out in wave 2, the following analyses are based on questions where the participants were asked to self-report a doctor's diagnosis of each of the following conditions: hypertension (High BP), diabetes mellitus, myocardial infarction (heart attack), angina, transient ischemic attack (TIA), atrial fibrillation (AF), stroke, heart failure $(10,11)$.

\subsubsection{Changes in prevalence of cardiovascular conditions}

Figure 3.3 shows changes in prevalence of cardiovascular conditions between wave 1 and wave 2. Hypertension (37.2\%) and diabetes (8.6\%) are currently the most prevalent cardiovascular conditions in older Irish adults. The prevalence of most conditions has remained stable since wave 1 except for angina, which has decreased, and atrial fibrillation, which has increased.

Figure 3.3: Prevalence of cardiovascular conditions

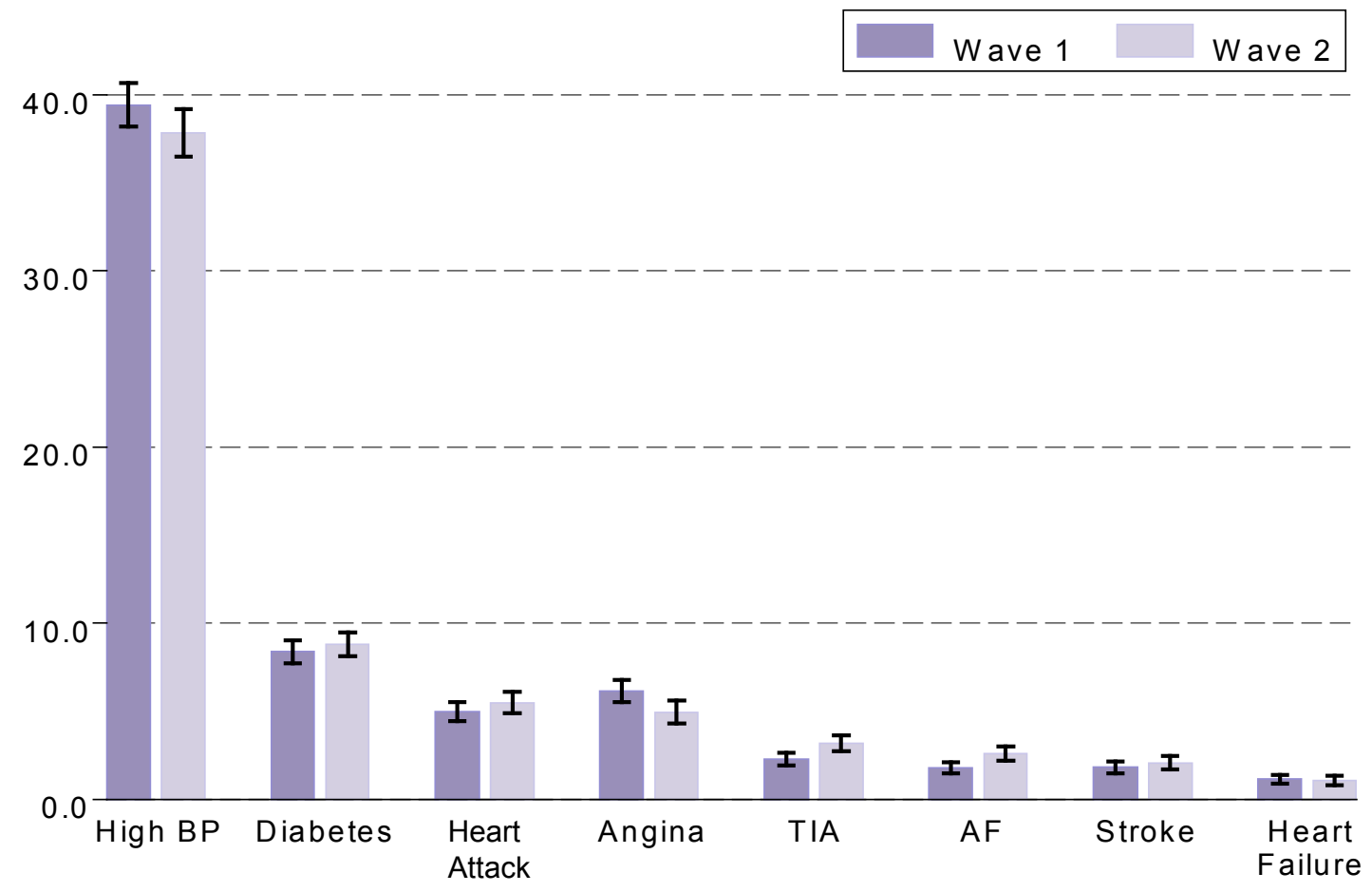

The prevalence of all cardiovascular conditions increases with age (see Appendix Table 3.A1a). For example the prevalence of hypertension is $29.2 \%$ in the youngest age group (52-64) rising to $50.3 \%$ in the oldest age group ( $\geq 75$ years). Similarly, the prevalence of atrial fibrillation is $1.3 \%$ in the youngest age group and increases to $4.3 \%$ in the oldest age group. In wave 1 men had a higher prevalence of diabetes, heart attacks, angina, AF, and 
heart failure than women. These differences between men and women remain in wave 2, however it has decreased notably for angina (see Appendix Table 3.A2).

\subsubsection{Two-year incidence of cardiovascular conditions}

Figure 3.4 presents the two-year incidence of cardiovascular conditions. Highest incidence rates are observed for hypertension (6.5\%) and diabetes (2\%). The incidence of other established cardiovascular conditions is less than $1 \%$ with the incidence of AF comparable to that of heart attacks and TIAs.

Figure 3.4: Two-year incidence of cardiovascular conditions

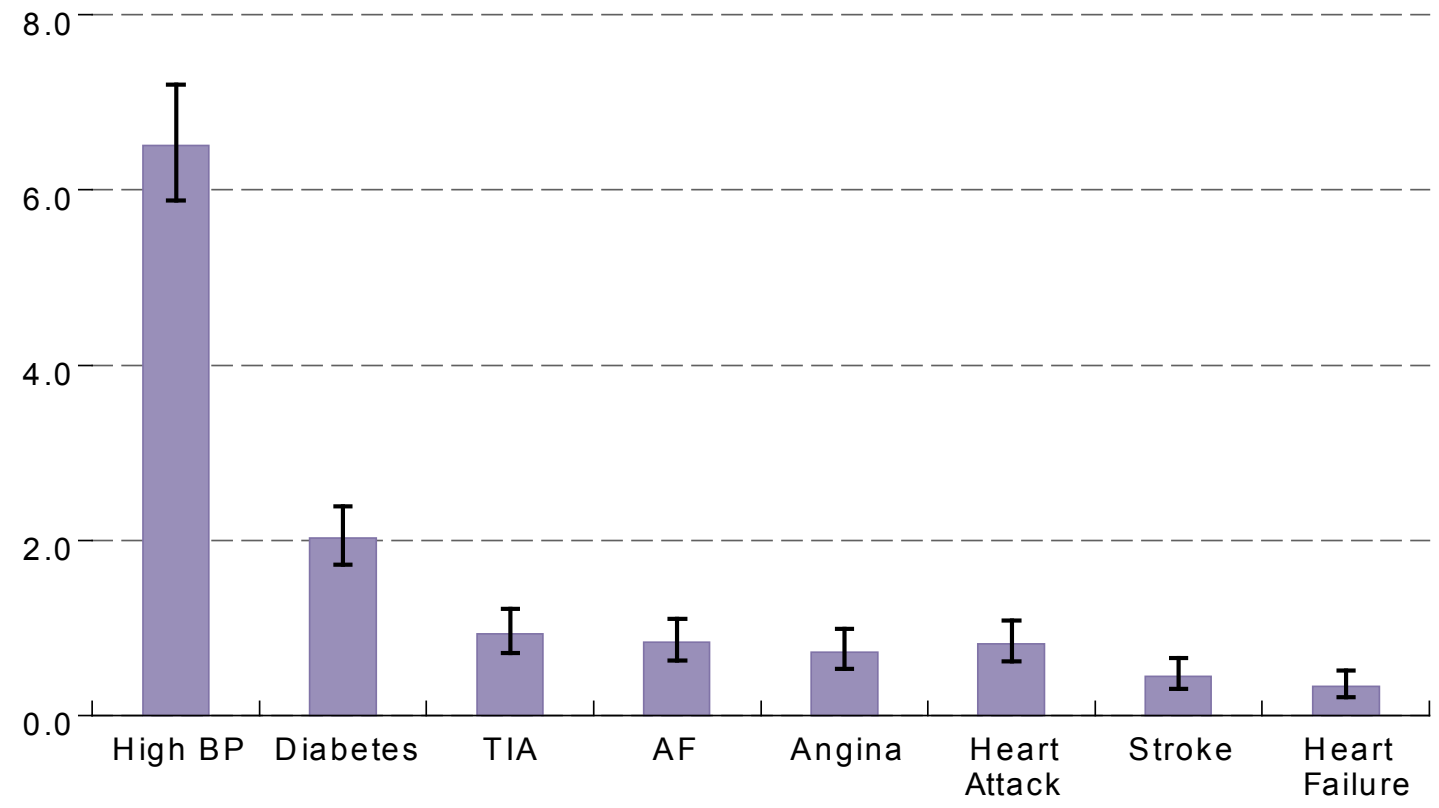

Note. $N=6916$; Missing obs $=0$; Error bars correspond to $95 \%$ confidence intervals

Incidence rates of cardiovascular conditions by age group and sex are shown in Appendix Table 3.A1b. Significant age gradients are observed for TIA, AF and stroke. For example $\mathrm{AF}$ is associated with a $0.4 \%$ incidence rate for adults aged $50-64$ compared to $1.5 \%$ for adults aged 75 and over. There are no significant differences between men and women in incidence of any of the cardiovascular conditions.

\subsection{Prevalence and incidence of chronic conditions (non- cardiovascular)}

In this section we report on the prevalence and incidence of (non-cardiovascular) chronic 
conditions such as arthritis, osteoporosis, fractures (hip and wrist), cancer, eye conditions and chronic lung disease.

\subsubsection{Changes in prevalence of chronic conditions (non-cardiovascular)}

Figure 3.5 shows changes in prevalence of chronic conditions between wave 1 and wave 2. Arthritis (33.9\%) and osteoporosis (14.3\%) are now the most prevalent chronic conditions among the over 50 s population. The prevalence of arthritis increased by 4.7 percentage points between waves, while the prevalence of osteoporosis increased by 4.5 percentage points. The prevalence of all other conditions has remained largely unchanged, with the exception of cancer, which has decreased by 3.6 percentage points, and cataracts, which has decreased by 1.8 percentage points.

Figure 3.5: Prevalence of chronic conditions (non-cardiovascular)

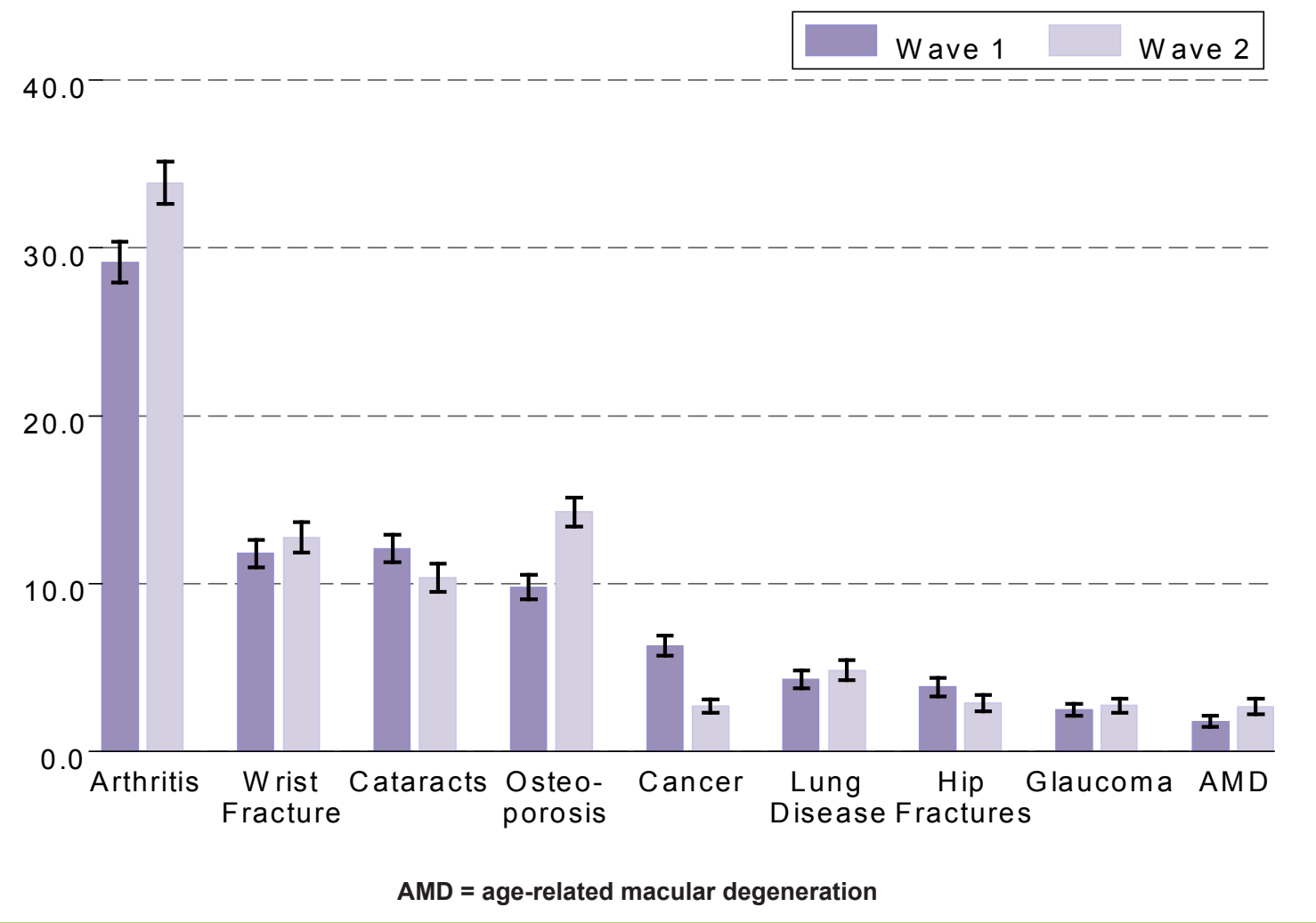

The prevalence of most chronic conditions increases with age (see Appendix Table 3.A3a). For example, the prevalence of arthritis at wave 2 is $23.6 \%$ in the youngest age group $(52-64)$ rising to $51.7 \%$ in the oldest age group ( $\geq 75)$. Significant age gradients are also evident for each of the eye conditions considered. For example the prevalence of cataracts increases by almost eight-fold from $3.1 \%$ in the youngest age category (52-64) to $24.9 \%$ in the 75 and over group. 
Appendix Table 3.A3a also shows the prevalence of chronic conditions by sex. Women demonstrate a higher prevalence of osteoporosis, arthritis, cataracts and AMD while men report a higher prevalence of cancer. Osteoporosis now affects $24.1 \%$ of women compared to $3.6 \%$ of men while arthritis affects $40.7 \%$ of women compared to $26.5 \%$ of men.

\subsubsection{Two-year incidence of chronic conditions (non-cardiovascular)}

Figure 3.6 presents the two-year incidence of chronic conditions. Incidence rates are highest for arthritis (7.6\%), osteoporosis (5.6\%) and cataracts (5.7\%). All other chronic conditions have an incidence rate of below $2 \%$.

Figure 3.6: Two-year incidence of chronic conditions (non-cardiovascular)

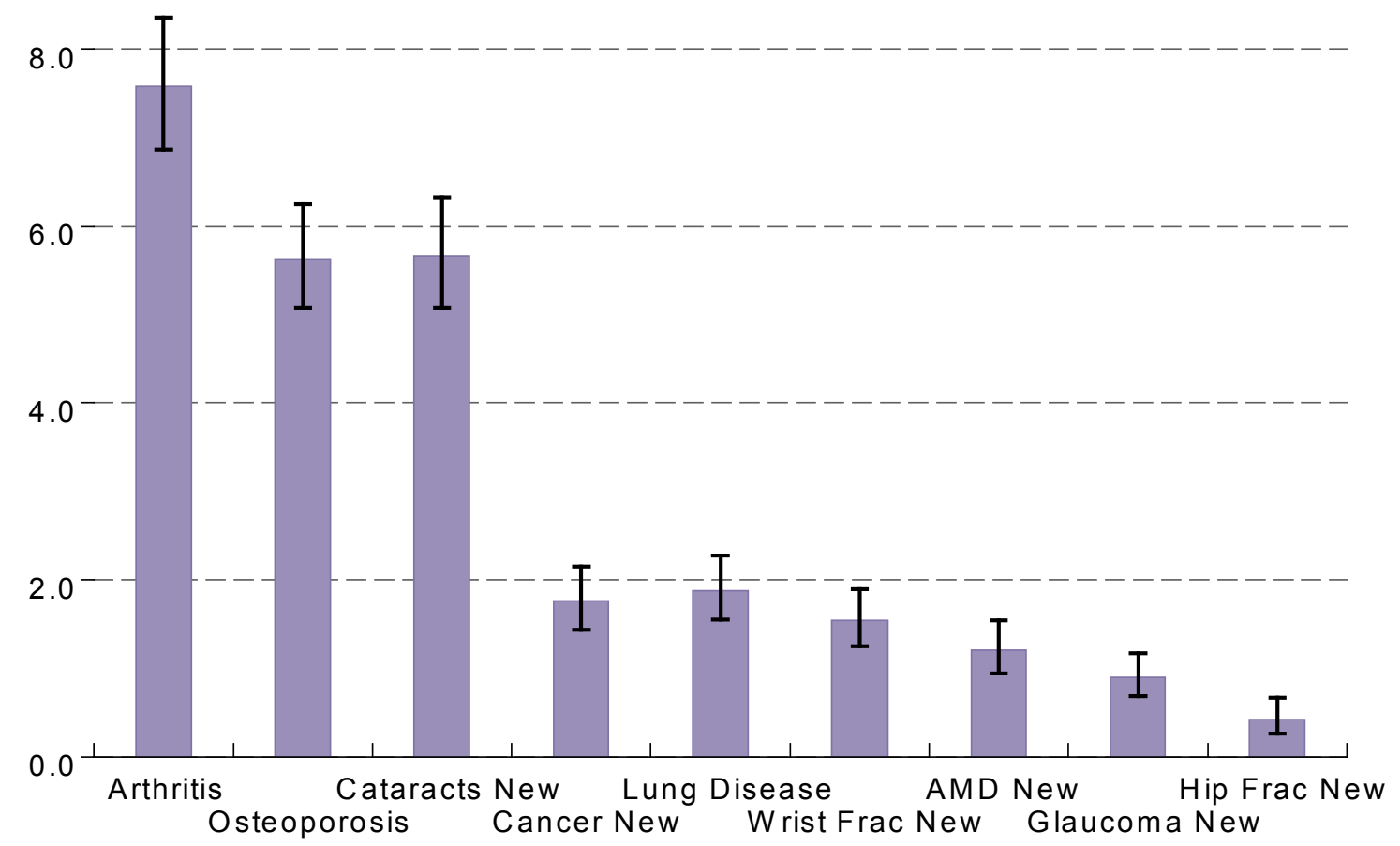

Note. $N=6916 ;$ Missing obs $=0$; Error bars correspond to $95 \%$ confidence intervals AMD = Age-related macular degeneration

The incidence of arthritis, cataracts, age related macular degeneration (AMD) and cancer increase with age (see Appendix Table 3.A3b). For example the incidence of arthritis rises from $6.2 \%$ in the youngest age category (50-64) to $10.2 \%$ in adults aged 75 and over. Similarly the incidence of cataracts is $12.2 \%$ for individuals aged 75 years and older, compared with just $1.8 \%$ in adults aged $50-64$ years.

The incidence of chronic conditions by sex is also shown in Appendix Table 3.A3b. Women report a significantly higher incidence of cataracts, wrist fractures and osteoporosis 
compared to men. For example the incidence of osteoporosis is almost four times higher in women $(8.7 \%)$ than men $(2.3 \%)$.

\subsection{Prevalence and incidence of falls}

Falls are commonly associated with ageing, with an estimated one in three older adults experiencing a fall each year (12). Falls account for a high proportion of national health expenditure and in Ireland the total annual costs of falls has been estimated at $€ 400$ million (13).

Participants were asked to report (a) the number of falls they had in the last year and (b) whether any of these falls caused an injury which required medical treatment (classified as an injurious fall). In addition, individuals who reported one fall were categorised as a faller while individuals who reported two or more falls were categorised as a recurrent faller.

\subsubsection{Changes in prevalence of falls}

The prevalence of falls has increased slightly between wave 1 and wave 2 (see Figure 3.7). For example $22.2 \%$ of adults aged 52 and over report a fall at wave 2 compared to $19.6 \%$ at wave 1 . The prevalence of recurrent falls is almost consistent across waves but the prevalence of injurious falls has risen from $7.1 \%$ at wave 1 to $9.9 \%$ at wave 2 .

Figure 3.8 shows the prevalence of falls, recurrent falls and injurious falls at wave 2 by age group. The prevalence of all types of falls increases significantly with age. For example the prevalence of falls rises from almost $18.4 \%$ in the youngest age group (52-64 years) to $29.8 \%$ in adults aged 75 and over. Similarly the prevalence of injurious falls rises from $7.3 \%$ in adults aged $52-64$ years to $15.8 \%$ in adults aged 75 and over.

Differences between men and women are evident in falls prevalence (see Appendix Table 3.A4a) with a higher proportion of women having have had a fall than men $(25.3 \% \mathrm{vs}$ $18.8 \%)$. A higher proportion of women have had an injurious fall $(12.7 \%)$ compared to men $(6.9 \%)$. Furthermore, while the prevalence of falls, recurrent falls or injurious falls has not increased much between waves for men, there is an increase in the percentage of women reporting falls and injurious falls at wave 2 (see Appendix Table 3.A4b). 
Figure 3.7: Prevalence of falls, recurrent falls and injurious falls

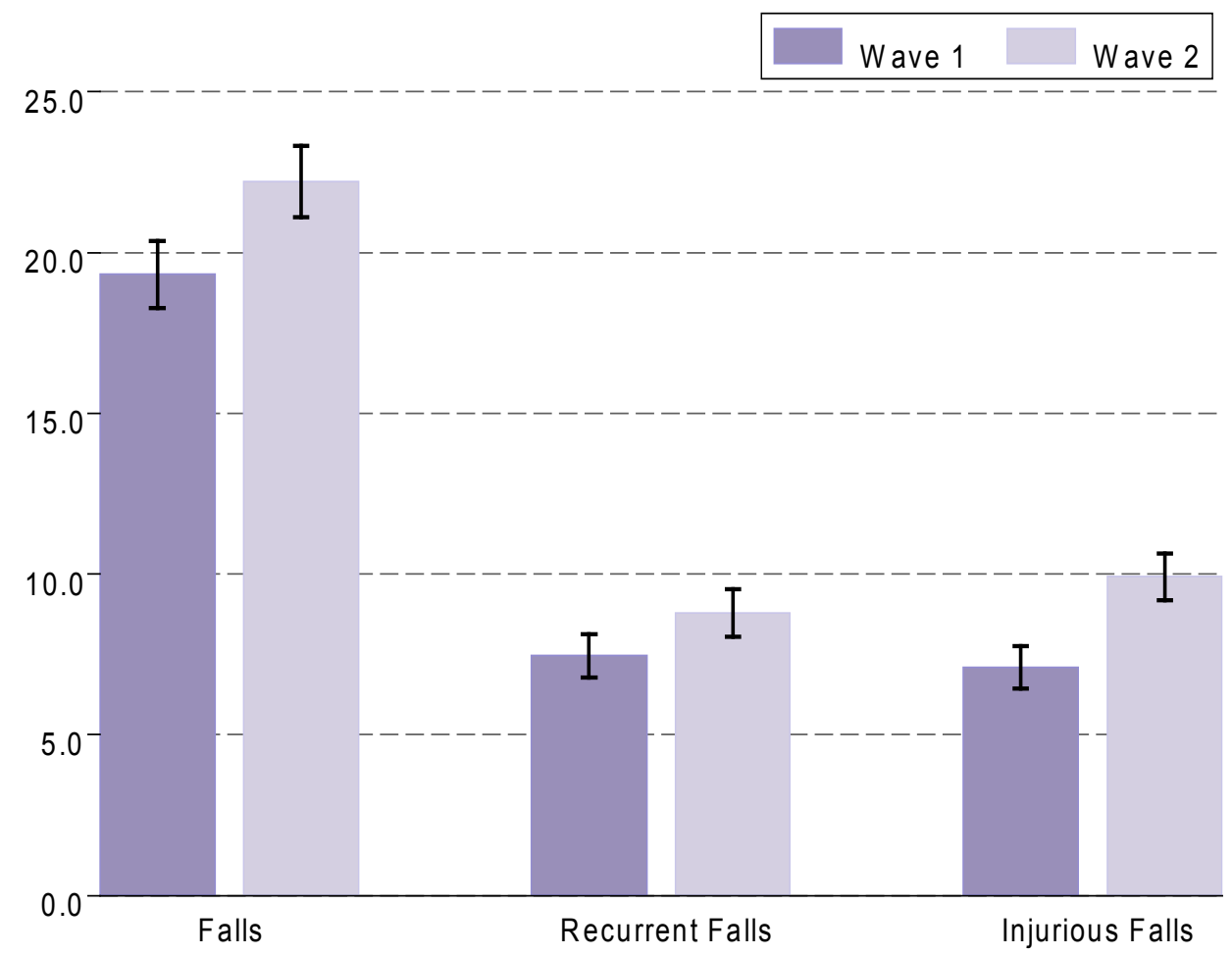

Figure 3.8: Prevalence of falls, recurrent falls and injurious falls at wave 2 by age
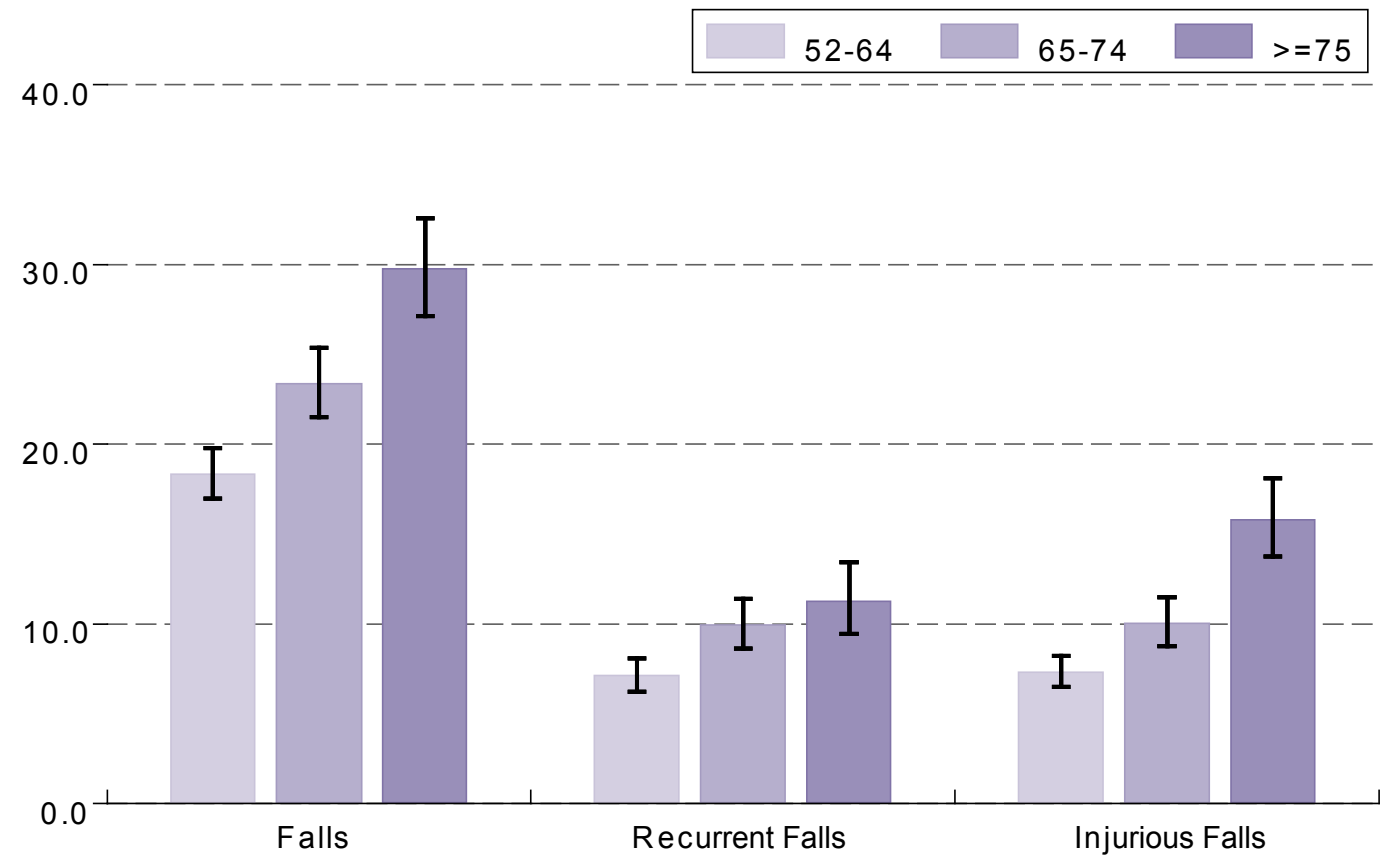

Note. $\mathrm{N}=6909$; Missing obs $=7$; Error bars correspond to $95 \%$ confidence intervals 


\subsubsection{Changes in falls prevalence}

Table 3.1 summarises changes in falls prevalence between wave 1 and wave 2 . Of those who had not previously reported a fall, $12 \%$ report a single fall by wave 2 . A further $6 \%$ report recurrent falls by wave 2 . Of those who reported a single fall at wave 1, 24\% had another fall by wave 2 and $12 \%$ progressed to having recurrent falls. Finally, $37 \%$ of adults with recurrent falls at wave 1 continued to experience recurrent falls by wave 2 , while $48 \%$ report no falls between waves.

Table 3.1: Changes in falls prevalence between wave 1 and wave 2

\begin{tabular}{|c|c|c|c|c|c|c|c|c|}
\hline & No & $\begin{array}{l}\text { Falls W2 } \\
\text { (95\% Cl) }\end{array}$ & $\%$ & $\begin{array}{l}\text { Fall } \\
\text { V2 } \\
5 \% \mathrm{Cl} \text { ) }\end{array}$ & $\begin{array}{r}\mathrm{R} \\
\mathrm{W} 2 \\
\%\end{array}$ & $\begin{array}{l}\text { ecurrent } \\
\text { Falls } \\
\text { ( } \geq 2 \text { falls) } \\
(95 \% \mathrm{Cl})\end{array}$ & Total & $\begin{array}{l}\text { Number } \\
\text { in } \\
\text { sample }\end{array}$ \\
\hline No Falls W1 & 82 & $(81-84)$ & 12 & $(11-13)$ & 6 & $(5-6)$ & 100 & 5567 \\
\hline One Fall W1 & 64 & $(61-68)$ & 24 & $(20-26)$ & 12 & $(10-14)$ & 100 & 846 \\
\hline $\begin{array}{l}\text { Recurrent Falls W1 } \\
\text { ( } \geq 2 \text { falls) }\end{array}$ & 48 & $(45-54)$ & 13 & $(10-16)$ & 37 & $(33-43)$ & 100 & 474 \\
\hline Total & 78 & (77-79) & 13 & $(12-14)$ & 9 & $(8-9)$ & 100 & 6887 \\
\hline
\end{tabular}

Note. $\mathrm{Cl}=$ confidence interval; Missing observations $=0.25 \%$

Note the total prevalence of fallers is calculated by summing the data presented in column 2 and column 3.

\subsection{Changes in Behavioural Health}

Behavioural health refers to modifiable lifestyle factors that can positively or negatively affect health. Three major lifestyle factors which are captured in TILDA are smoking, alcohol use and physical activity.

\subsubsection{Smoking}

It is well established that smoking negatively affects health and is a significant risk factor for a range of disorders including cardiovascular conditions, lung cancer and other respiratory disorders $(14,15)$.

In TILDA participants were asked to self-report their smoking status (never, past or current). Overall, the percentage of the population who are current smokers has decreased since wave 1 (see Figure 3.9). The prevalence of smoking at wave 2 is $16.5 \%$, down from 


\section{$18.3 \%$ at wave 1.}

Appendix Table 3.A5 shows smoking rates by age group. The prevalence of smoking in wave 2 decreases from $21.2 \%$ in the youngest age group (52-64 years) to $9.3 \%$ in the older adults aged 75 and over, a pattern similar to that noted in wave 1. Interestingly, as participants age a large drop in the prevalence of smoking is evident around the age of retirement i.e. 65 - 69 years at wave 2 (see Appendix Figure 3.B1a). No differences between men and women are noted in smoking behaviours (see Appendix Table 3.A6). Table 3.2 further details the transitions in smoking behaviours between wave 1 and wave 2. Encouragingly this table indicates that $16 \%$ of adults who smoked at wave 1 report that they have given up smoking in the past two years. Smoking transitions do not differ by age, or between men and women.

Figure 3.9: Prevalence of negative health behaviours
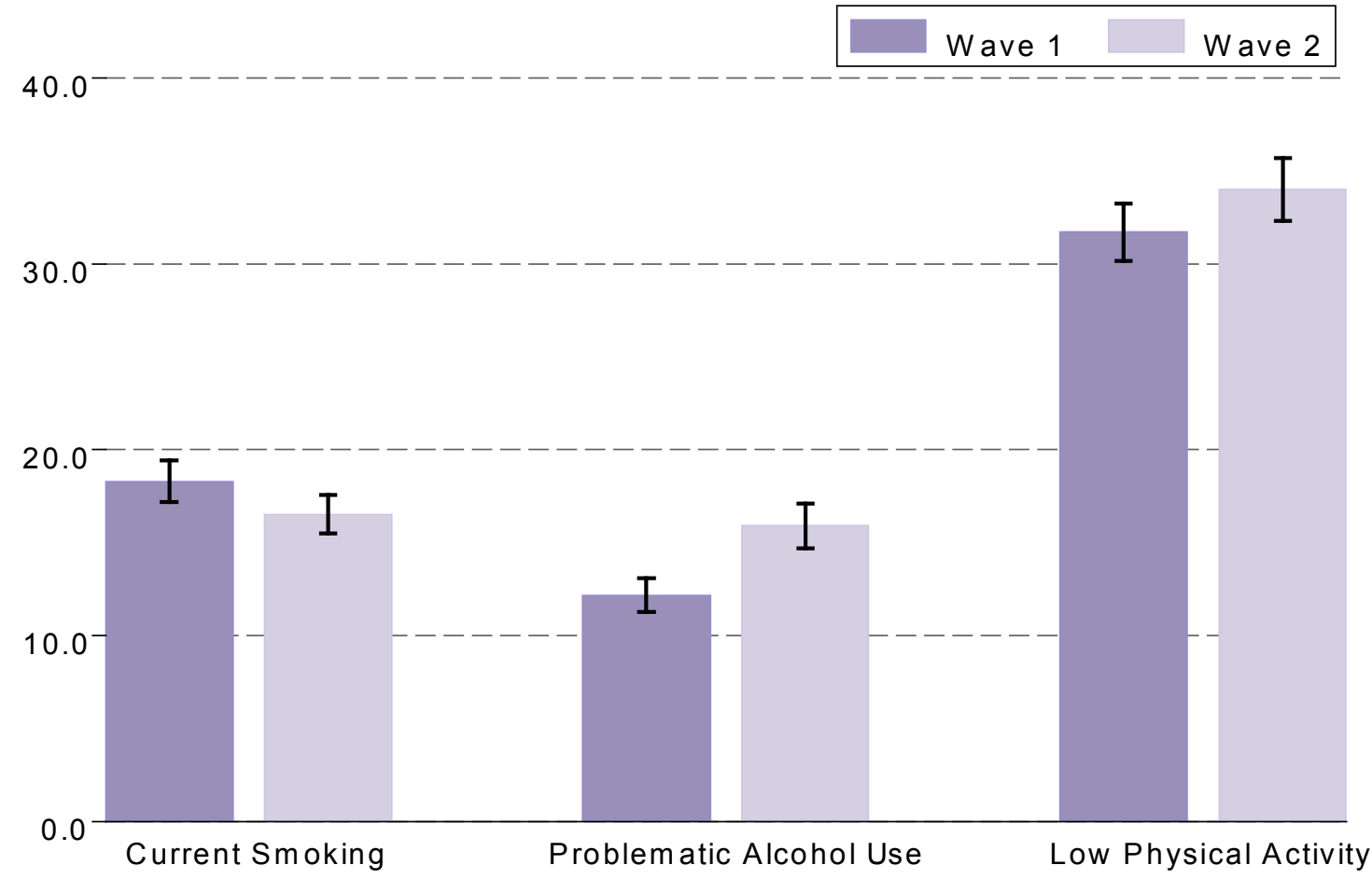
Table 3.2: Changes in smoking behaviour between wave 1 and wave 2

\begin{tabular}{|c|c|c|c|c|c|c|c|c|}
\hline & \multicolumn{2}{|c|}{ Never W2 } & \multicolumn{2}{|c|}{ Past W2 } & \multicolumn{2}{|c|}{ Current W2 } & \multirow{2}{*}{ Total } & \multirow{2}{*}{$\begin{array}{c}\text { Number in } \\
\text { sample }\end{array}$} \\
\hline & $\%$ & (95\% CI) & $\%$ & $(95 \% \mathrm{Cl})$ & $\%$ & (95\% CI) & & \\
\hline Never W1 & 99 & $(99-100)$ & 0 & - & 1 & $(0-1)$ & 100 & 3077 \\
\hline Past W1 & - & - & 98 & $(97-98)$ & 2 & $(2-3)$ & 100 & 2653 \\
\hline Current W1 & - & - & 16 & $(14-18)$ & 84 & $(82-86)$ & 100 & 1185 \\
\hline Total & 43 & $(42-45)$ & 40 & $(39-42)$ & 17 & $(16-18)$ & 100 & 6915 \\
\hline
\end{tabular}

Note. $\mathrm{Cl}=$ confidence interval; Missing observations $=0.00 \%$

\subsubsection{Alcohol}

In comparison to other European countries, Ireland has a high rate of harmful drinking habits (16). To examine harmful alcohol use, participant drinking habits were assessed using the CAGE (Cut-Annoyed-Guilty-Eye) questionnaire, a standard screening tool for problematic drinking patterns. A CAGE score $\geq 2$ indicates problematic alcohol use (See Appendix 3C).

The proportion of older Irish adults with problematic alcohol use has increased from $12.2 \%$ in wave 1 to $15.9 \%$ at wave 2 (see Figure 3.9). At wave 2, the prevalence of problematic alcohol use decreases with age from $19.9 \%$ in those aged $52-64$ years to $8.0 \%$ in those aged over 75 (see Appendix Table 3.A5). Similar to what is observed among smokers, there is a distinct drop in the prevalence of problematic alcohol use around the age of retirement (see Appendix Figure 3.B1b). A difference between men and women is also evident; nearly twice as many men report problematic alcohol use compared to women (21.7\% vs $11.0 \%$; see Appendix Table 3.A6).

Table 3.3 shows the transitions in problematic alcohol use between wave 1 and wave 2. $7 \%$ of those who did not have a drinking problem at wave 1 developed problematic drinking habits by wave 2 , while $31 \%$ of adults improved their drinking habits. No age gradient was observed for transitions in problematic alcohol use between waves (see Appendix Table 3.A7a). However, a higher proportion of men (10\%) transition to the problematic alcohol use category compared to women (5\%) but a similar proportion of men and women report a reduction in harmful drinking behaviours between waves (see Appendix Table 3.A7b). 
Table 3.3: Changes in problematic alcohol use between wave 1 and wave 2

\begin{tabular}{|c|c|c|c|c|c|c|}
\hline & \multicolumn{2}{|c|}{ CAGE<2 W2 } & \multicolumn{2}{|c|}{ CAGE>=2 W2 } & \multirow{2}{*}{ Total } & \multirow{2}{*}{$\begin{array}{l}\text { Number in } \\
\text { sample }\end{array}$} \\
\hline & $\%$ & (95\% Cl) & $\%$ & (95\% Cl) & & \\
\hline \multicolumn{7}{|l|}{ Total } \\
\hline CAGE<2 W1 & 93 & $(92-94)$ & 7 & $(6-8)$ & 100 & 3660 \\
\hline CAGE $>=2$ W1 & 31 & $(27-35)$ & 69 & $(66-74)$ & 100 & 617 \\
\hline Total & 84 & $(82-85)$ & 16 & $(15-17)$ & 100 & 4277 \\
\hline
\end{tabular}

\subsubsection{Physical Activity}

Physical activity is critically important for healthy ageing (17). Low levels of physical activity are associated with increased mortality, reduced quality of life and poorer self-rated health (17). Moderate to high levels of physical activity are associated with cardiovascular fitness which in turn is associated with better cardiovascular outcomes, flexibility and muscle strength (18). In TILDA, physical activity is measured using the International Physical Activity Questionnaire (IPAQ) which defines cut-offs for low, medium and high activity levels (4).

Overall, physical activity levels have remained similar at wave 2 with $34 \%$ reporting low physical activity at wave 2 compared to $31.7 \%$ at wave 1 (see Figure 3.9 ). The profile of self-reported physical activity is quite different across both age and sex. For example, an average of $50 \%$ of adults aged 75 and over consistently report low physical activity across waves compared to approximately $27 \%$ of adults aged 52-64 years (see Appendix Table 3.A5). At both waves, a significantly higher proportion of women report lower activity levels than men (see Appendix Table 3.A6).

Table 3.4 shows transitions in activity levels (low, medium and high) between wave 1 and wave 2. $53 \%$ of older adults maintained high levels of physical activity across waves, with $17 \%$ of adults who reported high activity levels at wave 1 transitioning to low activity levels by wave 2 . Of those who reported low activity levels at wave 1,25\% transitioned to medium activity levels by wave 2 and a further $17 \%$ transitioned to high activity levels. An age gradient is evident in transitioning to low physical activity from high activity levels; $29 \%$ of those in the 75 and over age group transition to low activity between waves, compared to only $14 \%$ of those aged 50-64 (see Appendix Table 3.A8). A higher proportion of women transition to low levels of physical activity than men; $31 \%$ of women previously reporting 
medium activity levels and $23 \%$ reporting high activity at wave 1 report low activity levels at wave 2 , compared to $25 \%$ and $14 \%$ of men respectively (see Appendix Table 3.A9).

Table 3.4: Changes in physical activity levels between wave 1 and wave 2

\begin{tabular}{|c|c|c|c|c|c|c|c|c|}
\hline & \multicolumn{2}{|c|}{$\begin{array}{l}\text { W2 Low } \\
\text { activity }\end{array}$} & \multicolumn{2}{|c|}{$\begin{array}{l}\text { W2 Medium } \\
\text { activity }\end{array}$} & \multicolumn{2}{|c|}{$\begin{array}{l}\text { W2 High } \\
\text { activity }\end{array}$} & \multirow{2}{*}{ Total } & \multirow{2}{*}{$\begin{array}{l}\text { Number } \\
\text { in sample }\end{array}$} \\
\hline & $\%$ & $(95 \% \mathrm{Cl})$ & & $(95 \% \mathrm{Cl})$ & & $(95 \% \mathrm{Cl})$ & & \\
\hline W1 Low activity & 38 & $(55-60)$ & 25 & $(23-27)$ & 17 & $(15-20)$ & 100 & 2131 \\
\hline $\begin{array}{l}\text { W1 Medium } \\
\text { activity }\end{array}$ & 28 & $(26-31)$ & 45 & $(43-48)$ & 26 & $(24-29)$ & 100 & 2382 \\
\hline W1 High activity & 17 & $(15-19)$ & 30 & $(28-32)$ & 53 & $(50-56)$ & 100 & 2378 \\
\hline Total & 34 & $(32-36)$ & 34 & $(32-35)$ & 32 & $(31-34)$ & 100 & 6891 \\
\hline
\end{tabular}

\subsection{Conclusion}

This chapter has provided an overview of the physical and behavioural health of the over 50 s in Ireland, focussing in particular on how health and health behaviours have changed over the period between wave 1 and wave 2 of the TILDA study. This information is vital for ensuring policy responses to population ageing are evidence-based, as outlined in recent health policy documents such as Healthy Ireland - A Framework for Improved Health and Well-Being 2013-2025 (2).

Although the TILDA participants are now two years older, it is encouraging to note an increase in the proportion of older adults who report that their health is 'excellent' or 'very good'. Hypertension and diabetes continue to be the most prevalent cardiovascular conditions among older Irish adults while arthritis and osteoporosis are the most prevalent non-cardiovascular chronic conditions. The prevalence of most conditions has remained largely stable since wave 1. However, some changes are observed most notably for angina, which has decreased and arthritis and osteoporosis, which have increased.

Falls continue to be a major problem for older adults and it is worrying to note an increase in the proportion of the older population who have experienced a fall that requires medical attention between wave 1 and wave 2 . On a positive note, there is some evidence that behavioural change is possible at any age; for example, 16 per cent of smokers at wave 1 had quit by wave 2 . Retirement age appears to be a key time for changes in smoking 
and problematic drinking behaviours among the older population in Ireland, and this is supported by international evidence (19). This suggests that intervention strategies may need to be structured to reflect this opportunity.

Finally, it is important to note that all of the data presented in this chapter is based on self-reported information. Findings from wave 1 and elsewhere indicate that measures of disease based on self-report tend to underestimate the true prevalence of a condition ( 5 , 20). An objective assessment of physical health, based on the same health assessment procedures as wave 1 , is planned for the next wave of the study in 2014 . The availability of objective health data from two time points will provide more reliable estimates of the true prevalence and incidence of disease over time and inform effective health planning for older adults.

\section{References}

1. CSO. This is Ireland - Part 1. Highlights from Census 2011. Dublin, Ireland: Stationary Office; 2012.

2. DOHC. Healthy Ireland - A Framework for Improved Health and Well-being 2013-2025. Government Publications, Dublin, Ireland; 2013.

3. DOHC. The National Positive Ageing Strategy. Government Publications, Dublin, Ireland; 2011.

4. Kenny R.A., Whelan B.J., al CHe. The Design of the Irish Longitudinal Study on Ageing (TILDA). ; 2010.

5. Cronin H., O Regan C., RA. K. Physical and Behavioural Health of Older Irish Adults. In: Barret A., Savva G., Timonen V., R.A. K, editors. Fifty Plus in Ireland 2011: First results from the Irish Longiudinal Study on Ageing (TILDA). Dublin, Ireland.2011.

6. Idler EL, Angel RJ. Self-rated health and mortality in the NHANES-I Epidemiologic Follow-up Study. American journal of public health. 1990;80(4):446-52.

7. Children DoHa. Health in Ireland: Key Trends. In: Children DoHa, editor. Dublin, Ireland: Government Publications; 2012.

8. DOHC. National Cardiovascular Health Policy 2010 -2019. Government Publications, Dublin, Ireland; 2010.

9. Kabir Z, Perry IJ, Critchley J, O’Flaherty M, Capewell S, Bennett K. Modelling Coronary Heart Disease Mortality declines in the Republic of Ireland, 1985-2006. International journal of cardiology. 2013;168(3):2462-7. 
10. Wolf PA, Abbott RD, Kannel WB. Atrial fibrillation as an independent risk factor for stroke: the Framingham Study. Stroke. 1991;22(8):983-8.

11. Duron E, Hanon O. [Atrial fibrillation and cognitive function]. Psychologie \& neuropsychiatrie du vieillissement. 2010;8(3):209-14.

12. Society AG, Society G, Of AA, On Falls Prevention OSP. Guideline for the Prevention of Falls in Older Persons. Journal of the American Geriatrics Society. 2001;49(5):664-72.

13. Gannon B, O'Shea E, Hudson E. Economic consequences of falls and fractures among older people. Irish medical journal. 2008;101(6):170-3.

14. Sees KL. Cigarette smoking, nicotine dependence, and treatment. West J Med. 1990;152(5):578-84.

15. Westmaas JL, Brandon TH. Reducing risk in smokers. Curr Opin Pulm Med. 2004;10(4):284-8.

16. Ramstedt M, Hope A. The Irish drinking culture: drinking and drinking-related harm, a European comparison. 2004.

17. Caspersen CJ, Pereira MA, Curran KM. Changes in physical activity patterns in the United States, by sex and cross-sectional age. Med Sci Sports Exerc. 2000;32(9):16019.

18. Warburton DE, Nicol CW, Bredin SS. Health benefits of physical activity: the evidence. CMAJ. 2006;174(6):801-9.

19. Lang IA, Rice NE, Wallace RB, Guralnik JM, Melzer D. Smoking cessation and transition into retirement: analyses from the English Longitudinal Study of Ageing. Age and Ageing. 2007 November 1, 2007;36(6):638-43.

20. Frewen J, Finucane C, Cronin H, Rice C, Kearney PM, Harbison J, et al. Factors that influence awareness and treatment of atrial fibrillation in older adults. QJM : monthly journal of the Association of Physicians. 2013;106(5):415-24. 
Appendix 3A: Tables on Changes in Physical and Behavioural Health in Older Irish Adults

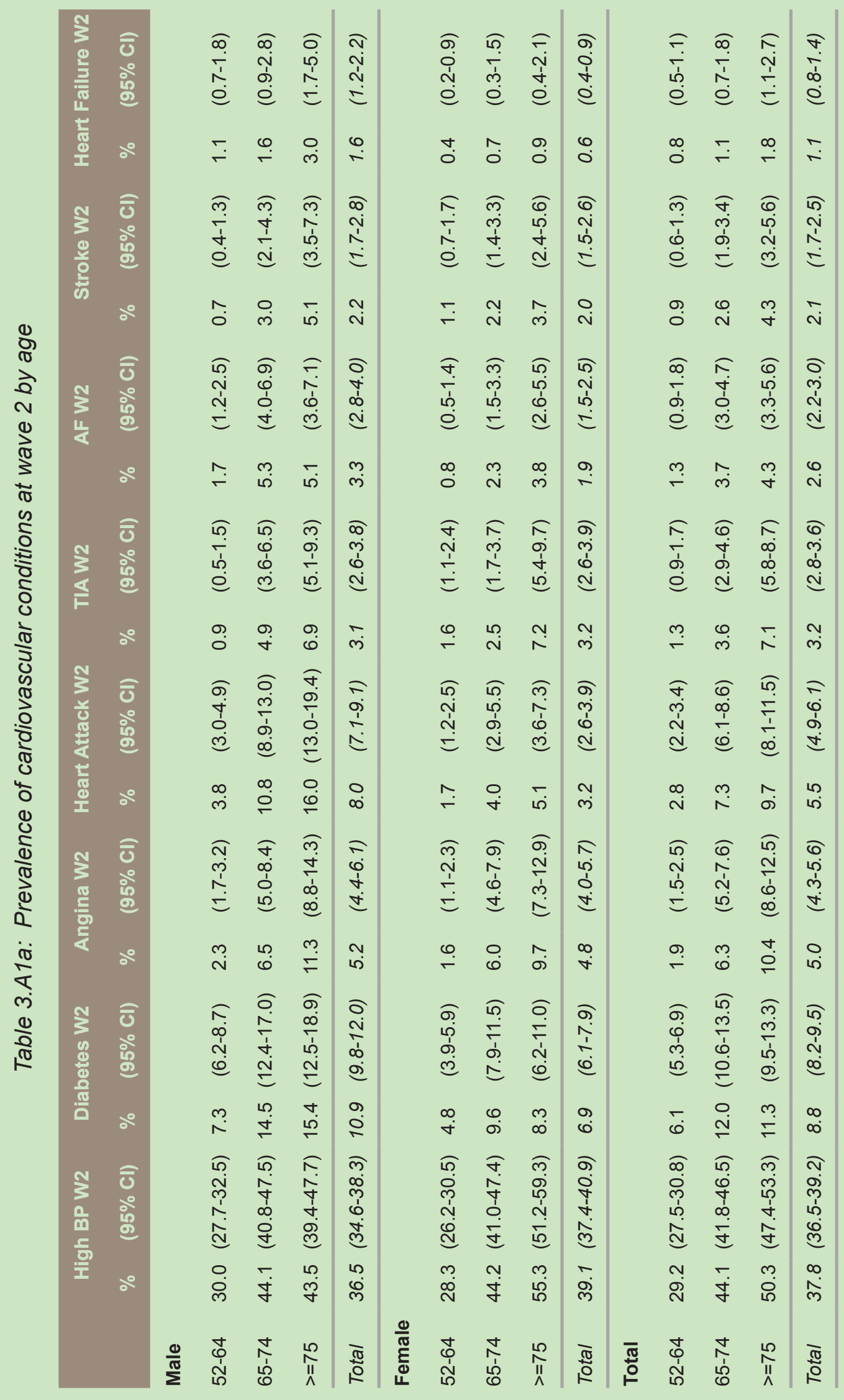




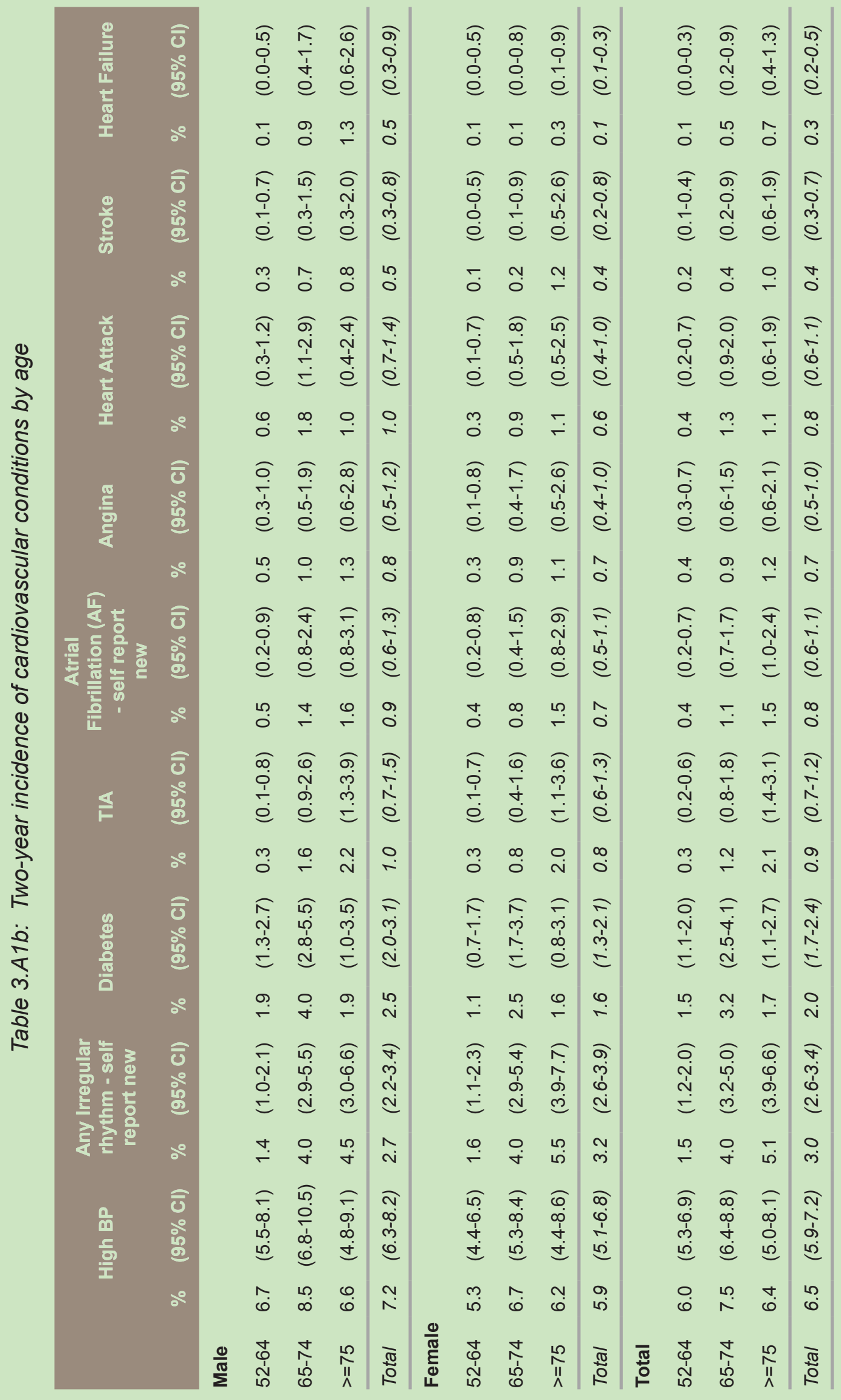




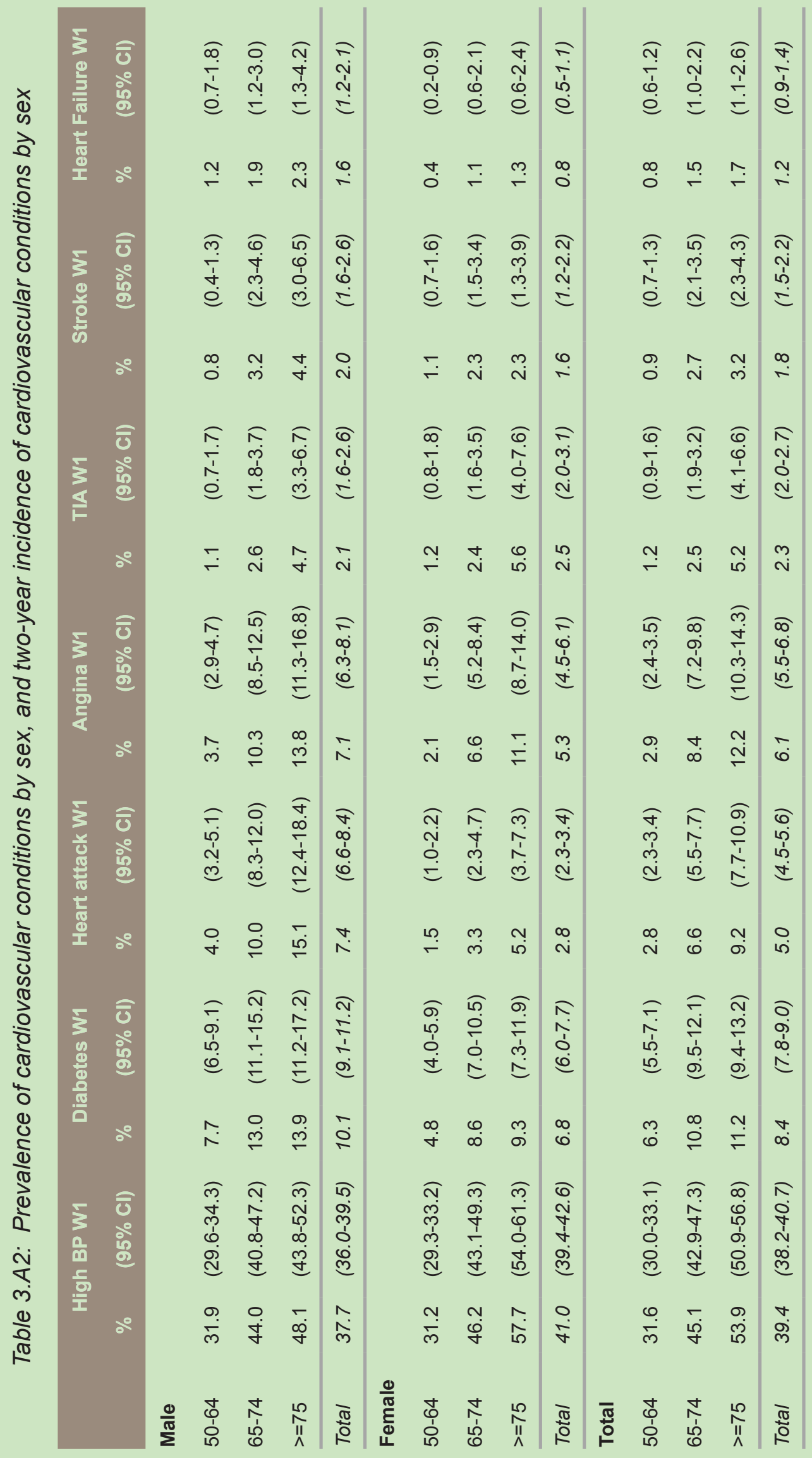




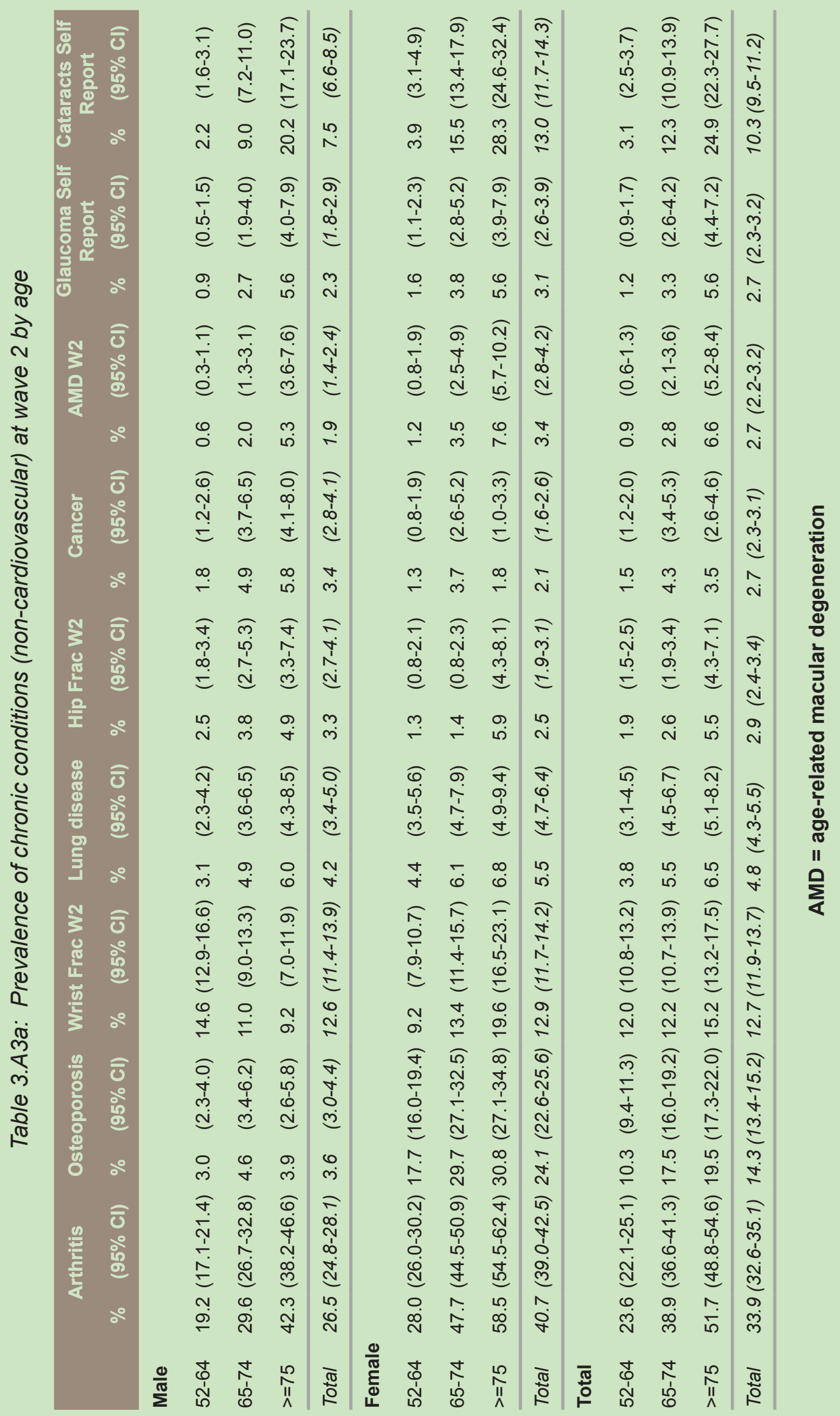




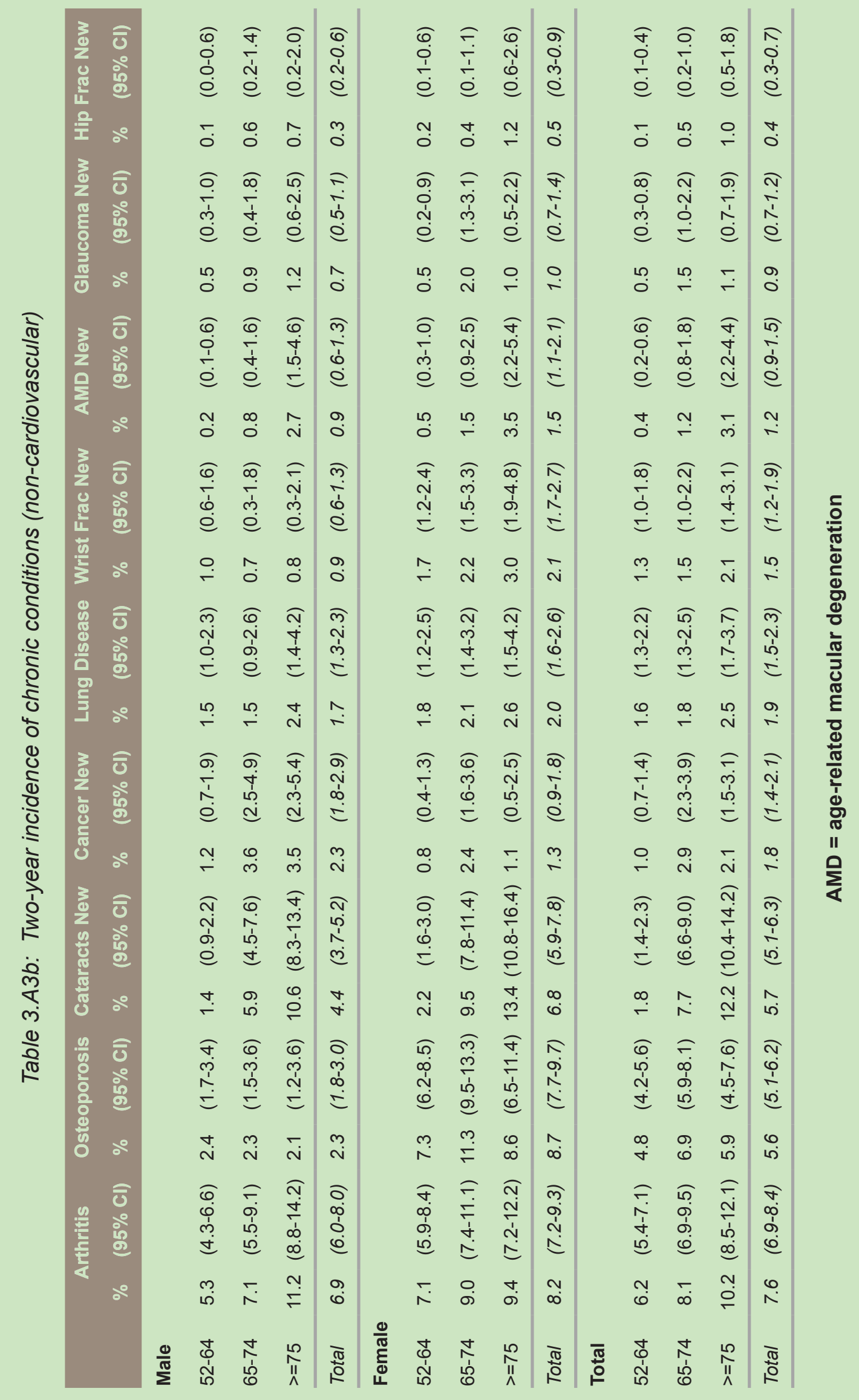




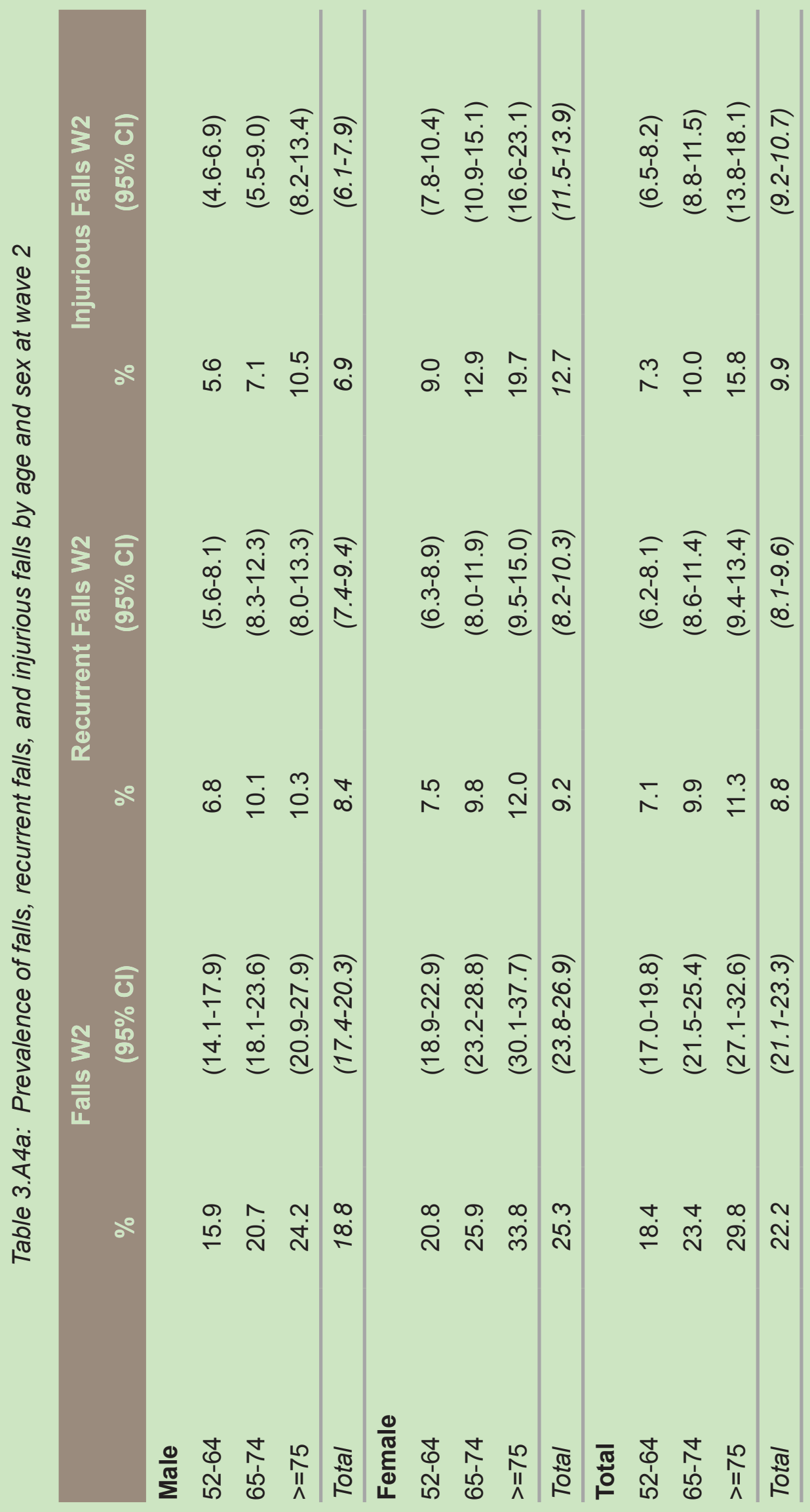




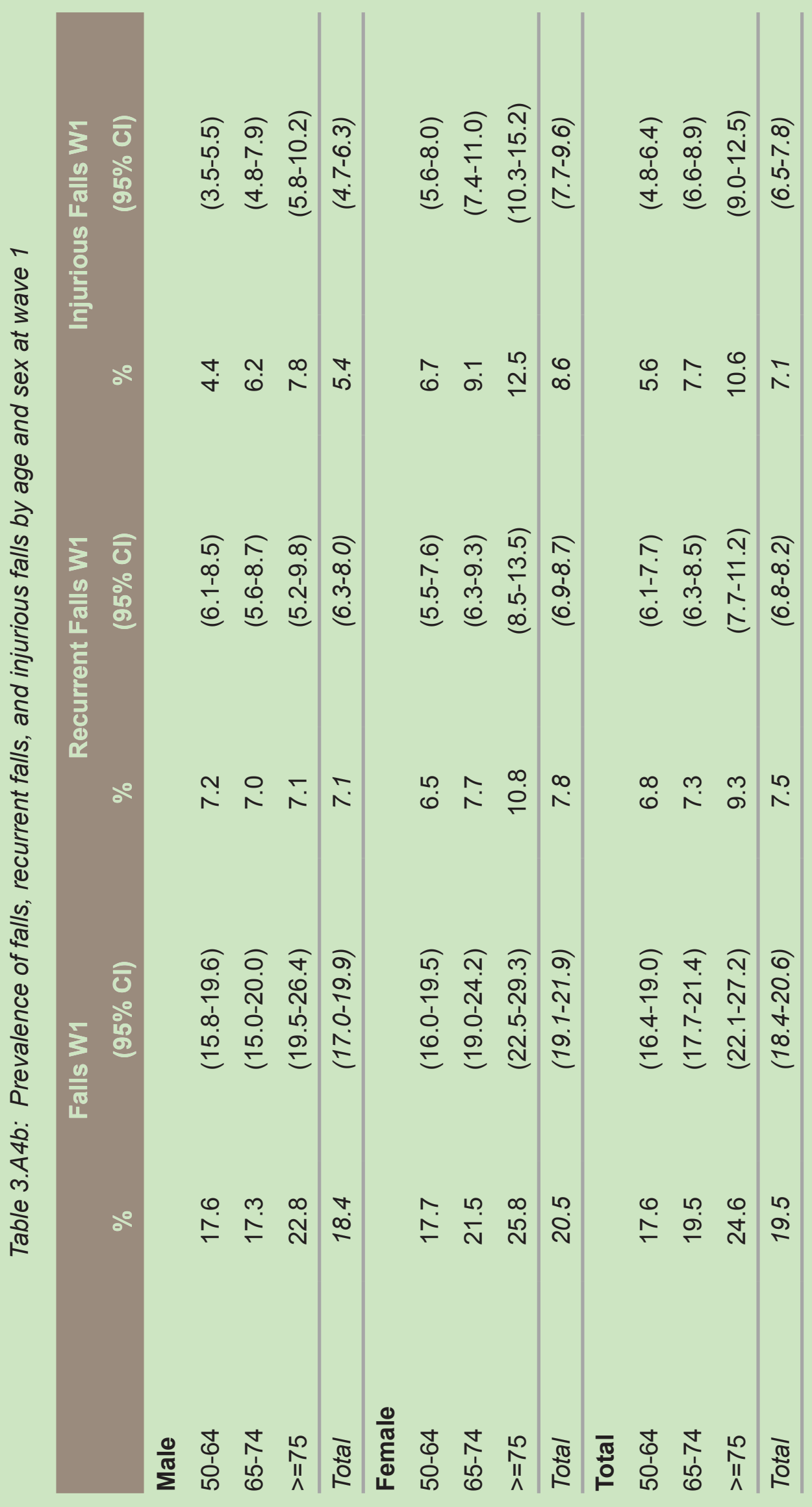


Table 3.A5: Prevalence of negative health behaviours by age

\begin{tabular}{|c|c|c|c|c|c|c|}
\hline \multirow{2}{*}{$\begin{array}{c}\text { Prevalence } \\
\text { Wave } 1\end{array}$} & \multicolumn{2}{|c|}{ Smoking } & \multicolumn{2}{|c|}{$\begin{array}{c}\text { Problematic Alcohol } \\
\text { Use }\end{array}$} & \multicolumn{2}{|c|}{ Low Physical Activity } \\
\hline & $\%$ & $(95 \% \mathrm{Cl})$ & $\%$ & $(95 \% \mathrm{CI})$ & $\%$ & (95\% CI) \\
\hline \multicolumn{7}{|l|}{$52-64$} \\
\hline Total & 21.7 & $(20-23)$ & 15.9 & $(15-17)$ & 27.3 & $(26-29)$ \\
\hline \multicolumn{7}{|l|}{$65-74$} \\
\hline Total & 15.3 & $(13-17)$ & 8.3 & $(7-10)$ & 31.9 & $(30-34)$ \\
\hline \multicolumn{7}{|l|}{$>=75$} \\
\hline Total & 9.5 & $(8-12)$ & 4.0 & $(3-6)$ & 48.5 & $(45-52)$ \\
\hline \multicolumn{7}{|l|}{ Total } \\
\hline Total & 18.3 & $(17-19)$ & 12.2 & $(11-13)$ & 31.7 & (30-33) \\
\hline \multirow{2}{*}{$\begin{array}{l}\text { Prevalence } \\
\text { Wave } 2\end{array}$} & \multicolumn{2}{|c|}{ Smoking } & \multicolumn{2}{|c|}{$\begin{array}{c}\text { Problematic Alcohol } \\
\text { Use }\end{array}$} & \multicolumn{2}{|c|}{ Low Physical Activity } \\
\hline & $\%$ & (95\% CI) & $\%$ & $(95 \% \mathrm{CI})$ & $\%$ & $(95 \% \mathrm{Cl})$ \\
\hline \multicolumn{7}{|l|}{$52-64$} \\
\hline Total & 21.2 & $(20-23)$ & 19.9 & $(18-22)$ & 26.9 & $(25-29)$ \\
\hline \multicolumn{7}{|l|}{$65-74$} \\
\hline Total & 13.5 & 12-15) & 12.5 & $(11-15)$ & 33.2 & $(31-36)$ \\
\hline \multicolumn{7}{|l|}{$>=75$} \\
\hline Total & 9.3 & $(8-11)$ & 8.0 & $(6-11)$ & 51.6 & $(48-55)$ \\
\hline \multicolumn{7}{|l|}{ Total } \\
\hline Total & 16.5 & $(16-18)$ & 15.9 & $(15-17)$ & 34.0 & $(32-36)$ \\
\hline
\end{tabular}


Table 3.A6: Prevalence of negative health behaviours by sex

\begin{tabular}{|c|c|c|c|c|c|}
\hline \multirow[t]{2}{*}{$\begin{array}{l}\text { Prevalence } \\
\text { Wave } 1\end{array}$} & \multicolumn{2}{|c|}{ Smoking } & \multicolumn{2}{|c|}{$\begin{array}{c}\text { Problematic Alcohol } \\
\text { Use }\end{array}$} & $\begin{array}{l}\text { Low Physical } \\
\text { Activity }\end{array}$ \\
\hline & $\%$ & $(95 \%$ CI) & $\%$ & $(95 \% \mathrm{Cl})$ & $\% \quad(95 \% \mathrm{Cl})$ \\
\hline \multicolumn{6}{|l|}{ Male } \\
\hline Total & 18.5 & $(17-20)$ & 16.6 & $(15-18)$ & $25.2 \quad(23-27)$ \\
\hline \multicolumn{6}{|l|}{ Female } \\
\hline Total & 18.1 & $(17-19)$ & 8.1 & $(7-9)$ & $37.8 \quad(36-40)$ \\
\hline \multicolumn{6}{|l|}{ Total } \\
\hline Total & 18.3 & $(17-19)$ & 12.2 & $(11-13)$ & $31.7 \quad(30-33)$ \\
\hline \multirow{2}{*}{$\begin{array}{l}\text { Prevalence } \\
\text { Wave } 2\end{array}$} & \multicolumn{2}{|c|}{ Smoking } & \multicolumn{2}{|c|}{$\begin{array}{c}\text { Problematic Alcohol } \\
\text { Use }\end{array}$} & $\begin{array}{l}\text { Low Physical } \\
\text { Activity }\end{array}$ \\
\hline & $\%$ & $(95 \%$ Cl) & $\%$ & $(95 \% \mathrm{CI})$ & (95\% Cl) \\
\hline \multicolumn{6}{|l|}{ Male } \\
\hline Total & 16.4 & $(15-18)$ & 21.7 & $(19-23)$ & $26.6 \quad(25-28)$ \\
\hline \multicolumn{6}{|l|}{ Female } \\
\hline Total & 16.6 & $(15-18)$ & 11.0 & $(10-12)$ & $40.8 \quad(39-43)$ \\
\hline \multicolumn{6}{|l|}{ Total } \\
\hline Total & 16.5 & $(15-18)$ & 15.9 & $(15-17)$ & $(32-36)$ \\
\hline
\end{tabular}




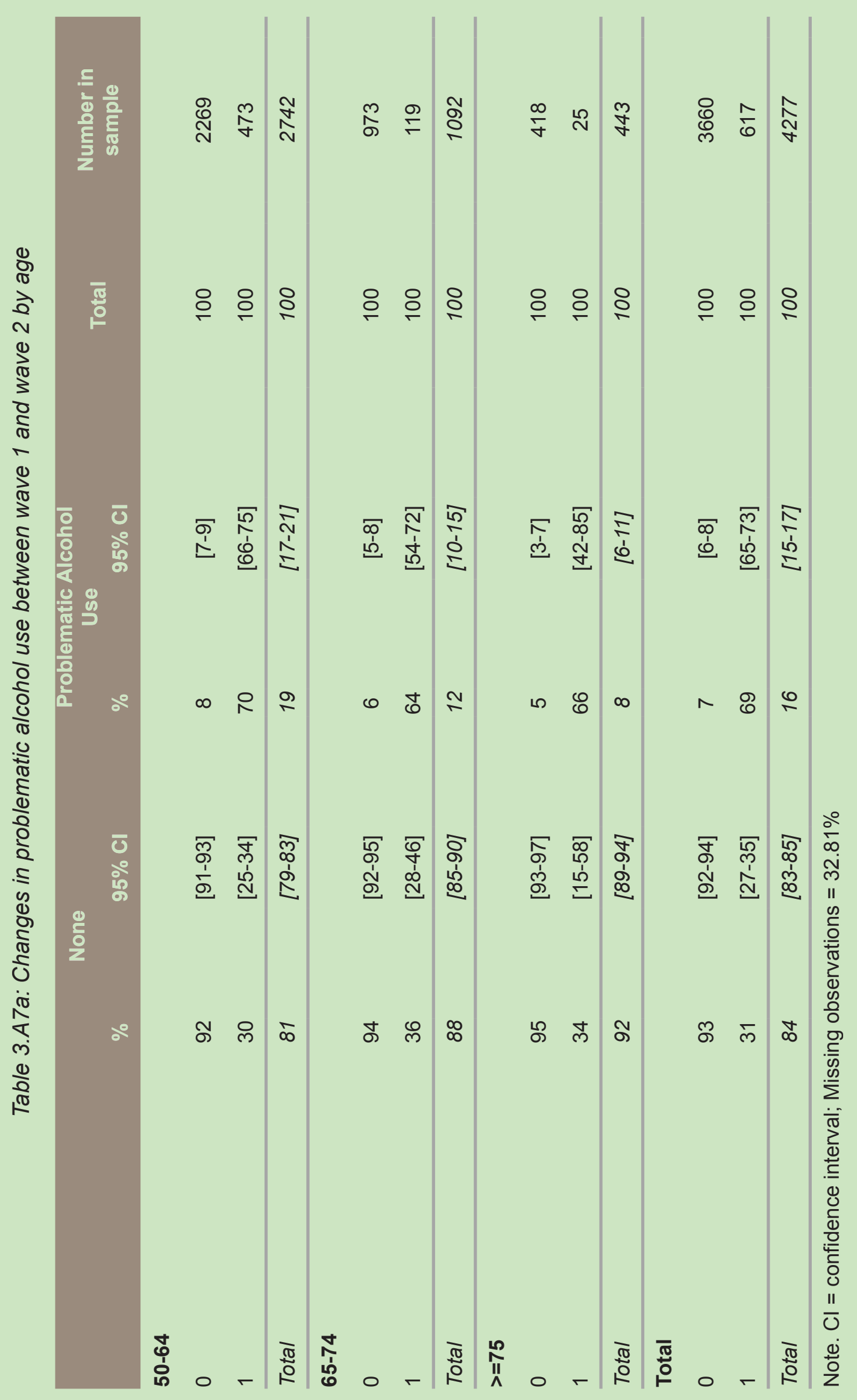




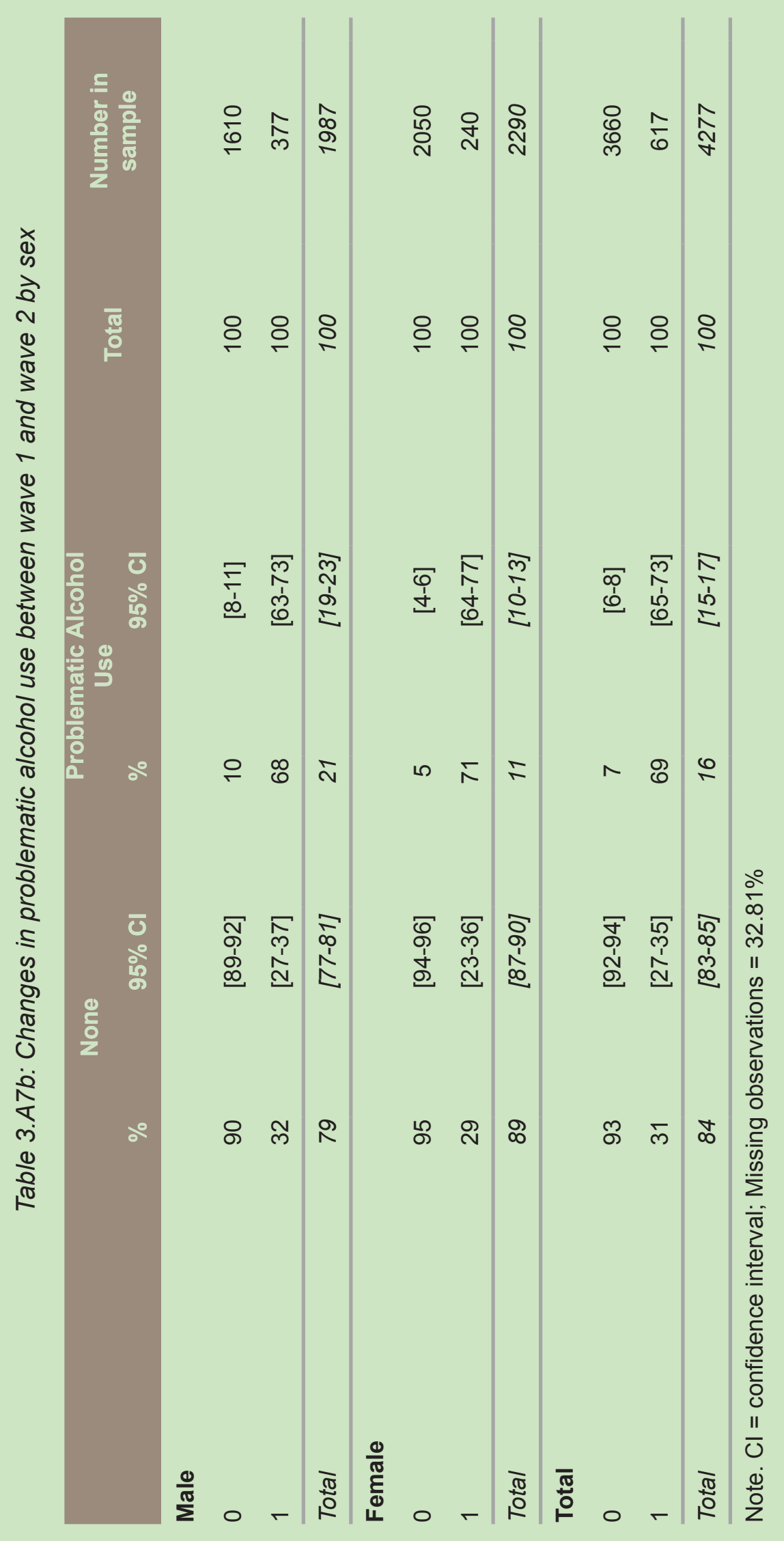




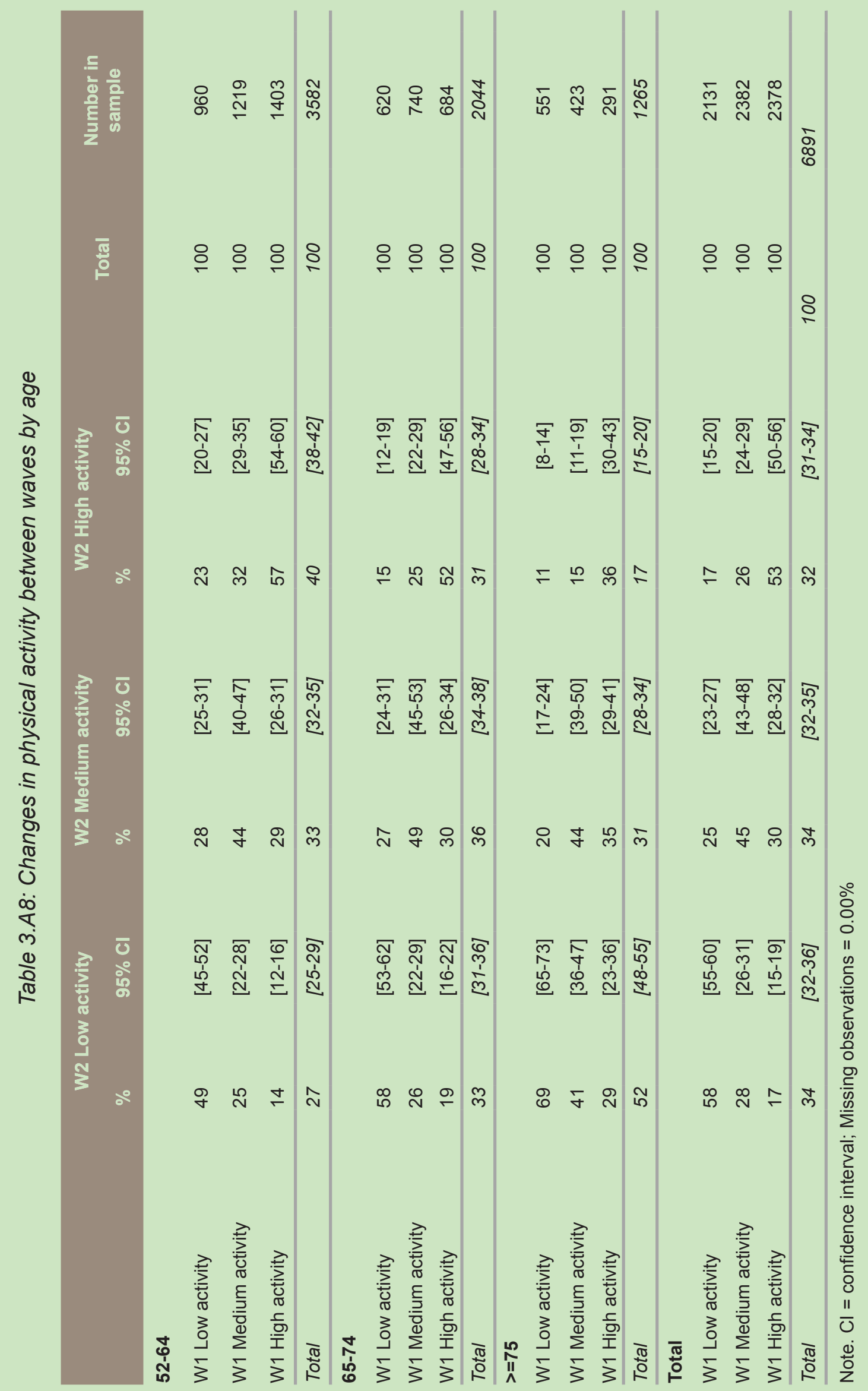




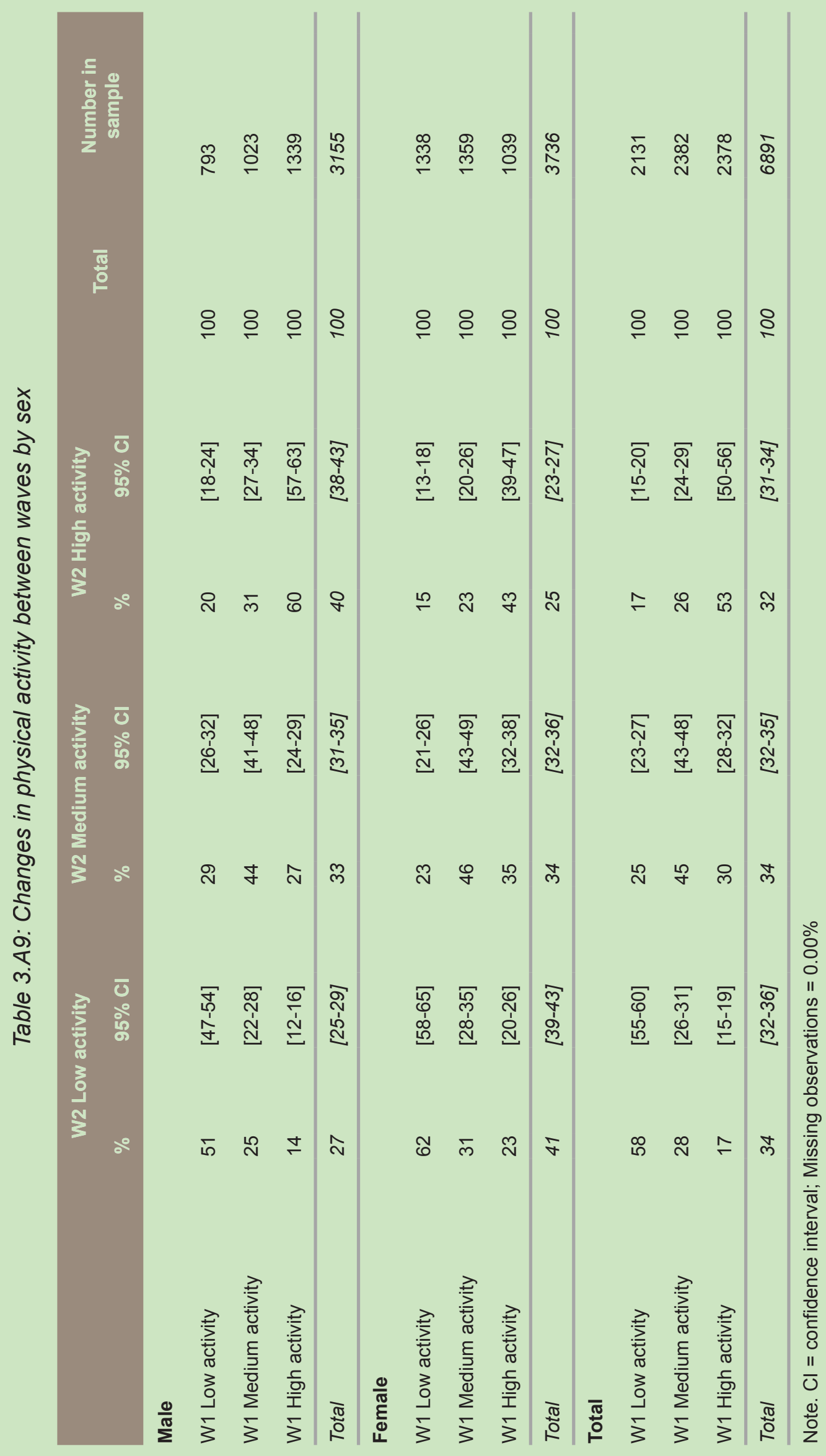




\section{Appendix 3B: Figures on Changes in Physical and Behavioural Health in Older Irish Adults}

Figure 3.B1a: Prevalence of smoking in wave 2 by age (5-year age groups)

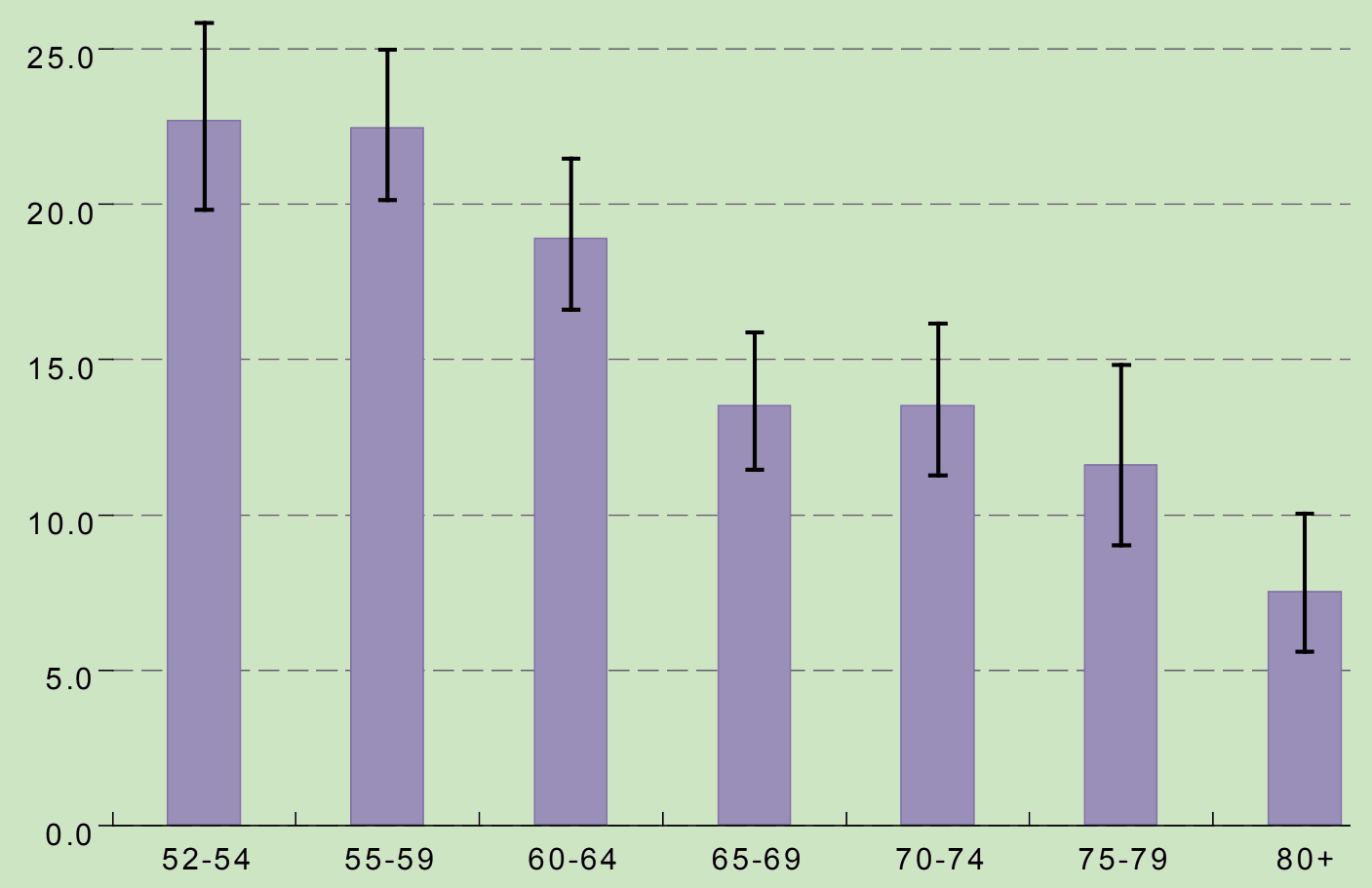

Figure 3.B1b: Prevalence of problematic alcohol use in wave 2 by age (5-year age groups)

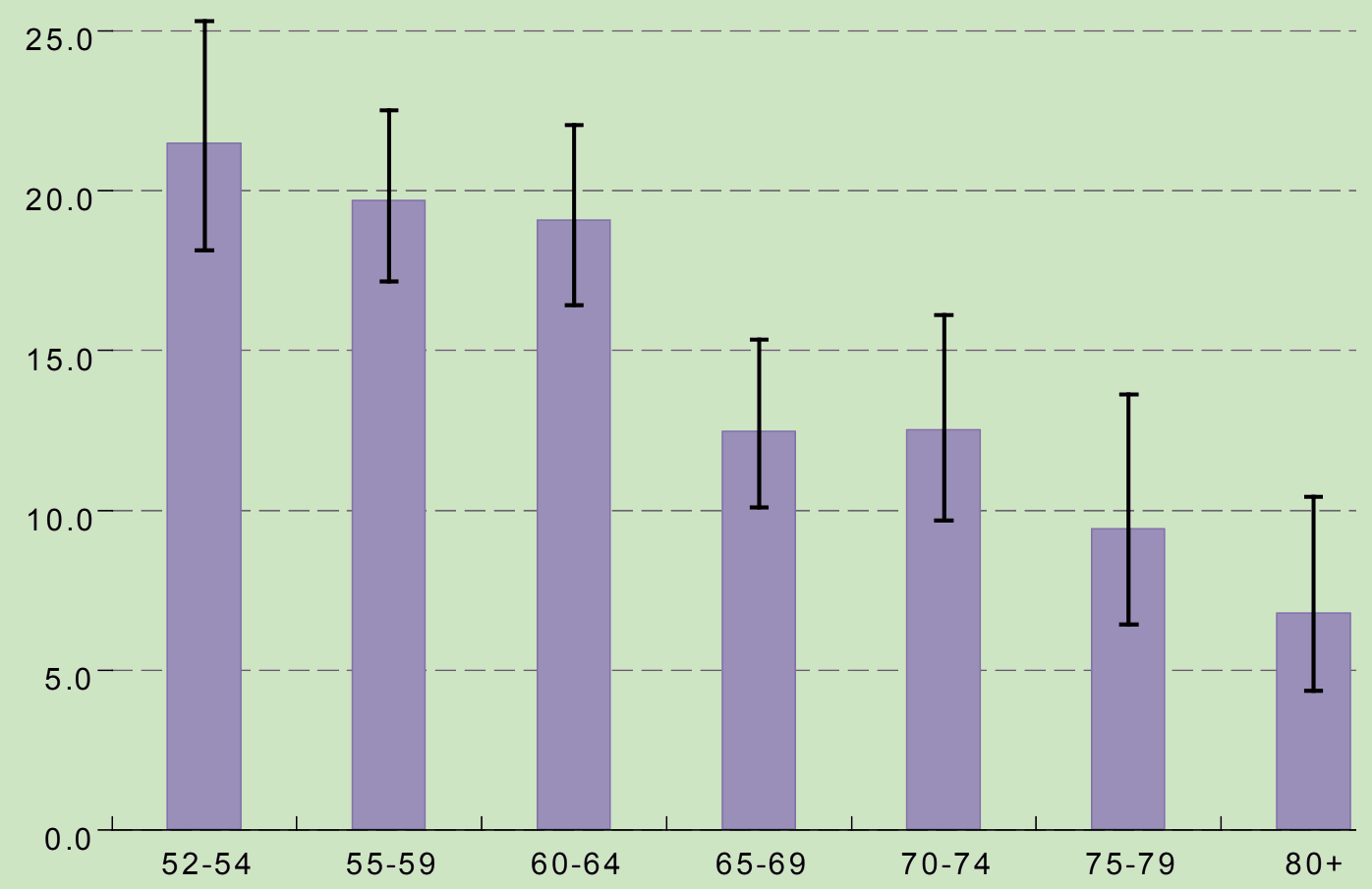




\section{Appendix 3C: The CAGE Screening Questionnaire Tool}

The CAGE questionnaire is a set of 4 questions that indicates the likelihood of a drinking problem. The questions are as follows:

1. Have you ever felt you needed to Cut down on your drinking?

2. Have people Annoyed you by criticizing your drinking?

3. Have you ever felt Guilty about drinking?

4. Have you ever felt you needed a drink first thing in the morning (Eye-opener) to steady your nerves or to get rid of a hangover?

A positive answer to each question is given a score of 1 and summed to give a total CAGE score, where a CAGE score $\geq 2$ is indicative of problem drinking. 


\title{
Obesity and Health Outcomes in Older Irish Adults
}

\author{
Siobhan Leahy, Orna Donoghue, Matthew \\ O'Connell, Celia O'Hare and Hugh Nolan
}

\section{Contents}

Key findings 86

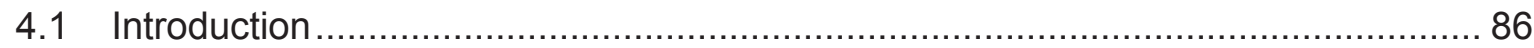

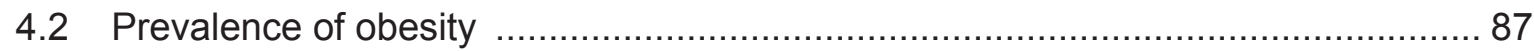

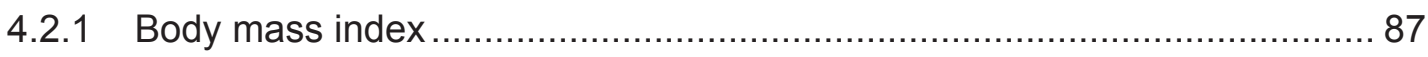

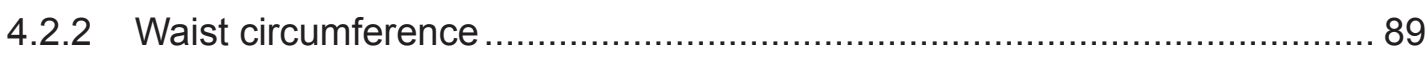

4.3 Obesity and cardiovascular disease ........................................................... 91

4.3.1 Obesity and prevalence of cardiovascular disease ............................... 91

4.3.2 Obesity and prevalence of cardiovascular disease risk factors................. 92

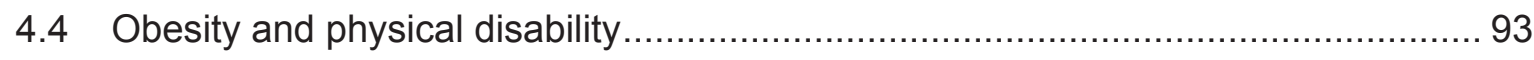

4.4.1 Obesity and prevalence of physical disability ........................................ 93

4.4.2 Obesity and prevalence of new disabilities ............................................. 94

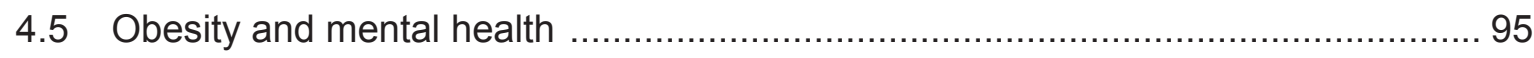

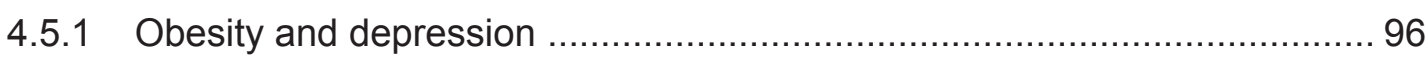

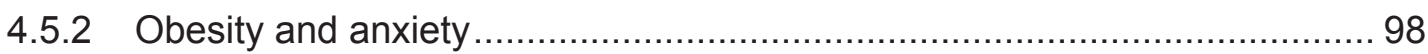

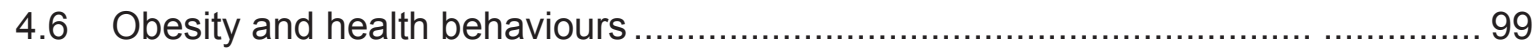

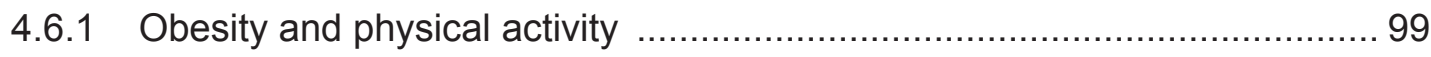

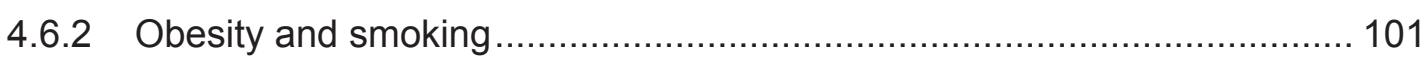

4.6.3 Obesity and alcohol consumption ...................................................... 101

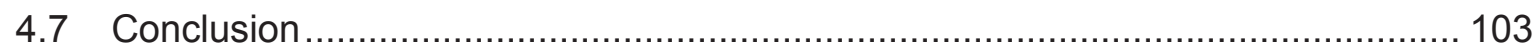

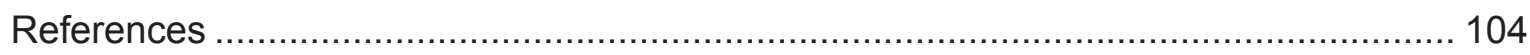

Appendix 4: Tables on Obesity and Health Outcomes in Older Irish Adults .................. 109 


\section{Obesity and Health
Outcomes in Older Irish Adults}

\section{Key findings}

- $35 \%$ of older Irish adults are classified as obese according to their body mass index; a further $44 \%$ are overweight.

- According to World Health Organisation criteria, $53 \%$ of older Irish adults are at a substantially increased risk of metabolic and cardiovascular disease based on their waist circumference.

- Obesity at wave 1 is strongly associated with cardiovascular disease at wave 2. Both men and women who were obese at wave 1 have a significantly higher prevalence of diabetes at wave 2, while obese men have a significantly higher prevalence of heart attacks, and obese women have a significantly higher prevalence of angina.

- Increased waist circumference at wave 1 is associated with the development of disability, particularly among women.

- A significantly higher proportion of men who were obese at wave 1 had reduced their alcohol intake by wave 2 (in comparison with men who were of normal weight at wave 1).

\subsection{Introduction}

Obesity is considered a chronic disease and is defined by the World Health Organisation (WHO) as excess body fat to the extent that health may be impaired (1). Worldwide, the prevalence of obesity has increased dramatically in recent decades, leading many to classify it as an epidemic (1). While the prevalence of obesity has begun to stabilise in some countries, Ireland has demonstrated one of the highest increases in obesity prevalence in the last decade (2). According to the 2011 National Adult Nutrition Survey (NANS) (3), the most dramatic increase in obesity among Irish adults was observed in 5164 year old men, rising from $11 \%$ to $42 \%$ over the past two decades.

These figures are based on Body Mass Index (BMI), which is an indicator of overall body fatness. In older adults waist circumference is considered to be a more useful measure of 
obesity than BMI (4). In the NANS survey (3), over half of all 50+ year olds were reported to have a substantially increased waist circumference.

In older adults obesity is associated with depression, disability, frailty $(5,6)$ and cardiovascular disease (7-9); however, the effects of rising obesity rates on the health and wellbeing of older Irish adults have yet to be examined. Using objective measures of BMI and waist circumference collected at wave 1 , this chapter will document the prevalence of overweight and obesity in our older population, and examine the association between excess body fat at wave 1 and the prevalence of cardiovascular disease, disability, mental and behavioural health at wave 2 .

\subsection{Prevalence of obesity}

In wave 1 of TILDA, height, weight and waist circumference were measured during the health assessment which took place in either a health centre or the participant's home. These measures were then used to calculate BMI and waist circumference. Detailed protocols for these measurements can be accessed on the TILDA website (http://www. tcd.ie/tilda/about/project-description/data-collection). The following analyses are based on participants who completed a health assessment at wave 1 and the computer assisted personal interview (CAPI) at wave 2, giving a total sample size of 5,349.

$\mathrm{BMI}$ is the metric traditionally used to define overweight and obesity. However, in older adults, BMI does not reflect age-related loss of muscle mass (10). Additionally, the distribution of body fat may change, with a greater proportion of fat deposited centrally, around the abdomen (11). Therefore in older adults, waist circumference (WC) may be a more useful indicator of obesity than BMI, since fat deposited in this region is associated with greater risk of cardiac and metabolic disease (4).

\subsubsection{Body mass index}

$\mathrm{BMI}$ is calculated as weight in kilograms divided by height in metres squared $(\mathrm{kg} / \mathrm{m} 2)$. WHO (1) cut-offs are used to define persons as 'underweight', 'normal', 'overweight' and 'obese' (see Table 4.1). In TILDA less than $1 \%$ of the population is classified as underweight so this group has been excluded from further analyses. 
Table 4.1: World Health Organisation body mass index classifications

\begin{tabular}{|l|r|}
\hline \multicolumn{1}{|c|}{ Classification } & BMI $\left(\mathbf{k g} / \mathrm{m}^{2}\right)$ \\
\hline Underweight & $<18.50$ \\
\hline Normal & $18.50-24.99$ \\
\hline Overweight & $25.00-29.99$ \\
\hline Obese & $\geq 30.00$ \\
\hline
\end{tabular}

Overall $35 \%$ of older Irish adults are obese, with a further $44 \%$ classed as overweight (see Figure 4.1).

Figure 4.1: Distribution of body mass index at wave 1

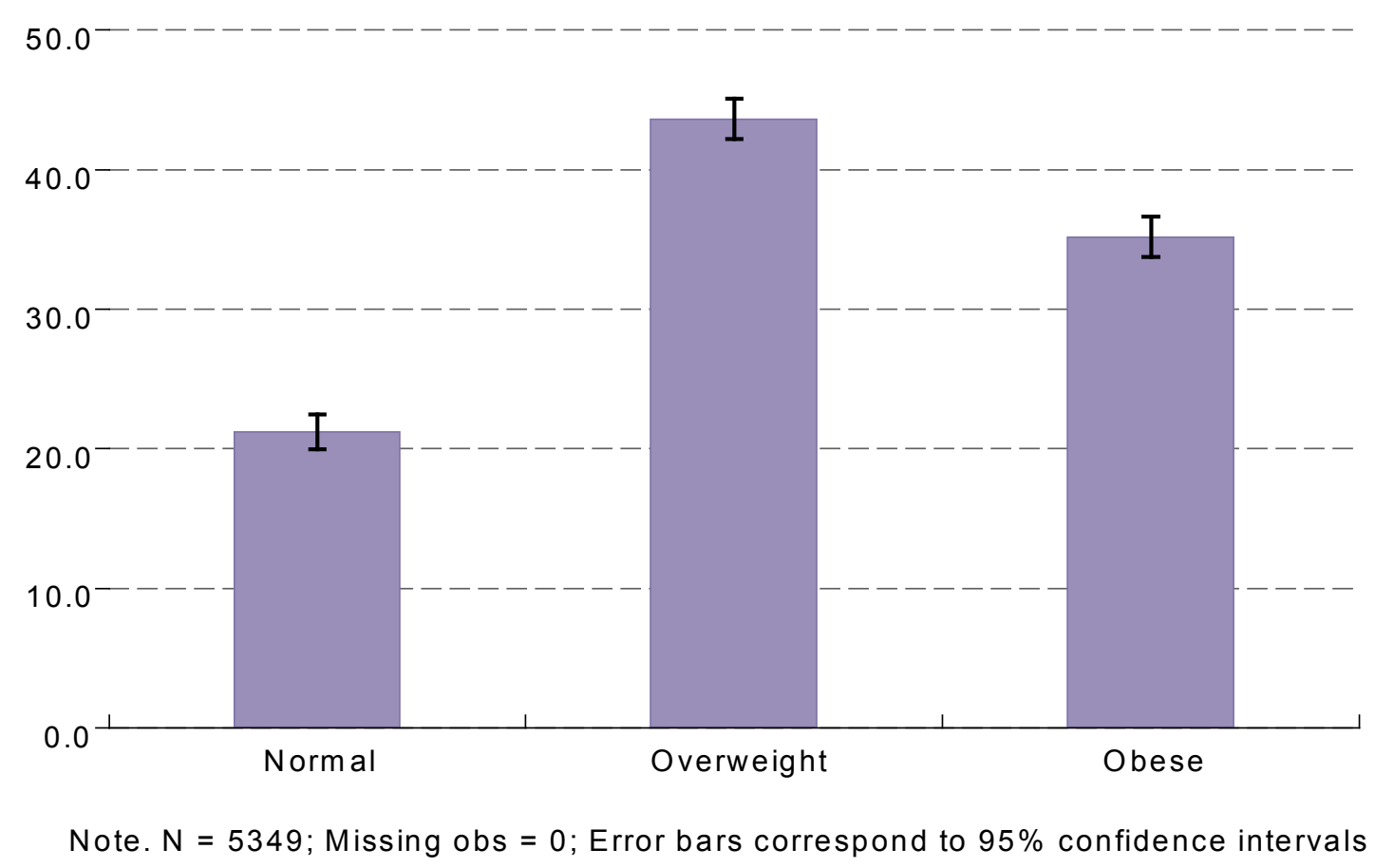

Figure 4.2 illustrates obesity prevalence by age and sex. Obesity is more prevalent among men (38\%) than women (33\%) (see Appendix Table 4.A1). This finding is contrary to what is found internationally where women tend to have higher rates of obesity compared to men (2). No age differences are observed in the prevalence of obesity among TILDA participants. 
Figure 4.2: Distribution of body mass index at wave 1 by age and sex

$52-64 \square \quad \square 5-74 \quad \square>=75$
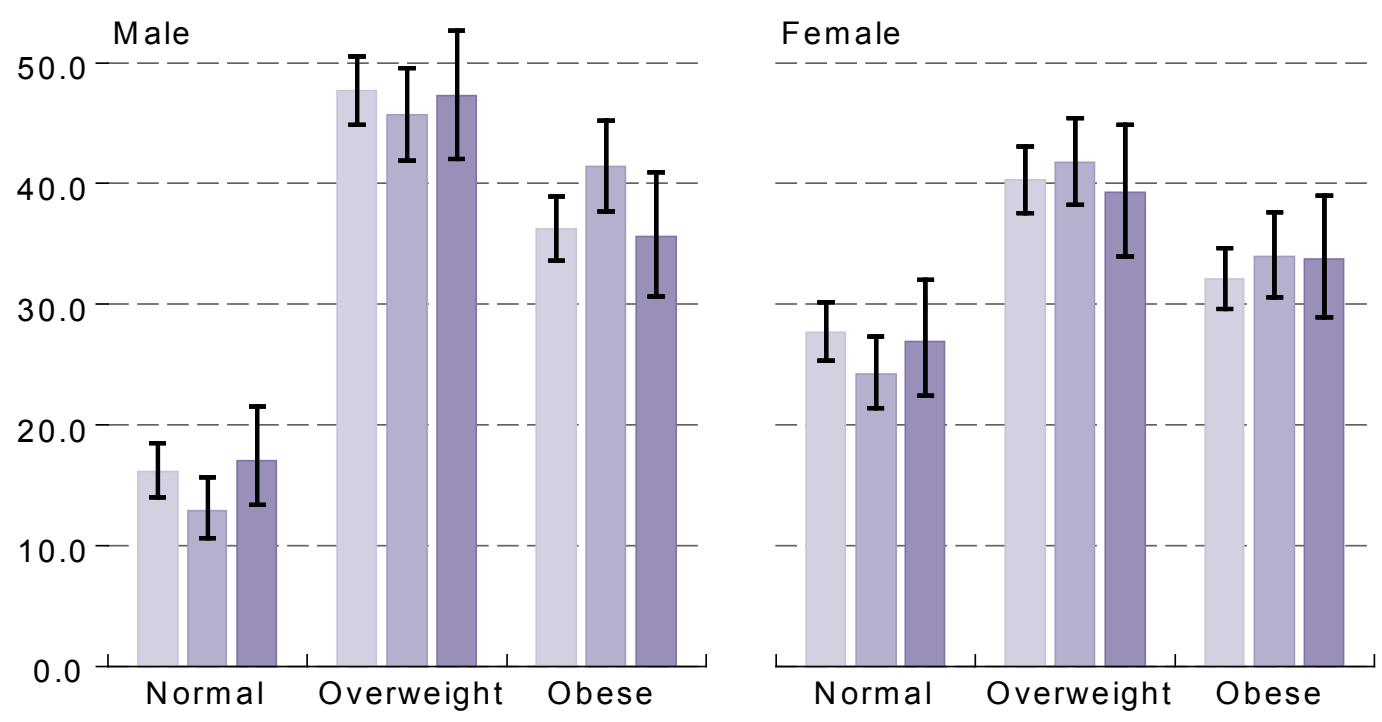

Note. $\mathrm{N}=5349 ;$ Missing obs $=0$; Error bars correspond to $95 \%$ confidence intervals

\subsubsection{Waist circumference}

Using WHO cut-offs (11), TILDA participants were classified into three categories of WC indicating 'normal', 'increased' or 'substantially increased' risk of metabolic complications (see Table 4.2).

Table 4.2: WHO waist circumference classifications

\begin{tabular}{|l|r|r|}
\hline \multicolumn{1}{|c|}{ Risk Classification } & \multicolumn{2}{|c|}{ Waist circumference (cm) } \\
& \multicolumn{1}{c|}{ Men } & Women \\
\hline Normal & $<94$ & $<80$ \\
\hline Increased & $94-101$ & $80-87$ \\
\hline Substantially Increased & $\geq 102$ & $\geq 88$
\end{tabular}

Based on the above criteria, 53\% of Irish adults aged 50 and over are classified as centrally obese and at substantially increased risk of metabolic complications (see Figure 4.3 and Appendix Table 4.A2). 
Figure 4.3: Distribution of waist circumference at wave 1

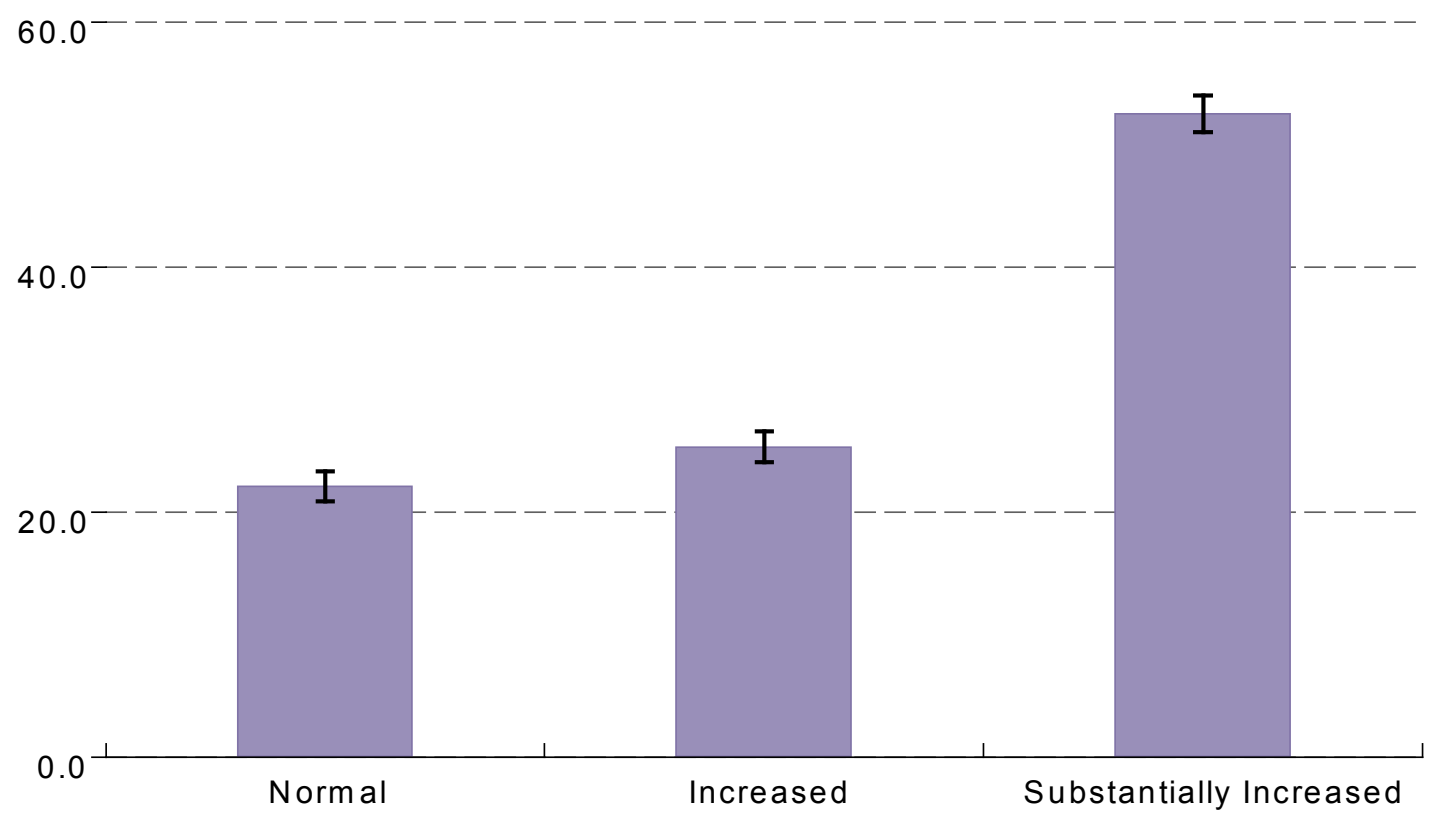

Note. $\mathrm{N}=5349 ;$ Missing obs $=0$; Error bars correspond to $95 \%$ confidence intervals

Figure 4.4: Distribution of waist circumference at wave 1 by age and sex

\begin{tabular}{l|l|l}
$52-64$ & $65-74$ & $\square=75$
\end{tabular}

$80.0^{-}$Male

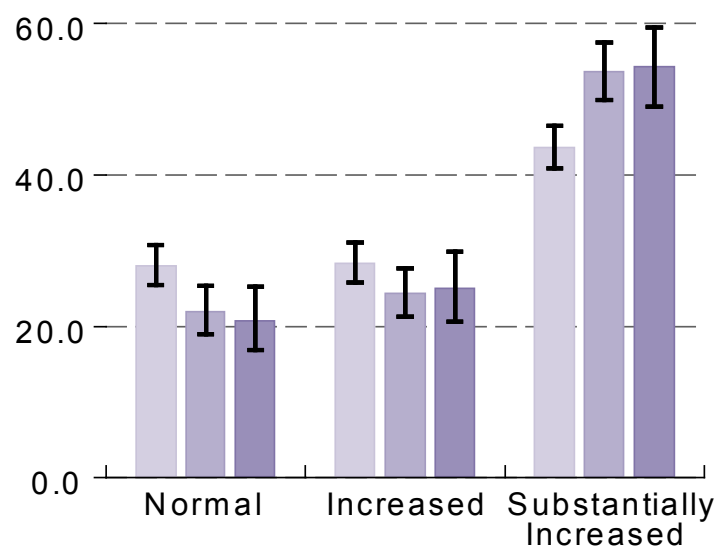

Female

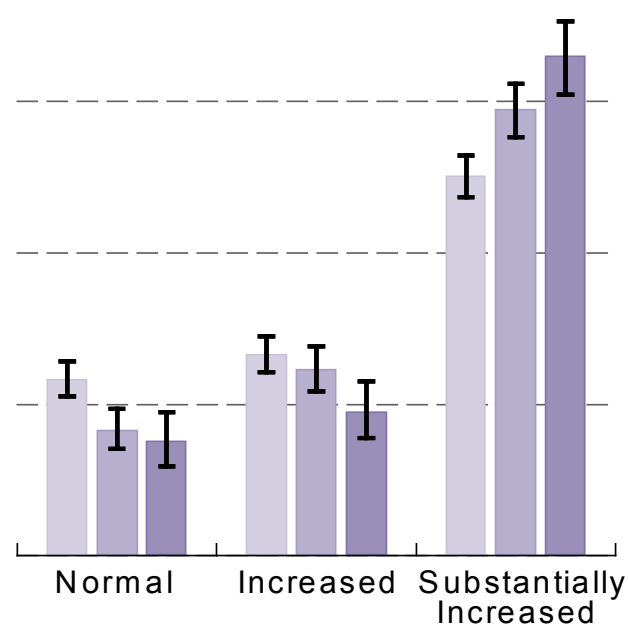

Note. $N=5349 ;$ Missing obs $=0 ;$ Error bars correspond to $95 \%$ confidence intervals 
A greater proportion of women (56\%) have a substantially increased WC compared to men (48\%) (see Appendix Table 4.A2). Age differences are apparent in the prevalence of WC with men and women aged 65 and over having significantly larger waist circumstances compared to younger adults aged 52-64 years (Figure 4.4).

Our findings show that obesity (defined by BMI) and central obesity (defined by WC) are major health concerns for Irish adults aged 50 years and over. International findings indicate that life expectancy at age 50 is decreased for obese men and women (12) and obesity also increases the number of years people live with disability (13). International findings indicate that this will have substantial social and economic costs, by increasing the number of years people live with disability and increasing the care burden on the state (13). Early interventions aimed at preventing and reversing this epidemic are therefore necessary, to avoid an unsustainable drain on future health and social services.

\subsection{Obesity and cardiovascular disease}

Cardiovascular disease (CVD) remains the leading cause of mortality in Ireland, accounting for $32 \%$ of deaths in 2012 (14). Obesity is an independent risk factor for CVD; for every $5 \mathrm{~kg} / \mathrm{m} 2$ increase in BMI above $25 \mathrm{~kg} / \mathrm{m} 2$, CVD mortality increases by $40 \%$ (15). Similarly a $1 \mathrm{~cm}$ increase in WC is associated with a $2 \%$ increased risk of incident CVD (16). Though the mechanisms behind these associations have not been fully elucidated, it is known that excess body fat directly impacts on insulin resistance, thus increasing the risk of type-2 diabetes (15). Excess fat in the abdominal area may directly affect how fats are broken down and transported in the body, leading to high cholesterol (17). These risk factors in turn increase the likelihood of developing further CVD.

\subsubsection{Obesity and prevalence of cardiovascular disease}

Figure 4.5 shows prevalence of cardiovascular disease at wave 2 by wave 1 WC classification and sex. A strong association is observed between WC and diabetes. Just over $15 \%$ of men with a substantially increased WC have been diagnosed with diabetes compared to $5 \%$ of men with a normal WC. Corresponding figures for women are $9.4 \%$ for substantially increased WC and $1 \%$ for normal WC. Differences between men and women are observed for other conditions whereby men with a substantially increased WC have a significantly higher prevalence of heart attacks (10\% versus $7 \%$ for normal WC) and women with substantially increased WC have a higher prevalence of angina $(6.2 \%$ versus $3.2 \%$ for normal WC). Similar associations are evident for BMI and can be seen in Appendix Table 4.A3. 
Figure 4.5: Prevalence of cardiovascular disease at wave 2 by wave 1 waist circumference classification and sex

\begin{tabular}{|l|l|}
\hline Normal & Increased \\
\hline
\end{tabular}

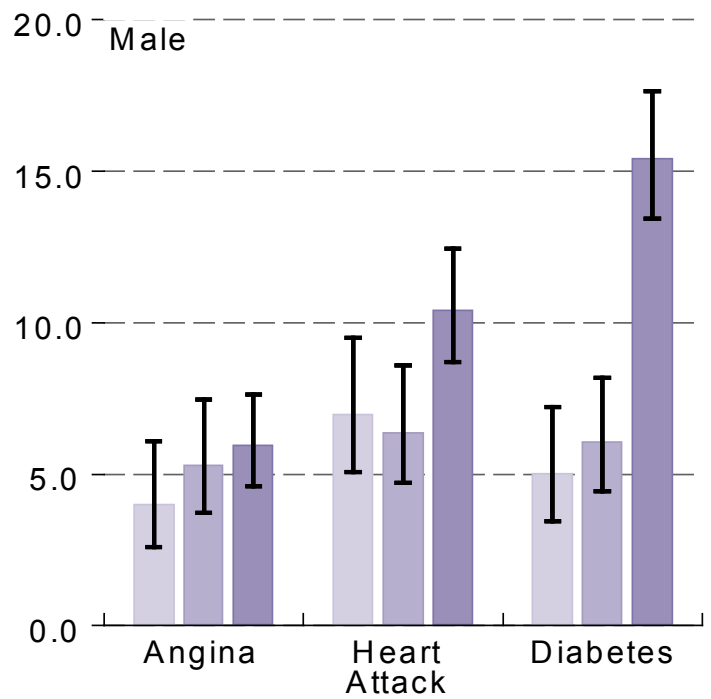

Female

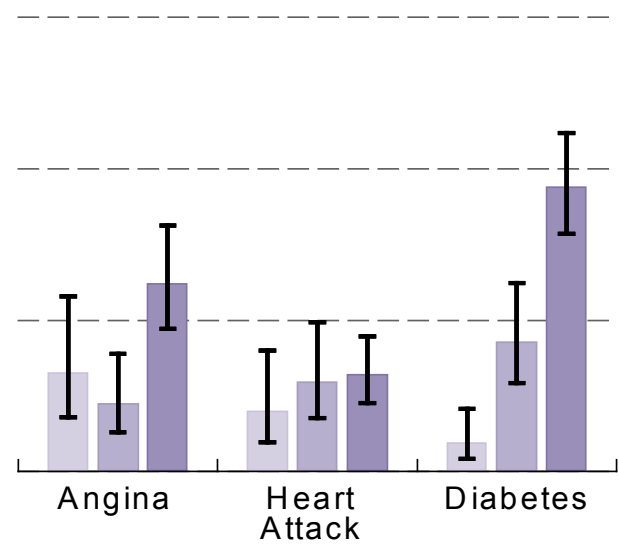

Note. $\mathrm{N}=5349$; Missing obs $=0$; Error bars correspond to $95 \%$ confidence intervals

\subsubsection{Obesity and prevalence of cardiovascular disease risk factors}

Figure 4.6 shows the wave 2 prevalence of CVD risk factors (high blood pressure or hypertension, high cholesterol and irregular heart rhythm) by wave $1 \mathrm{WC}$ classification and sex. Central obesity is strongly associated with high blood pressure. A higher proportion of men and women with both increased and substantially increased WC report a doctor's diagnosis of high blood pressure than adults with normal WC. For example, $49.1 \%$ of women with a substantially increased WC report high blood pressure compared to $21.7 \%$ of women with normal WC. Corresponding figures for men are $44.2 \%$ for substantially increased WC and $24.4 \%$ for normal WC.

No differences by sex are observed for the association with high blood pressure or irregular heart rhythm; however, a higher proportion of women with a substantially increased WC report high cholesterol compared to those with a normal WC $(43.8 \%$ vs $36.0 \%)$. The associations presented here are consistent for $\mathrm{BMI}$ and can be seen in Appendix Table 4.A4. 
Figure 4.6: Prevalence of cardiovascular disease risk factors at wave 2 by wave 1 waist circumference classification and sex

\begin{tabular}{|l|l|}
\hline Normal & Increased \\
\hline
\end{tabular}
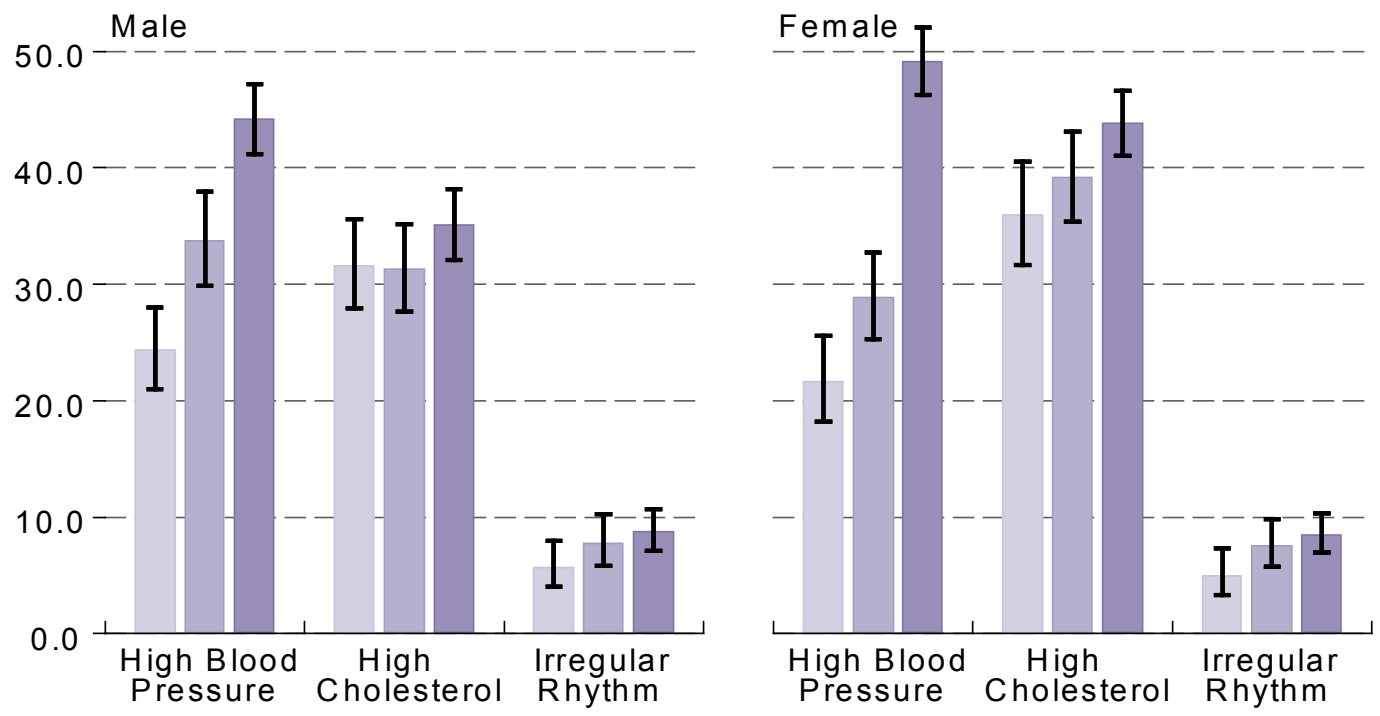

Note. $\mathrm{N}=5349 ;$ Missing obs $=0$; Error bars correspond to $95 \%$ confidence intervals

While CVD mortality rates have decreased over the last number of decades (see also Chapter 3), the increasing prevalence of obesity and associated disease risk is in danger of reversing this trend. In older Irish adults increased WC and BMI are strongly associated with an increased prevalence of diabetes, high blood pressure and heart attacks. Tackling the high rates of obesity must be a priority for public health intervention given its strong association with CVD.

\subsection{Obesity and physical disability}

\subsubsection{Obesity and prevalence of physical disability}

Disability is common in older adults and has important implications for individual quality of life and health and social care costs. There are many types of disability; but this report will focus specifically on difficulties in activities of daily living (ADLs) and instrumental activities of daily living (IADLs). ADLs include activities such as washing, eating and toileting, which are essential to daily life. IADLs include activities like preparing meals, managing money and household chores, which, while not fundamental to everyday functioning are important in maintaining independence $(18,19)$. This analysis includes only those difficulties for which comparable information was collected between waves, leaving a total of five ADLs 
and six IADLs. Further discussion of ADL and IADL disability is presented in Chapters 5 and 6; however these analyses are based on slightly different sample sizes and are not comparable to the results outlined below.

Table 4.3: Changes in ADL and IADL disability between wave 1 and wave 2

\begin{tabular}{|c|c|c|c|c|c|}
\hline & & \multicolumn{4}{|c|}{ wave 2} \\
\hline \multirow{7}{*}{$\begin{array}{l}\bar{\Phi} \\
\overbrace{\pi}^{\pi} \\
3\end{array}$} & & \multicolumn{2}{|c|}{ No ADL Disability } & \multicolumn{2}{|c|}{ Any ADL Disability } \\
\hline & & $\%$ & $(95 \% \mathrm{Cl})$ & $\%$ & $(95 \% \mathrm{Cl})$ \\
\hline & No ADL Disability & 91.5 & $(90-92)$ & 3.7 & $(3-4)$ \\
\hline & Any ADL Disability & 2.5 & $(2-3)$ & 2.3 & $(2-3)$ \\
\hline & & \multicolumn{2}{|c|}{ No IADL Disability } & \multicolumn{2}{|c|}{ Any IADL Disability } \\
\hline & No IADL Disability & 87.6 & $(86-89)$ & 5.1 & $(4-6)$ \\
\hline & Any IADL Disability & 3.3 & $(3-4)$ & 4.1 & $(3-5)$ \\
\hline
\end{tabular}

Table 4.3 summarises transitions in ADL and IADL disability status between wave 1 and wave 2. The majority of adults report no ADL or IADL disability at either wave. Just 2$4 \%$ report an $A D L$ or IADL disability in both waves. These findings reflect the relatively young age profile of the TILDA population. Just over $2.5 \%$ of the population transitioned out of ADL disability between waves and 3.7\% developed a new ADL disability by wave 2 . Comparable trends are seen for IADL disabilities, with $3.3 \%$ of adults transitioning out of IADL disability and $4.1 \%$ developing a new IADL disability by wave 2 .

\subsubsection{Obesity and prevalence of new disabilities}

Figure 4.7 shows the relationship between WC at wave 1 and disability at wave 2 . Compared to those with a normal WC, having a substantially increased WC is associated with the development of ADL disability in both men and women. Associations between WC and IADL disability are evident for women only, where $6.9 \%$ of those with a substantially increased WC developed a new IADL at wave 2 compared to $3.4 \%$ of women with a normal WC. No association was observed between BMI at wave 1 and new disability at wave 2 (see Appendix Table 4.A5). As only a small number of participants reported a new disability at wave 2 it was not possible to carry out further analyses by age group. 
Figure 4.7: Proportion reporting new ADL and IADL disabilities at wave 2 by wave 1 waist circumference classification and sex
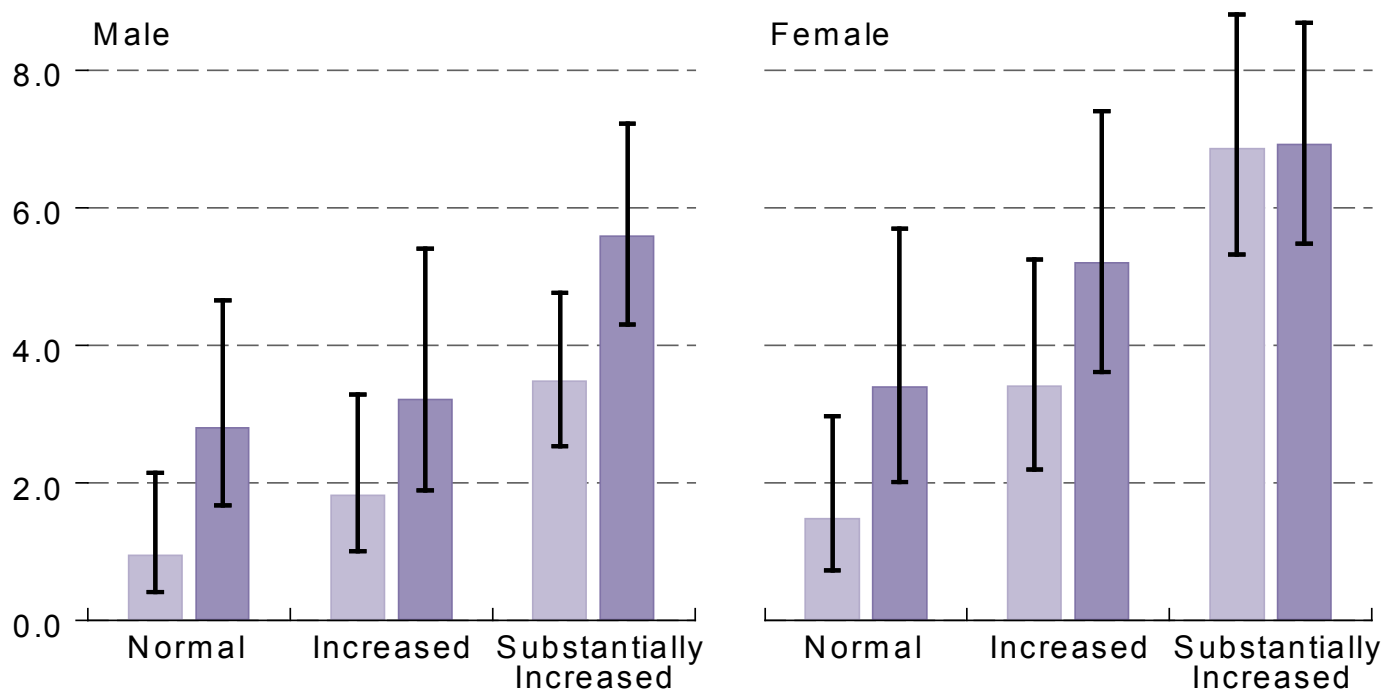

Note. $\mathrm{N}=5349 ;$ Missing obs $=0$; Error bars correspond to $95 \%$ confidence intervals

Despite the low frequency of physical disabilities in the older Irish population, substantially increased WC is associated with a higher incidence of ADL disability in both men and women and a higher incidence of IADL disability in women. This finding, coupled with the high prevalence of obesity in this population, highlights the importance of appropriate weight management strategies for older adults to improve health and function and maintain independence in later life.

\subsection{Obesity and mental health}

High levels of both obesity and mental health difficulties were found among older Irish adults at wave 1 (20). A burgeoning field of research suggests that this may be more than simple coincidence reflecting a complex interplay of biological, psychological and social phenomena (21-24).

Depression that presents for the first time in late life may share some of the same risk factors as heart disease and stroke (25). Eating habits and lifestyle choices which adversely affect BMI and WC may therefore also have a detrimental effect on the brain and in turn negatively impact mood. 
At wave 1 , depressive symptoms were measured with the 20 -item Center for Epidemiologic Studies Depression (CES-D) scale which assesses depressive symptoms over the previous week (26). Symptoms of anxiety were measured at wave 1 using the anxiety subscale of the Hospital Anxiety and Depression Scale (HADS-A), a self-report questionnaire, which assesses the frequency of anxiety symptoms over the last week (27). High levels of depressive and anxiety symptoms were observed among older Irish adults (20).

In response to these findings a more in-depth measure of depression and anxiety was introduced at wave 2 to gain a more accurate estimate of the true burden of these conditions in older Irish adults. The Composite International Diagnostic Interview - Short Form (CIDI-SF) is designed to be used by lay interviewers for the assessment of mental disorders according to well established definitions and criteria. It can be used to classify individuals as having 'probable' Major Depressive Disorder (MDD) or General Anxiety Disorder (GAD) and more closely reflects the way a doctor would diagnose a mental illness (28).

\subsubsection{Obesity and depression}

Table 4.4a and 4.4b show depression at wave 2 by wave $1 \mathrm{WC}$ and BMI. According to the CIDI-SF, $6.1 \%$ of adults aged 52 and over met criteria for a MDD within the last year. The prevalence of MDD is higher in older adults who have a substantially increased WC or who are obese according to their BMI. Interestingly, adults who have moderate levels of obesity, as defined by increased WC or overweight, report the lowest prevalence of MDD.

Table 4.4a: Depression at wave 2 by wave 1 waist circumference classification

\begin{tabular}{|l|cr|}
\hline & \multicolumn{3}{|c|}{ Major Depressive Disorder } \\
& $\%$ & $(95 \% \mathrm{CI})$ \\
\hline Normal & 5.8 & $(5-7)$ \\
\hline Increased & 4.9 & $(4-6)$ \\
\hline Substantially Increased & 6.9 & $(6-8)$ \\
\hline Total & 6.1 & $(6-7)$ \\
\hline
\end{tabular}


Table 4.4b: Depression at wave 2 by wave 1 body mass index classification

\begin{tabular}{|l|cr|}
\hline & \multicolumn{3}{|c|}{$\begin{array}{c}\text { Major Depressive Disorder } \\
\text { \% }\end{array}$} & $(95 \% \mathrm{Cl})$ \\
\hline Normal & 5.5 & $(4-7)$ \\
\hline Overweight & 5.2 & $(4-6)$ \\
\hline Obese & 7.7 & $(7-9)$ \\
\hline Total & 6.1 & $(6-7)$ \\
\hline
\end{tabular}

Figure 4.8 shows wave 2 prevalence of depression by WC at wave 1 in men and women. Although group numbers are small when the analysis is stratified by sex, there is evidence that WC is associated with depression in men but not in women. Men with a substantially increased WC have a higher prevalence of MDD (5.9\%) than men who have an increased WC $(2.8 \%)$, although there is no difference between men with substantially increased WC and men with a normal WC. There are no associations with age. A similar pattern is observed with BMI and can be seen in Appendix Table 4.A6.

Figure 4.8: Depression at wave 2 by wave 1 waist circumference classification and sex
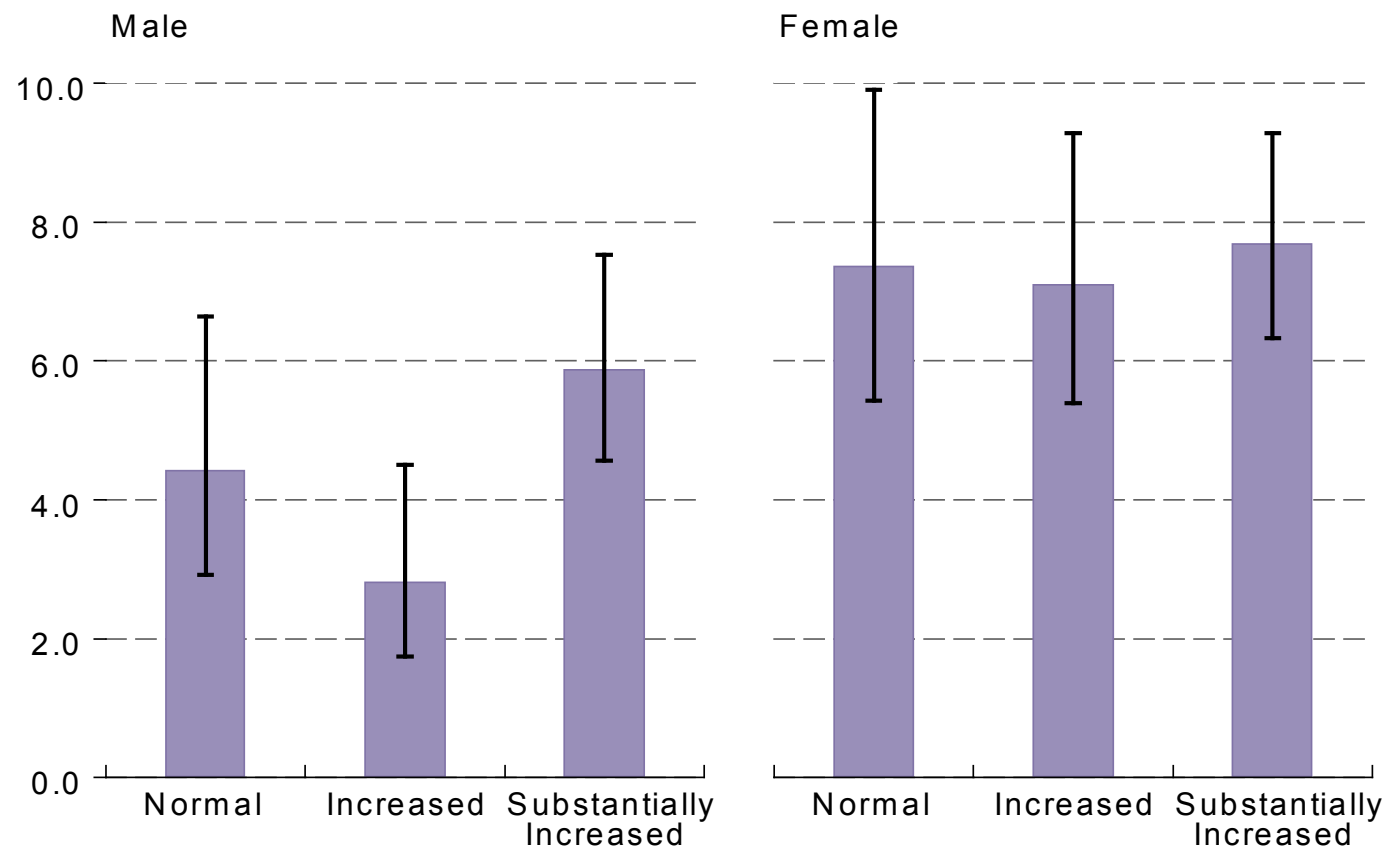

Note. $\mathrm{N}=5349 ;$ Missing obs $=0$; Error bars correspond to $95 \%$ confidence intervals 


\subsubsection{Obesity and anxiety}

The CIDI-SF for Generalised Anxiety Disorder (GAD) was also included in wave 2 to gain a better understanding of the true prevalence of clinical anxiety in older Irish adults. Again, this is an interview-based approach which better reflects how a mental health professional would diagnose an anxiety disorder.

According to the CIDI-SF, 3.1\% of adults aged 52 and over met diagnostic criteria for GAD within the past year. Rates of GAD decline with age, from 3.9\% in those aged 52-65 to just $1.1 \%$ in adults aged 75 and over (see Appendix Table 4.A7) and are higher among women (see Figure 4.9) (Appendix Tables 4.A8 and 4.A9 show the same relationships for BMI). Tables $4.5 \mathrm{a}$ and $4.5 \mathrm{~b}$ shows anxiety at wave 2 by wave $1 \mathrm{WC}$ and BMI. Regardless of the measure of obesity, no association with anxiety is observed.

Table 4.5a: Anxiety at wave 2 by wave 1 waist circumference classification

\begin{tabular}{|l|cr|} 
& \multicolumn{2}{|c|}{$\begin{array}{c}\text { General Anxiety } \\
\text { Disorder }\end{array}$} \\
& $\%$ & $(95 \% \mathrm{Cl})$ \\
\hline Normal & 3.5 & $(3-5)$ \\
\hline Increased & 3.1 & $(2-4)$ \\
\hline Substantially Increased & 3.0 & $(2-4)$ \\
\hline Total & 3.2 & $(3-4)$ \\
\hline
\end{tabular}

Table 4.5b: Anxiety at wave 2 by wave 1 body mass index classification

\begin{tabular}{|l|cr|}
\hline & \multicolumn{3}{|c|}{ General Anxiety Disorder } \\
& $\%$ & $(95 \% \mathrm{Cl})$ \\
\hline Normal & 3.3 & $(2-4)$ \\
\hline Overweight & 2.8 & $(2-4)$ \\
\hline Obese & 3.3 & $(2-4)$ \\
\hline Total & 3.1 & $(3-4)$ \\
\hline
\end{tabular}


Figure 4.9: Anxiety at wave 2 by wave 1 waist circumference classification and sex
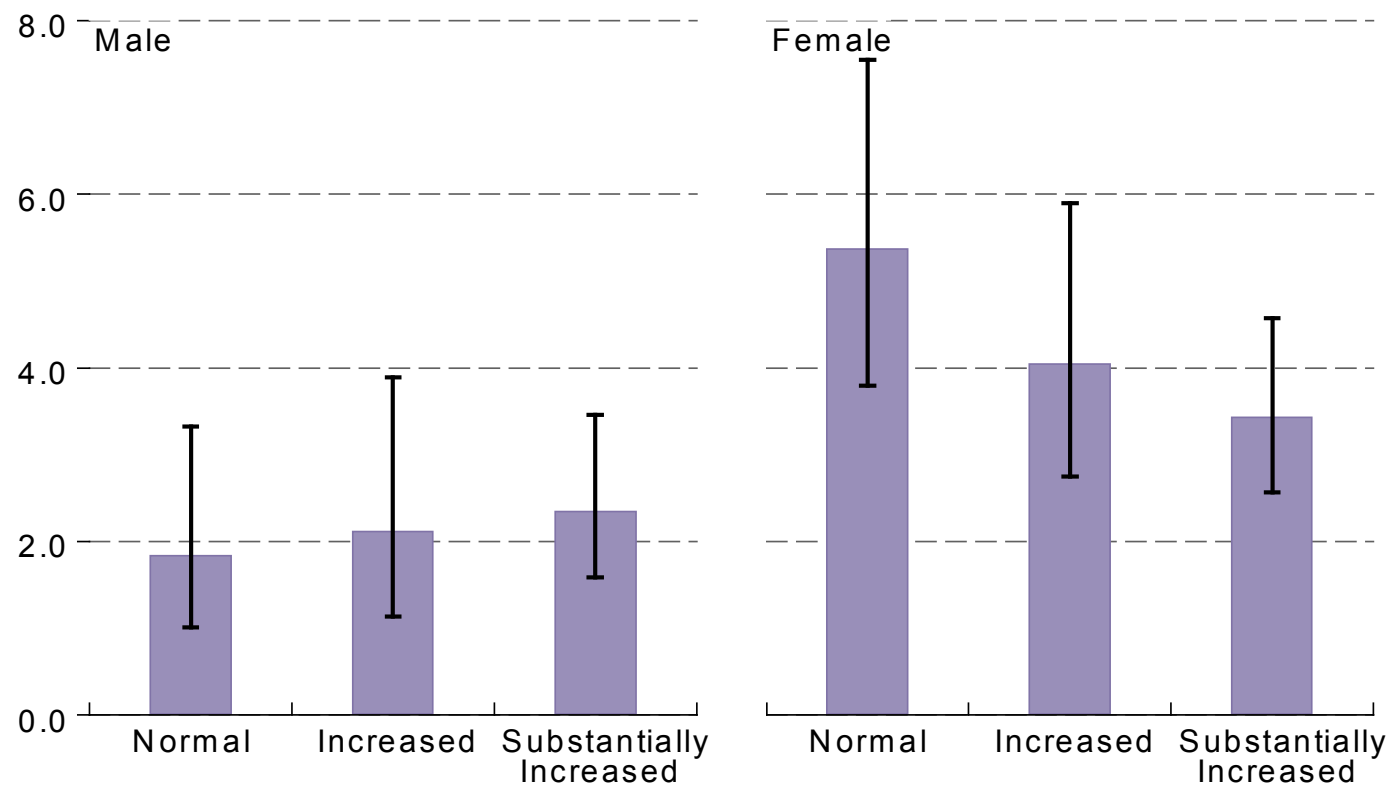

Note. $\mathrm{N}=5349 ;$ Missing obs $=0$; Error bars correspond to $95 \%$ confidence intervals

\subsection{Obesity and health behaviours}

Obesity is caused by an energy imbalance, whereby more calories are consumed than spent. An increase in calorie consumption through the availability of high energy convenience foods, combined with increasingly sedentary lifestyles, has coincided with the increased rates of obesity worldwide (1). Previous research indicates that energy intake does not increase with ageing, therefore changes in energy balance and body weight are mainly believed to be due to decreased physical activity (29). This was reflected in the findings from wave 1 where the prevalence of 'high' physical activity decreased from $40 \%$ in adults aged $50-64$ to $18 \%$ in adults aged 75 and over (20). In addition to its effects on body weight, higher levels of physical activity are associated with lower rates of CVD mortality, disability and depressive symptoms in older adults (30-32). Research also shows that smoking and alcohol consumption impact upon food intake and eating habits $(33,34)$.

\subsubsection{Obesity and physical activity}

Physical activity is assessed in TILDA using the International Physical Activity Questionnaire (IPAQ), which classifies individuals as having 'low', 'medium' or 'high' 
levels of physical activity. Figure 4.10 shows wave 2 physical activity level by wave 1 WC category and sex. $32 \%$ of men with a substantially increased WC report 'low' levels of physical activity compared to $20 \%$ of men with a normal WC. Corresponding figures for women are $47 \%$ and $30 \%$. For all age groups, the lowest levels of physical activity were reported in those with a substantially increased WC (see Appendix Table 4.A10).

Overall, only a third of older adults are classified as having 'high' levels of physical activity. Men with a normal WC have the highest levels of physical activity (47\%), whereas lowest levels of physical activity are seen in women with a substantially increased WC (23\%). Similar associations are seen for BMI and physical activity and can be seen in Appendix Table 4.A11.

Figure 4.10: Physical activity levels at wave 2 by wave 1 waist circumference classification and sex

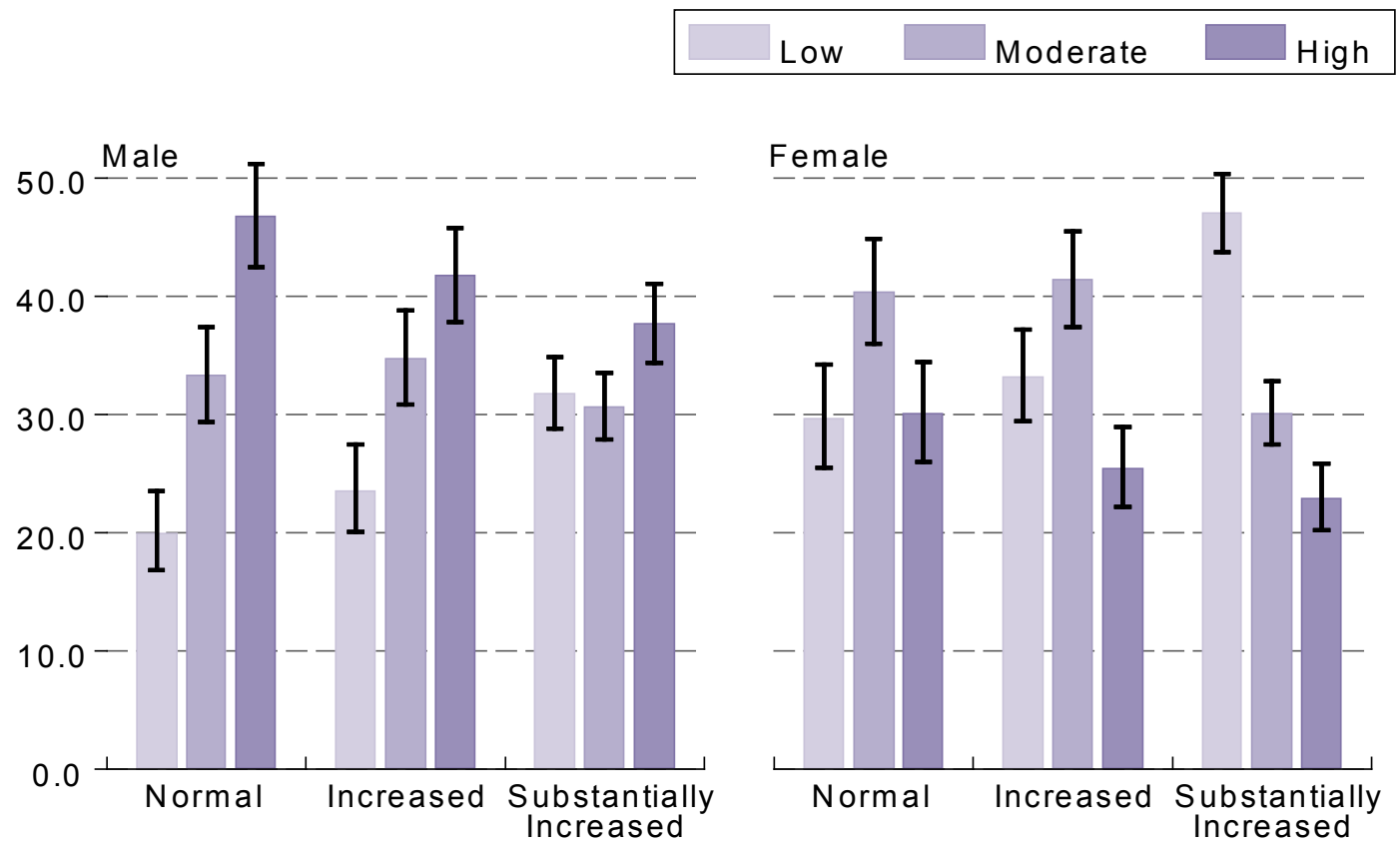

Note. $N=5298 ;$ Missing obs $=51$; Error bars correspond to $95 \%$ confidence intervals

Given that the IPAQ is based on self-report, participants are likely to overestimate physical activity (35), so the proportion of the population engaging in high levels of physical activity is likely to be even lower than the results presented here. An objective measure of physical activity will be incorporated into wave 3 of the TILDA study to facilitate a more robust examination of the relationship between obesity and physical activity and inform intervention strategies for obesity that are based on physical activity. 


\subsubsection{Obesity and smoking}

Figure 4.11 shows smoking behaviour at wave 2 by wave 1 WC classification and sex. In men, a history of smoking is associated with obesity, with $53 \%$ of men classified as having a substantially increased WC being past smokers, compared to $43 \%$ of men with normal WC.

Current smoking is strongly associated with having a normal WC in both men and women. For example $21 \%$ of men with a normal WC smoke compared to $12 \%$ with a substantially increased WC. Corresponding figures for women are $18 \%$ and $13 \%$. Similar findings are observed between BMI and smoking (Appendix Table 4.A12).

Figure 4.11: Smoking behaviour at wave 2 by wave 1 waist circumference classification and sex

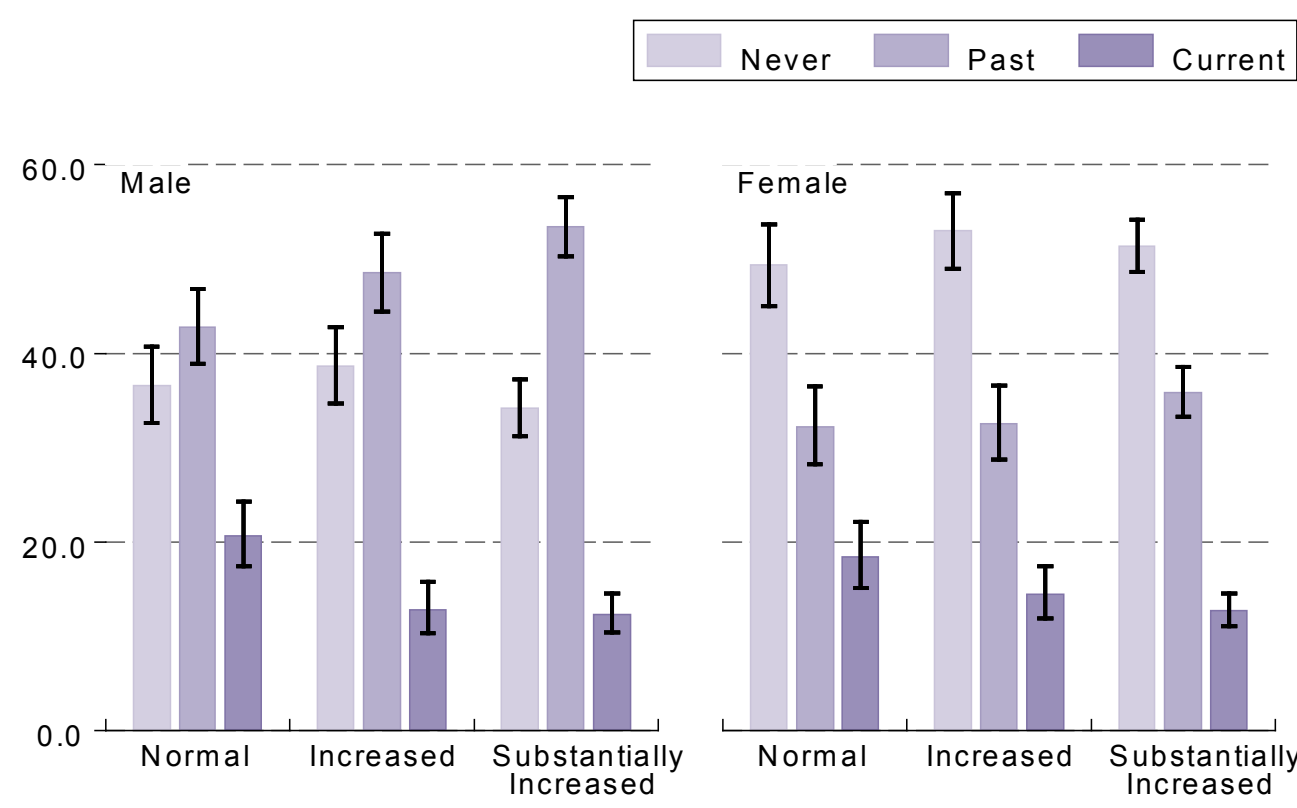

Note. $\mathrm{N}=5349$; Missing obs $=0$; Error bars correspond to $95 \%$ confidence intervals

\subsubsection{Obesity and alcohol consumption}

In wave 2 of the TILDA study, participants were asked about how frequently they consumed alcohol, and if they had reduced their alcohol intake since wave 1. Figure 4.12 shows frequency of alcohol consumption at wave 2 by wave 1 WC classification and sex. In women, obesity is associated with lower alcohol consumption. $3 \%$ of women with a substantially increased WC report daily consumption of alcohol compared to $7 \%$ with a normal WC. No association was observed between WC and alcohol consumption in men. 
Figure 4.12: Frequency of alcohol consumption at wave 2 by wave 1 waist circumference classification and sex

Daily $\quad 2$ - 6 days a week $\square$ Once a week or less
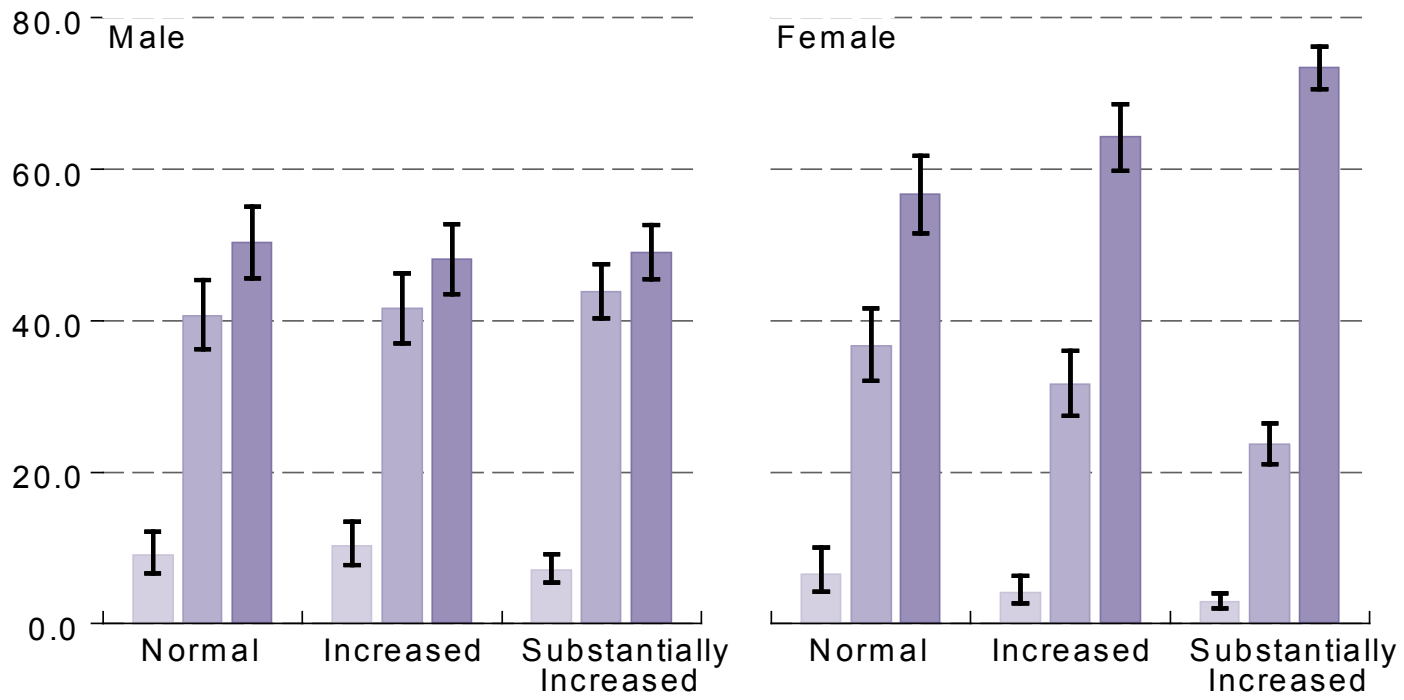

Note. $\mathrm{N}=3785 ;$ Missing obs $=1564 ;$ Error bars correspond to $95 \%$ confidence intervals

Figure 4.13: Proportion reporting reduction in alcohol use by wave 1 waist circumference classification and sex

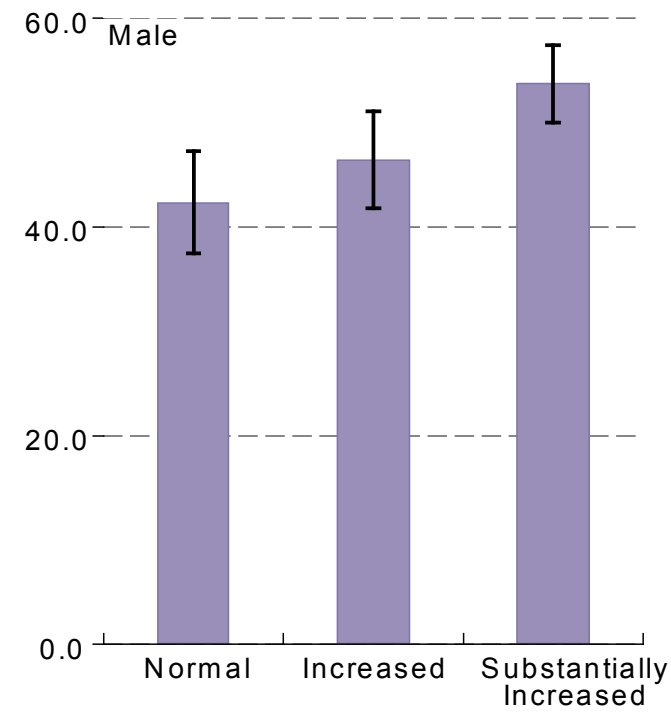

Female

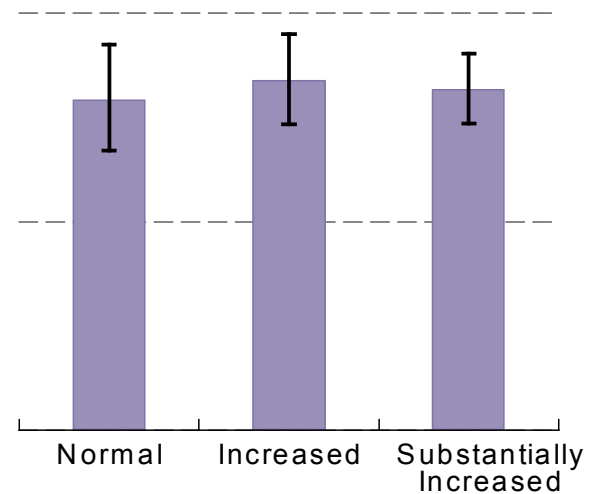

Note. $\mathrm{N}=3687$; Missing obs $=1662$; Error bars correspond to $95 \%$ confidence intervals 
A higher proportion of men with substantially increased WC have reduced their alcohol intake between waves (54\%) than men with a normal WC (42\%). There is no change in reported alcohol reduction among women (see Figure 4.13). Similar associations are observed for BMI and alcohol consumption (see Appendix Tables 4.A13 and 4.A14).

Recent research has demonstrated that poor health behaviours may compound the effects of obesity on health, specifically CVD $(37,38)$. Results presented here suggest that low physical activity and being a past smoker are associated with obesity in older Irish adults however no association was observed for alcohol.

\subsection{Conclusion}

Data presented in this chapter indicate that obesity, measured either by waist circumference or body mass index, is highly prevalent among older Irish adults. $35 \%$ of TILDA participants are classified as obese according to their body mass index; a further $44 \%$ are overweight. Using the WHO waist classification, $53 \%$ of this population have a waist circumference measurement placing them at substantially increased risk of cardiac and metabolic disease. This finding is confirmed by the higher prevalence of diabetes, heart attack (men only) and angina (women only) in adults who had an increased BMI or waist circumference.

Irish rates of obesity are among the highest in Europe, and show no sign of decline (2). Obesity is currently estimated to cost the Irish economy over $€ 1$ bn per year in work absenteeism, premature mortality and increased health service usage. For example, an obese person incurs $25 \%$ higher health expenditures than a person of normal weight in any given year $(2,39)$.

This chapter has documented an association between a number of negative health outcomes and obesity. Specifically obesity is strongly associated with heart attacks, diabetes and disability. Differences between men and women are also observed for a number of conditions and behaviours. In particular obese men have the highest rates of cardiovascular disease, while a higher proportion of obese women report low physical activity levels and increased physical disability.

The strong associations observed between obesity and health behaviours are difficult to disentangle using just two waves of data and future waves of TILDA will add to our understanding of these complex relationships. Detailed information on food consumption will be collected during wave 3 of the study along with an objective measure of physical 
activity. This will further add to our understanding of the interplay between obesity, disease and health behaviours in older adults.

Obesity is associated with poor physical and mental health outcomes and health behaviours in older Irish adults. Public health campaigns aimed at educating older Irish adults to the importance of maintaining a healthy body weight could greatly reduce the burden of ill-health and disability associated with obesity, and lessen consequent demands on the healthcare system.

\section{References}

1. WHO. Obesity: preventing and managing the global epidemic. Report of a WHO Consultation (WHO Technical Report Series 894). Geneva: World Health Organisation, 2000 .

2. OECD. Obesity Update 2012. Organisation for Economic Co-operation and Development, 2012.

3. IUNA. National Adult Nutrition Survey Summary Report. Irish Universities Nutrition Alliance 2011

4. Lee CM, Huxley RR, Wildman RP, Woodward M. Indices of abdominal obesity are better discriminators of cardiovascular risk than BMI: a meta-analysis. Journal of Clinical Epidemiology. 2008;61:646-53.

5. Blaum CS, Xue QL, Michelon E, Semba RD, Fried LP. The Association Between Obesity and the Frailty Syndrome in Older Women: The Women's Health and Aging Studies. J Am Geriatr Soc. 2005;53:927-34.

6. Arterburn D, Westbrook EO, Ludman EJ, Operskalski B, Linde JA, Rohde P, et al. Relationship between obesity, depression, and disability in middle-aged women. Obesity Research \& Clinical Practice. 2012;6(3):e197-e206.

7. Katsiki N, Ntaios G, Vemmos K. Stroke, obesity and gender: A review of the literature. Maturitas. 2011;69(3):239-43.

8. Magnani JW, Hylek EM, Apovian CM. Obesity begets Atrial Fibrillation : A Contemporary Summary. Circulation. 2013;128:401-5.

9. Mokdad AH, Ford ES, Bowman BA, Dietz WH, Vinicor F, Bales VS, et al. Prevalence of Obesity, Diabetes, and Obesity-Related Health Risk Factors, 2001. JAMA. 2003;289:76-9. 
10. Jackson AS, Janssen I, Sui X, Church TS, Blair SN. Longitudinal changes in body composition associated with healthy ageing men, aged 20-96 years. Br J Nutr. 2012;107:1085-91.

11. WHO. Waist Circumference and Waist-Hip Ratio: Report of a WHO Expert Consultation. Geneva, Switzerland: World Health Organization, 2008.

12. Preston S, Stokes A. Contribution of Obesity to International Differences in Life Expectancy. Am J Public Health. 2011;101(11):2137-43.

13. Reuser M, Bonneux LG, Willekens FJ. Smoking Kills, Obesity Disables: A Multistate Approach of the US Health and Retirement Survey. Obesity. 2009;17(4):783-9.

14. CSO. Statistics: Fourth Quarter and Yearly Summary 2012. 2013.

15. Marinou K, Tousoulis D, Antonopoulos AS, Stefanadi E, Stefanadis C. Obesity and cardiovascular disease: From pathophysiology to risk stratification. International Journal of Cardiology. 2010;138:3-8.

16. de Koning L, Merchant AT, Pogue J, Anand SS. Waist circumference and waist-to-hip ratio as predictors of cardiovascular events: meta-regression analysis of prospective studies. European Heart Journal. 2007;28(7):850-6.

17. Wajchenberg BL. Subcutaneous and Visceral Adipose Tissue: Their Relation to the Metabolic Syndrome. Endocrine Reviews. 2000;21(6):697-738.

18. Katz S, Ford AB, Moskowitz RW, Jackson BA, Jaffe MW. Studies of illness in the aged, the index of ADL: A standardised measure of biological and psychosocial function. JAMA. 1963;21(185):914-9.

19. Lawton MP, Brody EM. Assessment of Older People: Self-Maintaining and Instrumental Activities of Daily Living The Gerontologist. 1969;9(3 Part 1).

20. Barrett A, Savva G, Timonen V, Kenny RA. Fifty Plus in Ireland 2011: First Results from The Irish Longitudinal Study on Ageing. Trinity College Dublin, 2011.

21. van Reedt Dortland AK, Giltay EJ, van Veen T, Zitman FG, Penninx BW. Longitudinal relationship of depressive and anxiety symptoms with dyslipidemia and abdominal obesity. Psychosomatic Medicine. 2013;75(1):83-9.

22. van Reedt Dortland AK, Vreeburg SA, Giltay EJ, Licht CM, Vogelzangs N, van Veen T, et al. The impact of stress systems and lifestyle on dyslipidemia and obesity in anxiety and depression. Psychoneuroendocrinology. 2013;38(2):209-18. 
23. Rivenes AC, Harvey SB, Mykletun A. The relationship between abdominal fat, obesity, and common mental disorders: results from the HUNT study. Journal of Psychosomatic Research. 2009;66(4):269-75.

24. Pagoto S, Schneider KL, Whited MC, Oleski JL, Merriam P, Appelhans B, et al. Randomized controlled trial of behavioral treatment for comorbid obesity and depression in women: the Be Active Trial. International Journal of Obesity. 2013;37:1427-34.

25. Allan CL, Sexton CE, Kalu UG, McDermott LM, Kivimäki M, Singh-Manoux A, et al. Does the Framingham Stroke Risk Profile predict white-matter changes in late-life depression? International Psychogeriatrics. 2012;24(4):524-31.

26. Beekman AT, Deeg DJ, van Limbeek J, Braam AW, de Vries MZ, van Tilburg W. Criterion validity of the Center for Epidemiologic Studies Depression scale (CESD): results from a community-based sample of older subjects in The Netherlands. Psychological Medicine. 1997;27:231-5.

27. Zigmond AS, Snaith RP. The hospital anxiety and depression scale. Acta Psychiatrica Scandinavica. 1983;67(6):361-70.

28. Kessler RC, Andrews G, Mroczek D, Ustun TB, Wittchen H-U. The World Health Organization Composite International Diagnostic Interview Short Form (CIDI-SF). International Journal of Methods in Psychiatric Research. 1998;7(4):171-85.

29. Villareal DT, Apovian CM, Kushner RF, Klien S. Obesity in Older Adults: Technical Review and Position Statement of the American Society for Nutrition and NAASO, The Obesity Society. Obesity Research. 2005;13(11):1849-63.

30. Reddigan JI, Ardren Cl, Riddell MC, Kuk JL. Relation of Physical Activity to Cardiovascular Disease Mortality and the Influence of Cardiometabolic Risk Factors. Am J Cardiol. 2011;108:1426-31.

31. Tak E, Kuiper R, Chorus A, Hopman-Rock M. Prevention of onset and progression of basic ADL disability by physical activity in community dwelling older adults: A metaanalysis. Ageing Research Reviews. 2013;12:329-228.

32. Morgan K, O' Farrell J, Doyle F, McGee H. Physical activity and core depressive symptoms in the older Irish adult population. Centre for Ageing Research and Development in Ireland (CARDI), 2011.

33. Filozof C, Fernandez-Pinalla MC, Fernandez-Cruz A. Smoking Cessation and weight gain. Obesity Reviews. 2004;5(2):95-103. 
34. Yeomans MR. Alcohol, appetite and energy balance: Is alcohol intake a risk factor for obesity? Physiology \& Behavior. 2010;100:82-9.

35. Rzewnicki R, Vanden Auweele Y, De Bourdeaudhuji I. Addressing overreporting on the International physical acticity questionnaire (IPAQ) telephone survey with a population sample. Public Health Nutr. 2003;6:299-305.

36. Sulander T, Rahkonen O, Nissinen A, Uutela A. Association of smoking status with obesity and diabetes among elderly people. Archives of Gerontology and Geriatrics. 2007;45:159-67.

37. Luo W, Guo Z, Hao C, Yao X, Zhou Z, Wu M, et al. Interaction of current alcohol consumption and abdominal obesity on hypertension risk. Physiology \& Behavior. 2013;122:182-6.

38. Ma J, Jemal A, Flanders D, Ward EM. Joint association of adiposity and smoking with mortality among U.S. adults. Preventative Medicine. 2013;56:178-84.

39. Safefood. The cost of overweight and obesity on the island of Ireland. 2012. 


\section{Appendix 4: Tables on Obesity and Health Outcomes in Older Irish} Adults

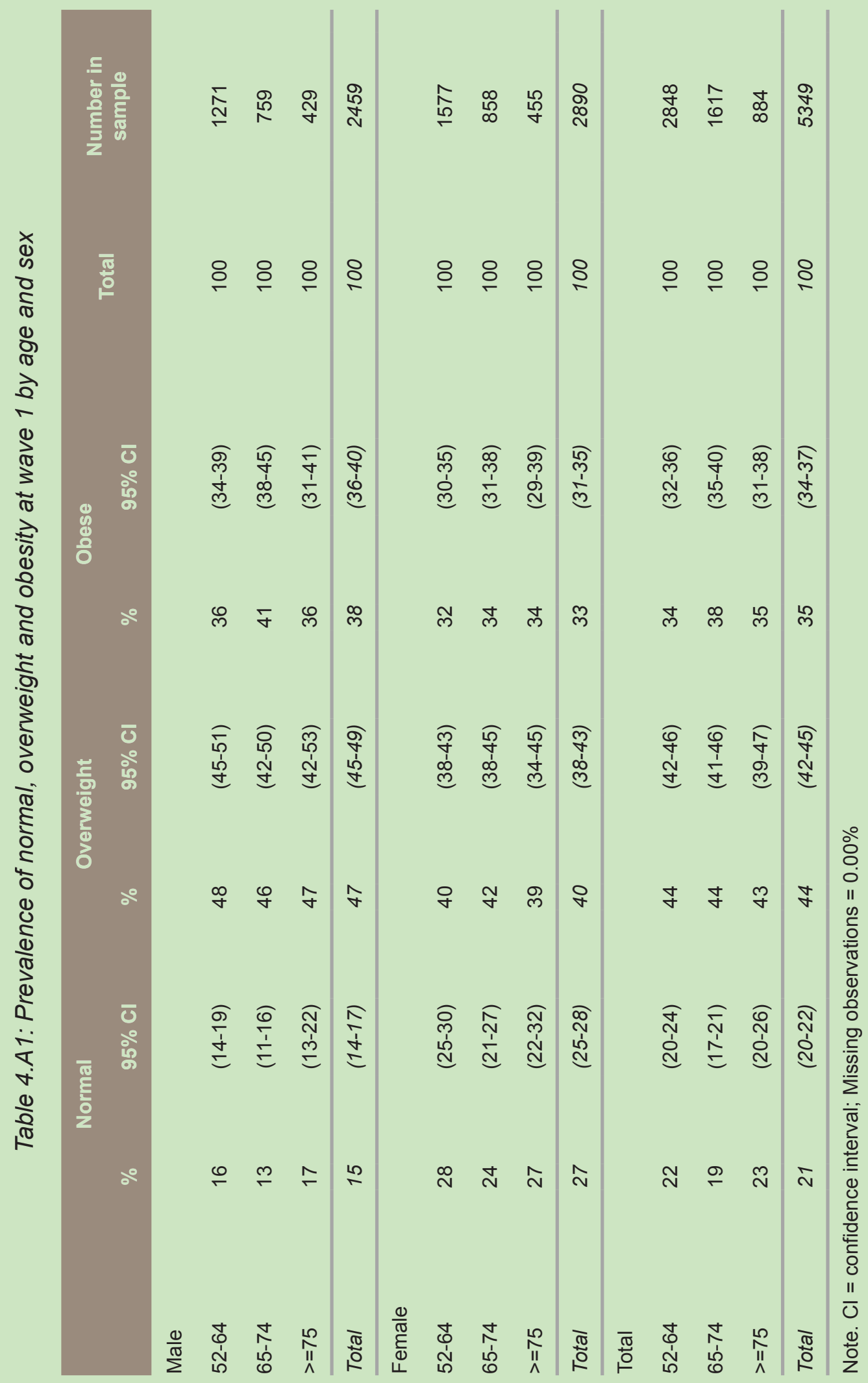




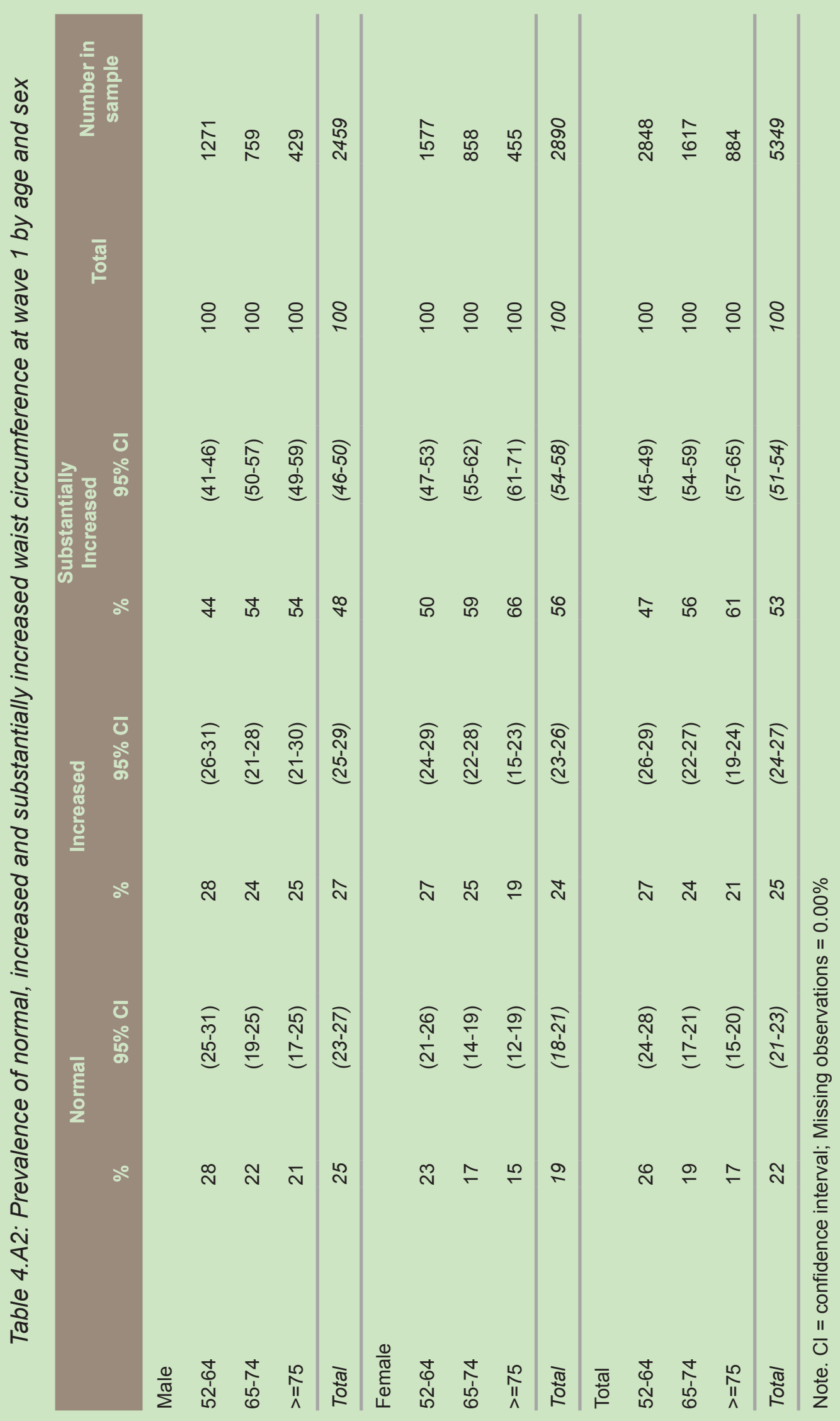


Table 4.A3: Prevalence of cardiovascular disease at wave 2 by wave 1 body mass index classification and sex

\begin{tabular}{lcccccc} 
& \multicolumn{3}{c}{ Angina } & \multicolumn{3}{c}{ Heart Attack } \\
& $\%$ & $(95 \% \mathrm{Cl})$ & $\%$ & $(95 \% \mathrm{Cl})$ & $\%$ & $(95 \% \mathrm{Cl})$ \\
Male & & & & & & \\
Normal & 4.6 & $(2.6-7.8)$ & 5.4 & $(3.4-8.6)$ & 4.8 & $(2.9-7.9)$ \\
Overweight & 4.5 & $(3.3-6.0)$ & 8.2 & $(6.6-10.3)$ & 8.2 & $(6.6-10.0)$ \\
Obese & 6.6 & $(5.0-8.6)$ & 10.1 & $(8.1-12.4)$ & 15.3 & $(13.0-17.9)$ \\
\hline Total & 5.3 & $(4.4-6.4)$ & 8.5 & $(7.3-9.8)$ & 10.3 & $(9.1-11.7)$ \\
\hline Female & & & & & & \\
Normal & 3.9 & $(2.5-6.1)$ & 2.5 & $(1.4-4.3)$ & 2.6 & $(1.6-4.2)$ \\
Overweight & 3.8 & $(2.6-5.6)$ & 2.9 & $(1.9-4.4)$ & 4.5 & $(3.2-6.3)$ \\
Obese & 6.4 & $(4.5-9.0)$ & 3.2 & $(2.1-5.0)$ & 12.1 & $(10.0-14.7)$ \\
\hline Total & 4.7 & $(3.7-5.9)$ & 2.9 & $(2.2-3.8)$ & 6.5 & $(5.6-7.6)$ \\
\hline Total & & & & & & \\
Normal & 4.1 & $(2.9-5.8)$ & 3.5 & $(2.4-5.0)$ & 3.4 & $(2.4-4.7)$ \\
Overweight & 4.1 & $(3.2-5.3)$ & 5.7 & $(4.6-6.9)$ & 6.4 & $(5.3-7.7)$ \\
Obese & 6.5 & $(5.2-8.1)$ & 6.7 & $(5.5-8.2)$ & 13.8 & $(12.2-15.5)$ \\
\hline Total & 5.0 & $(4.2-5.8)$ & 5.6 & $(4.9-6.4)$ & 8.3 & $(7.6-9.2)$ \\
\hline & & & & & & \\
\hline
\end{tabular}


The Irish Longitudinal Study on Ageing

Table 4.A4: Prevalence of cardiovascular disease risk factors at wave 2 by wave 1 body mass index classification and sex

\begin{tabular}{lcccccc} 
& \multicolumn{2}{c}{ High Blood Pressure } & \multicolumn{2}{c}{ High Cholesterol } & \multicolumn{3}{c}{ Irregular Rhythm } \\
\cline { 3 - 5 } & $\%$ & $(95 \% \mathrm{Cl})$ & $\%$ & $(95 \% \mathrm{Cl})$ & $\%$ & $(95 \% \mathrm{Cl})$ \\
Normal & 23.2 & $(18.9-28.0)$ & 31.4 & $(26.6-36.7)$ & 7.6 & $(5.1-11.0)$ \\
Overweight & 32.8 & $(29.8-35.9)$ & 32.2 & $(29.4-35.2)$ & 6.4 & $(5.0-8.2)$ \\
Obese & 46.5 & $(42.9-50.0)$ & 35.1 & $(31.8-38.6)$ & 9.4 & $(7.6-11.6)$ \\
\hline Total & 36.4 & $(34.4-38.6)$ & 33.2 & $(31.2-35.3)$ & 7.7 & $(6.7-8.9)$ \\
\hline Female & & & & & & \\
Normal & 23.7 & $(20.4-27.4)$ & 37.1 & $(33.2-41.1)$ & 7.5 & $(5.7-10.0)$ \\
Overweight & 37.9 & $(34.6-41.3)$ & 42.9 & $(39.6-46.3)$ & 7.2 & $(5.6-9.2)$ \\
Obese & 52.3 & $(48.5-56.2)$ & 42.3 & $(38.7-45.9)$ & 8.0 & $(6.1-10.5)$ \\
\hline Total & 38.9 & $(36.8-41.1)$ & 41.2 & $(39.1-43.3)$ & 7.6 & $(6.5-8.8)$ \\
\hline Total & & & & & & \\
Normal & 23.5 & $(20.8-26.5)$ & 35.1 & $(32.0-38.3)$ & 7.5 & $(6.0-9.5)$ \\
Overweight & 35.3 & $(32.9-37.7)$ & 37.4 & $(35.1-39.8)$ & 6.8 & $(5.7-8.1)$ \\
Obese & 49.3 & $(46.7-52.0)$ & 38.6 & $(36.1-41.3)$ & 8.7 & $(7.3-10.4)$ \\
\hline Total & 37.7 & $(36.2-39.3)$ & 37.3 & $(35.8-38.9)$ & 7.6 & $(6.8-8.5)$ \\
\hline
\end{tabular}


Table 4.A5: Proportion reporting new ADL and IADL disabilities at wave 2 by wave 1 body mass index category and sex

\begin{tabular}{lcccc} 
& \multicolumn{2}{c}{ New ADL } & \multicolumn{3}{c}{ New IADL } \\
Male & $\%$ & $(95 \% \mathrm{Cl})$ & $\%$ & $(95 \% \mathrm{CI})$ \\
Normal & 1.1 & $(0.5-2.8)$ & 4.1 & $(2.4-7.1)$ \\
Overweight & 2.3 & $(1.5-3.4)$ & 3.5 & $(2.4-5.0)$ \\
Obese & 3.1 & $(2.1-4.6)$ & 5.3 & $(3.8-7.2)$ \\
\hline Total & 2.4 & $(1.9-3.1)$ & 4.3 & $(3.4-5.3)$ \\
\hline Female & & & & \\
Normal & 4.1 & $(2.7-6.2)$ & 5.8 & $(4.1-8.3)$ \\
Overweight & 4.3 & $(2.9-6.2)$ & 5.1 & $(3.7-6.9)$ \\
Obese & 6.5 & $(4.8-8.9)$ & 6.7 & $(5.0-8.9)$ \\
\hline Total & 5.0 & $(4.0-6.2)$ & 5.8 & $(4.8-7.0)$ \\
\hline Total & & & & \\
Normal & 3.1 & $(2.1-4.5)$ & 5.3 & $(3.9-7.1)$ \\
Overweight & 3.2 & $(2.4-4.3)$ & 4.3 & $(3.3-5.5)$ \\
Obese & 4.8 & $(3.7-6.1)$ & 6.0 & $(4.8-7.4)$ \\
\hline Total & 3.7 & $(3.2-4.4)$ & 5.1 & $(4.4-5.9)$ \\
\hline & & & & \\
\hline
\end{tabular}


Table 4.A6: Prevalence of major depressive disorder at wave 2 by wave 1 body mass index classification and sex

\begin{tabular}{lcc} 
& Major Depressive Disorder \\
& $\%$ & $(95 \% \mathrm{Cl})$ \\
Male & 5.5 & $(3.4-8.8)$ \\
Normal & 3.0 & $(2.1-4.3)$ \\
Overweight & 6.5 & $(5.0-8.4)$ \\
Obese & 4.7 & $(3.8-5.8)$ \\
\hline Total & & \\
\hline Female & 5.6 & $(4.1-7.5)$ \\
Normal & 7.6 & $(6.1-9.4)$ \\
Overweight & 8.9 & $(7.0-11.2)$ \\
Obese & 7.5 & $(6.5-8.6)$ \\
\hline Total & & \\
\hline Total & 5.5 & $(4.3-7.2)$ \\
Normal & 5.2 & $(4.3-6.3)$ \\
Overweight & 7.7 & $(6.4-9.1)$ \\
\hline Obese & 6.1 & $(5.5-6.9)$ \\
\hline Total & & \\
\hline
\end{tabular}


Table 4.A7: Prevalence of generalised anxiety disorder at wave 2 by wave 1 waist circumference classification and age

\begin{tabular}{|c|c|c|}
\hline & \multicolumn{2}{|c|}{ Generalised Anxiety Disorder } \\
\hline & $\%$ & $(95 \% \mathrm{Cl})$ \\
\hline \multicolumn{3}{|l|}{$52-64$} \\
\hline Normal & 4.5 & $(3.1-6.5)$ \\
\hline Increased & 4.0 & $(2.8-5.7)$ \\
\hline Substantially Increased & 3.6 & $(2.7-4.8)$ \\
\hline Total & 3.9 & $(3.2-4.8)$ \\
\hline \multicolumn{3}{|l|}{$65-74$} \\
\hline Normal & 3.3 & $(1.8-6.0)$ \\
\hline Increased & 3.3 & $(1.7-6.4)$ \\
\hline Substantially Increased & 3.0 & $(2.0-4.5)$ \\
\hline Total & 3.1 & $(2.3-4.2)$ \\
\hline \multicolumn{3}{|l|}{$>=75$} \\
\hline Normal & 0.0 & $(.-)$. \\
\hline Increased & 0.0 & $(.-)$. \\
\hline Substantially Increased & 1.8 & $(0.8-3.8)$ \\
\hline Total & 1.1 & $(0.5-2.3)$ \\
\hline \multicolumn{3}{|l|}{ Total } \\
\hline Normal & 3.5 & $(2.5-4.7)$ \\
\hline Increased & 3.1 & $(2.2-4.3)$ \\
\hline Substantially Increased & 3.0 & $(2.3-3.8)$ \\
\hline Total & 3.1 & $(2.6-3.7)$ \\
\hline
\end{tabular}


Table 4.A8: Prevalence of generalised anxiety disorder at wave 2 by wave 1 body mass index classification and age

\begin{tabular}{|c|c|c|}
\hline & \multicolumn{2}{|c|}{ Generalised Anxiety Disorder } \\
\hline & $\%$ & $(95 \% \mathrm{Cl})$ \\
\hline \multicolumn{3}{|l|}{$52-64$} \\
\hline Normal & 4.6 & $(3.1-6.6)$ \\
\hline Overweight & 3.6 & $(2.6-4.8)$ \\
\hline Obese & 4.0 & $(2.9-5.5)$ \\
\hline Total & 3.9 & $(3.2-4.8)$ \\
\hline \multicolumn{3}{|l|}{$65-74$} \\
\hline Normal & 3.6 & $(1.9-6.6)$ \\
\hline Overweight & 2.7 & $(1.6-4.3)$ \\
\hline Obese & 3.4 & $(2.1-5.6)$ \\
\hline Total & 3.1 & $(2.3-4.2)$ \\
\hline \multicolumn{3}{|l|}{$>=75$} \\
\hline Normal & 0.0 & $(.-)$. \\
\hline Overweight & 1.3 & $(0.4-4.1)$ \\
\hline Obese & 1.5 & $(0.6-4.2)$ \\
\hline Total & 1.1 & $(0.5-2.3)$ \\
\hline \multicolumn{3}{|l|}{ Total } \\
\hline Normal & 3.3 & $(2.4-4.5)$ \\
\hline Overweight & 2.8 & $(2.2-3.7)$ \\
\hline Obese & 3.3 & $(2.5-4.3)$ \\
\hline Total & 3.1 & (2.6-3.7) \\
\hline
\end{tabular}


Table 4.A9: Prevalence of generalised anxiety disorder at wave 2 by wave 1 body mass index classification and sex

\begin{tabular}{lcc} 
& $\begin{array}{c}\text { Generalised Anxiety Disorder } \\
\text { Male }\end{array}$ & $(95 \% \mathrm{Cl})$ \\
Normal & 2.0 & $(0.9-4.2)$ \\
Overweight & 2.0 & $(1.3-3.2)$ \\
Obese & 2.4 & $(1.6-3.6)$ \\
\hline Total & 2.2 & $(1.6-2.9)$ \\
\hline Female & & \\
Normal & 3.9 & $(2.8-5.6)$ \\
Overweight & 3.7 & $(2.7-5.1)$ \\
Obese & 4.3 & $(3.1-5.9)$ \\
\hline Total & 4.0 & $(3.3-4.8)$ \\
\hline Total & & \\
Normal & 3.3 & $(2.4-4.5)$ \\
Overweight & 2.8 & $(2.2-3.7)$ \\
Obese & 3.3 & $(2.5-4.3)$ \\
\hline Total & 3.1 & $(2.6-3.7)$ \\
\hline
\end{tabular}




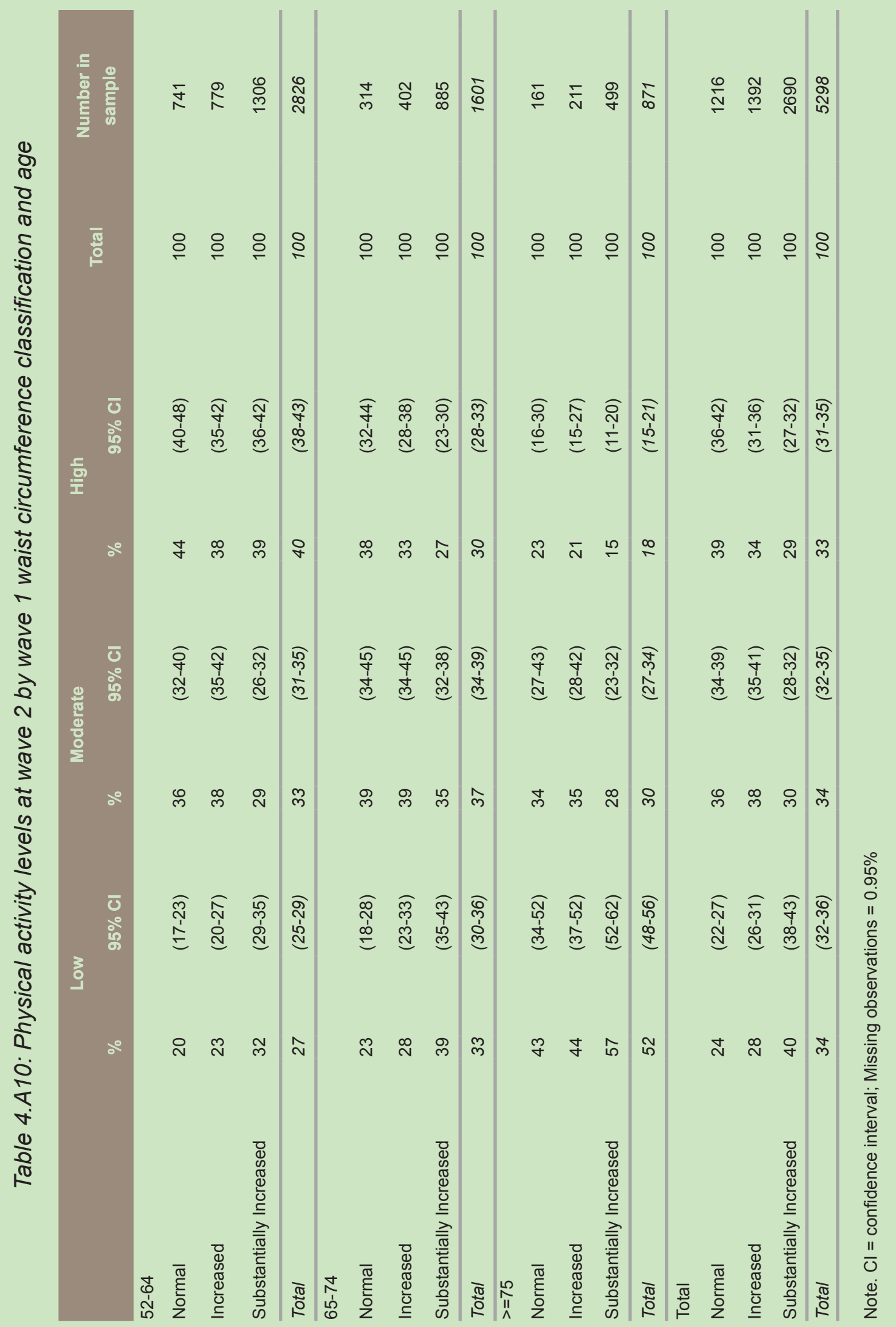




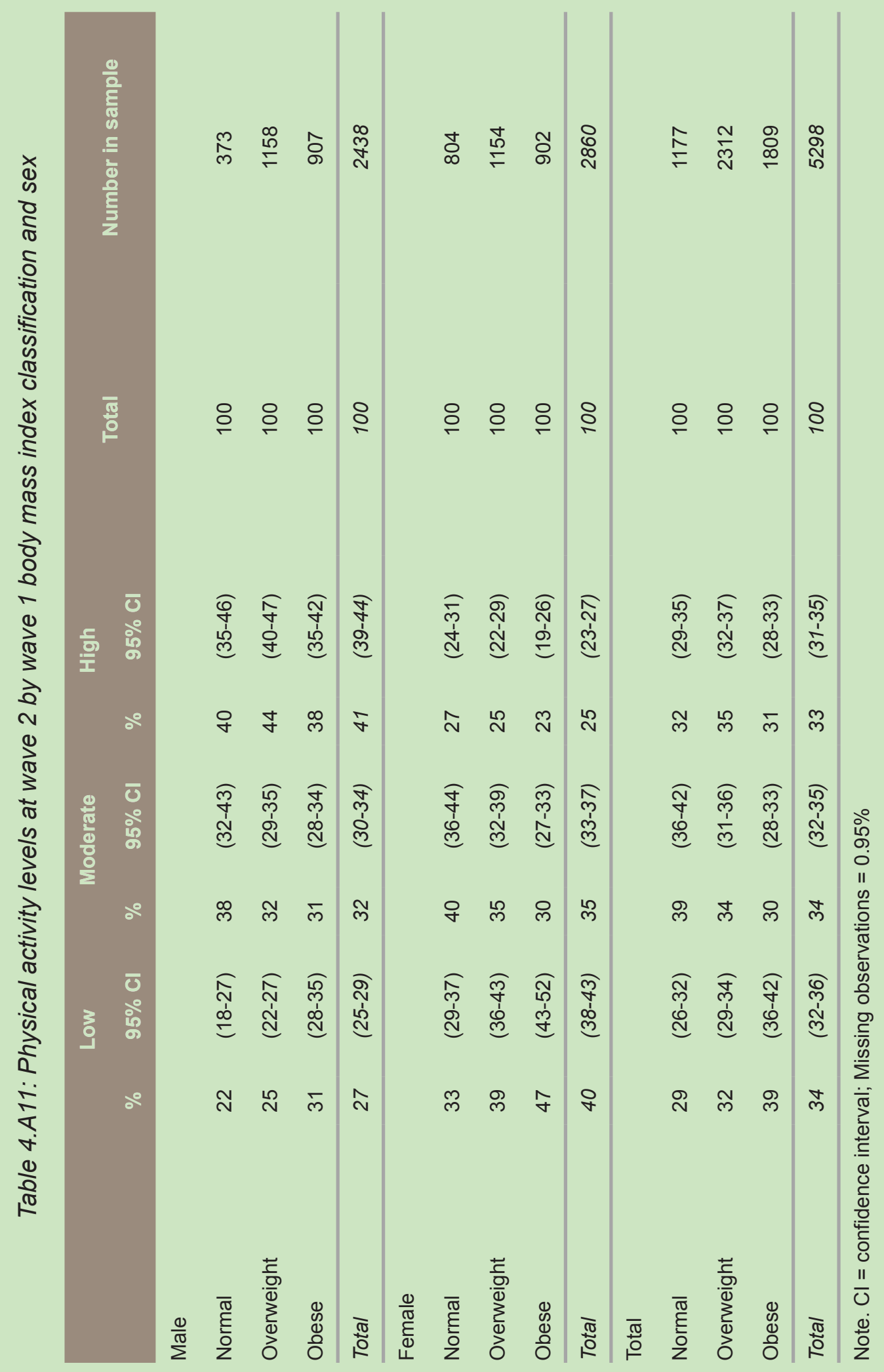




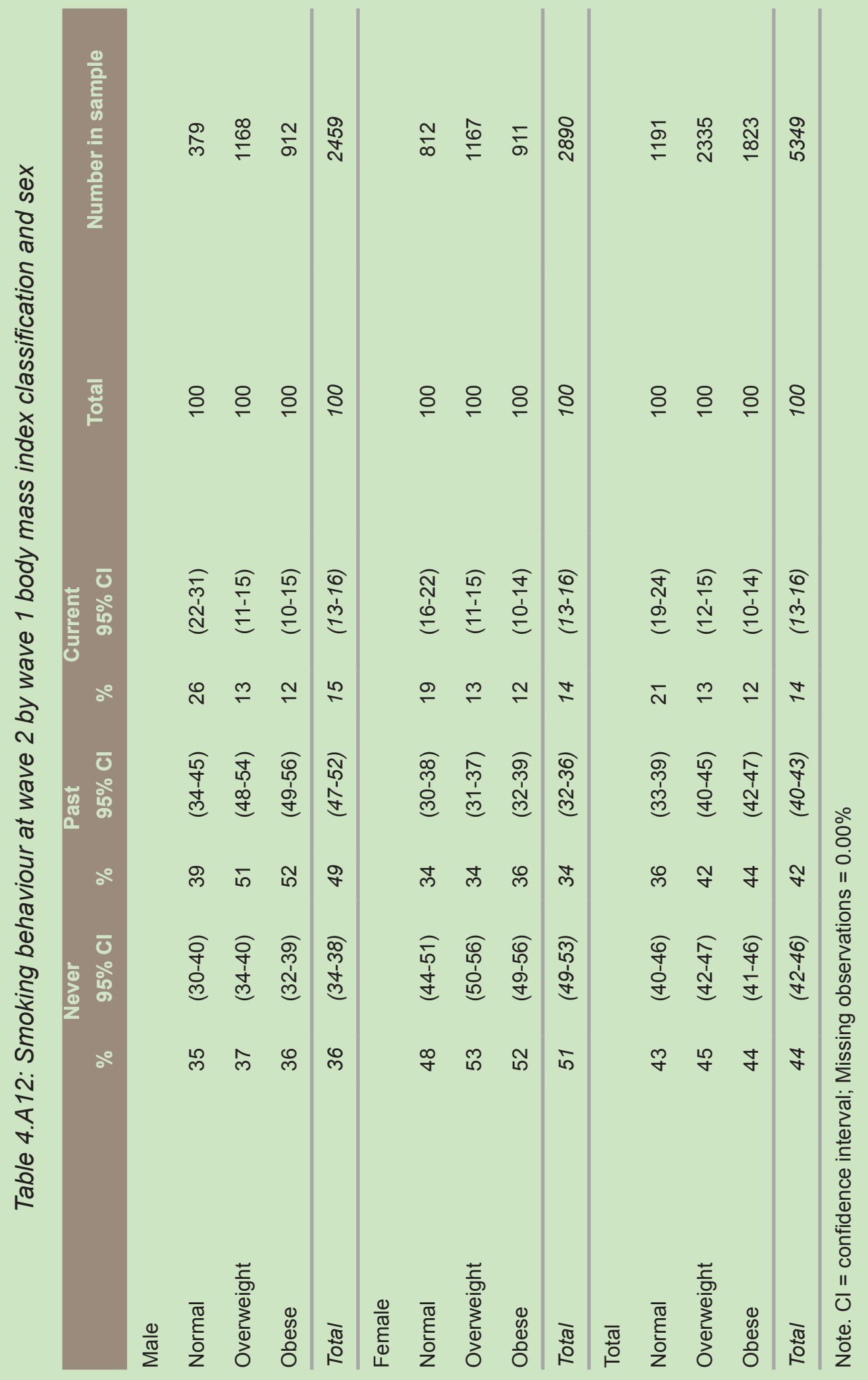




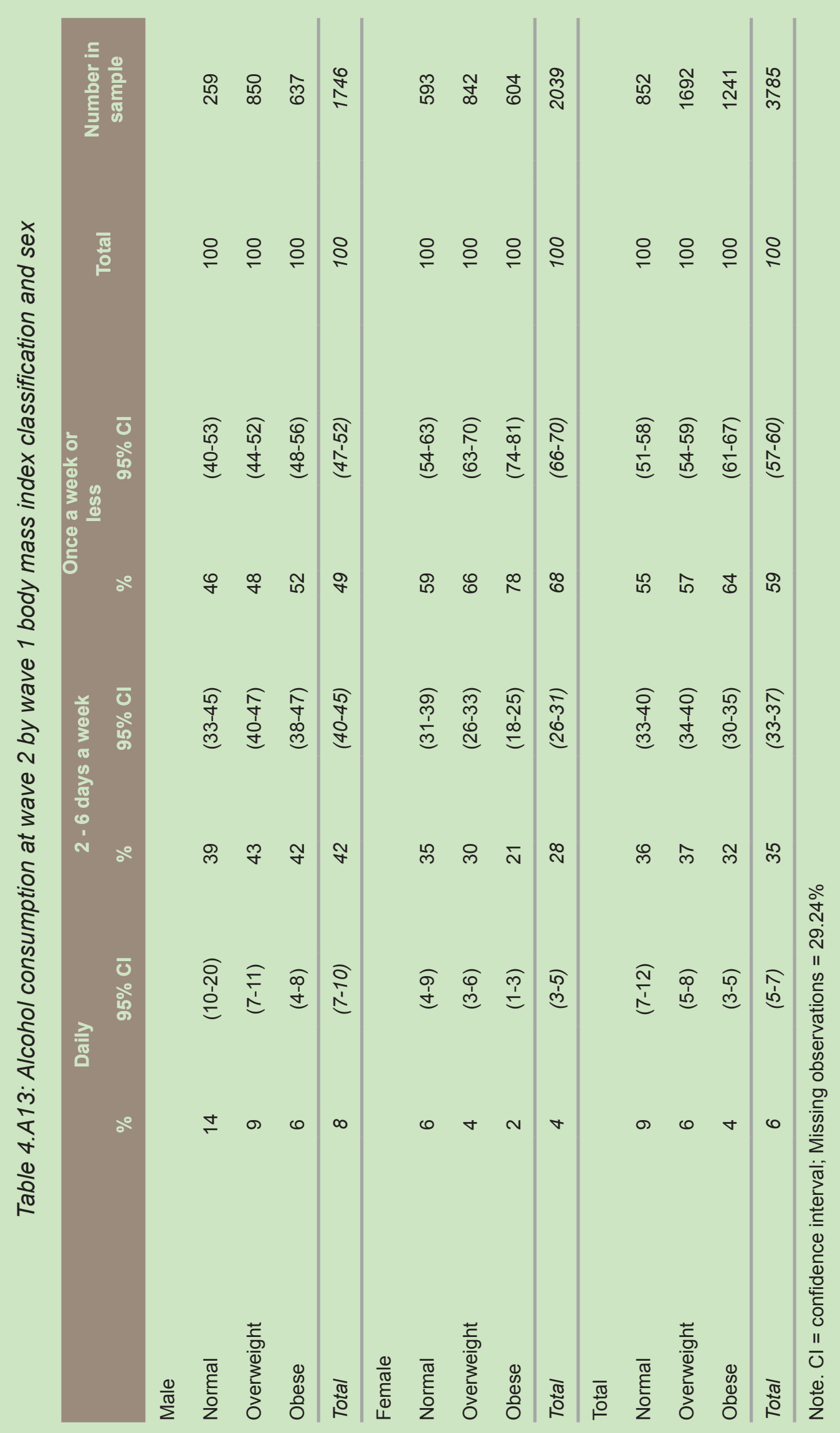




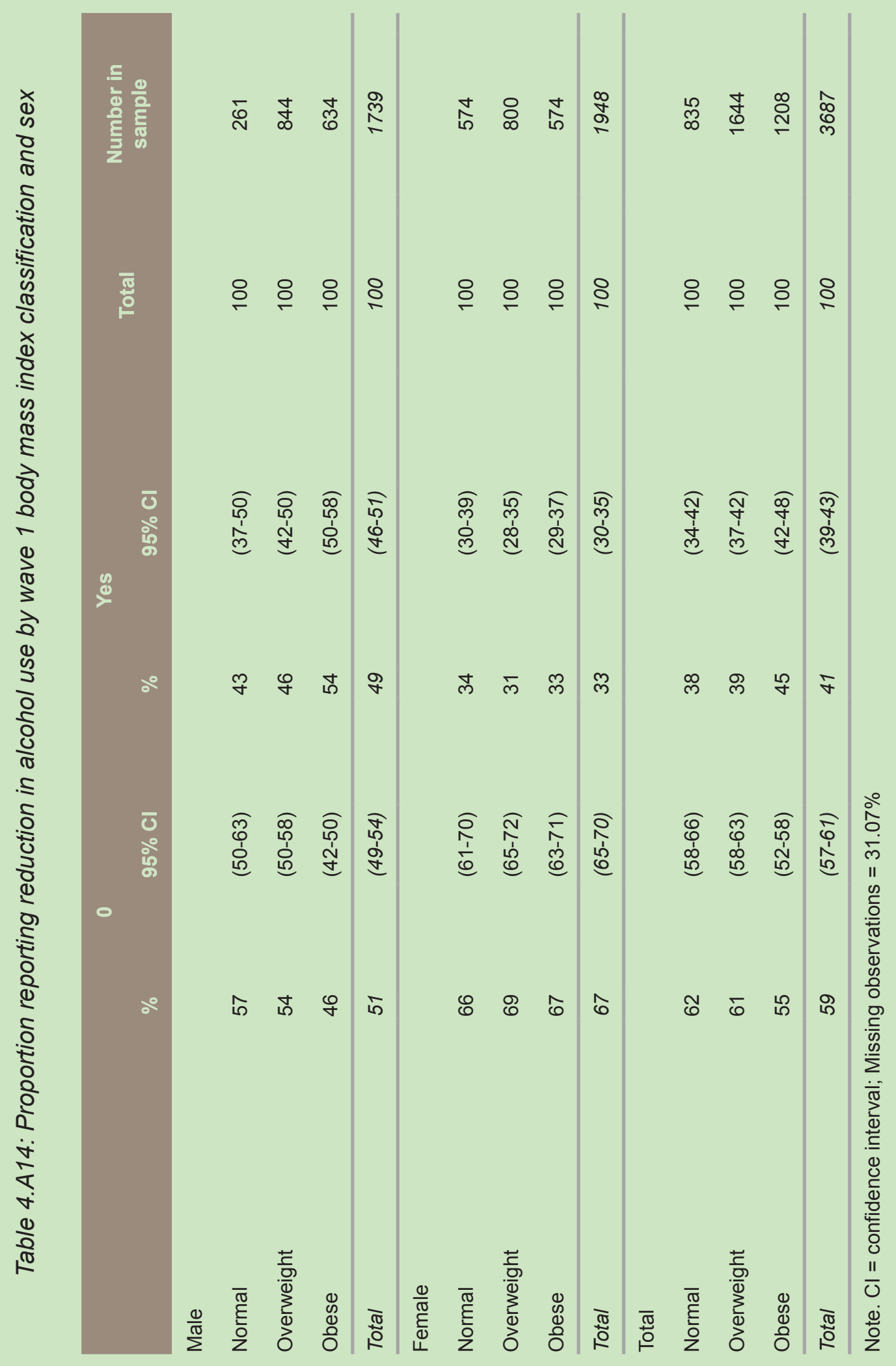




\title{
Health and Social Care Utilisation
}

\author{
Catriona Murphy, Patrick Moore, Sheena McHugh, \\ Hugh Nolan
}

\section{Contents}

Key Findings 124

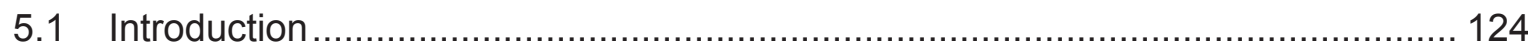

5.2 Medical card and private health insurance coverage ....................................... 125

5.3 Changes in medical card and private health insurance coverage ...................... 128

5.4 Utilisation of primary and secondary care services ......................................... 129

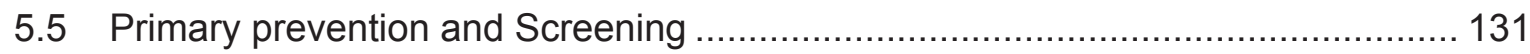

5.5.1 Prostate cancer screening ............................................................. 131

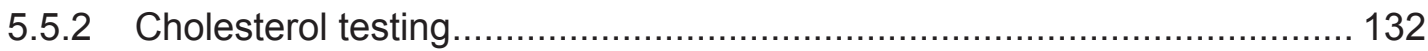

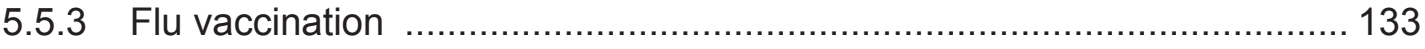

5.4.4 Breast Cancer Screening ................................................................. 133

5.6 Utilisation of community-based state care services......................................... 134

5.7 Disability prevalence and utilisation of home care services ................................ 135

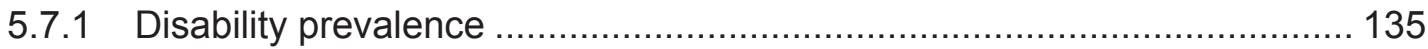

5.7.2 Utilisation of home help, personal care and meals services .................. 137

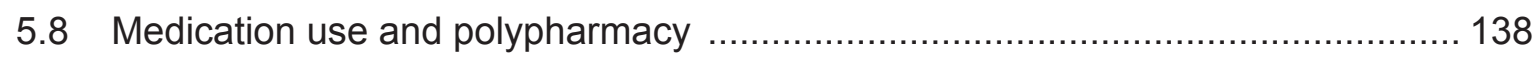

5.8.2 Use of generics: the case of Atorvastatin ............................................ 141

5.9 Health service utilisation at the end of life ....................................................... 143

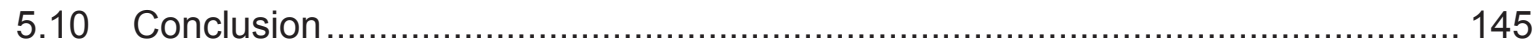

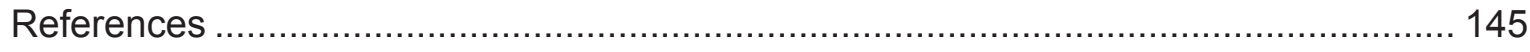

Appendix 5A: Tables on Health and Social Care Utilisation ................................... 147

Appendix 5B: Figures on Health and Social Care Utilisation..................................... 152 


\section{Health and Social Care Utilisation}

\section{Key Findings}

- The proportion of TILDA participants with a medical card or GP visit card increased overall between wave 1 and wave 2 (from $52 \%$ to $57 \%$ ), but declined in those aged $70+$ years.

- Between wave 1 and wave 2, private health insurance cover declined in those under 65 years and increased in those aged over 65 years.

- In wave 2, $21.1 \%$ of participants aged $80+$ years old had attended an Emergency Department (ED) at least once in the previous year (the corresponding figure for wave 1 was $15.1 \%)$.

- Utilisation of community health and social care services by the older population remains low.

- The uptake of prostate cancer screening services in men and breast cancer screening services women is high but the uptake of flu vaccination is low, particularly for those who do not have a medical or GP visit card.

- Polypharmacy (i.e., taking five or more medications) has increased from $21 \%$ at wave 1 to $26 \%$ at wave 2 .

- Participants who had died between wave 1 and wave 2 had higher levels of secondary care service utilisation (ED visits and hospital admissions) than survivors.

\subsection{Introduction}

Health service utilisation was reported in the first wave of TILDA on all those aged 50 years and over. This chapter reports on the health service utilisation two years later in those aged 52 years and older who took part in the second wave of the study $(n=7,134)$. This includes 7,010 participants who took part in both waves and 124 new participants. New participants in wave 2 include those previously deemed eligible to participate in wave 1 but who declined to do so at that time $(n=122)$ and new partners/spouses of study participants $(n=2)$. Wave 2 participants are therefore slightly older on average than participants in wave 
1 (mean age 65.5 years vs $63.8 \mathrm{yrs}$ ).

In this chapter an expanded age categorisation is used to highlight the different patterns of service utilisation with increasing age, as well as differing public healthcare entitlements by age. Although differences in the cohort between the first and second waves of TILDA are discussed in detail in Chapter 7, differences across the age groups are highlighted here due to their relevance in the context of health service utilisation. The youngest age group (52-59 years) in wave 2 is systematically different to the youngest age group in wave 1 which included participants aged $50-52$ years. The oldest age group ( $\geq 80$ years) are also older than the corresponding group in wave 1 (mean age 84.4 years vs 83.8 years). This reflects differences in eligibility to participate between the waves. In wave 2 it became possible to interview participants or their proxy where the participant had been admitted to a nursing home or had become cognitively impaired.

The chapter begins with a focus on health care entitlement status followed by utilisation of primary, secondary, community and home based services. The focus then turns to changes in prescribing patterns for older adults between the two waves. The final part of the chapter reports on health service utilisation in participants who died between wave 1 and wave 2 of the TILDA study.

\subsection{Medical card and private health insurance coverage}

There are two main categories of eligibility for public health services in Ireland, those with a medical card and those without. Those with a medical card are entitled to free General Practitioner (GP) care and public hospital services, free prescribed drugs and medicines subject to a $€ 2.50$ charge per item (from 1 December 2013), free dental, optical and aural services subject to certain limitations and a range of community care and personal social services. Eligibility for a medical card is means tested with different income thresholds applied at different ages. Those who do not meet the eligibility criteria for a medical card may qualify for a GP visit card, where the income thresholds are $50 \%$ higher than those for the medical card. The GP visit card entitles the holder to free GP visits; however, unlike the medical card the holder must pay out of pocket for all prescribed drugs and medicines. Under the Drugs Payment Scheme, all those without a medical card must pay the full cost of prescribed drugs and medicines up to a monthly deductible limit of $€ 144$ per family.

Universal entitlement to a medical card for all adults over 70 years was introduced in 2001 . This universal entitlement was removed in 2009 and an income threshold for eligibility reintroduced. The over 70 s income threshold has subsequently been revised downwards 
on an annual basis. During wave 2, a single person aged 70 years and older with a gross income of $€ 700$ per week or less or a couple over 70 years with a gross income of $€ 1,400$ per week or less qualified for a medical card under the scheme. Under The Health (Alteration of Criteria for Eligibility) Act 2013 this was revised downwards to $€ 600$ for a single person and $€ 1,200$ for a couple (1). The income thresholds for a medical card for persons over 70 years will be further reduced in 2014 to $€ 500$ per single person or $€ 900$ per couple (2)

During wave 2 adults over 70 years with a gross weekly income of over $€ 600$ but not exceeding $€ 700$ for a single person (over $€ 1,200$ and not exceeding $€ 1,400$ for a couple) were entitled to a GP visit card (3). Prescription charges were subsidised above a threshold of $€ 132$ per month under the Drugs Payment Scheme during the data collection period for wave 2, and this was increased to $€ 144$ per month from 1 January 2013.

Those without a medical card or GP visit card must pay out of pocket for GP services. This group are entitled to free public hospital services subject to in-patient and out-patient hospital charges, subsidised prescription charges under the Drugs Payment Scheme and have no entitlement to personal social services. Supplementary private health insurance is purchased by many individuals in order to gain quicker access to hospital services. Some individuals with entitlement to a medical card or GP visit card purchase private health insurance in addition to these entitlements; this group is described as having 'dual cover' in this report. Those without private health insurance, a GP visit card or a medical card are described as having 'no cover' in this report.

During the period between wave 1 and wave 2 (wave 1 commenced in 2009, wave 2 in 2012), due to the impact of the economic recession in Ireland, the number of Irish people eligible for medical cards increased and the number purchasing private health insurance decreased. In this period, the proportion of people with medical cards in the Irish population increased from 33.2\% (1.4 million) at the beginning of 2010 to $37 \%$ (1.7 million) at the beginning of 2012. The proportion of the population with GP visit cards also increased from $2.2 \%(98,300)$ to $3.1 \%(142,500)$ in the same time period $(4,5)$.

For ease of comparison with wave 1, Table 5.1 shows the pattern of health care cover for all participants aged 50 years and older in wave 1 and Table 5.2 shows the pattern in all participants aged 52 years and older in wave 2 . Due to the small number of participants with GP visit only cards this category is combined with the medical card category. The first four columns provide information on exclusive categories, i.e., an individual can belong to one category only. The sixth column 'All medical cards' combines the two categories 
of 'Medical card only' and 'Dual cover'. The seventh column 'All private health insurance' combines the two categories 'Private health insurance only' and 'Dual cover'.

Table 5.1: Health care entitlement status at wave 1 by age

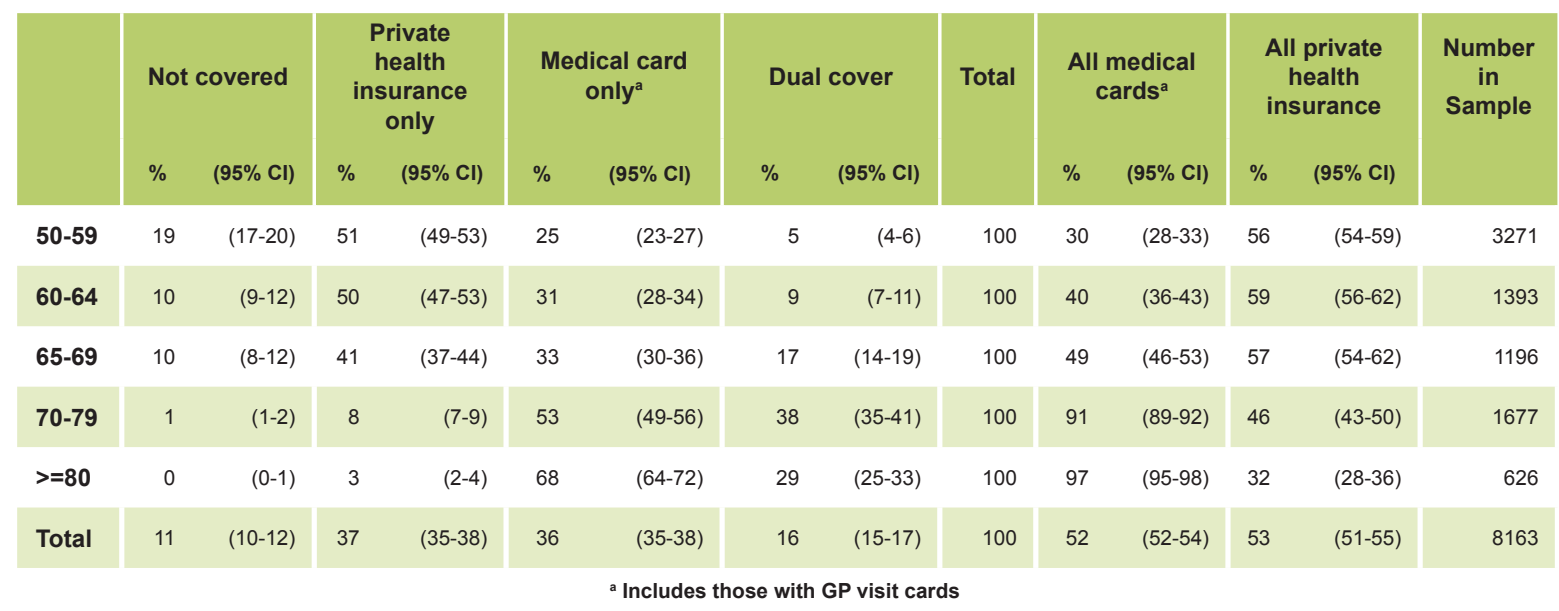

Table 5.2: Health care entitlement status at wave 2 by age

\begin{tabular}{|c|c|c|c|c|c|c|c|c|c|c|c|c|c|c|}
\hline & \multicolumn{2}{|c|}{ Not covered } & \multicolumn{2}{|c|}{$\begin{array}{c}\text { Private } \\
\text { health } \\
\text { insurance } \\
\text { only }\end{array}$} & \multicolumn{2}{|c|}{$\begin{array}{l}\text { Medical card } \\
\text { only }^{\mathrm{a}}\end{array}$} & \multicolumn{2}{|c|}{ Dual cover } & \multirow[t]{2}{*}{ Total } & \multicolumn{2}{|c|}{$\begin{array}{c}\text { All medical } \\
\text { cards }^{\mathrm{a}}\end{array}$} & \multicolumn{2}{|c|}{$\begin{array}{l}\text { All private } \\
\text { health } \\
\text { insurance }\end{array}$} & \multirow[t]{2}{*}{$\begin{array}{l}\text { Number } \\
\text { in } \\
\text { Sample }\end{array}$} \\
\hline & $\%$ & $(95 \% \mathrm{Cl})$ & $\%$ & $(95 \% \mathrm{Cl})$ & $\%$ & $(95 \% \mathrm{Cl})$ & $\%$ & $(95 \% \mathrm{Cl})$ & & $\%$ & $(95 \% \mathrm{Cl})$ & $\%$ & $(95 \% \mathrm{Cl})$ & \\
\hline $52-59$ & 18 & $(16-20)$ & 48 & $(46-51)$ & 27 & $(25-30)$ & 6 & $(5-7)$ & 100 & 34 & $(31-36)$ & 54 & $(52-57)$ & 2344 \\
\hline $65-69$ & 7 & $(5-9)$ & 42 & $(38-45)$ & 35 & $(32-38)$ & 17 & $(14-19)$ & 100 & 52 & $(48-55)$ & 58 & $(55-62)$ & 1182 \\
\hline $70-79$ & 1 & $(0-1)$ & 10 & $(9-12)$ & 50 & $(46-53)$ & 39 & $(36-42)$ & 100 & 89 & $(87-90)$ & 50 & $(46-53)$ & 1579 \\
\hline
\end{tabular}

The second wave of TILDA provides information on changing eligibility for free public health care in Ireland. While most of the changes between waves are not statistically significant, some interesting patterns emerge. Overall, the proportion of participants with medical /GP visit cards has increased from $52 \%$ at wave 1 (see Table 5.1 ) to $57 \%$ in wave 2 (see Table 5.2). This increase however is confined to those aged less than 70 years. The proportion with a medical/GP visit card decreased from $91 \%$ to $89 \%$ between waves in those aged $70-79$ years and from $97 \%$ to $95 \%$ between waves in those aged 80 years and older. In total $92 \%$ of participants aged 70 years and older have a medical card or GP visit card in wave 2.

A similar but opposite pattern can be seen in relation to private health insurance. The 
overall proportion of the older population with private health insurance is slightly reduced from $53 \%$ at wave 1 to $52 \%$ at wave 2 (see Table 5.1 and Table 5.2). A decrease in the proportion with private health insurance can be seen in those aged under 65 years and an increase in those aged 65 years and older, although none of these comparisons are statistically significant. The largest increase between the two waves can be seen in the 7079 year age group where $46 \%$ had private health insurance at wave 1 compared to $50 \%$ at wave 2.

The increase in private health insurance uptake at older ages is consistent with reports on the current age profile of the private health insurance market in Ireland. The numbers of people aged 60 years and over with private health insurance have increased annually between 2009 and 2011 compared to annual decreases in all age groups younger than 60 years (6). As the income thresholds for entitlement to a medical card among the over 70 s have been reduced recently, this increase in uptake of private health insurance may suggest a need for reassurance by older people that they have sufficient cover in the event of need for health care.

Recently published data from the Central Statistics Office revealed that $44 \%$ of Irish adults aged 65 years and older had private health insurance in 2011 (7). Using this age as a cutoff point, $46.5 \%$ of TILDA participants were found to have private health insurance in wave 1 and $48 \%$ to have private health insurance in wave 2 , representing a gradual increase in private health insurance uptake in this age group in the inter-wave period.

Almost a fifth of older adults have dual cover (private health insurance in addition to a medical/GP visit card). Dual cover is uncommon in the 52-59 year age group and is relatively static between the two waves in those under 70 years. The proportion of the population with no cover has changed little across the waves.

\subsection{Changes in medical card and private health insurance coverage}

To examine transitions in health care entitlement categories between wave 1 and wave 2, in this sub-section we focus just on individuals that took part in both waves and provided details of their health care entitlement status at both waves $(n=6,904)$. Table 5.3 provides detailed information on the transitions from wave 1 to wave 2 between the five mutually exclusive health care entitlement categories defined in Tables 5.1 and 5.2. 
Table 5.3: Changes in health care entitlement status between wave 1 and wave 2

\begin{tabular}{|c|c|c|c|c|c|c|c|}
\hline & $\begin{array}{c}\begin{array}{c}\text { Medical } \\
\text { card } \\
\text { only } \\
\text { (wave 2) }\end{array} \\
\%\end{array}$ & $\begin{array}{c}\begin{array}{c}\text { GP card } \\
\text { only } \\
\text { (wave 2) }\end{array} \\
\%\end{array}$ & $\begin{array}{c}\text { Private } \\
\text { health } \\
\text { insurance } \\
\text { only } \\
\text { (wave 2) } \\
\%\end{array}$ & $\begin{array}{c}\text { Dual private } \\
\text { Health } \\
\text { Insurance } \\
\text { plus } \\
\text { Medical/GP } \\
\text { Card } \\
\text { (wave 2) } \\
\%\end{array}$ & $\begin{array}{c}\text { No Cover } \\
\text { (wave 2) } \\
\\
\%\end{array}$ & $\begin{array}{c}\text { Total } \\
\\
\%\end{array}$ & $\begin{array}{c}\text { Number } \\
\text { in } \\
\text { sample } \\
\text { (wave 1) }\end{array}$ \\
\hline Medical card only (wave 1) & 96.0 & 0.3 & 0.3 & 2.4 & 1.0 & 100 & 2,001 \\
\hline GP card only (wave 1) & 42.2 & 29.8 & 0.0 & 1.2 & 26.8 & 100 & 62 \\
\hline $\begin{array}{l}\text { Private health insurance only } \\
\text { (wave 1) }\end{array}$ & 1.0 & 0.1 & 87.0 & 8.9 & 3.0 & 100 & 2,929 \\
\hline $\begin{array}{l}\text { Dual private health } \\
\text { insurance plus medical card/ } \\
\text { GP card (wave 1) }\end{array}$ & 10.5 & 0.3 & 4.9 & 83.9 & 0.5 & 100 & 1,201 \\
\hline No cover (wave 1) & 20.5 & 3.8 & 4.5 & 0.9 & 70.2 & 100 & 711 \\
\hline Number in sample (wave 2) & 2210 & 60 & 2682 & 1334 & 618 & 100 & 6904 \\
\hline
\end{tabular}

Of those who had a medical card only at wave 1 , almost all continued to have a medical card only at wave $2(96 \%)$ and a small proportion had purchased private health insurance in addition to their medical card cover by wave $2(2.4 \%)$ (see Table 5.3 ). While the number of participants with a GP visit card only at wave 1 was small, less than a third of these continued to have a GP visit card only at wave $2,42.2 \%$ had obtained a medical card and $26.8 \%$ had no cover at wave 2 . Almost $96 \%$ of those with private health insurance only at wave 1 retain their private health insurance alone or in conjunction with a medical card or GP visit card in wave 2 with a small proportion (3\%) transitioning to no cover. This contrasts with those who held private health insurance in addition to either a medical card or a GP visit card at wave 1, a proportion of whom have relinquished their private health insurance in the inter-wave period and now rely more heavily on a medical card only $(10.5 \%)$. Of those with no cover at wave $1,70.2 \%$ continued to have no cover at wave 2 and $20.5 \%$ had become eligible for a medical card with only $3.8 \%$ becoming eligible for a GP visit card.

\subsection{Utilisation of primary and secondary care services}

Primary and secondary care service utilisation increased between wave 1 and wave 2 . Utilisation of GP services remains high with $89.6 \%$ of participants in wave 2 indicating that they had visited their GP at least once in the previous year compared to $87.4 \%$ in wave 1 (see Table 5.4). Utilisation was highest in those with dual cover, followed by those with medical or GP visit cards. The lowest level of utilisation was found in those classified as having no cover. 
Frequency of GP visiting was examined at wave two. One tenth of those aged 52 years and older did not visit a GP in the previous year and $63 \%$ visited between one and four times, $25 \%$ visited between 5 and 19 times and only $2 \%$ visited 20 or more times in the previous year (See Appendix Table 5.A1). Frequency increased with age however a similar pattern can still be seen in those aged 80 years and older where $5 \%$ did not visit a GP in the previous year, $53 \%$ visited $1-4$ times, 39\% visited $5-19$ times and $3 \%$ visited a GP 20 times or more.

Table 5.4: Proportion utilising primary and secondary care services by age and health care entitlement status

\begin{tabular}{|c|c|c|c|c|c|c|c|c|}
\hline & \multicolumn{2}{|c|}{ GP visit (\%) } & \multicolumn{2}{|c|}{$\begin{array}{l}\text { Outpatient } \\
\text { visit (\%) }\end{array}$} & \multicolumn{2}{|c|}{$\begin{array}{l}\text { Emergency } \\
\text { Department } \\
\text { (ED) visit (\%) }\end{array}$} & \multicolumn{2}{|c|}{$\begin{array}{c}\text { Hospital } \\
\text { Admission } \\
(\%)\end{array}$} \\
\hline & $\begin{array}{c}\text { wave } \\
1\end{array}$ & $\begin{array}{c}\text { wave } \\
2\end{array}$ & $\begin{array}{c}\text { wave } \\
1\end{array}$ & $\begin{array}{c}\text { wave } \\
2\end{array}$ & $\begin{array}{c}\text { wave } \\
1\end{array}$ & $\begin{array}{c}\text { wave } \\
2\end{array}$ & $\begin{array}{c}\text { wave } \\
1\end{array}$ & $\begin{array}{c}\text { wave } \\
2\end{array}$ \\
\hline \multicolumn{9}{|l|}{ Age } \\
\hline $\begin{array}{l}50-59 \text { (wave 1) } \\
52-59 \text { (wave 2) }\end{array}$ & 80.7 & 84.3 & 35.7 & 38.6 & 14.0 & 14.4 & 10.5 & 10.2 \\
\hline $60-64$ & 88.0 & 88.0 & 42.0 & 42.2 & 14.3 & 14.0 & 11.3 & 11.3 \\
\hline $65-69$ & 90.8 & 91.7 & 45.2 & 51.0 & 16.0 & 15.9 & 15.0 & 14.7 \\
\hline $70-79$ & 94.7 & 94.7 & 46.2 & 51.5 & 16.7 & 19.4 & 16.6 & 18.2 \\
\hline$>=80$ & 95.4 & 94.1 & 36.9 & 47.0 & 15.1 & 21.1 & 15.6 & 24.8 \\
\hline Total & 87.4 & 89.6 & 40.2 & 45.0 & 14.9 & 16.4 & 12.9 & 14.6 \\
\hline \multicolumn{9}{|l|}{ Health entitlement status } \\
\hline Not covered & 74.3 & 75.1 & 31.3 & 31.2 & 13.2 & 11.6 & 5.9 & 6.8 \\
\hline $\begin{array}{l}\text { Private health insurance } \\
\text { only }\end{array}$ & 82.3 & 86.0 & 36.9 & 39.3 & 11.8 & 12.5 & 10.0 & 9.8 \\
\hline Medical/GP visit card only & 93.0 & 92.8 & 43.3 & 49.4 & 18.0 & 19.5 & 15.9 & 16.9 \\
\hline Dual cover & 95.3 & 97.0 & 46.8 & 53.1 & 16.2 & 19.7 & 17.1 & 22.6 \\
\hline Total & 87.4 & 89.6 & 40.2 & 45.0 & 14.9 & 16.5 & 12.9 & 14.6 \\
\hline
\end{tabular}

The proportion of older adults attending hospital as on outpatient in the year prior to the survey has increased by almost 5 percentage points between wave 1 and wave 2 (see Table 5.4). Utilisation increased the most between the two waves in those with dual cover and those with medical or GP visit cards only. The increase is especially apparent in those over 80 years where the proportion attending hospital as an outpatient in the previous year increased by over 10 percentage points between the two waves ( $36.9 \%$ to $47 \%)$. The increase in outpatient activity found at wave 2 may reflect a changing waiting pattern for outpatient services which came about as a result of the Department of Health's Special 
Delivery Unit (SDU). The SDU was set up in 2011 by the Minister for Health and tasked with implementing performance improvement in Irish hospitals. One of the targets set was to reduce outpatient waiting lists to no more than 12 months in the 2011 period and to reduce this further to 9 months in 2012. As a result there was an increase in activity in the outpatient sector aimed at addressing those who had been waiting longest.

Utilisation of emergency department (ED) services in the year prior to the survey increased slightly between waves 1 and 2 of TILDA (see Table 5.4). Utilisation was highest and increased the most in those with dual cover. The largest increase in ED utilisation can be seen in those aged 80 years and older. Just over $15 \%$ of this age group reported an ED visit in the first wave compared to $21.1 \%$ in wave 2 (see Table 5.4). Some of this change is likely due to the older age profile of those over 80 years in wave 2. Given the high levels of multi-morbidity in older adults, this finding highlights the need for service providers to actively consider the needs of this older age group in EDs and to provide renewed focus on primary care and community-based interventions which aim to reduce dependency on the ED.

Admission to hospital in the previous year has also increased in the older age group $80+$ years) in wave $2 ; 24.8 \%$ of those aged 80 and over had experienced at least one admission in the previous year compared to $15.6 \%$ in wave 1 .

\subsection{Primary prevention and Screening}

\subsubsection{Prostate cancer screening}

Excluding non-melanoma skin cancer, prostate cancer is the most frequently diagnosed cancer in men in Ireland (8). There is no population-based screening programme for prostate cancer in Ireland due to insufficient evidence to recommend the introduction of a prostate cancer screening programme (9). Despite this, there is widespread screening at a local level. The majority of men in TILDA have had a prostate cancer test (an examination of their prostate to screen for cancer or a Prostate Specific Antigen (PSA) test). In wave 1 $72.8 \%$ of men aged 50 years and older indicated that they had previously had a prostate cancer test. At wave 2 this proportion rose to $81.8 \%$ in those aged 52 years and older (see Table 5.5).

As this test is not population-based, health care entitlement status provides an insight into the pattern of uptake. A higher proportion of those with private health insurance (either in combination with a medical/GP visit card or private health insurance only) had prostate 
cancer screening carried out compared to those with a medical or GP visit card only or those with no cover (in both waves). Overall the proportion of men being screened for prostate cancer is high suggesting perceived importance of this test and a willingness to pay for this service even in the group of men classified as having no cover.

Men who indicated that they had a PSA test carried out at wave 1 were asked in wave 2 if they had a repeat test conducted since the time of their first interview. Almost $79 \%$ had a repeat test carried out between the two waves. Men who had not been tested at the time of their first interview were asked if they had been tested between the two waves. In this group $44 \%$ were found to have been tested for the first time in the inter-wave period.

Table 5.5: Proportion utilising primary and secondary prevention services by age and health care entitlement status

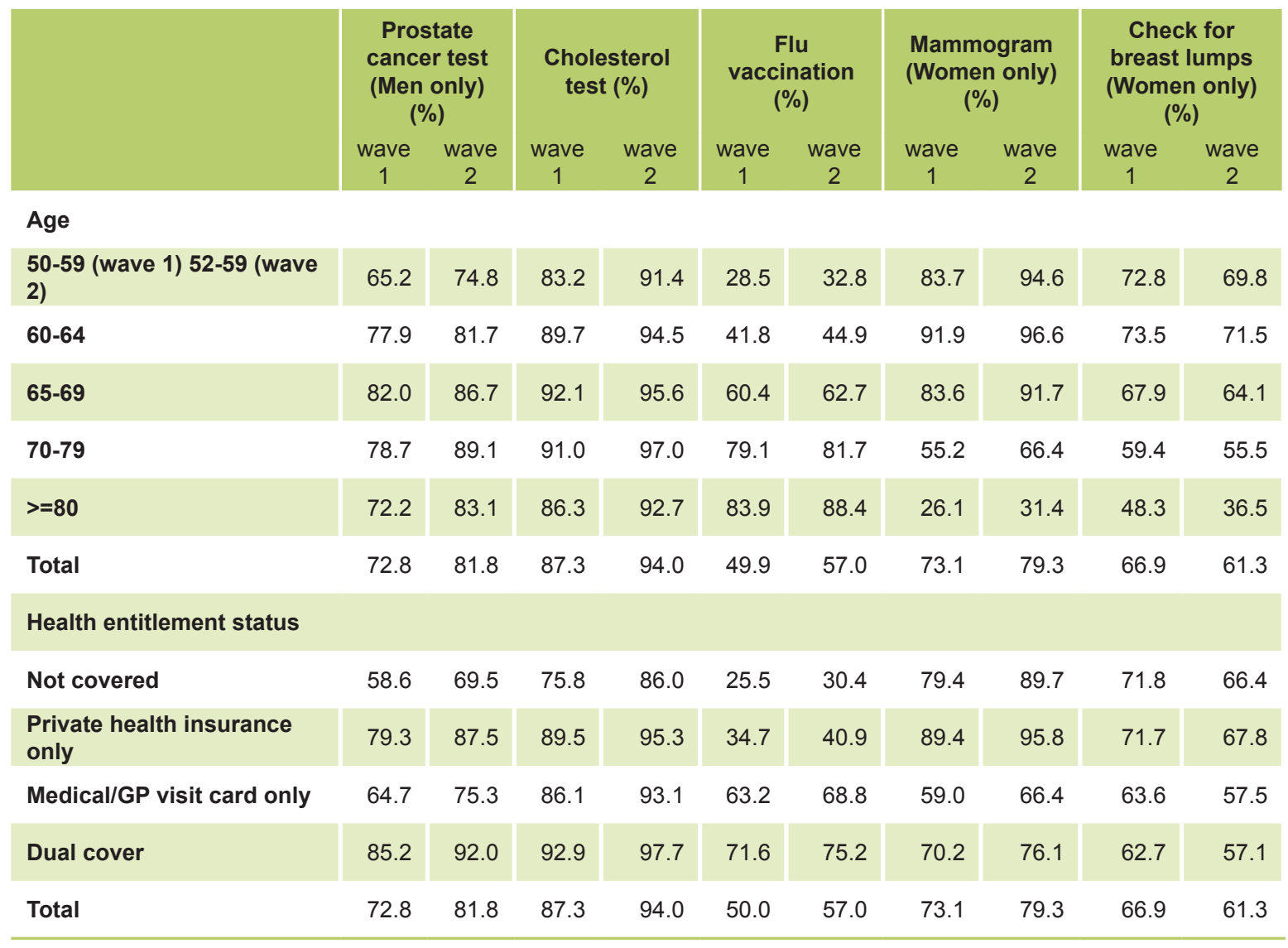

\subsubsection{Cholesterol testing}

Cholesterol testing is widespread in this population of older adults. In wave $187.3 \%$ of those aged 50 years and older had ever had a blood test for cholesterol, and this rose to $94 \%$ at wave 2 in those aged 52 years and older (see Table 5.5). The proportions of men and women tested were similar. 
Cholesterol testing was highest in those with dual cover and lowest in those with no cover. Participants who indicated that they had previously had a blood test for cholesterol carried out at wave 1 were asked in their second interview if they had a repeat test conducted since the time of their first interview. Of these $85 \%$ had a repeat cholesterol test carried out between the two waves. In those that had never had a cholesterol test at wave 1 , $61 \%$ were tested for the first time between their two interviews. More than two thirds of these participants had their cholesterol tested as part of the health assessment in the first wave of TILDA suggesting that the study has impacted on the higher uptake of cholesterol testing at wave 2.

\subsubsection{Flu vaccination}

Annual vaccination for influenza with the most recent virus strains was previously recommended for all adults over 65 years of age but from 2013 it is recommended for all adults over 50 years of age (10). The vaccine is provided free of charge but for those without a medical or GP visit card a consultation fee for administering the vaccine must be paid. A GP consultation costs from $€ 45-€ 60$ or higher compared to a community pharmacy consultation which costs from $€ 15-€ 27.50$ (11-13). Evidence from TILDA suggests that the uptake of the flu vaccine is low overall. In the first wave of TILDA $49.9 \%$ of those over 50 years had ever received a flu vaccination; this increased to $57 \%$ of those aged 52 years and older in wave 2 (see Table 5.5).

A higher proportion of those with dual cover or with medical/GP cards received flu vaccination compared to those with private health insurance only or no cover. Although the vaccine is free to all, less than a third of those with no cover had received a flu vaccination in both waves. This suggests that the GP or pharmacy consultation fees for those without a medical or GP visit card may constitute a barrier to flu vaccination uptake.

There was a high level of repeat flu vaccination $(81 \%)$ in those that had been vaccinated at wave 1. Repeat vaccination was especially high in those aged 80 years and older which reached almost $89 \%$. This suggests that the perceived importance of this vaccine and the acceptability of it are high in this older age group. In those that had never been vaccinated against flu in wave 1 , only $17 \%$ had received a flu vaccination by the time of their interview for wave 2 . These figures are low considering the widespread campaigns for flu vaccination which are run on an annual basis.

\subsubsection{Breast Cancer Screening}

In Ireland the National Breast Screening Programme (BreastCheck) offers women aged 
50-64 years a free mammogram every two years. The proportion of women over 50 years who had ever had a mammogram was $73.1 \%$ in wave 1 . This increased to $79.3 \%$ of those over 52 years at wave 2 (see Table 5.5). The success of this national screening programme is reflected in the fact that breast screening by women in the target age groups is $95 \%$ at wave 2 .

Of those that had a mammogram at wave $165 \%$ had undergone a repeat test in the interwave period. Repeat testing was highest in the younger age groups targeted for screening.

In wave $166.9 \%$ of women over 50 years indicated that they checked their breasts regularly for lumps; and this dropped to $61.3 \%$ of women over 52 years at wave 2 (see Table 5.5). A very clear age gradient can be seen in relation to breast self-examination with a lower proportion of older women conducting breast self-examination.

\subsection{Utilisation of community-based state care services}

Participants were asked if they had utilised any of the community-based state care services in Table 5.6 in the preceding twelve months. They were asked to exclude any services for which they had paid anything other than a token or nominal amount. Unlike utilisation of GP services and acute hospital services which increased between the two waves, three of the community-based services outlined below show decreases in utilisation.

Table 5.6: Proportion utilising community-based state care services

\begin{tabular}{|c|c|c|c|c|c|}
\hline & \multicolumn{2}{|c|}{$\begin{array}{c}\text { wave } 1 \\
(\geq 50 \mathrm{yrs})\end{array}$} & \multicolumn{2}{|c|}{$\begin{array}{c}\text { wave } 2 \\
\text { ( } \geq 52 \mathrm{yrs} \text { ) }\end{array}$} & \multirow{2}{*}{$\begin{array}{c}\text { Change } \\
\text { Between } \\
\text { waves }\end{array}$} \\
\hline & $\%$ & $(95 \% \mathrm{Cl})$ & $\%$ & $(95 \% \mathrm{CI})$ & \\
\hline Public Health or Community Nurse & 6.6 & $(5.9-7.3)$ & 6.5 & $(5.8-7.3)$ & -0.1 \\
\hline Occupational therapy & 1.5 & $(1.2-1.8)$ & 1.7 & $(1.4-2.1)$ & 0.2 \\
\hline Chiropody/podiatry services & 4.5 & $(4.0-5.2)$ & 5.2 & $(4.6-5.9)$ & 0.7 \\
\hline Physiotherapy services & 5.2 & $(4.7-5.7)$ & 5.8 & $(5.2-6.5)$ & 0.6 \\
\hline Psychological/counselling services & 0.8 & $(0.7-1.1)$ & 1.0 & $(0.8-1.3)$ & 0.2 \\
\hline Day centre & 1.2 & $(1.0-1.5)$ & 1.5 & $(1.2-1.8)$ & 0.3 \\
\hline Optician & 12.3 & $(11.3-13.3)$ & 14.8 & $(13.8-15.9)$ & 2.5 \\
\hline Dental services & 10.7 & $(9.9-11.6)$ & 9.2 & $(8.4-10.1)$ & -1.5 \\
\hline Hearing services & 1.8 & $(1.5-2.1)$ & 3.2 & $(2.8-3.7)$ & 1.4 \\
\hline Dietician services & 1.5 & $(1.2-1.8)$ & 1.4 & $(1.2-1.8)$ & -0.1 \\
\hline Respite services & 0.5 & $(0.3-0.7)$ & 0.6 & $(0.4-0.9)$ & 0.1 \\
\hline
\end{tabular}


Utilisation rates range from $14.8 \%$ for optician services to $0.6 \%$ for respite services (see Table 5.6). There was little change in utilisation of community-based services between the two waves. The largest increase can be seen in the optician services, where the proportion of the population utilising the service increased from $12.3 \%$ in wave 1 to $14.8 \%$ in wave 2. Utilisation of dental services, public health nurse or community nurse services and dietician services recorded small decreases between wave 1 and wave 2 .

Almost $70 \%$ of participants in wave 2 use none of these community services. Utilisation is highest in those over 80 years where $59 \%$ of participants use at least one of the services identified.

The vast majority of older people utilising community-based state care services are medical card holders (see Appendix Table 5.A2). An interesting pattern is seen in these data in relation to those with dual cover. The data suggest that those with medical cards as well as private health insurance may also gain additional access to community-based state services where co-payments are a feature of the service. In the case of chiropody/podiatry services, $66 \%$ of users were medical card holders and a further $29 \%$ had dual cover (private health insurance in addition to a medical card or GP visit card) (see Appendix Table 5.A2). Although state chiropody/podiatry services are available to medical card holders, individuals are required to pay an additional co-payment of $€ 15-40$ per visit when attending private practitioners to avail of the service (14). These results suggest that the presence of a co-payment in some services may negatively impact access to services. As health care entitlement status is also strongly related to age and need for health care, this issue requires further investigation.

\subsection{Disability prevalence and utilisation of home care services}

\subsubsection{Disability prevalence}

Disability prevalence will now be discussed in relation to the wave 2 cohort aged 52 years and older. Disability prevalence has been discussed previously in a subgroup in Chapter 4 and will be discussed further in Chapter 6 in a subgroup who completed the self-completion questionnaire. The results in this section are not comparable with either of these chapters due to the different samples used in the analyses.

The prevalence of disability by age and sex is described in Table 5.7. Disability is defined here as difficulty in carrying out activities of daily living (ADL) and instrumental activities of daily living (IADL). ADL are the basic tasks of everyday life that pertain to personal care, 
and six items are included in this scale: difficulty with dressing; walking across a room; bathing or showering; eating, getting in and out of bed; and using the toilet. IADL assesses difficulty in relation to carrying out household activity including: preparing a hot meal; doing household chores; shopping for groceries; making telephone calls; taking medications; and managing money. In the case of both ADL and IADL difficulties, participants were asked to exclude any activities that they expected would last less than three months.

The data revealed a slight increase in the proportion of older people in Ireland who are not disabled ( $87 \%$ in wave 1 to $88 \%$ in wave 2) (see Table 5.7 ). This positive trend can be seen in all age groups under 80 years, however the trend is in the opposite direction in those aged 80 years and older. Systematic differences in the older age category described at the beginning of this chapter may account for some of this difference.

The pattern of disability in wave 2 is broadly similar to wave 1 with more women than men experiencing disability. There is a strong age gradient in disability, only $5 \%$ of the youngest age group in wave 2 experience disability compared to $39 \%$ of those aged 80 years and older (Table 5.7). Although the number of participants aged 90 years and older is small, examination of the data using an expanded age category reveal that $65 \%$ experience some form of ADL or IADL disability (see Appendix Table 5.A3). These findings have particular policy relevance in relation to independent living for older adults and the support required to remain living at home in advanced older age.

Table 5.7: Prevalence of ADL and IADL disability by age and sex

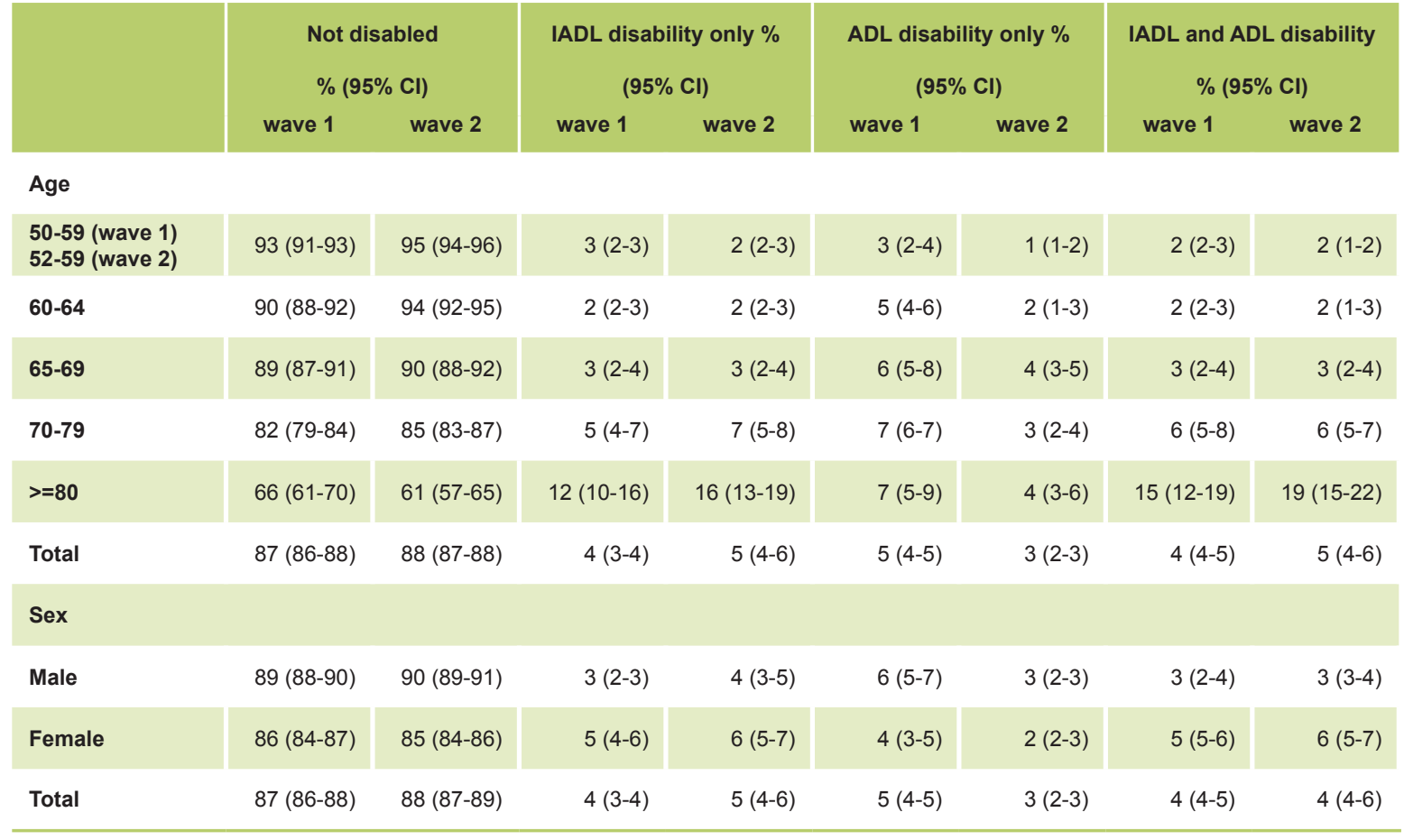


A decrease of two percentage points can be seen between the two waves in ADL disability. In wave 1, participants were asked about difficulty with dressing which included difficulty with putting on socks and shoes. At wave 2 the question was asked about difficulty with dressing only. This change in wording is likely to have impacted on the endorsement of this item in the survey. Future waves will capture both items.

\subsubsection{Utilisation of home help, personal care and meals services}

There was a slight change in the proportions utilising home-based social care services between the two waves. Home help utilisation increased from $3.5 \%$ at wave 1 to $4.4 \%$ at wave 2. In the context of an overall reduction in home help service hours from 11.9 million at the end of 2009 to 11 million hours at the end of 2011, this result appears counter intuitive $(15,16)$. Utilisation is concentrated in those over 80 years with one fifth of this group using home help services at wave 2 (see Table 5.8). It is likely that the increase found is related to the older age profile of community-living participants in this cohort as discussed earlier in this chapter.

Table 5.8: Proportion utilising home help, personal care and meals services by age, sex, health care entitlement status and disability status

\begin{tabular}{|c|c|c|c|c|c|c|}
\hline & \multicolumn{2}{|c|}{ Home help (\%) } & \multicolumn{2}{|c|}{ Personal care attendant (\%) } & \multicolumn{2}{|c|}{ Meals services(\%) } \\
\hline & wave 1 & wave 2 & wave 1 & wave 2 & wave 1 & wave 2 \\
\hline \multicolumn{7}{|l|}{ Age } \\
\hline 50-59 (wave 1) 52-59 (wave 2) & 0.5 & 0.5 & 0.1 & 0.3 & 0.1 & 0.1 \\
\hline $60-64$ & 1.0 & 1.2 & 0.1 & 0.5 & 0.3 & 0.2 \\
\hline $65-69$ & 1.6 & 2.0 & 0.2 & 0.9 & 0.3 & 0.5 \\
\hline $70-79$ & 6.2 & 5.4 & 0.9 & 1.7 & 2.4 & 1.8 \\
\hline$>=80$ & 19.2 & 20.5 & 3.4 & 5.2 & 3.3 & 3.6 \\
\hline Total & 3.5 & 4.4 & 0.6 & 1.3 & 0.9 & 1.0 \\
\hline \multicolumn{7}{|l|}{ Entitlement status } \\
\hline Not covered & 0.1 & 0.6 & 0.0 & 0.0 & 0.0 & 0.0 \\
\hline Private health insurance only & 0.4 & 0.3 & 0.1 & 0.1 & 0.1 & 0.1 \\
\hline Medical card only & 6.7 & 8.3 & 1.2 & 2.5 & 2.0 & 2.0 \\
\hline Dual cover & 5.7 & 5.1 & 0.7 & 1.7 & 1.0 & 0.7 \\
\hline Total & 3.5 & 4.3 & 0.6 & 1.3 & 0.9 & 0.9 \\
\hline \multicolumn{7}{|l|}{ Disability status } \\
\hline Not disabled & 1.8 & 1.9 & 0.2 & 0.2 & 0.5 & 0.4 \\
\hline IADL disability only & 16.6 & 20.5 & 1.1 & 2.4 & 4.6 & 3.3 \\
\hline ADL disability only & 5.2 & 8.2 & 0.8 & 3.2 & 1.4 & 1.1 \\
\hline IADL and ADL disability & 24.0 & 30.1 & 7.9 & 19.8 & 5.3 & 7.9 \\
\hline Total & 3.5 & 4.4 & 0.6 & 1.3 & 0.9 & 1.0 \\
\hline
\end{tabular}


In wave 1 IADL difficulty was found to be a strong driver of home help services for older adults (17). While this continues to be the case in wave 2 it is important to point out that $1.9 \%$ of the non-disabled population (i.e., those that self-report no ADL or IADL difficulty) are availing of home help services (see Table 5.8). While this constitutes a small percentage the numbers are large relative to the total number utilising home help services.

Intensity of home help service utilisation was examined in those that utilised the service in the previous month. The majority $(70 \%)$ received one hour of help on the days when they received home help. The total number of hours of service utilised in the previous month was between one and eight hours for $37 \%$ of home help service users and was greater than 32 hours for just $12 \%$ of service users. These results paint a picture of a home help service which provides a low level of care intensity.

The proportion of the population using personal care services increased from $0.6 \%$ to $1.3 \%$ between the two waves. This result is likely to reflect the increase in the provision of home care packages by the Health Service Executive (HSE). These packages of care provide an enhanced level of support above the normal levels of home help and personal care available from mainstream community services. The number of older people in receipt of home care packages increased from 12,000 at the end of 2009 to 15,000 at the end of 2011(15, 16). The TILDA results reveal that utilisation of personal care services increased from $7.9 \%$ of those with a combined ADL and IADL disability at wave 1 to $19.8 \%$ at wave 2. Although the proportion utilising the service overall is low, the increased utilisation of personal care services by those with higher levels of ADL/IADL disability is consistent with Government policy to provide an enhanced level of home support for older people. Home care packages are allocated on the basis of assessed need and there is no requirement to have a medical card (18). Wave two data indicate that personal care utilisation increased between wave 1 and wave 2 in those with a medical card only (from $1.2 \%$ to $2.5 \%$ ) and in those with dual insurance cover $(0.7 \%$ to $1.7 \%)$. There was no change in the proportions of older people reporting use of meals services between the two waves.

\subsection{Medication use and polypharmacy}

Medication use in the older population is particularly important given the high levels of multi-morbidity and increased predisposition to side effects which comes with age. Polypharmacy, defined as the regular use of 5 or more medicines, is common among the older population and is associated with lower health and increased morbidity. Polypharmacy is often necessary for management of difficult illnesses or conditions, which require complex care. However, inappropriate or over-prescribing is also a factor, exposing 
patients to risks of drug interactions and adverse drug reactions.

Changes in medication use in participants who took part in wave 1 and wave 2 is examined in Table 5.9. Total prevalence of medication use in wave 1 is displayed in the first column and total prevalence at wave 2 in the last row. As expected medication use has increased as the cohort is two years older. At wave $121 \%$ of participants reported using 5 or more medications regularly, and this increased to $26 \%$ in wave 2 . Correspondingly, the number of participants reporting no regular medication use dropped from $28 \%$ in wave 1 to $24 \%$ in wave 2.

Changing patterns of medication use is also examined in Table 5.9. For those who have increased their medication use in wave 2 the majority have just moved up one group. For example of those who were not regularly taking medications at wave 1, the majority $69 \%$ were still not taking any regular medications at wave 2 while $24 \%$ had progressed to the 1-2 medications group. The same holds true for the other groups. The numbers who have significantly increased their medication use is relatively low; $2 \%$ of those using no medication and $7 \%$ of those using $1-2$ medications in wave 1 are now in the polypharmacy category ( $5+$ medications). While the prevalence of polypharmacy has increased overall, $15 \%$ of those who were taking 5 or more medications regularly in wave 1 have reduced their medication use in wave 2.

Table 5.9: Changes in medication use between wave 1 and wave 2

\begin{tabular}{|c|c|c|c|c|c|c|c|}
\hline & $\begin{array}{c}\text { Total } \\
\text { (wave 1)\% }\end{array}$ & $\begin{array}{c}0 \\
\text { Medications } \\
\text { (wave 2) } \\
\%\end{array}$ & $\begin{array}{c}1-2 \\
\text { Medications } \\
\text { (wave 2) } \\
\%\end{array}$ & $\begin{array}{c}\text { 3-4 } \\
\text { Medications } \\
\text { (wave 2) } \\
\%\end{array}$ & $\begin{array}{c}5+ \\
\text { Medications } \\
\text { (wave 2) } \\
\%\end{array}$ & Total & $\begin{array}{l}\text { Number } \\
\text { in sample }\end{array}$ \\
\hline 1-2 Medications (wave 1) & 29 & 8 & 62 & 23 & 7 & 100 & 2215 \\
\hline 3-4 Medications (wave 1) & 21 & 2 & 14 & 52 & 33 & 100 & 1377 \\
\hline 5+ Meds (wave 1) & 21 & 1 & 2 & 12 & 85 & 100 & 1216 \\
\hline
\end{tabular}

Figure 5.1 breaks down the wave 2 numbers by 5-year age groups, revealing a broadly linear increase with age in the mean number of medications used until age 80 , after which it levels off at age $85+$.

Further information on medication use in wave 2 by both age and sex is available in 
Appendix Figure 5.B1. Men report less medication use than women, particularly in the age range 52-64 years. This trend decreases over age, with both sexes reporting nearly the same medication use after age 75. Larger proportions of the older age groups use more medications, with nearly $50 \%$ of those aged 75 years and over reporting polypharmacy. Reporting higher medication use is also strongly associated with lower education, lower self-rated health and decreased physical activity (see Appendix Tables 5.A4-5.A6).

Figure 5.1: Mean number of medications (excluding food supplements) used in wave 2 by age

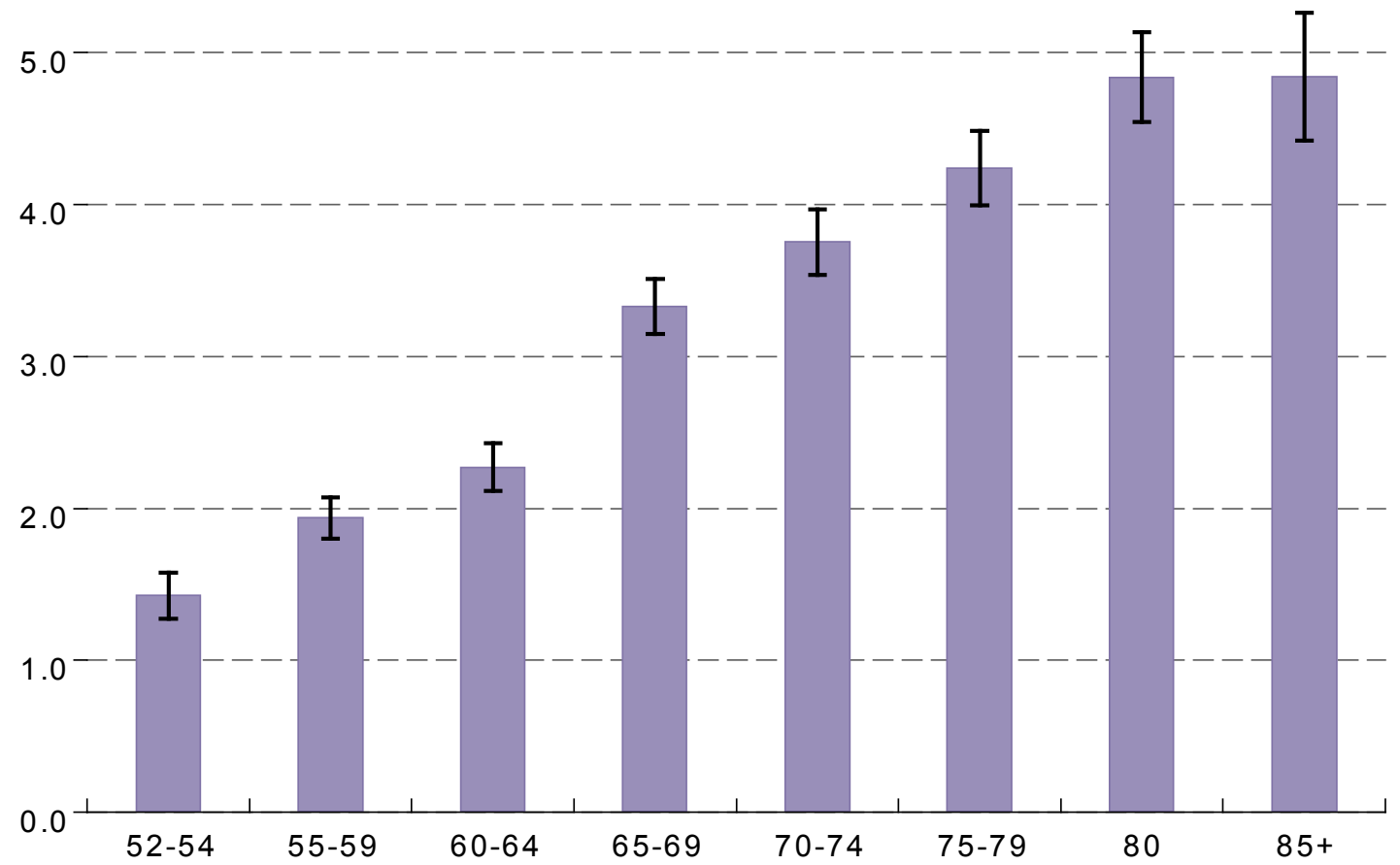

Note. $\mathrm{N}=7282$; Missing obs $=0$; Error bars correspond to $95 \%$ confidence intervals

The five most common medications has remained similar across both waves with a slight alteration in order (see Table 5.10). Medication classes (ATC level 2) and food supplements have remained the same. Food supplements were defined according to the European Directive 2002/46/EC as any substance with a nutritional effect which is taken to supplement the normal diet. The five most frequently reported food supplements account for a similar proportion of the total supplements used ( $79 \%$ in wave 1 and $78 \%$ in wave 2). 
Table 5.10: Top five most commonly used medications, medication classes and food supplements

\begin{tabular}{|c|c|c|c|c|c|c|}
\hline & \multicolumn{2}{|c|}{$\begin{array}{l}\text { Individual medications } \\
\text { (International Non- } \\
\text { proprietary name) }\end{array}$} & \multicolumn{2}{|c|}{$\begin{array}{l}\text { Medication classes } \\
\text { (ATC Level 2) }\end{array}$} & \multicolumn{2}{|c|}{ Food supplements } \\
\hline & wave 1 & wave 2 & wave 1 & wave 2 & wave 1 & wave 2 \\
\hline 1 & Aspirin & Aspirin & $\begin{array}{l}\text { Lipid modifying } \\
\text { agents }(\mathrm{C} 10)\end{array}$ & $\begin{array}{l}\text { Lipid modifying } \\
\text { agents }(C 10)\end{array}$ & $\begin{array}{l}\text { Calcium } \\
\text { carbonate, } \\
\text { combinations }\end{array}$ & $\begin{array}{c}\text { Calcium } \\
\text { carbonate, } \\
\text { combinations }\end{array}$ \\
\hline 2 & Atorvastatin & Atorvastatin & $\begin{array}{l}\text { Agents acting } \\
\text { on the rennin- } \\
\text { angiotensin } \\
\text { system (C09) }\end{array}$ & $\begin{array}{l}\text { Agents acting } \\
\text { on the rennin- } \\
\text { angiotensin } \\
\text { system (C09) }\end{array}$ & $\begin{array}{l}\text { Omega-3- } \\
\text { triglycerides }\end{array}$ & $\begin{array}{l}\text { Omega-3- } \\
\text { triglycerides }\end{array}$ \\
\hline 3 & Levothyroxine & Rosuvastatin & $\begin{array}{l}\text { Anti-thrombotic } \\
\text { drugs (B01) }\end{array}$ & $\begin{array}{l}\text { Anti-thrombotic } \\
\text { drugs (B01) }\end{array}$ & Glucosamine & Glucosamine \\
\hline 4 & Bisoprolol & Bisoprolol & $\begin{array}{l}\text { Drugs for acid } \\
\text { related disorders } \\
\text { (A02) }\end{array}$ & $\begin{array}{l}\text { Drugs for acid } \\
\text { related disorders } \\
\text { (A02) }\end{array}$ & $\begin{array}{l}\text { Vitamin B, } \\
\text { combinations }\end{array}$ & $\begin{array}{l}\text { Vitamin B, } \\
\text { combinations }\end{array}$ \\
\hline 5 & Rosuvastatin & Levothyroxine & $\begin{array}{l}\text { Beta blocking } \\
\text { agents (C07) }\end{array}$ & $\begin{array}{l}\text { Beta blocking } \\
\text { agents (C07) }\end{array}$ & Multivitamins & Multivitamins \\
\hline
\end{tabular}

\subsubsection{Use of generics: the case of Atorvastatin}

Statins are one of the most commonly prescribed medicines in the older population and generate the largest expenditure (19). They are used to help lower low density lipoprotein cholesterol (LDL-C) in the prevention and treatment of cardiovascular disease. When looking at generic drug use we can use four broad categories of drug type: pure generic which is sold using the active pharmaceutical name (e.g. Atorvastatin); branded generic which is sold using a marketing name (e.g. Torvacol); proprietary brand with a generic equivalent (e.g. Lipitor); proprietary brand without a generic equivalent (i.e. a drug still under patent protection). Generic medicines are usually cheaper than the proprietary brand, and thus they provide the same level of medication intervention at a lower cost. Of all the medications used by the older population only $20 \%$ were generics at wave 1 with a slight increase to $22 \%$ at wave 2 . There is a more dramatic increase in generic use for the statin group of medications, with the proportion of generics increasing from $8.5 \%$ at wave 1 to $23.5 \%$ at wave 2 due to the expiry of patents. Between the first and second waves of TILDA data collection the most prevalent statin, Atorvastatin, came off patent which allowed the entry of generic competitor medicines by wave 2 . This provides an interesting insight into the initial effect of a drug patent expiry on medication use. 
Table 5.11: Generic share of Atorvastatin at wave 2 by wave 1 use and medical card status

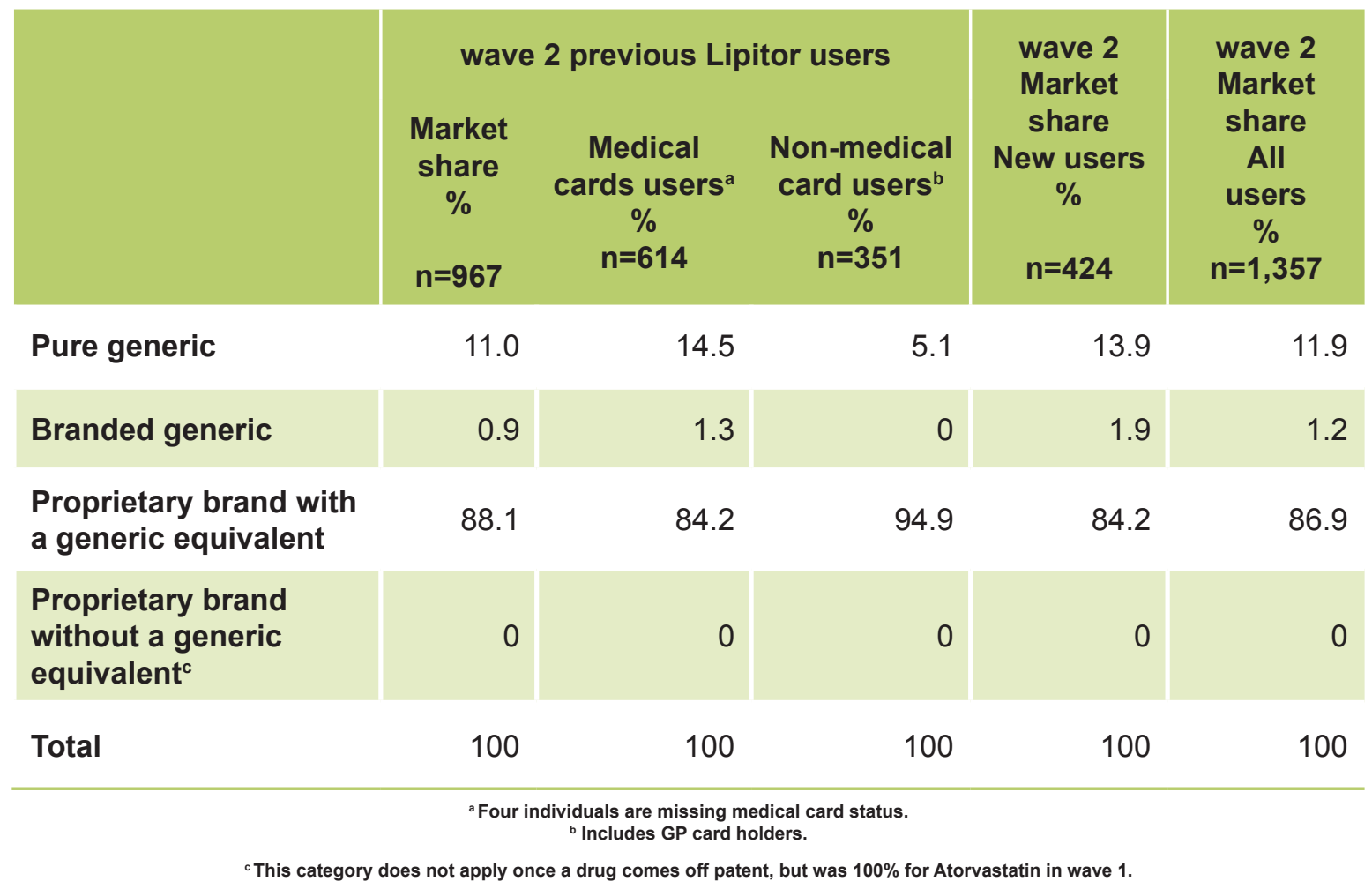

Atorvastatin accounts for $57 \%$ of all statin use in wave 1 and $56 \%$ in wave 2 , in addition to being the second most used medication in both waves. Table 5.11 shows the effect of the patent expiry on Lipitor (the branded version of Atorvastatin, which did not have a generic equivalent in wave 1) which occurred during the inter-wave period. While some individuals who were using Lipitor in wave 1 have moved to generic versions (11\%) the majority of patients have remained on the proprietary brand $(88.1 \%)$. This is most evident in those who do not have a medical card, with $94.9 \%$ remaining on the proprietary brand. This contrasts sharply with previous Lipitor users in England where only $31 \%$ of patients have initially remained on the proprietary brand (20). Evidence from TILDA wave 2 suggests that private patients (i.e., those without a medical card) in this case are more resistant to generic substitution, with only $5 \%$ switching. In general there is a higher use of generics in wave 2 among those who were not previously using Lipitor.

Two recent measures should have a considerable impact on future prescribing patterns in Ireland. Firstly, the HSE has commenced a medicines management programme to encourage cost effective prescribing. As part of this programme, Simvastatin has been designated the preferred statin for initial treatment. Secondly, the Health (Pricing and Supply of Medical Goods) Act 2013 has introduced the legislation to implement generic substitution at the pharmacy level and a system of drug group reference pricing for reimbursement (21). Generic substitution for Atorvastatin was introduced in August 2013 
and drug group reference pricing was introduced in November 2013. The effects of both of these measures will be visible in future waves of TILDA.

\subsection{Health service utilisation at the end of life}

In this section the health service use of those who died since wave 1 of the TILDA survey is described. Patterns of service use among the deceased are compared to participants who were still alive at wave 2 . At the end of wave 2 data collection, there were a total of 205 deaths among participants. Data from 'end of life' interviews were available from 155 individuals acting as a proxy participant for deceased participants. Most proxy participants were relatives of the deceased participant including the son or daughter (including inlaw) $(43.8 \%)$, or the spouse or partner of the deceased $(30.9 \%)$. Other proxy participants included siblings $(7.7 \%)$, other relatives $(8.4 \%)$ and other non-relatives $(8.4 \%)$. The end of life interview included questions on use of health services in the 12 months before the TILDA participant died, his/her physical and behavioural health, cognitive function and financial circumstances.

Of those who died, $55 \%$ were men and the average age of the deceased was 75.5 years (median 77 years). Most of those who died were married (40.6\%) or widowed $(40.0 \%)$ and $19.3 \%$ were single separated or divorced at the time of death. Almost half of the deceased died in hospital (48.4\%), approximately one quarter died at home $(24.5 \%)$ and $9.7 \%$ died in a nursing home or residential care setting. Approximately $13 \%$ died in a hospice and $4.5 \%$ died at other locations.

The most common causes of death reported by proxy participants were cancer (37.5\%), followed by cardiovascular-related causes $(28.9 \%)$, other causes such as digestive disorders, infectious disease, accidents $(21.1 \%)$ and respiratory causes $(12.5 \%)$. There were no differences between men and women in terms of the main causes of death. There was some evidence that more people died from respiratory diseases in the older age groups (3.4\% of those aged $50-64$ compared to $13.3 \%$ of those aged $65-74$ and $15.2 \%$ of those aged $\geq 75$ years) but the association between age and cause of death was not statistically significant. In terms of physical health prior to death, $41.3 \%$ of proxy participants described the deceased as mostly active and disability free but declining during the last few months before death. In total, $25.8 \%$ of proxy participants reported that the deceased had been ill for one year or more before he/she died. 
Table 5.12: Proportion of deceased and survivors utilising primary and secondary care services at wave 2

\begin{tabular}{|l|cr|cr|}
\hline & \multicolumn{2}{|c|}{ Deceased } & \multicolumn{2}{c|}{ wave 2 Survivors } \\
\hline GP visit & $\%$ & $(95 \% \mathbf{C l})$ & $\%$ & $(95 \% \mathrm{CI})$ \\
\hline Outpatient & 87.1 & $(81.8-92.4)$ & 89.6 & $(88.7-90.2)$ \\
\hline Emergency Department & 44.5 & $(36.7-50.5)$ & 45.0 & $(43.4-46.2)$ \\
\hline Hospital admission & 59.4 & $(51.5-67.2)$ & 14.6 & $(15.3-17.2)$ \\
\hline
\end{tabular}

Table 5.12 shows the pattern of utilisation of different types of health services in the 12 months before death. Health service use in the deceased group is compared to those survivors who participated in wave 2 . The percentages are for those who used the services at least once in the previous year. The majority of those who died had attended the GP in the 12 months before death according to the proxy respondent. In contrast, less than half had attended an out-patient clinic or the ED. A higher proportion of people who died had attended an ED or had a hospital admission in the 12 months preceding death compared to participants in wave 2 .

The end-of-life interviews also allow for an examination of the proportions of deceased individuals who received three types of state-provided home care services in the last 12 months of life: home help, meals services and the services provided by personal care attendants. Approximately $25 \%$ of deceased individuals received home help in the year preceding death, $11 \%$ had the help of a state-provided personal care attendant and $7.7 \%$ received meals services (Table 5.13). The majority of proxy respondents reported that the deceased received none of the state services outlined above (67.1\%). A higher proportion of those who died were utilising state-provided home services in the preceding 12 months, compared to survivors at wave 2 .

Table 5.13: Proportion of deceased and survivors utilising home help, personal care and meals services at wave 2

\begin{tabular}{l|cr|cr|} 
& \multicolumn{2}{|c|}{ Deceased } & \multicolumn{2}{c|}{ wave 2 Survivors } \\
& $\%$ & $(95 \% \mathrm{CI})$ & $\%$ & $(95 \% \mathrm{CI})$ \\
\hline Home help & 25.2 & $(18.3-32.1)$ & 4.4 & $(3.5-4.6)$ \\
\hline Personal care attendant & 11.0 & $(6.0-15.9)$ & 1.3 & $(0.9-1.5)$ \\
\hline Meals services & 7.7 & $(3.5-12.0)$ & 1.0 & $(0.7-1.2)$ \\
\hline
\end{tabular}




\subsection{Conclusion}

Maintaining and improving population health and well-being is a key goal of Irish health policy. Current Government policy aims to manage and prevent illness at the earliest stage possible (22). It is encouraging to find that the uptake of primary prevention and screening programmes has increased in the older population across the first two waves of TILDA, although there is some evidence that those without a medical card or GP visit card may face access barriers with regard to flu vaccination. The data identify a reduction in the proportion of older people over 70 years with full access to primary and secondary care services at a time in their life when their need for health and social care is increasing, especially in the period at the end of life. Current health service reforms are aimed at reducing the reliance on secondary care services and providing integrated primary and community-based care where possible. The findings in this chapter reveal a continued and increasing utilisation of primary GP services and secondary care services but minimal change in the community health and social care sector.

\section{References}

1. Government of Ireland. Health (Alteration of Criteria for Eligibility) Act 2013. In: Department of Health, editor. Dublin: Government Publications, 2013.

2. Reilly J. Opening Statement by the Minister for Health, Dr. James Reilly TD, at the Joint Oireachtas Committee on Health and Children, 2013.

3. Health Service Executive. Medical Card/GP Visit Card National Assessment Guidelines for People aged 70 years and over. Dublin: Health Service Executive, 2013.

4. Department of Health. Health in Ireland: Key Trends 2012. Dublin: Department of Health, 2012.

5. Department of Health and Children. Health in Ireland Key Trends 2010. Dublin: Department of Health and Children, 2010.

6. Health Insurance Authority. The Health Insurance Authority Annual Report and Accounts 2012. Dublin: Health Insurance Authority, 2013.

7. Central Statistics Office. Survey on Income and Living Conditions (SILC) Thematic Report on the Elderly. Dublin: Central Statistics Office, 2013.

8. National Cancer Registry. Cancer in Ireland 2013: Annual Report of the National Cancer Registry. Cork: National Cancer Registry Ireland, 2013.

9. Department of Health and Children. A Strategy for Cancer Control in Ireland. Dublin: 
Department of Health and Children, 2006.

10. Health Service Executive. Chapter 11: Influenza. 2013. In: Immunisation guidelines for Ireland (Internet). Dublin: HSE, ICGP, HPSC. Available from: http://www.immunisation. ie/en/Downloads/NIACGuidelines/PDFFile_17361_en.pdf.

11. Pharmhealth integrative pharmacy. Pharmacy-services winter flu vaccination service 2013 (cited 2013 6/12/13). Available from: http://www.pharmhealth.ie/Pharmacyservices/winter-flu-vaccination-service.html.

12. Travel Health. Flu Vaccine Dublin,2013 (cited 2013 6/12/13). Available from: http://www. travelhealth.ie/FluVaccine/

13. The Competition Authority. Competiton in Professional Services: General Medical Practitioners. Dublin: The Competiton Authority, 2010.

14. Chiropody service. Advertisment for fees including Co-payment for chiropody card holders 2013 (cited 2013 9/12/13). Available from: http://www.treesroad.com/fees.htm; http://www.spectrumhealth.ie/our-fees/.

15. Department of Health and Children. Annual Output Statement 2010 for Health Group Votes. Dublin: Department of Health and Children, 2010.

16. Department of Health. Annual Output Statement for Health Group Votes 2012-38 and 39. Dublin: Department of Health, 2012.

17. Murphy C. Unpublished PhD thesis: The Distribution and Determinants of Home-Based Social Care Utilisation in Older People: Irish and Comparative Perspectives: Dublin, Trinity College; 2012.

18. Health Service Executive. National Guidelines and Procedures for Standardised Implementation of the Home Care Package Scheme. Dublin: Health Service Executive, 2010.

19. Primary Care Reimbursement Service. Statistical analysis of claims and payments 2011. Dublin: Health Service Executive, 2012.

20. Leonard S.A. Wilson T.L. Hamerslaget, L. Patterns of Generic and Proprietary Prescribing of Statins Over Time in England. Value in Health. 2013;16(7):A328.

21. Government of Ireland. Health (Pricing and Supply of Medical Goods) Act 2013. Government of Ireland; 2013.

22. Layte R, Sexton E, Savva G. Quality of Life in Older Age: Evidence from an Irish Cohort Study. Journal of the American Geriatrics Society. 2013;61:S299-S305. 


\section{Appendix 5A: Tables on Health and Social Care Utilisation}

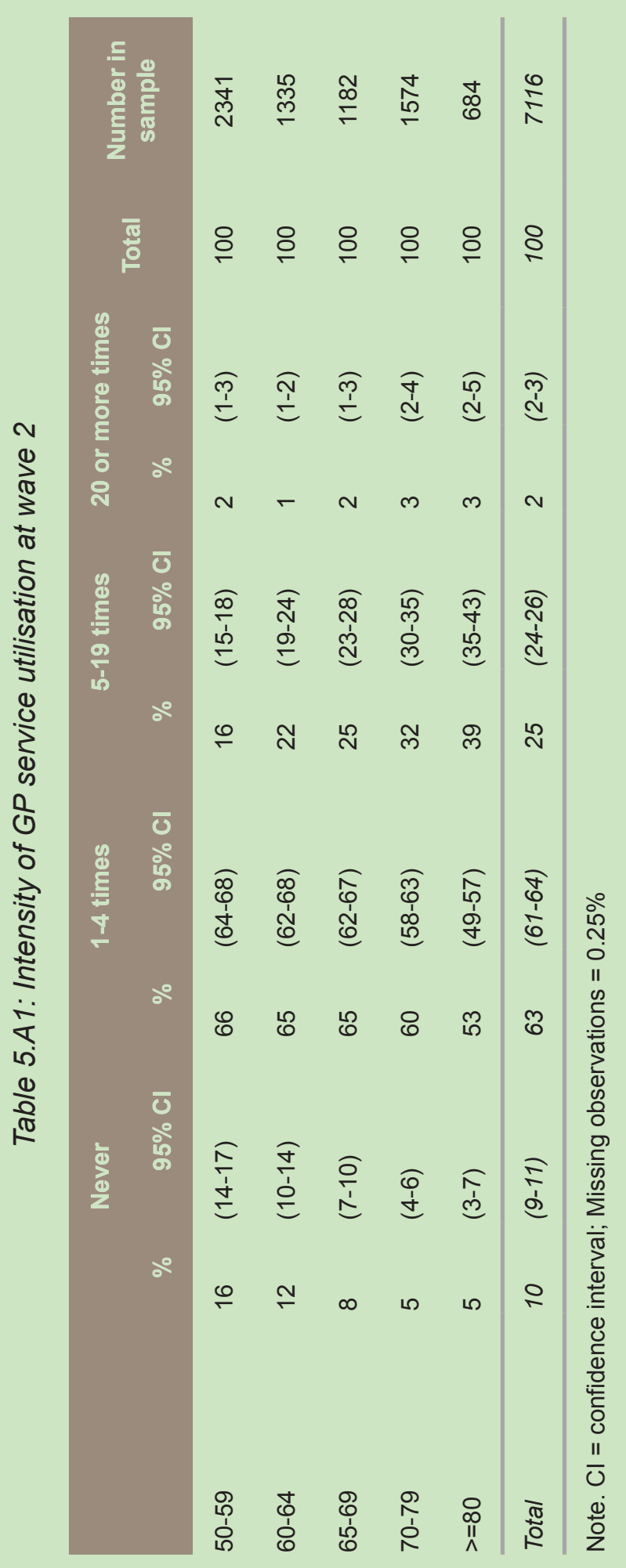




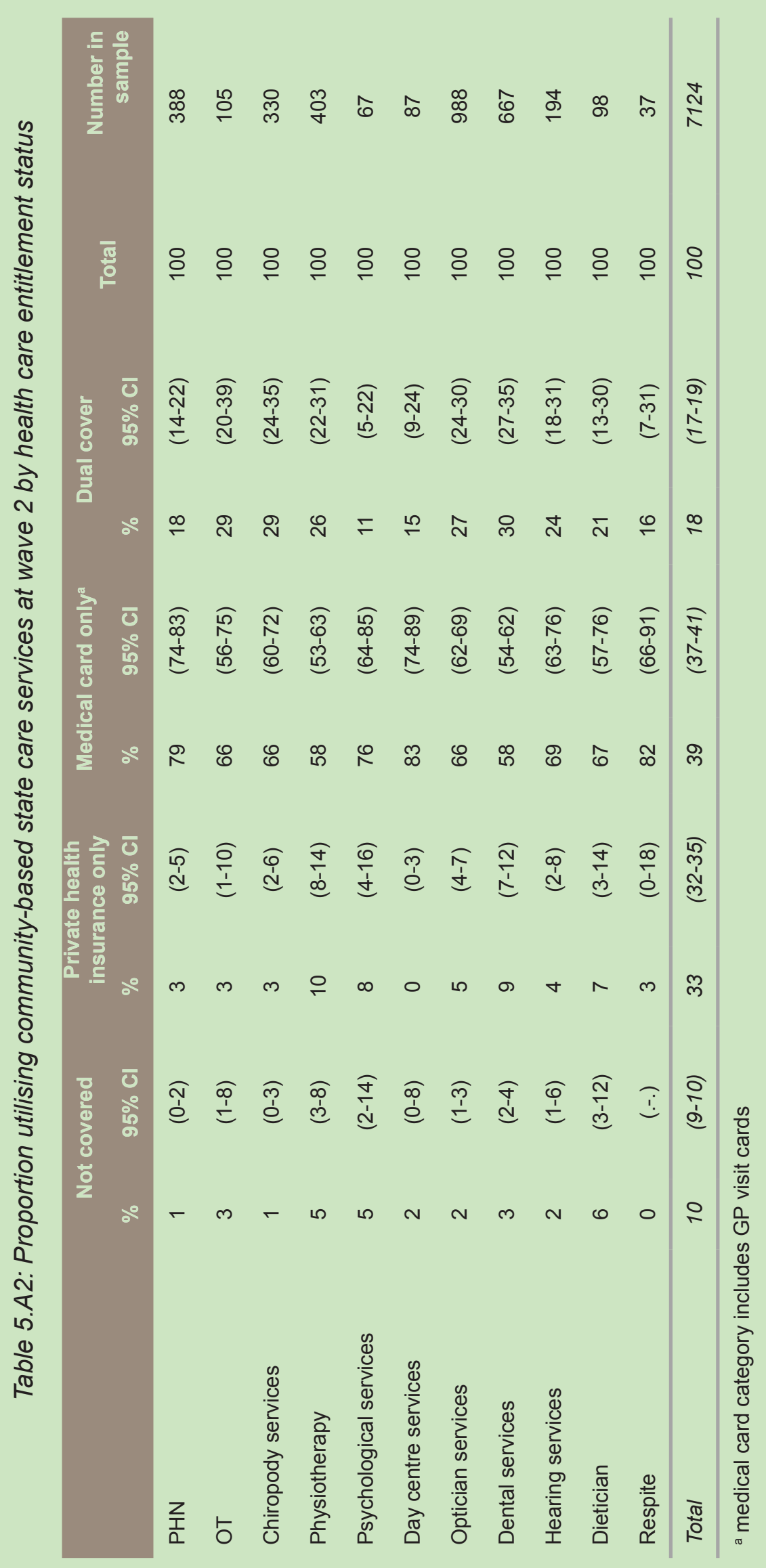




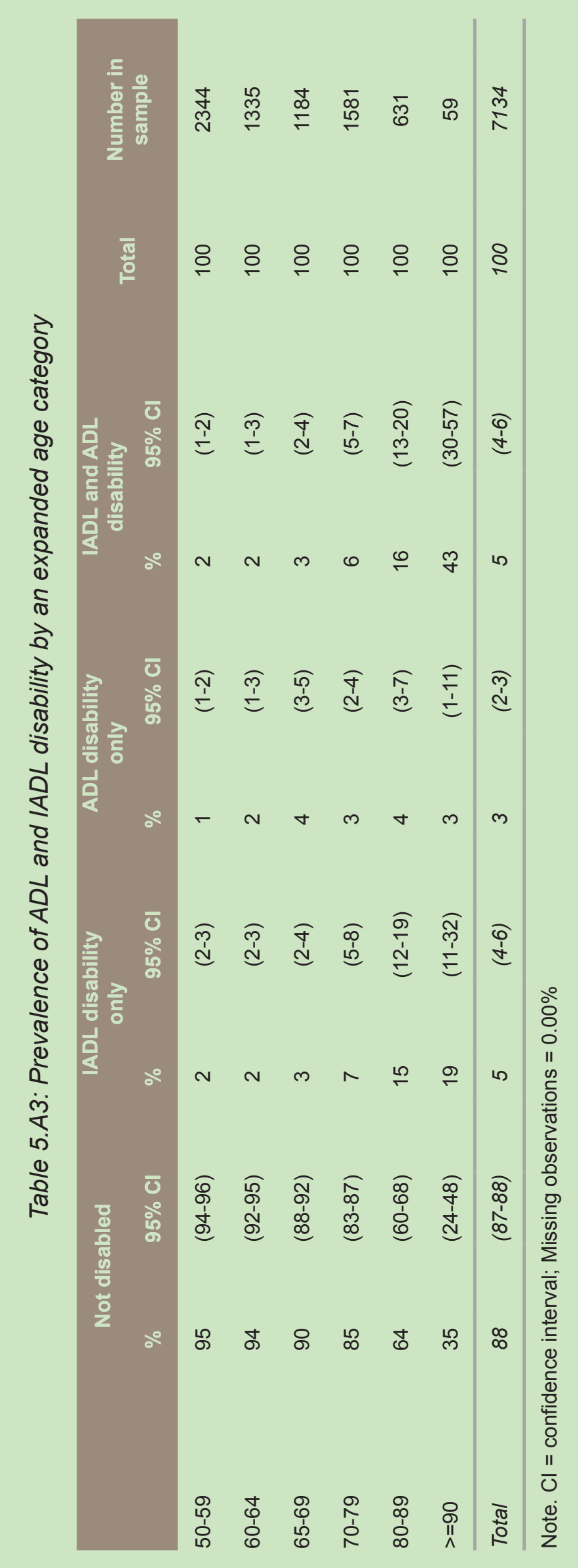



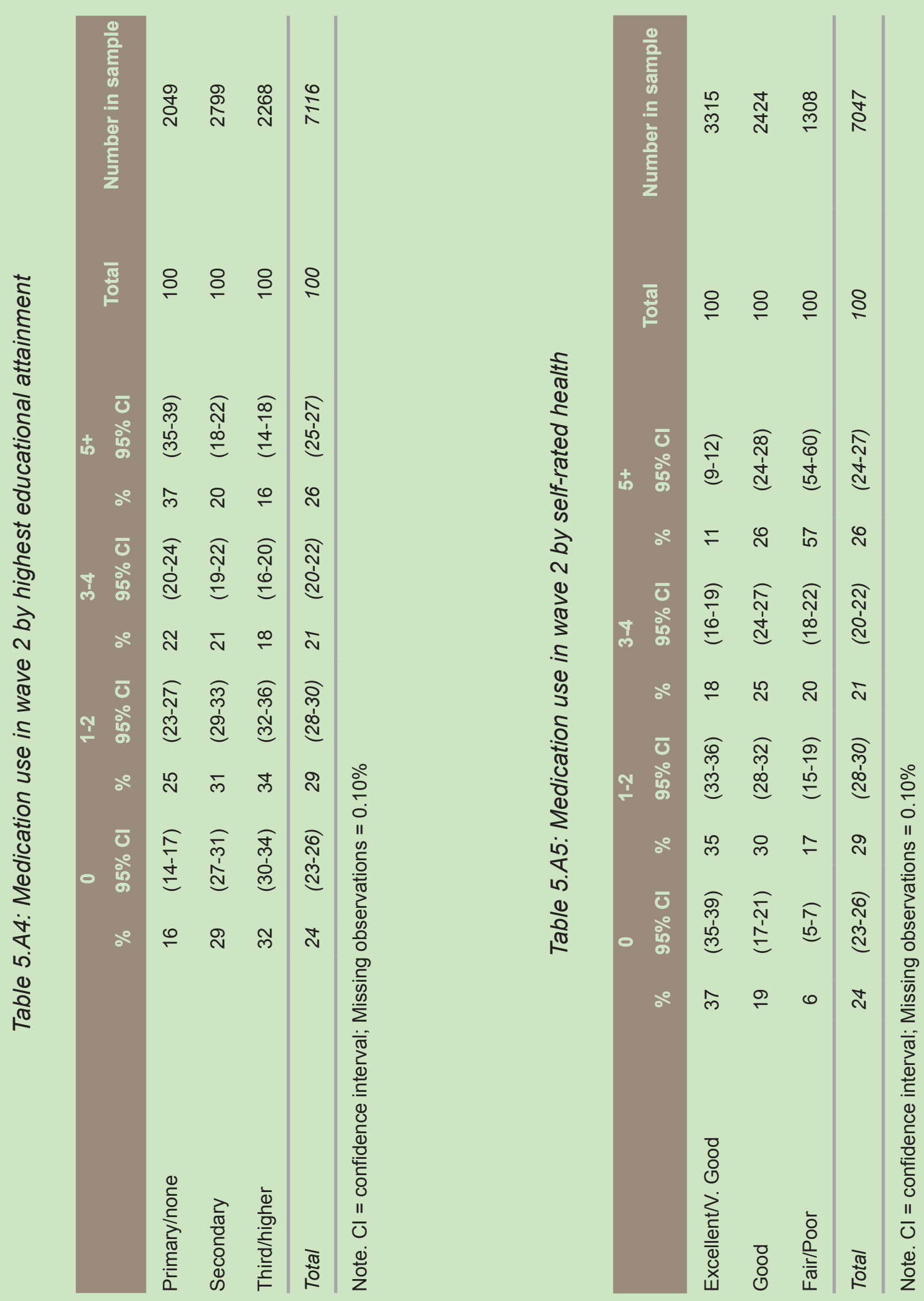


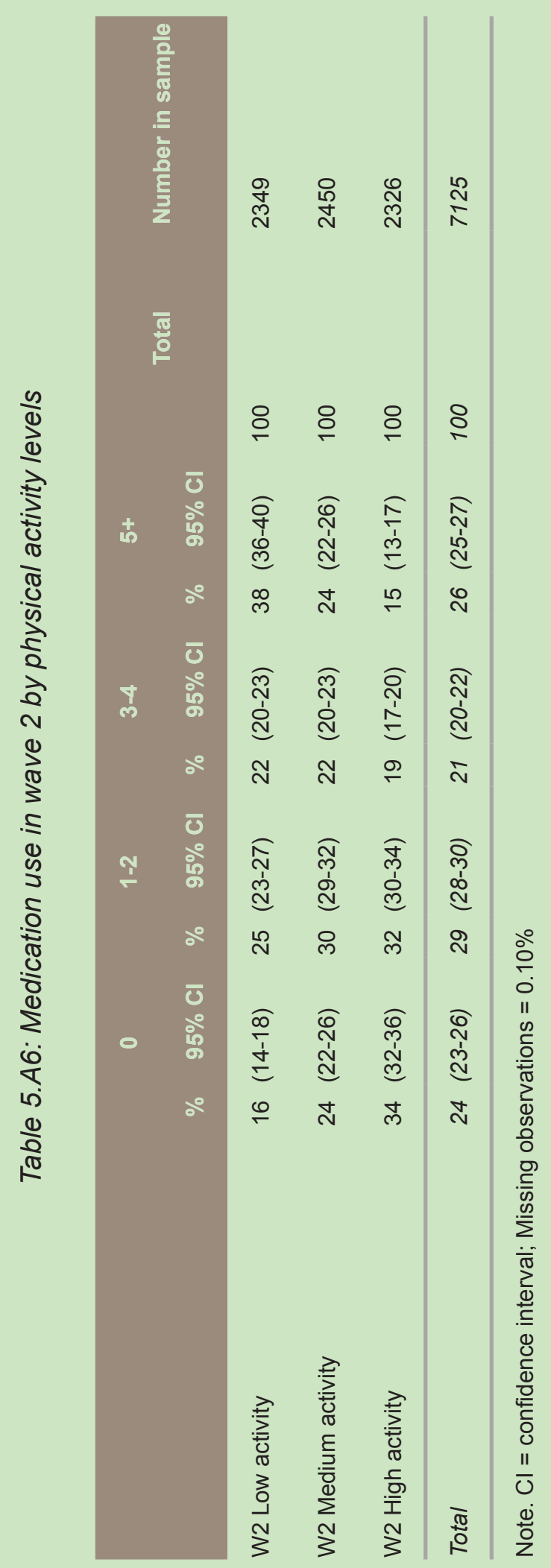




\section{Appendix 5B: Figures on Health and Social Care Utilisation}

Figure 5.B1: Medication use in wave 2 by age and sex

\begin{tabular}{l|l|l|l|}
0 & $1-2$ & $3-4$ & $5+$
\end{tabular}
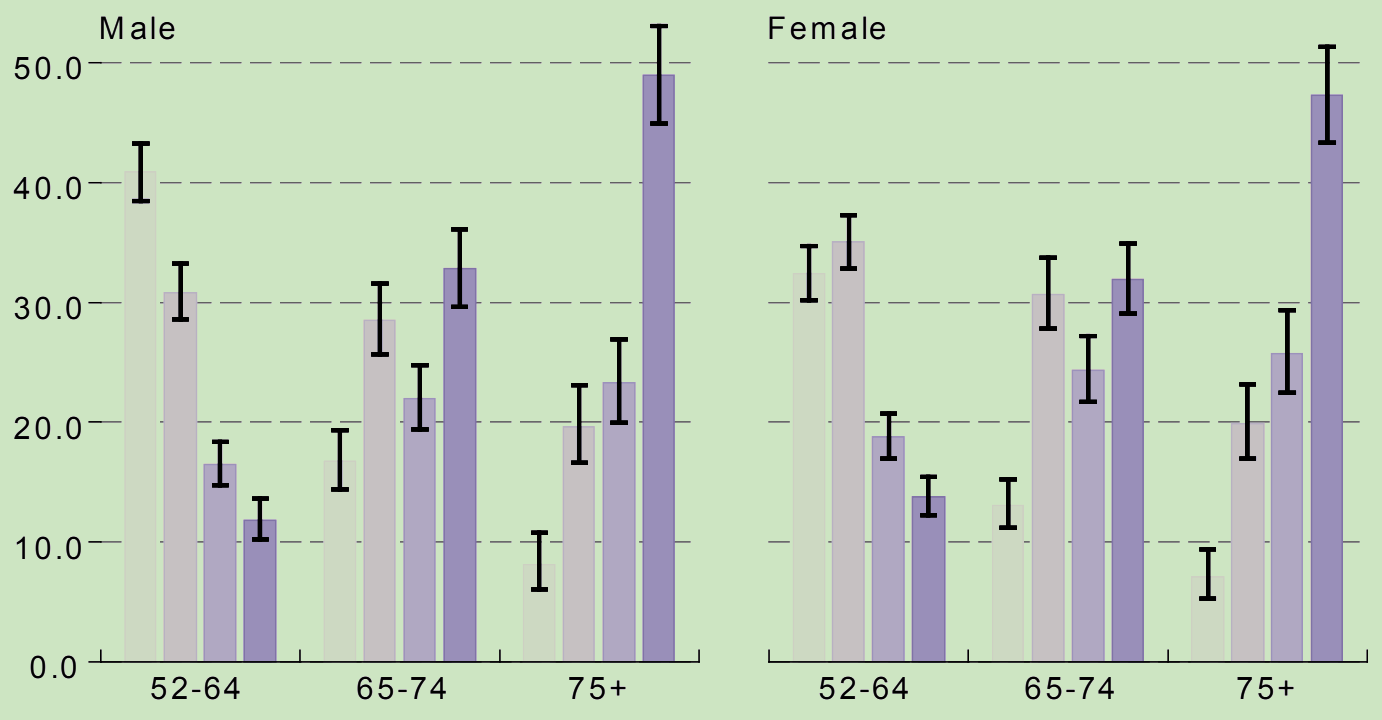

Note. $\mathrm{N}=7127$; Missing obs $=7$; Error bars correspond to $95 \%$ confidence intervals 


\section{What Factors are Associated with Change in Older People's Quality of Life?}

Cathal McCrory, Siobhan Leahy and Christine McGarrigle

\section{Contents}

Key Findings 154

6.1 Introduction 154

6.2 Measuring quality of life. 156

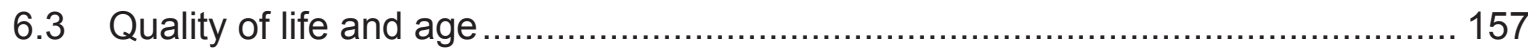

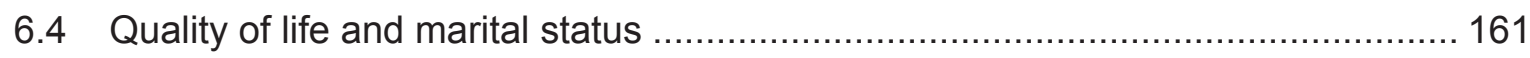

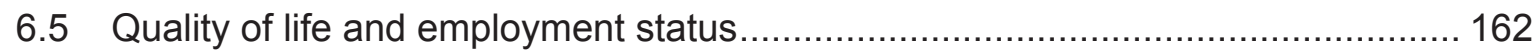

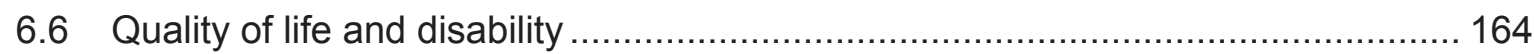

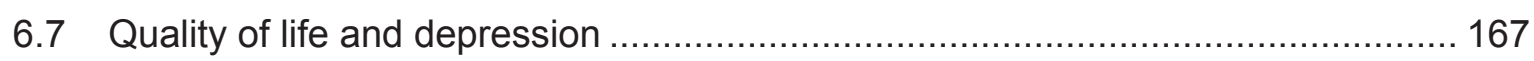

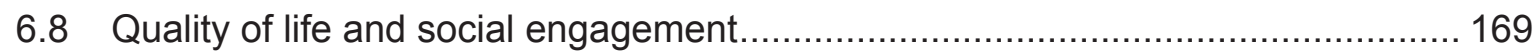

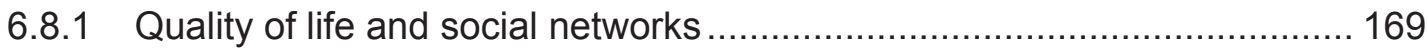

6.8.2 Quality of life and social participation ............................................ 171

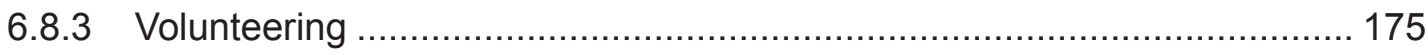

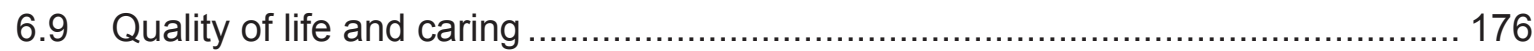

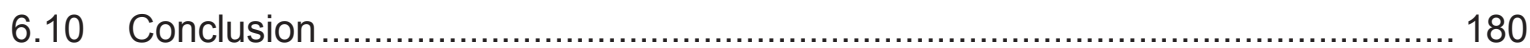

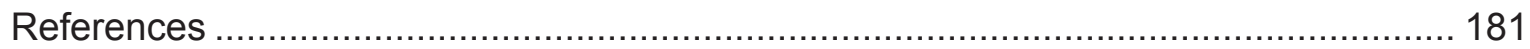

Appendix 6: Questions on caring for parents and children in TILDA ............................ 185 


\section{What Factors Are Associated with Change in Older People's Quality of Life?}

\section{Key Findings}

- Self-reported quality of life peaks around 65-67 years, and declines rapidly after the age of 80 .

- Between wave 1 and wave 2 of TILDA, overall quality of life declined for all age groups, but the decline was greatest for those aged $75+$ years.

- Those who were married at both waves have a higher quality of life than those who remain never married, divorced/separated, or widowed between waves.

- Those who reported that they no longer suffer from a disability in relation to activities of daily living (e.g., dressing, eating, bathing) have a significantly higher quality of life than those reporting a disability in both wave 1 and wave 2 .

- TILDA participants whose depressive symptoms had remitted between wave 1 and wave 2 experienced a significant improvement in quality of life.

- Based on their social networks (i.e., marital status, close ties with family and friends and membership of voluntary and religious organisations), $27 \%$ of men and $22 \%$ of women in TILDA are classed as 'most socially integrated', and these proportions have only changed slightly between wave 1 and wave 2 of the study.

- Participants with strong social networks, who engage in various types of active social relationships and who volunteer regularly have a higher quality of life than those who are less socially active.

- Overall, 35\% of TILDA participants look after their grandchildren for at least one hour a week, and those who care for their grandchildren have a higher quality of life than those who do not.

\subsection{Introduction}

The demographic shift in the number of people living into late life brings with it a number of challenges; not least of which is how to ensure that gains in longevity are matched by 
gains in quality of life so that the ageing population can continue to participate in society and enjoy life into old age. In fact, the promotion of healthy ageing now features as a major component of public health strategy in most developed countries $(1,2)$. This has contributed to an increase in the volume of research that is concerned with investigating older people's quality of life, the factors that contribute to it, and the potential ways in which it can be enhanced (3). Monitoring trends in quality of life is important from a public policy perspective because it allows one to examine how the quality of life of society is changing over time coincident with demographic transitions, technological progression, changes in the social environment, and emerging social policies. As summarised by Netuvelli and Blane (3), interest in quality of life during later life stems from the belief that the older population are more vulnerable in this regard because of: 1) declining physical and mental health status, 2) exit from the labour market, 3 ) changes in family circumstances (e.g. migration of children), and 4) isolation due to death of contemporaries or the inability to participate as an active member of the community.

Despite this burgeoning interest in quality of life research, consensus around a definition for quality of life remains elusive and there exist many different measures for assessing it (4). For one thing, quality of life is often confused or considered synonymous with successful ageing. Although there is substantial conceptual overlap between the terms, and reciprocity in the sense that quality of life can be viewed as a cause or a consequence of successful ageing, there are also some important differences. For example, many definitions of successful ageing would view the presence of disease as antithetical to healthy ageing whereas quality of life research tends to be less prescriptive in this regard. A recent meta-analysis of 29 studies (5) found that estimates regarding the proportion of successful agers ranged from $0.4 \%$ to $95 \%$ because of widely varying operational definitions of what constitutes success in ageing terms. Averaged across studies, approximately one third of older people were characterised as ageing successfully. However, these findings conflict strongly with the results emerging from studies in the UK $(6,7)$ and Ireland (8) which show that older people continue to enjoy a high quality of life well into their later years despite increasing levels of morbidity.

Researchers have also debated whether quality of life should be measured using objective or subjective measures $(9,10)$, and these disputes largely reflect different disciplinary interpretations of what quality of life comprises and how it should be assessed. Objective assessments typically involve economic (e.g. standard of living), social (e.g. social networks) or health-related (e.g. healthy life years) indicators, whereas subjective measures tend to involve self-appraisal of social, emotional and psychological well-being, such as life satisfaction and happiness. This latter approach takes the view that a good 
life is one that is experienced as such and has tended to predominate in social science research in recent years (3). TILDA uses such a measure to index quality of life among the older population.

This chapter uses TILDA data to describe variations in quality of life across the age spectrum before going on to explore the extent of change in older people's quality of life between wave 1 and wave 2 by important demographic characteristics such as age and sex. In these sections we also consider whether quality of life is affected by various changes in older people's lives, such as changes in marital status, employment status, disability, depression, social engagement and caring.

\subsection{Measuring quality of life}

Quality of life in TILDA is indexed using the CASP-19 measure, which is a brief (19-item) self-report inventory that is designed to measure quality of life independent of the factors that might influence it such as health, social supports and material circumstances (11). Participants indicate the extent to which they agree with each statement on a four-point frequency scale ranging from 'Often' through 'Never' and responses are scored such that the most positive responses are given a score of 3 and the most negative responses are given a score of 0 . The instrument produces scores for each of four subscales: control, autonomy, self-realisation, and pleasure. These subscales are considered important dimensions of quality of life among older people. A total quality of life score is calculated by summing scores across the four subscales with a higher score indicating a higher quality of life (range 0-57). The instrument has been used to measure quality of life in other longitudinal ageing studies such as the English Longitudinal Study of Ageing (ELSA) and the Survey of Health, Ageing and Retirement in Europe (SHARE). It has been shown to be responsive to changes in the participant's circumstances over time that reflect changes in quality of life (12). Table 6.1 describes the dimension of quality of life that is measured by each subscale of the measure and a sample item for each subscale.

Results from wave 1 of the TILDA study (13) established that the majority of older people in Ireland enjoy a high quality of life and that the Irish population score higher than their English counterparts in terms of quality of life. Nevertheless, there were some important variations in quality of life across the older population with those from more disadvantaged socio-economic backgrounds having lower self-rated quality of life for example. Similarly, those who lived alone had lower scores compared with those who were living with a partner. There was also a curvilinear relationship between age and quality of life with those in the 64-74 age group having the highest quality of life ratings. Wave 2 of TILDA affords 
the opportunity to look at changes in quality of life and the factors associated with change over a two-year follow-up interval in a population of community-dwelling adults who were aged 50 years and over at baseline, i.e., wave 1 . We restrict the analysis to include only those participants for whom we have a self-reported quality of life measure at both waves $(n=4,423)$. This chapter will explore change in quality of life using a simple metric known as the change score which represents intra-individual (within-person) variation in scores over time and is calculated as follows:

Change score $=($ wave 2 quality of life score - wave 1 quality of life score)

Table 6.1: Scale composition and sample items on the CASP-19 quality of life measure

\begin{tabular}{|c|c|c|c|c|}
\hline Scale & Description & Sample item & $\begin{array}{l}\text { No. of } \\
\text { items }\end{array}$ & $\begin{array}{l}\text { Score } \\
\text { Range }\end{array}$ \\
\hline Control & $\begin{array}{l}\text { The ability to actively } \\
\text { participate in one's } \\
\text { environment }\end{array}$ & $\begin{array}{l}\text { 'I feel what happens to } \\
\text { me is out of my control ' }\end{array}$ & 4 & $0-12$ \\
\hline Autonomy & $\begin{array}{l}\text { The right of the individual to } \\
\text { be free from the unwanted } \\
\text { interference of others }\end{array}$ & $\begin{array}{l}\text { 'I can do the things that I } \\
\text { want to do' }\end{array}$ & 5 & $0-15$ \\
\hline $\begin{array}{l}\text { Self- } \\
\text { realisation }\end{array}$ & $\begin{array}{l}\text { The fulfilment of one's } \\
\text { potential }\end{array}$ & $\begin{array}{l}\text { 'I feel that my life has } \\
\text { meaning' }\end{array}$ & 5 & $0-15$ \\
\hline Pleasure & $\begin{array}{l}\text { The sense of happiness } \\
\text { or enjoyment derived from } \\
\text { engaging with life. }\end{array}$ & $\begin{array}{l}\text { 'I feel satisfied with the } \\
\text { way my life has turned } \\
\text { out' }\end{array}$ & 5 & $0-15$ \\
\hline $\begin{array}{l}\text { CASP-19 } \\
\text { total score }\end{array}$ & $\begin{array}{l}\text { Sum of the four CASP-19 } \\
\text { subscales }\end{array}$ & - & 19 & $0-57$ \\
\hline
\end{tabular}

\subsection{Quality of life and age}

The extent to which quality of life varies by age has been a subject of debate among scholars $(6,7,14)$. Results from the first wave of ELSA showed that quality of life increases from 50 years of age onward, peaking at 68 years of age and declining gradually thereafter (7). An interesting finding to emerge from the ELSA analysis was that quality of life only decreased below the value recorded among 50 year-olds after 86 years of age. Similar patterns are evident in the TILDA data at wave 2. Figure 6.1 shows that quality of life increases from an average of 41.7 at 52 years of age, peaking at 43.5 between 65 67 years of age and drops off fairly rapidly after 80 years of age. The wider confidence intervals around the mean in later life reflect the fact that there is larger variation in scores as people age and there are fewer respondents in the older age groups. 
Figure 6.1: Mean CASP-19 quality of life score at wave 2 by age

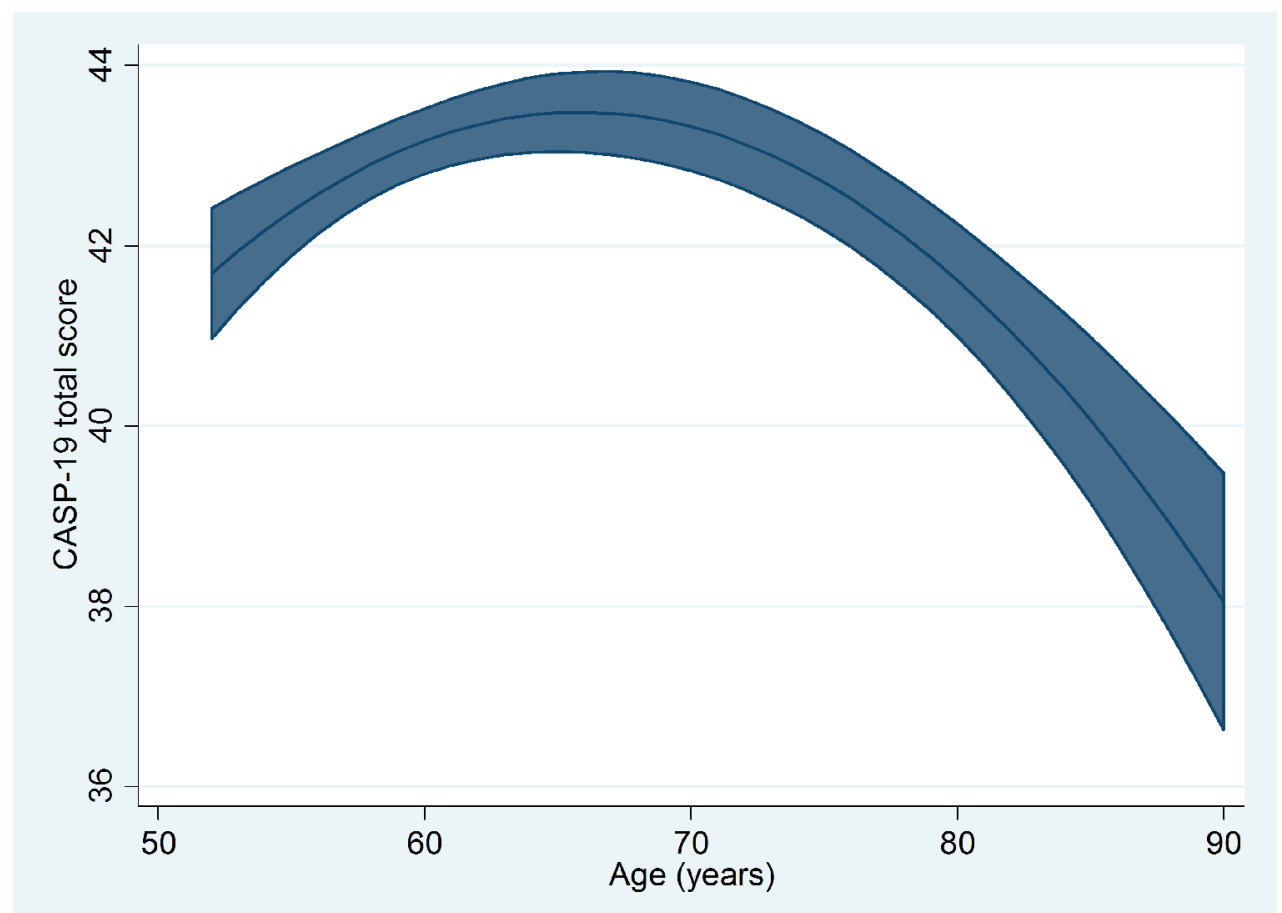

Of course, focusing on the overall quality of life measure disguises considerable heterogeneity within different facets of quality of life. If the measure is decomposed into its constituent parts then a more nuanced picture of how quality of life varies across the age spectrum emerges (see Figure 6.2). For example, the level of control older people feel they exert over their social environment peaks at about 58 years of age and declines fairly rapidly thereafter, whereas scores on the autonomy dimension continue to increase until about 74 years of age followed by a more shallow rate of decline in the years subsequent to this. Scores on the self-realisation dimension, which reflects the extent to which participants feel they have lived a fulfilling life peak at 64 years of age. A positive message to emerge from the TILDA data at wave 2 is that older people report high levels of happiness and enjoyment into later life with scores on the pleasure dimension of the CASP-19 continuing to increase as people age.

Table 6.2 summarises the mean score on the CASP-19 quality of life measure at wave 2 and the mean change in quality of life across waves and for each of the subscales. The mean score for the sample at wave 2 is 42.6 out of a total score of 57 , which indicates generally high levels of quality of life in the TILDA cohort. Comparison of responses from wave 1 and wave 2 of the study reveals that the overall score on the CASP-19 quality of life measure decreased by 1.3 CASP units over the two-year follow up period (see Table 6.2). Statistically significant reductions in quality of life were observed across each of the 
subscales that comprise the CASP-19 measure, but the decline was particularly marked on the control dimension, which reflects the ability to actively participate in one's social environment, and accounted for more than $40 \%$ of the reduction in quality of life over time. The rate of decline in quality of life was comparable for men and women as shown in Table 6.2 .

A recent study utilising three waves of data from the ELSA cohort documented a higher rate of intra-individual decline in quality of life among the oldest old (14). Similarly, analysis of responses from wave 2 of the TILDA study reveals that quality of life declines across all age groups over the two-year follow-up interval, but the rate of decline is steepest for those in the oldest age group (see Table 6.3). The mean change in the overall CASP-19 quality of life score across waves is - 0.83 CASP units among those aged 52-64 years, increasing through -1.48 CASP units for those in the 65-74 year age group, and -2.34 for those aged 75 years and above (see Table 6.3). Deterioration in self-rated quality of life between waves is evident across each age group for each subscale of the CASP-19 measure. The control subscale accounts for the largest proportionate drop in quality of life across all three age groups.

Figure 6.2: Mean scores on the control, autonomy, self-realisation and pleasure subscales of the CASP-19 quality of life measure at wave 2 by age
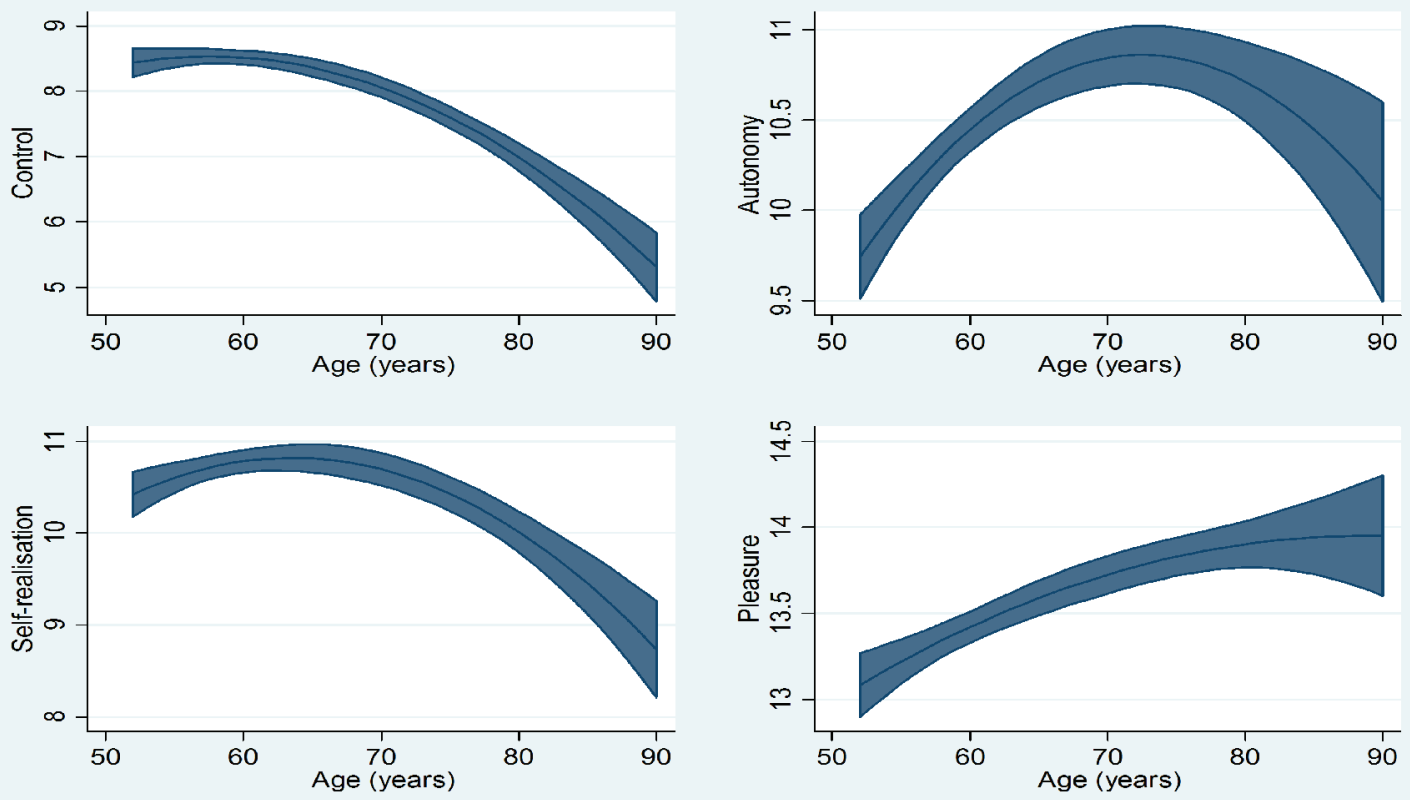
Table 6.2: Mean CASP-19 quality of life score at wave 2 and mean change in quality of life by sex

\begin{tabular}{|c|c|c|c|c|}
\hline & Mean (W2) & $95 \% \mathrm{Cl}$ & $\begin{array}{l}\text { Mean } \\
\text { Change }\end{array}$ & $\begin{array}{l}95 \% \text { Cl change } \\
\text { score }\end{array}$ \\
\hline \multicolumn{5}{|c|}{ All } \\
\hline Control & 8.0 & $(7.9,8.1)$ & -0.58 & $(-0.67,-0.49)$ \\
\hline Autonomy & 10.5 & $(10.3,10.6)$ & -0.30 & $(-038 .,-0.21)$ \\
\hline Self-realisation & 10.5 & (10.4 10.6) & -0.25 & $(-0.35,-0.15)$ \\
\hline Pleasure & 13.5 & $(13.4,13.6)$ & -0.20 & $(-0.27,-0.13)$ \\
\hline CASP-19 total score & 42.6 & $(42.3,42.9)$ & -1.33 & $(-1.56,-1.10)$ \\
\hline \multicolumn{5}{|c|}{ Male } \\
\hline Control & 8.1 & $(8.0,8.2)$ & -0.53 & $(-0.65,-0.42)$ \\
\hline Autonomy & 10.5 & $(10.4,10.7)$ & -0.28 & $(-0.39,-0.16)$ \\
\hline Self-realisation & 10.5 & $(10.4,10.6)$ & -0.22 & $(-0.35,-0.09)$ \\
\hline Pleasure & 13.5 & $(13.4,13.6)$ & -0.19 & $(-0.29,-0.10)$ \\
\hline CASP-19 total score & 42.7 & $(42.3,43.0)$ & -1.22 & $(-1.53,-0.91)$ \\
\hline \multicolumn{5}{|c|}{ Female } \\
\hline Control & 7.9 & $(7.7,8.0)$ & -0.63 & $(-0.76,-0.50)$ \\
\hline Autonomy & 10.4 & $(10.3,10.6)$ & -0.32 & $(-0.44,-0.20)$ \\
\hline Self-realisation & 10.5 & $(10.4,10.7)$ & -0.28 & $(-0.43,-0.13)$ \\
\hline Pleasure & 13.6 & $(13.5,13.7)$ & -0.20 & $(-0.30,-0.11)$ \\
\hline CASP-19 total score & 42.5 & $(42.0,42.9)$ & -1.43 & $(-1.77,-1.08)$ \\
\hline
\end{tabular}

Between-group comparisons reveal that participants aged 75 years and over experienced larger declines in quality of life across three of the four CASP-19 subscales (control, autonomy, self-realisation) compared with those in the 52-64 age group; while those in the 65-74 age group experienced larger declines on all of the subscales (control, autonomy, self-realisation and pleasure) compared with those aged 52-64. Interestingly, there are no significant differences between groups in terms of the rate of decline on the pleasure subscale of the CASP-19 which is a positive finding and suggests that this dimension of quality of life is less sensitive to decline across the age span.

Table 6.3: Mean CASP-19 quality of life score at wave 2 and mean change in quality at life score by age

\begin{tabular}{|c|c|c|c|c|c|c|c|c|c|}
\hline & \multicolumn{3}{|c|}{$52-64$ years } & \multicolumn{3}{|c|}{$65-74$ years } & \multicolumn{3}{|c|}{$75+$ years } \\
\hline & Mean & $95 \% \mathrm{Cl}$ & Change & Mean & $95 \% \mathrm{Cl}$ & Change & Mean & $95 \% \mathrm{Cl}$ & Change \\
\hline Control & 8.5 & $(8.4,8.6)$ & -0.39 & 8.1 & $(7.9,8.3)$ & -0.61 & 6.8 & $(6.5,7.0)$ & -1.00 \\
\hline Autonomy & 10.3 & $(10.1,10.4)$ & -0.10 & 10.8 & $(10.6,11.0)$ & -0.35 & 10.6 & $(10.3,10.9)$ & -0.72 \\
\hline Pleasure & 13.3 & $(13.2,13.4)$ & -0.20 & 13.7 & $(13.5,13.8)$ & -0.26 & 13.9 & $(13.8,14.0)$ & -0.11 \\
\hline $\begin{array}{l}\text { CASP-19 } \\
\text { total score }\end{array}$ & 42.8 & $(42.4,43.2)$ & -0.83 & 43.3 & $(42.7,43.9)$ & -1.48 & 41.1 & $(40.3,42.0)$ & -2.34 \\
\hline
\end{tabular}




\subsection{Quality of life and marital status}

A large number of studies have shown that people who are married report higher levels of happiness and life satisfaction compared with those who are not married (15). Transitions in marital status between waves was characterised using the classification shown in Table 6.4. ${ }^{1}$ For example, $72.8 \%$ of TILDA participants were married at both waves, while only a small percentage $(0.4 \%)$ divorced or separated between waves. The data show that participants who were married at both waves have a higher quality of life score compared with those who remained never married, divorced/separated, or widowed across waves. Another interesting trend to emerge from the data is that participants who were married at wave 1, but for whom circumstances had changed at wave 2 (i.e. had become divorced/ separated or widowed), and those who were unmarried/divorced/separated/widowed at wave 1 , but were married at wave 2, tend to score higher than those who were never married (although these differences are not statistically significant).

Table 6.4: Mean CASP-19 quality of life score at wave 2 by transitions in marital status

\begin{tabular}{|l|ccc|}
\hline & $\begin{array}{c}\text { \% of the } \\
\text { sample }\end{array}$ & Mean & $\mathbf{9 5 \%} \mathbf{~ C l}$ \\
\hline Married (wave 1 and wave 2) & 72.8 & 43.2 & $(42.9,43.6)$ \\
\hline Never Married (wave 1 and wave 2) & 8.0 & 41.2 & $(40.1,42.1)$ \\
\hline Divorced/Separated (wave 1 and wave 2) & 6.2 & 41.0 & $(39.6,42.5)$ \\
\hline Widowed (wave 1 and wave 2) & 11.2 & 41.2 & $(40.1,42.3)$ \\
\hline Married wave 1, Divorced/separated wave 2 & 0.4 & 43.4 & $(40.6,46.1)$ \\
\hline Married wave 1, Widowed wave 2 & 1.1 & 41.9 & $(39.6,44.2)$ \\
\hline $\begin{array}{l}\text { Never married | Divorced/separated } \\
\text { Widowed wave 1, Married wave 2 }\end{array}$ & 0.5 & 42.4 & $(38.6,46.2)$ \\
\hline
\end{tabular}

Quality of life shows a small improvement for those who were married at wave 1, but widowed at wave 2 . While initially surprising, this may reflect the fact that participants who were widowed during the follow-up period had a lower quality of life at wave 1 because their spouse/partner was in poor health prior to their death (Figure 6.3).

1. A small number of transitions $(n=30)$ are omitted due to small numbers (e.g. those who went from divorced/separated in wave 1 to widowed in wave 2). 
Figure 6.3: Mean change in CASP-19 quality of life score by transitions in marital status

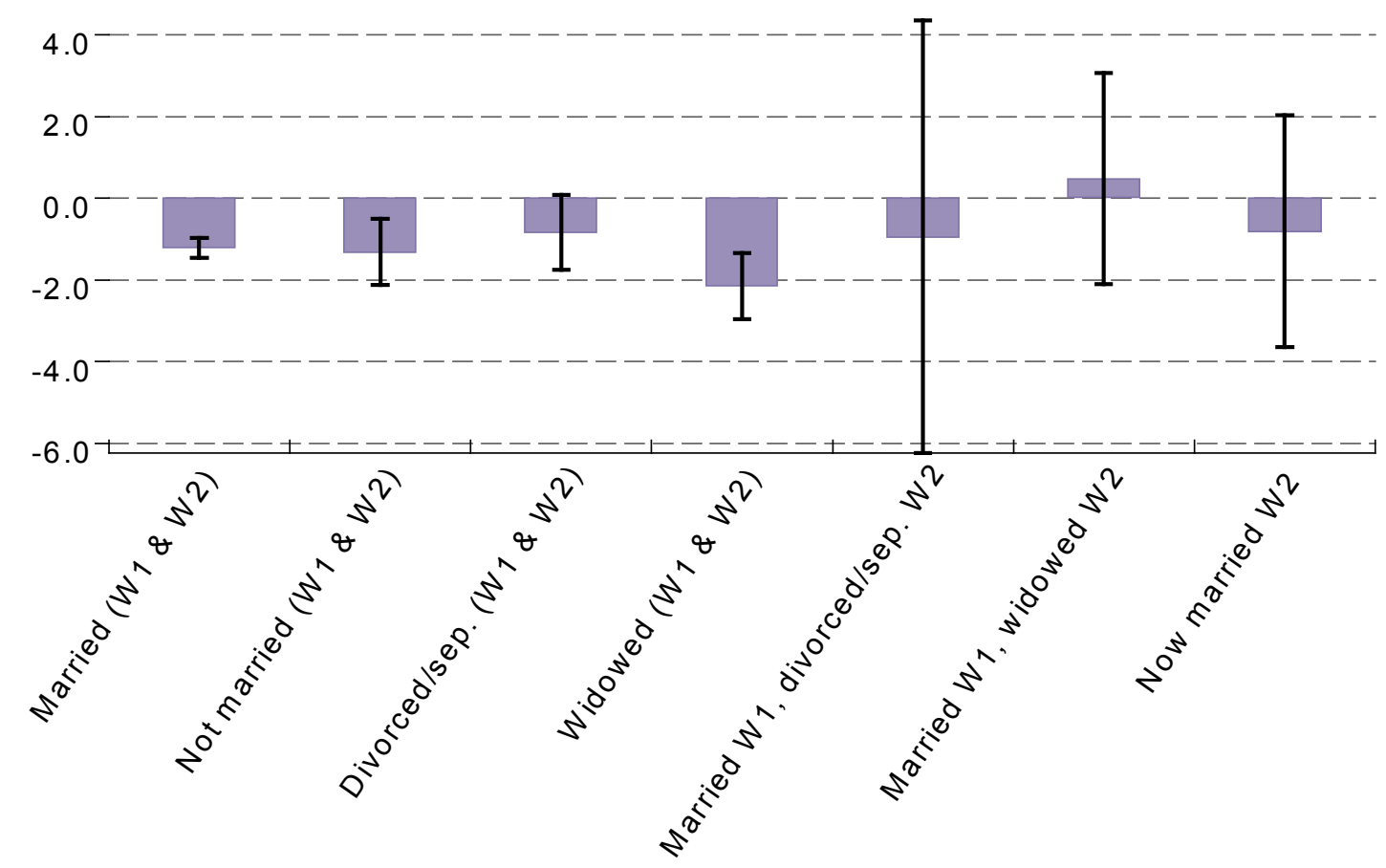

Note. $N=4393 ;$ Missing obs $=30$; Error bars correspond to $95 \%$ confidence intervals

\subsection{Quality of life and employment status}

Retirement from employment is considered an important milestone as it marks a transition in one's daily routines, responsibilities, social relationships and income (16). Indeed researchers continue to debate whether retirement is associated with increases in levels of subjective wellbeing and quality of life or whether this major life transition contributes to psychological distress. TILDA participants were asked to describe their employment status during the course of the survey which allows for an investigation of how quality of life varies by transitions in employment status between wave 1 and wave 2 . The major transitions in employment status are characterised using the classification shown in Table 6.5. ${ }^{2}$ It describes the percentage of participants falling within each category and the mean score on the quality of life measure for each group. For example, $31.2 \%$ of participants were employed at both waves, while $3.9 \%$ of participants who were unemployed at wave 1 had gained employment at wave 2 .

2. Some transitions have been combined due to small numbers (e.g., those who transitioned from being unemployed (wave 1) to permanently sick (wave 2) are included in the 'permanently sick (wave 2) category'). 
Table 6.5: Mean CASP-19 quality of life score at wave 2 by transitions in employment status

\begin{tabular}{|l|c|c|c|}
\hline & $\begin{array}{c}\text { \% of the } \\
\text { sample }\end{array}$ & Mean & (95\% CI) \\
\hline Employed (wave 1 and wave 2) & 31.2 & 44.3 & $(43.9,44.7)$ \\
\hline Unemployed wave 1, Employed wave 2 & 3.9 & 42.2 & $(40.4,43.5)$ \\
\hline Unemployed (wave 1 and wave 2) & 2.5 & 41.7 & $(40.1,43.2)$ \\
\hline Became unemployed (wave 2) & 2.0 & 40.7 & $(38.8,42.7)$ \\
\hline Newly retired (wave 2) & 11.0 & 43.1 & $(42.2,44.1)$ \\
\hline Retired (wave 1 and wave 2) & 31.8 & 42.9 & $(42.4,43.4)$ \\
\hline Homemaker (wave 2) & 13.6 & 41.7 & $(40.8,42.6)$ \\
\hline Permanently sick (wave 2) & 4.1 & 35.5 & $(33.9,37.0)$ \\
\hline
\end{tabular}

Participants who are employed at both waves have the highest quality of life score (mean score $=44.3$ ), although it should be acknowledged that this may simply reflect the fact that those who are currently employed are younger and tend to be in better physical health. Participants who are unemployed in both waves have lower scores on the quality of life measure compared with those who are employed at both waves. Finally, those who were permanently sick have the lowest quality of life score of all the groups considered (mean score $=35.5$.

Figure 6.4 shows the mean change in the overall CASP-19 quality of life score by transitions in employment status. Participants who have gained employment between waves recorded only a small decline in quality of life (-0.3 CASP units), while those who became unemployed are characterised by steeper declines in quality of life (-1.8 CASP units). Similarly, quality of life declines at a faster rate (-1.7 CASP) for those who are retired at both waves compared with those who are employed at both waves (-1.1 CASP units), but this is likely attributable to the fact that retirees are older and tend to be in worse health. 
Figure 6.4: Mean change in the CASP-19 quality of life score by transitions in employment status

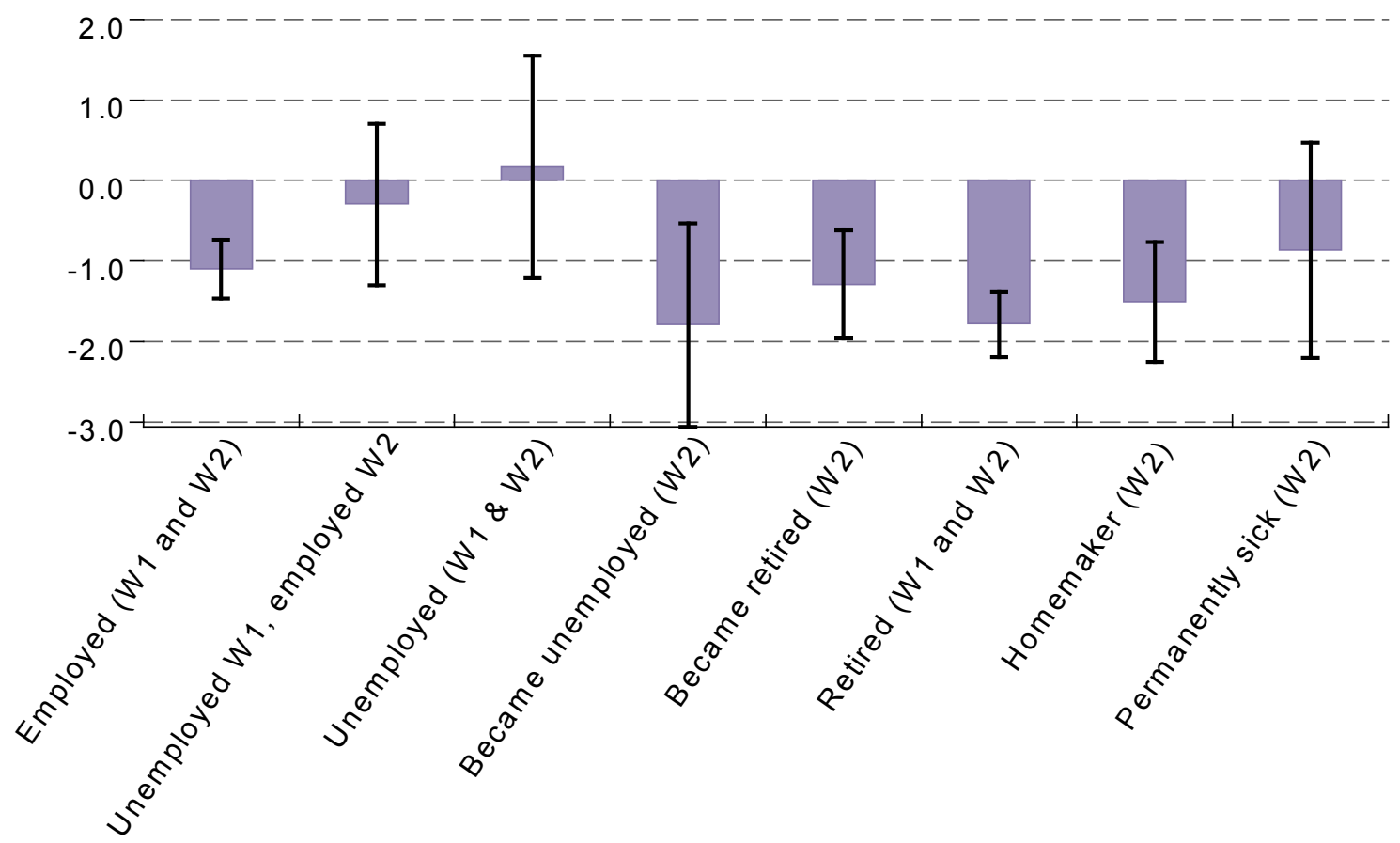

Note. $N=4423$; Missing obs $=0$; Error bars correspond to $95 \%$ confidence intervals

\subsection{Quality of life and disability}

Disability is common in later life and affects up to $20 \%$ of the US population aged 65 years and over (17). Disability is usually defined in terms of restrictions in the ability to perform activities of daily living (ADL), or the inability to function independently in terms of basic ADLs or instrumental ADLs (IADLs) (18). A study from the ELSA team found that the effect of having a longstanding illness on quality of life was compounded if it co-existed with a functional limitation (19). Furthermore, disability is one of the strongest predictors of nursing home admissions (20). In this section, we focus on the relationship between quality of life and disability, defined as having at least one ADL limitation.

Participants completed a 6-item checklist to establish whether they experience any limitations in activities of daily living (ADLs). This includes difficulties with: (1) dressing; (2) walking across a room; (3) bathing or showering; (4) eating, such as cutting up food (5); getting in or out of bed; and (6) using the toilet, including getting up or down. Overall, $4.2 \%$ of those who have a valid CASP-19 score report an ADL limitation at wave 2, with $2.6 \%$ having one ADL, $0.7 \%$ having two ADLs, and $1 \%$ having three or more ADLs. There is a strong inverse relationship between the number of reported ADLs and participants' self- 
rated quality of life (see Figure 6.5). Those who are free of disability have a significantly higher quality of life score (mean score $=43.2$ ) compared with those who report one or more ADLs. Moreover, quality of life continues to deteriorate as the number of experienced ADLs increases with the mean score on the CASP-19 declining from 36.4 for those with one ADL, through 33.9 for those with two ADLs, and 29.7 among those with three or more ADLs.

Figure 6.5: Mean CASP-19 quality of life score at wave 2 by the number of ADLs

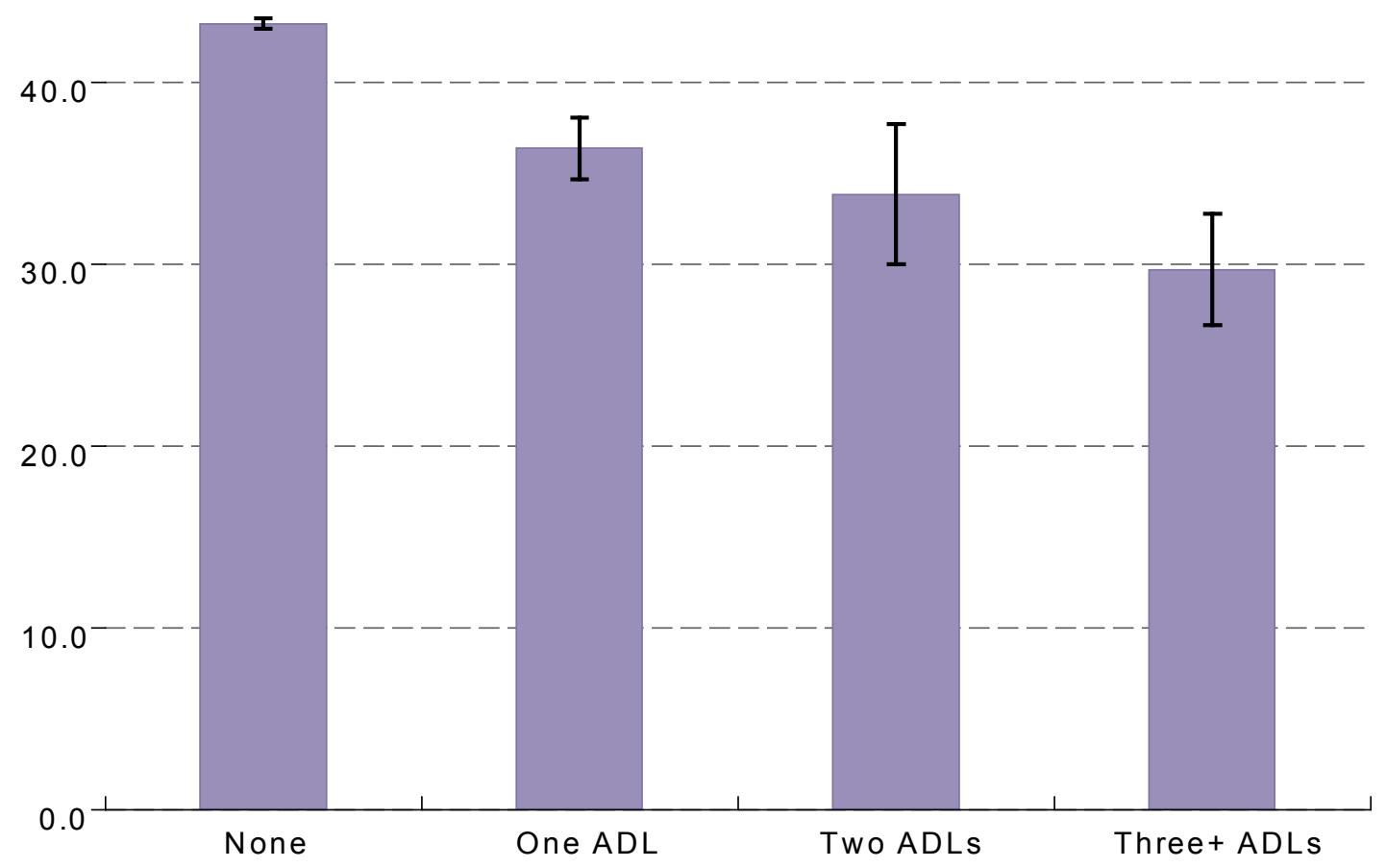

Note. $\mathrm{N}=4423$; Missing obs $=0$; Error bars correspond to $95 \%$ confidence intervals

To examine how transitions in disability status over time affect quality of life, information provided by participants at each wave is used to classify participants into four groups based on their functional status:

- None - Free of limiting disability at wave 1 and wave 2;

- Conversion - Free of limiting disability at wave 1 but reporting impairment at wave 2;

- Remission - Limiting disability at wave 1 but no impairment at wave 2;

- Persistence - Limiting disability at both wave 1 and wave 2 .

The vast majority of participants $(90.9 \%)$ who have a valid score on the CASP-19 measure are free of disability at both waves. A further $2.2 \%$ are accounted for by those who were 
free of disability at wave 1 but report an ADL limitation at wave 2, while $4.9 \%$ experience remission of their disability across waves. About $2.0 \%$ experience persistence of disability between waves. Participants who are free of disability at both waves have the highest quality of life ratings at wave 2 (see Figure 6.6) with a mean score on the CASP-19 scale that is almost 10 CASP units higher than the score for those who report the presence of activity limitations at both waves (mean score $=43.4$ vs 33.1). Quality of life is lower for those who were free of disability at wave 1 , but are affected by an activity limitation at wave 2 (mean score $=34.5$ ), relative to those who are free of disability at both waves. Conversely, participants who indicate that their activity limitation had resolved from wave 1 to wave 2 (remission) have a higher quality of life (mean score $=39.8$ ) than those for whom disability persists, though they continue to score significantly lower than those who are free of disability at both waves.

Similar patterns are observed using the change score as an index of within-person change in quality of life over time. Figure 6.7 shows that participants who are free of disability at both waves experience a reduction of 1.3 CASP units in their quality of life. Those who develop an activity limitation between waves experience the greatest diminution in their quality of life (-2.7 CASP units) over time. By contrast, participants whose disability limitation resolves between waves do not experience a significant change in their quality of life between waves.

Figure 6.6: Mean CASP-19 quality of life score at wave 2 by transitions in ADL status

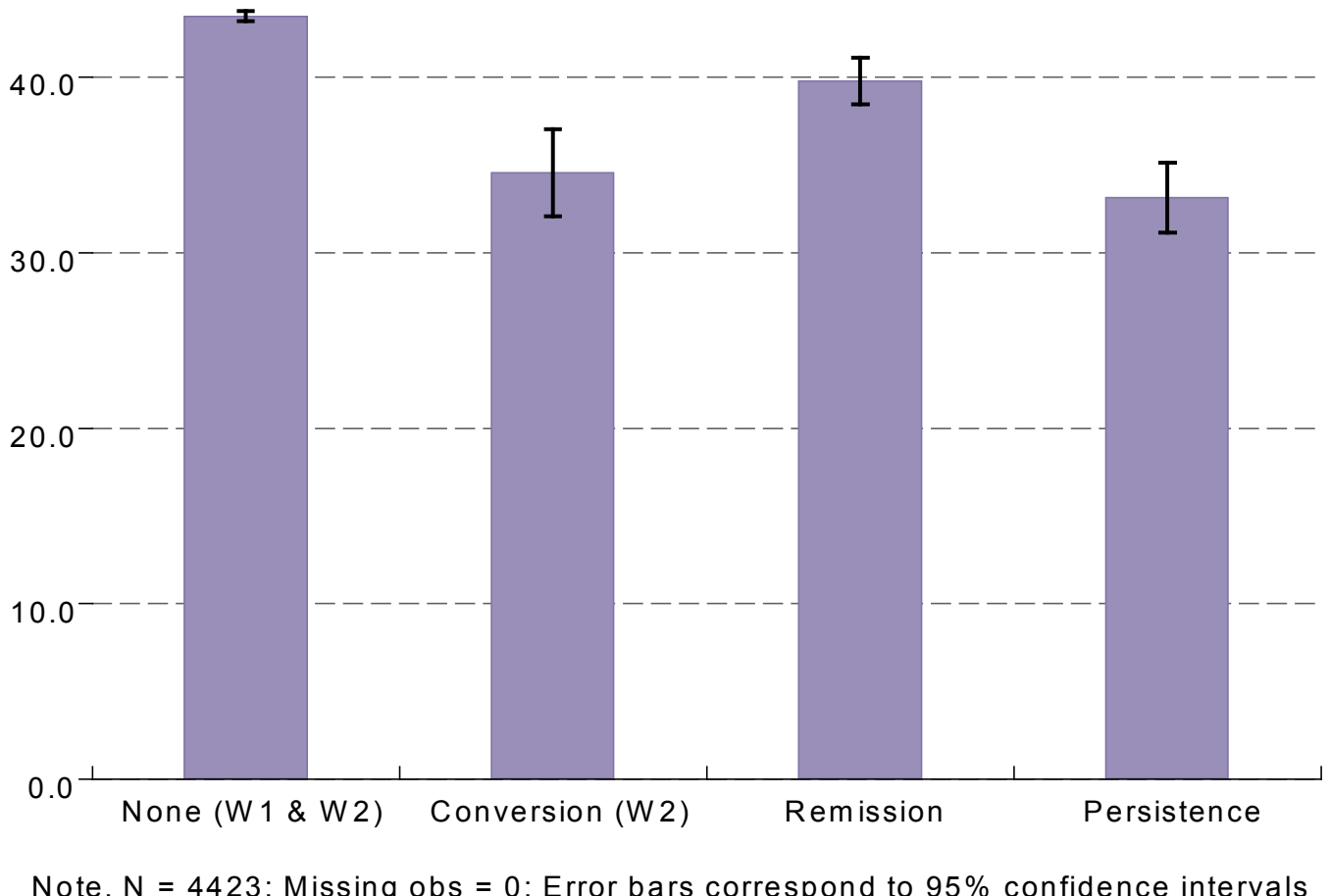


Figure 6.7: Mean change in CASP-19 quality of life score by transitions in ADL status

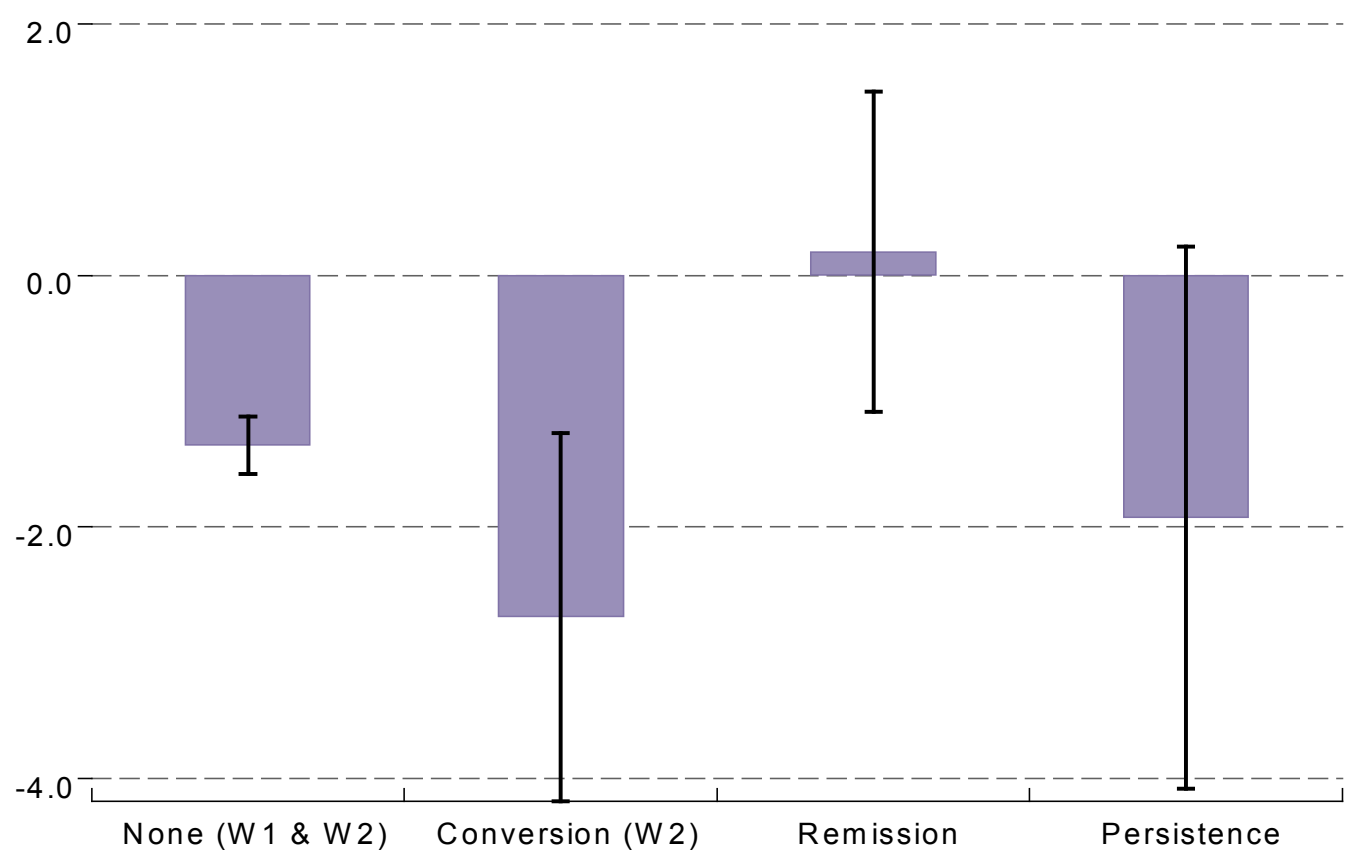

Note. $N=4423$; Missing obs $=0$; Error bars correspond to $95 \%$ confidence intervals

\subsection{Quality of life and depression}

Studies have shown that depressive illness is associated with lower self-rated quality of life $(21,22)$. In TILDA, depression is measured using the 20-item Centre for Epidemiological Studies (CES-D) depression scale, which is a widely used self-report screening instrument for depression in the general population (23). A total score is calculated by summing responses across the 20 items (range 0-60), with a score of 16 or more implying a clinically significant level of psychological distress. A similar classification to that described at section 6.5 is used to characterise transitions in depression status across waves:

- Not depressed (wave 1 or wave 2);

- Conversion - Not depressed (wave 1), depressed (wave 2);

- Remission - Depressed (wave 1), not depressed (wave 2);

- Persistence - Depressed (wave 1 and wave 2).

Overall, $88.1 \%$ of TILDA participants may be classified as not depressed at both waves, while $3.3 \%$ are depressed in both waves. There is a remission in depressive symptoms for $4.8 \%$ of the older population while $3.8 \%$ experience a clinically significant increase in their symptoms between waves. Participants who are free of depression at both waves 
report significantly higher quality of life scores at wave 2 (mean score $=44.0$ ) compared with the other groups (see Figure 6.8). Those who develop depression between waves have a significantly lower quality of life score (mean score $=34.4$ ) compared with those who are free of depression at both waves. By contrast, quality of life is higher for those who experience remission of depressive symptoms between waves (mean score $=37.3$ ) compared with those who are depressed at both waves (mean score $=30.9$ ).

Figure 6.9 shows that those who develop depression between waves experience the greatest fall in quality of life over time with their mean score on the CASP-19 measure decreasing by -4.4 CASP units over the two-year follow-up interval. Respondents for whom depression persists experience a decline in quality of life that is of similar magnitude to those who are free of depressive illness at both time points (approximately 1.4 CASP units) (although it should be acknowledged that the former group are declining from a much lower wave 1 quality of life score). Those who experience remission of depressive symptoms between waves are characterised by gains in quality of life (+ 1.2 CASP units).

Figure 6.8: Mean CASP-19 quality of life score at wave 2 by transitions in depression status

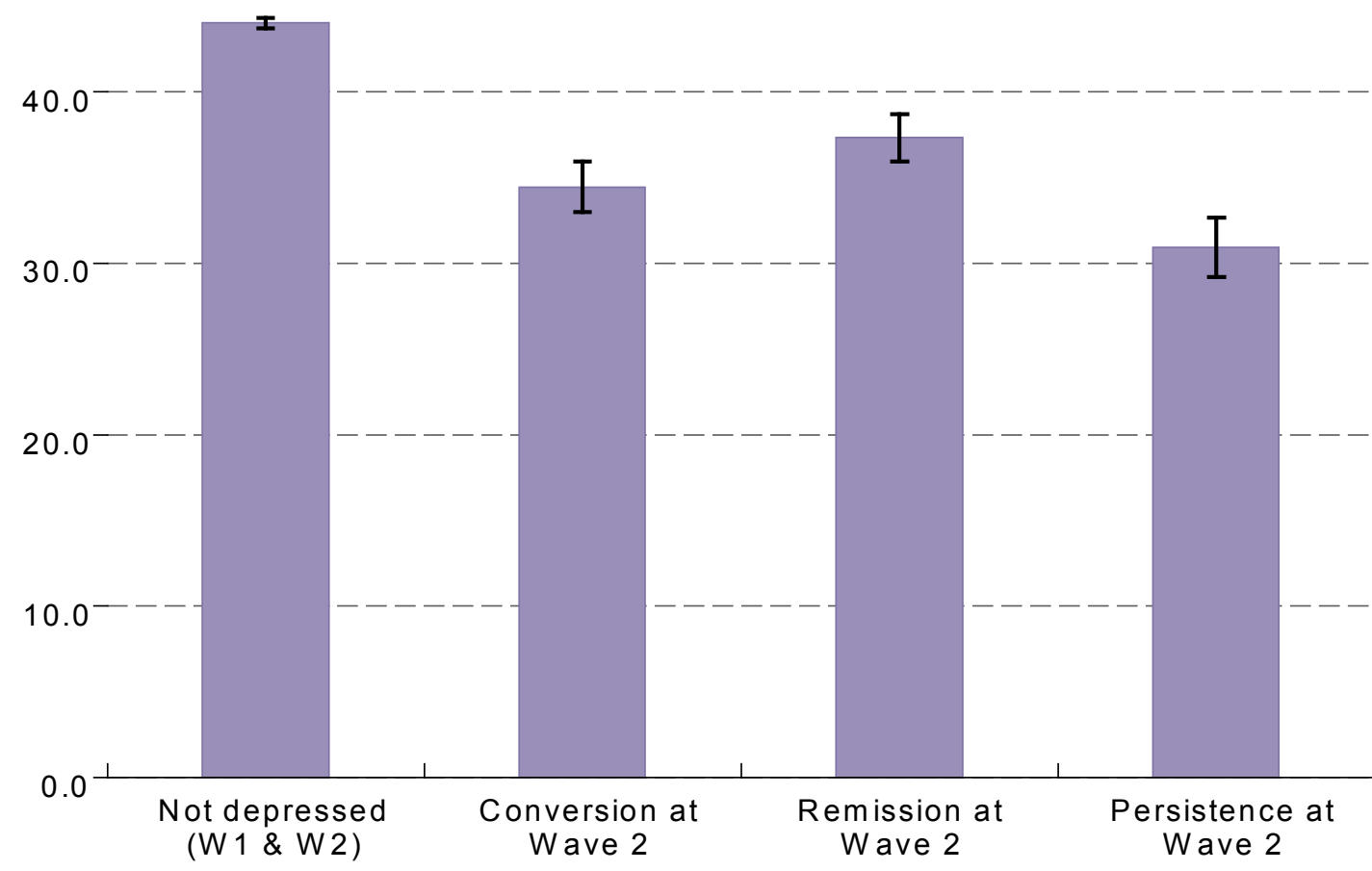

Note. $N=4318 ;$ Missing obs $=105$; Error bars correspond to $95 \%$ confidence intervals 
Figure 6.9: Mean change in CASP-19 quality of life score by transitions in depression status

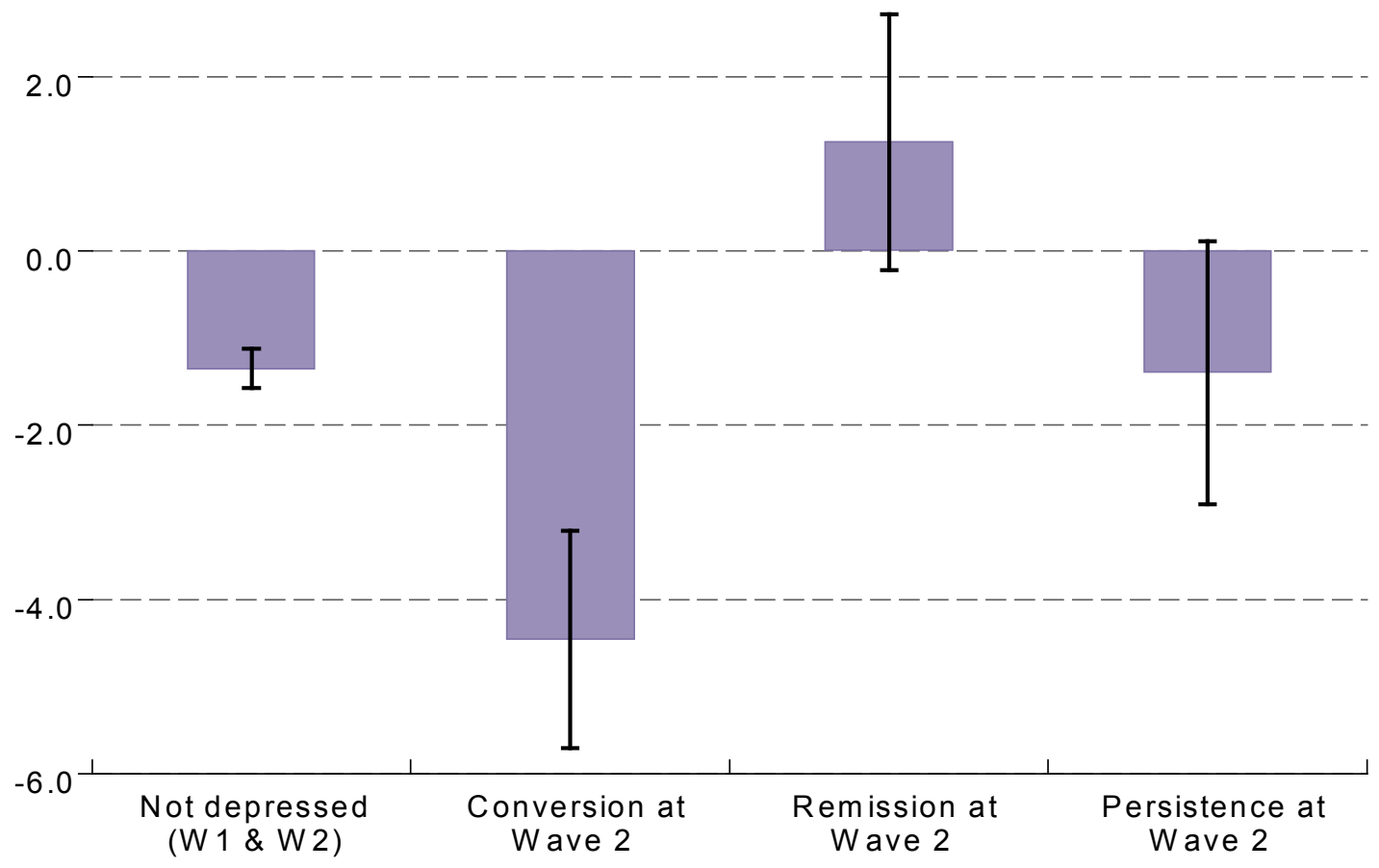

Note. $N=4318$; Missing obs = 105; Error bars correspond to $95 \%$ confidence intervals

\subsection{Quality of life and social engagement}

Social engagement, social support and trusting relationships have all been associated with improved quality of life in older adults (24). TILDA collects a wide range of information from participants relating to social participation and interaction. This information is used to assess types of relationships and levels of social connection, including participation in various types of social and leisure activities, church-going and volunteering. This section documents the relationships between such social structures and quality of life in older Irish adults.

\subsubsection{Quality of life and social networks}

Findings from ELSA indicate that having strong social networks is consistent with a higher quality of life score (25). The strength of social networks among TILDA participants is measured using the Berkman-Syme Social Network Index (SNI) (26). This index is scored on a 0-4 composite scale quantifying four types of social connection: (1) marital status; (2) close ties with children, relatives and friends; (3) membership of a church group, and (4) membership of voluntary organisations. A score of 0-1 identifies a participant as 'most 
isolated', with a score of 4 indicating 'most integrated'. Results from wave 1 of TILDA revealed that $26 \%$ of men and $23 \%$ of women over the age of 50 were classified as 'most integrated' using the Berkman-Syme SNI classification (13). The corresponding figures for 'most isolated' were $6 \%$ and $7 \%$ respectively. These figures only changed slightly in wave 2 , with $27 \%$ of men and $22 \%$ of women classified as 'most integrated' and $8 \%$ of men and $9 \%$ of women classified as 'most isolated'.

Participants aged 65-74 have the highest proportion of 'most integrated' (30\%) compared to $24 \%$ in the younger age group and $19 \%$ in the older age group (see Figure 6.10 ). This is notable given that this age group may have transitioned into retirement more recently. It is possible that this allows for more time and opportunity to develop and interact with social networks. By contrast, smaller social networks in the over 75 s may be linked to poorer health and disability. Figure 6.11 indicates mean CASP-19 score in each Social Network Index category by age. In participants over the age of 65 , quality of life is highest among those who are 'most integrated' (mean score = approximately 45.0) and lowest among those 'mostly isolated' (mean score = approximately 37.0). Change in Social Network Index values between waves is not related to changes in quality of life between waves.

Figure 6.10: Distribution of Berkman-Syme Social Network Index of social connection at wave 2 by age

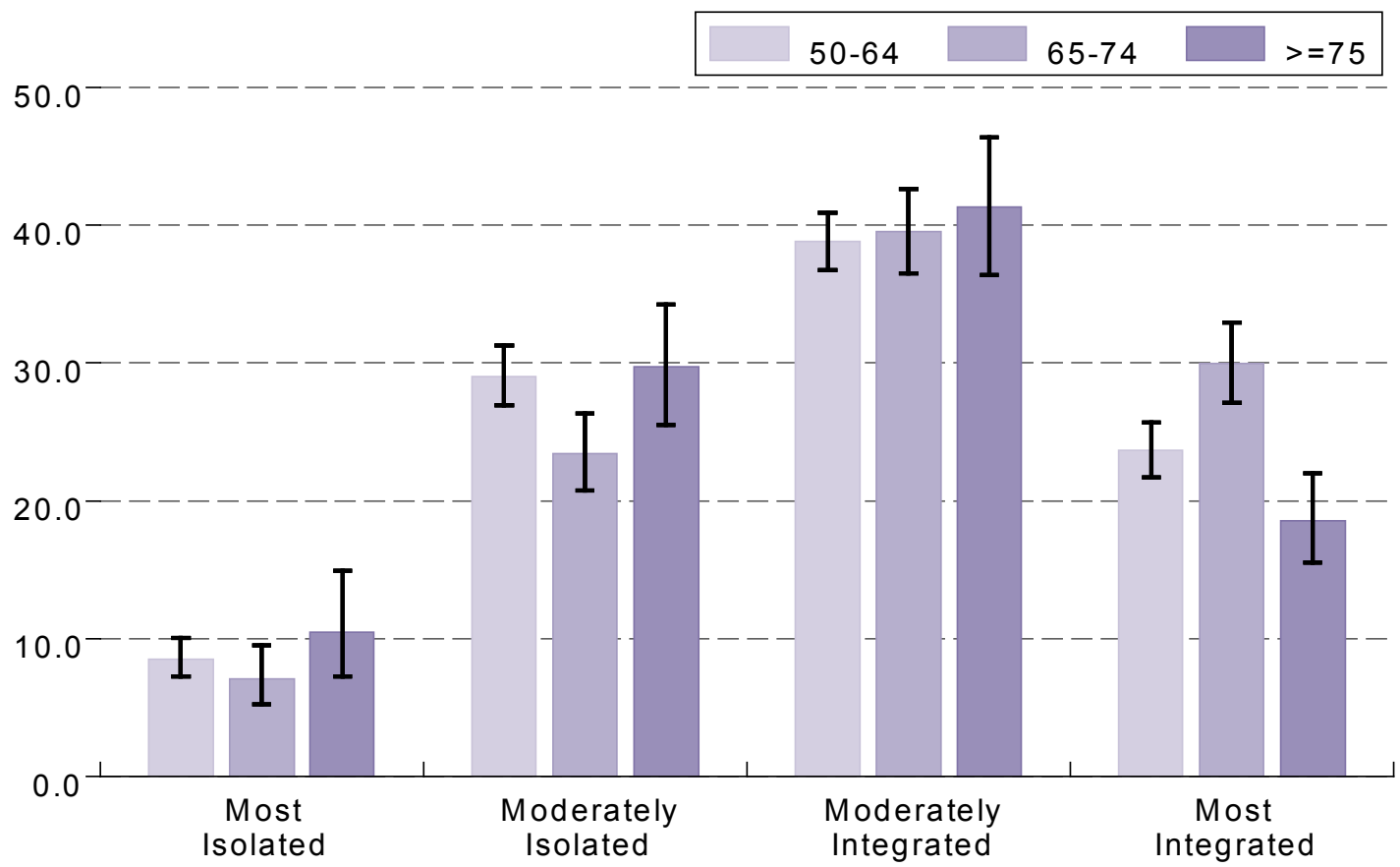

Note. $N=4416 ;$ Missing obs $=7$; Error bars correspond to $95 \%$ confidence intervals 
Figure 6.11: Mean CASP-19 quality of life score at wave 2 by Berkman-Syme Social Network Index and age

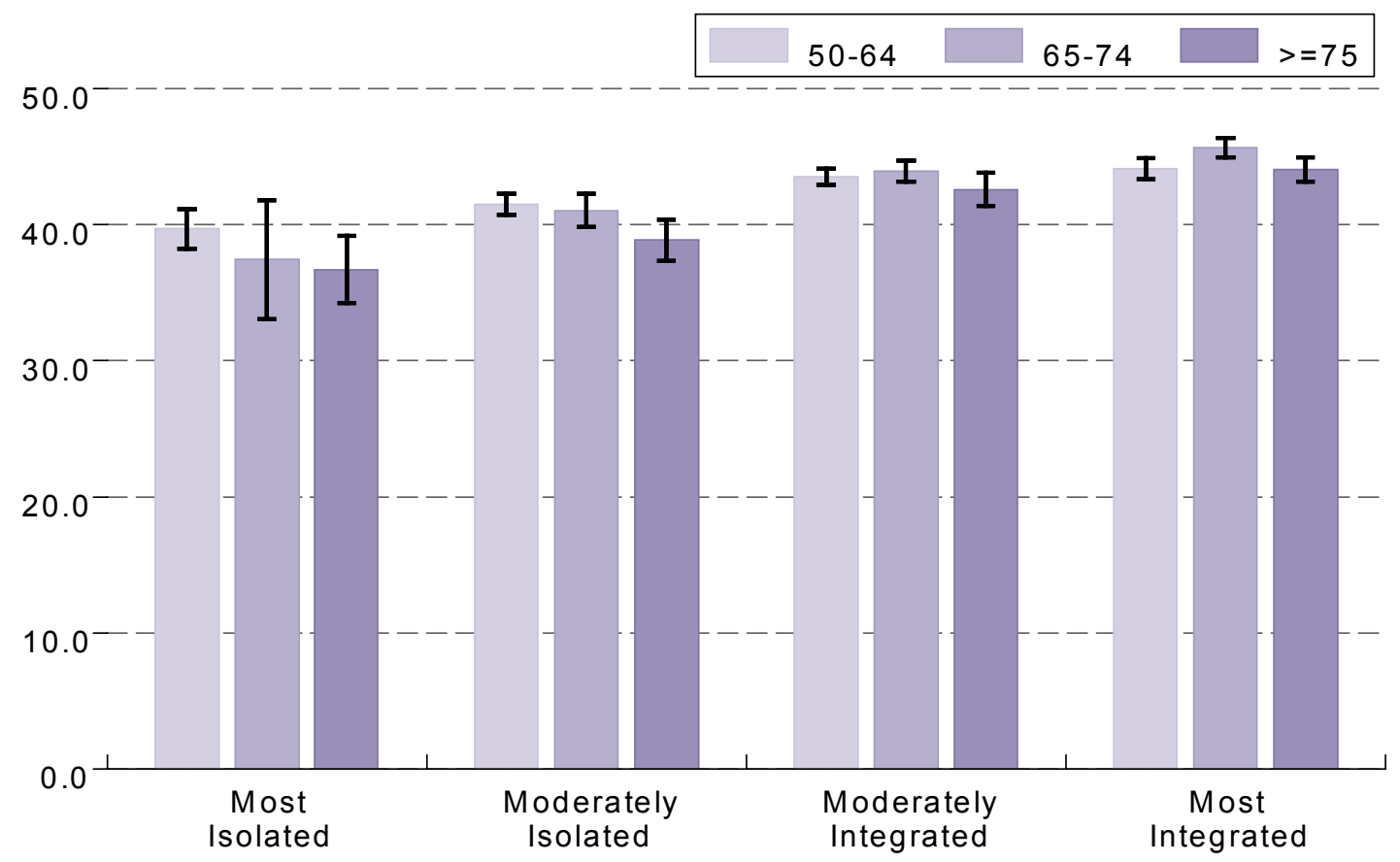

Note. $N=4416$; Missing obs = 7; Error bars correspond to $95 \%$ confidence intervals

\subsubsection{Quality of life and social participation}

Increased social participation in older age is associated with improved life expectancy, better self rated health and a higher quality of life $(27,28)$. TILDA measures frequency of participation in social activities and relationships in four domains: (1) intimate social relationships (i.e., daily contact with family or friends); (2) formal organisational involvement; (3) active and social leisure activities; (4) passive and solitary leisure activities, adapted from House et al. (29).

The proportion of older adults engaging in active and social leisure, and passive and solitary leisure, activities has remained relatively unchanged between waves at $87 \%$ and 99\% respectively. Less than half of TILDA participants report engagement in intimate social relationships at wave $2(43.9 \%)$, while the majority (64\%) engage in formal organisational involvement outside of work. The proportion of 52-64 year olds participating in intimate social relationships has decreased from approximately $43 \%$ at wave 1 to $38 \%$ at wave 2 (see Figure 6.12), and remains lower than their older counterparts. However, the proportion of this age group engaged in formal organisational involvement outside of work has increased from $61.7 \%$ in wave 1 to $64.1 \%$ in wave 2 (see Figure 6.13 ). 
Figure 6.12: Percentage engaging in intimate social relationships by age

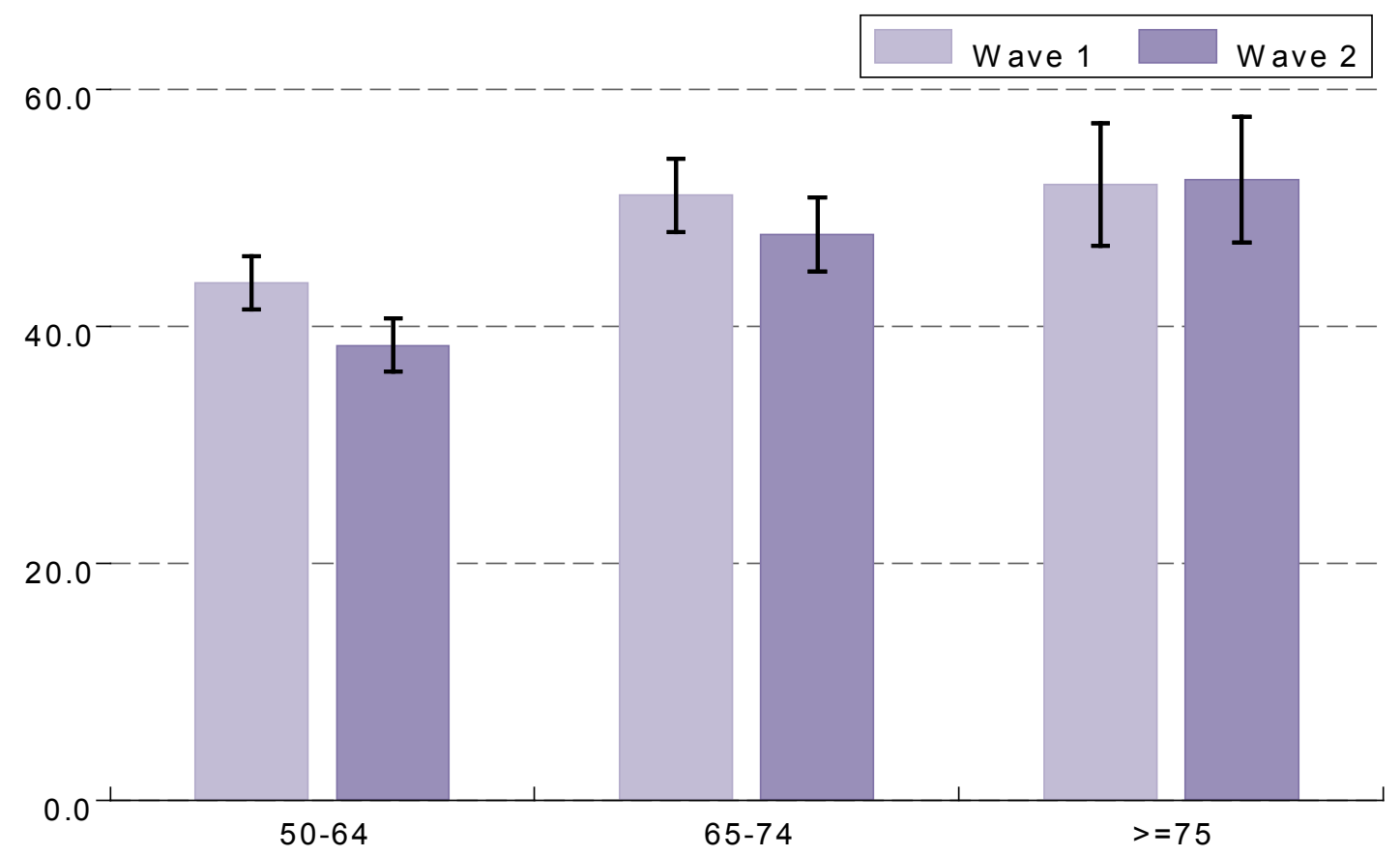

Note. $N=4382 ;$ Missing obs $=41$; Error bars correspond to $95 \%$ confidence intervals

Figure 6.13: Percentage engaging in formal organisational involvement outside of work 2 by age

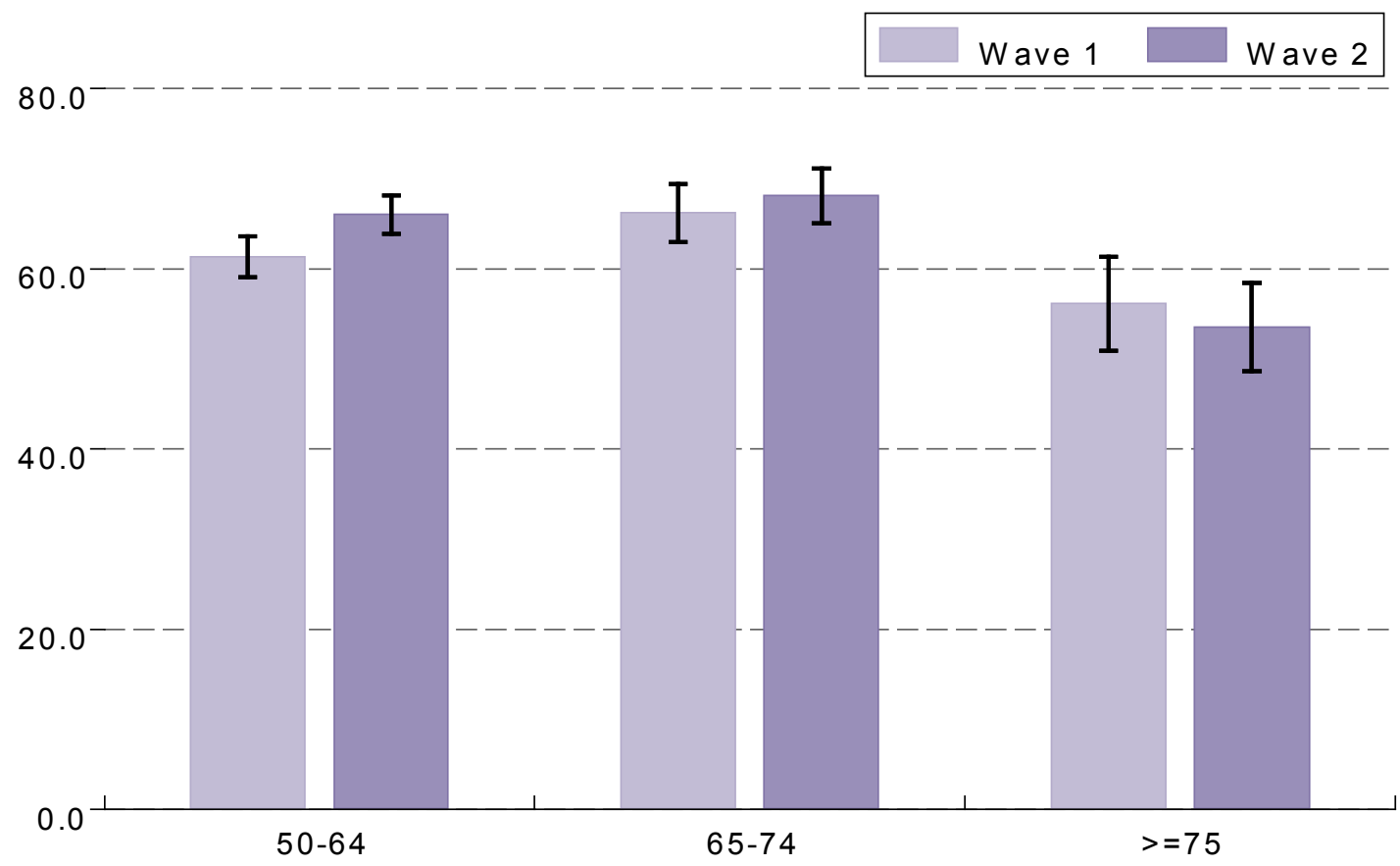

Note. $\mathrm{N}=4423$; Missing obs $=0$; Error bars correspond to $95 \%$ confidence intervals 
Quality of life is significantly higher for those who engage in social relationships compared with those who do not. The largest discrepancy is seen in 'active and social leisure', where there is a mean difference of 5.8 CASP units between those who report engaging in the activities and those who do not (see Table 6.6).

Table 6.6: Mean CASP-19 quality of life score at wave 2 by social participation

\begin{tabular}{|l|rr|rrr|}
\hline & \multicolumn{3}{c}{ Participation } \\
& \multicolumn{2}{c}{ Yes } & \multicolumn{2}{c|}{ No } \\
& Mean & $(95 \%$ CI) & Mean & $(95 \%$ CI) \\
\hline Intimate social relationships & 43.3 & $(42.8,43.8)$ & 42.0 & $(41.6,42.4)$ \\
\hline Formal activity outside work & 44.0 & $(43.6,44.3)$ & 40.1 & $(39.4,40.6)$ \\
\hline Active and social leisure & 43.3 & $(43.0,43.6)$ & 37.5 & $(36.5,38.5)$ \\
\hline Passive and solitary leisure & 42.6 & $(42.2,42.9)$ & 37.7 & $(33.5,41.9)$ \\
\hline
\end{tabular}

To examine whether changes in social relationships and participation between waves influences self-reported quality of life, TILDA participants were categorised into one of four groups as shown below:

- Reporting no relationships/activities in wave 1 and wave 2;

- Reporting relationships/activities in wave 1 only;

- Reporting relationships/activities in wave 2 only;

- $\quad$ Reporting relationships/activities in wave 1 and wave 2.

Table 6.7 shows that the largest proportion of transitions is evident in 'intimate and social relationships' where just $31 \%$ of the population indicate that they have such relationships at both waves. Very little change is noted in 'active and social leisure' or 'passive and solitary leisure' with $82 \%$ and $99 \%$ respectively participating in these activities at both waves.

With the exception of 'passive and solitary leisure', mean quality of life score is lowest in the groups reporting no participation in both waves compared to those indicating participation at wave 2 (see Table 6.8). 
Table 6.7: Changes in social participation between wave 1 and wave 2

\begin{tabular}{|c|c|c|c|c|c|}
\hline & $\begin{array}{c}\text { None at wave } 1 \\
\text { or wave } 2 \\
\%(n)\end{array}$ & $\begin{array}{l}\text { wave } 1 \\
\text { only } \\
\% \text { (n) }\end{array}$ & $\begin{array}{l}\text { wave } 2 \\
\text { only } \\
\%(n)\end{array}$ & $\begin{array}{c}\text { wave } 1 \& \text { wave } 2 \\
\% \text { (n) }\end{array}$ & $\begin{array}{l}\text { Total } \\
\% \text { (n) }\end{array}$ \\
\hline $\begin{array}{l}\text { Intimate social } \\
\text { relationships }\end{array}$ & $40(1786)$ & $16(710)$ & $13(540)$ & $31(1346)$ & $100(4382)$ \\
\hline $\begin{array}{l}\text { Formal activity } \\
\text { outside work }\end{array}$ & $26(952)$ & $10(372)$ & 12 (492) & 52 (2607) & $100(4423)$ \\
\hline $\begin{array}{l}\text { Active and social } \\
\text { leisure }\end{array}$ & $6(169)$ & $7(221)$ & $5(191)$ & $82(3842)$ & $100(4423)$ \\
\hline $\begin{array}{l}\text { Passive and } \\
\text { solitary leisure }\end{array}$ & $0(0)$ & $0(11)$ & $0(8)$ & $99(4404)$ & $100(4423)$ \\
\hline
\end{tabular}

Table 6.8: Mean CASP-19 quality of life score at wave 2 by transitions in social participation

\begin{tabular}{|c|c|c|c|c|c|c|c|c|}
\hline & \multicolumn{2}{|c|}{$\begin{array}{c}\text { None at wave } 1 \text { or } \\
\text { wave } 2\end{array}$} & \multicolumn{2}{|c|}{ wave 1 only } & \multicolumn{2}{|c|}{ wave 2 only } & \multicolumn{2}{|c|}{ wave $1 \&$ wave 2} \\
\hline & Mean & $(95 \% \mathrm{Cl})$ & Mean & $(95 \% \mathrm{Cl})$ & Mean & $(95 \% \mathrm{Cl})$ & Mean & $(95 \% \mathrm{Cl})$ \\
\hline $\begin{array}{l}\text { Intimate social } \\
\text { relationships }\end{array}$ & 41.7 & $(41.2,42.2)$ & 42.6 & $(41.9,43.3)$ & 43.7 & $(42.7,44.6)$ & 43.2 & $(42.6,43.8)$ \\
\hline $\begin{array}{l}\text { Formal activity } \\
\text { outside work }\end{array}$ & 39.5 & $(38.7,40.2)$ & 41.7 & $(40.7,42.7)$ & 43.1 & $(42.2,44.0)$ & 44.2 & $(43.8,44.5)$ \\
\hline $\begin{array}{l}\text { Active and social } \\
\text { leisure }\end{array}$ & 37.1 & $(35.6,38.6)$ & 37.8 & $(36.5,39.2)$ & 40.0 & $(38.3,41.7)$ & 43.5 & $(43.2,43.8)$ \\
\hline $\begin{array}{l}\text { Passive and } \\
\text { solitary leisure* }\end{array}$ & - & - & 37.7 & $(33.5,41.9)$ & 37.8 & $(32.7,43.0)$ & 42.6 & $(42.3,42.9)$ \\
\hline
\end{tabular}

* There were no cases that did not participate in passive or solitary leisure at either wave.

Table 6.9: Mean change in CASP-19 quality of life score by transitions in social participation

\begin{tabular}{|c|c|c|c|c|c|c|c|c|}
\hline & \multicolumn{2}{|c|}{$\begin{array}{c}\text { None at wave } 1 \text { or } \\
\text { wave } 2\end{array}$} & \multicolumn{2}{|c|}{ wave 1 only } & \multicolumn{2}{|c|}{ wave 2 only } & \multicolumn{2}{|c|}{ wave $1 \&$ wave 2} \\
\hline & Mean & $(95 \% \mathrm{Cl})$ & Mean & $(95 \% \mathrm{CI})$ & Mean & $(95 \% \mathrm{CI})$ & Mean & $(95 \% \mathrm{Cl})$ \\
\hline $\begin{array}{l}\text { Formal } \\
\text { activity } \\
\text { outside work }\end{array}$ & -1.8 & $(-2.3,-1.2)$ & -1.4 & $(-2.3,-0.5)$ & -0.8 & $(-1.5,0.1)$ & -1.2 & $(-1.5,-0.9)$ \\
\hline $\begin{array}{l}\text { Active and } \\
\text { social leisure }\end{array}$ & -1.7 & $(-3.3,-0.1)$ & -2.7 & $(-3.8,-1.7)$ & 0.2 & $(-1.4,1.0)$ & -1.2 & $(-1.5,-1.0)$ \\
\hline $\begin{array}{l}\text { Passive } \\
\text { and solitary } \\
\text { leisure }\end{array}$ & $N / A$ & N/A & -4.2 & $(-11.0,2.6)$ & -2.6 & $(-0.5,5.8)$ & -1.3 & $(-1.5,-1.1)$ \\
\hline
\end{tabular}


Across all domains of social relationships, those who increased their level of participation between waves experienced a smaller decline in quality of life compared with the other groups (see Table 6.9). This is most notable for participation in the 'active and social leisure' domain, where those indicating new participation at wave 2 had a mean change of 0.2 CASP units compared to -2.7 CASP units for those who ceased participation in this domain between waves.

\subsubsection{Volunteering}

In wave $1,58 \%$ of the over 50 s reported never volunteering, with $15 \%$ volunteering once a week, $11 \%$ once a month and $16 \%$ once a year. The frequency of volunteering has increased slightly between waves; $16 \%$ of the older population now volunteer weekly, $12 \%$ monthly and $18 \%$ yearly, with $54 \%$ never volunteering. In women and men, those who never volunteer have a lower quality of life than those volunteering at least once a year (see Figure 6.14).

For participants who increased their frequency of volunteering between waves, there was no significant change in quality of life score. Conversely, mean CASP-19 quality of life score decreased by almost 1.5 and 1.7 CASP units respectively in those who did not change or who decreased their frequency of volunteering (see Figure 6.15).

Figure 6.14: Mean CASP-19 quality of life score by frequency of volunteering and sex

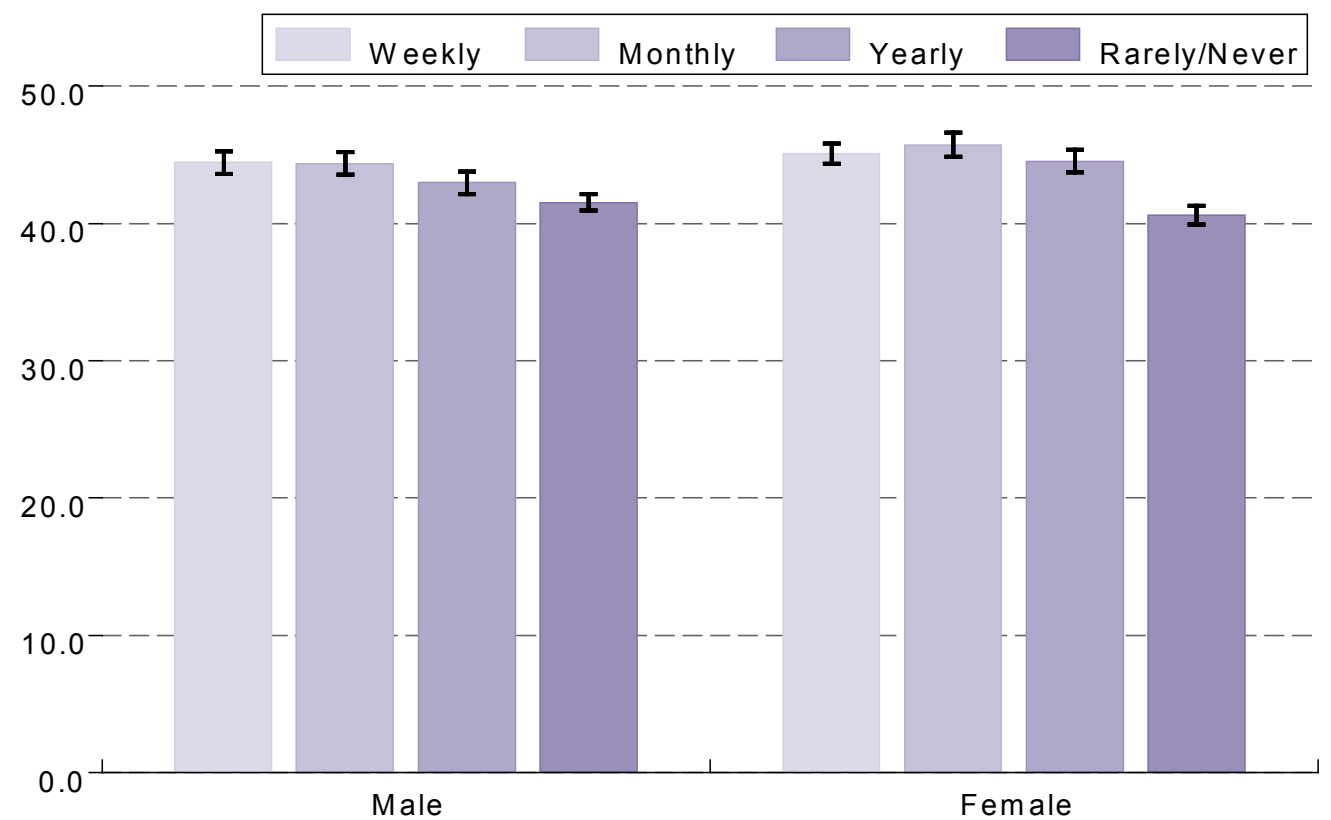

Note. $N=4358$; Missing obs $=65$; Error bars correspond to $95 \%$ confidence intervals 
Figure 6.15: Mean change in CASP-19 quality of life score by transitions in volunteering frequency

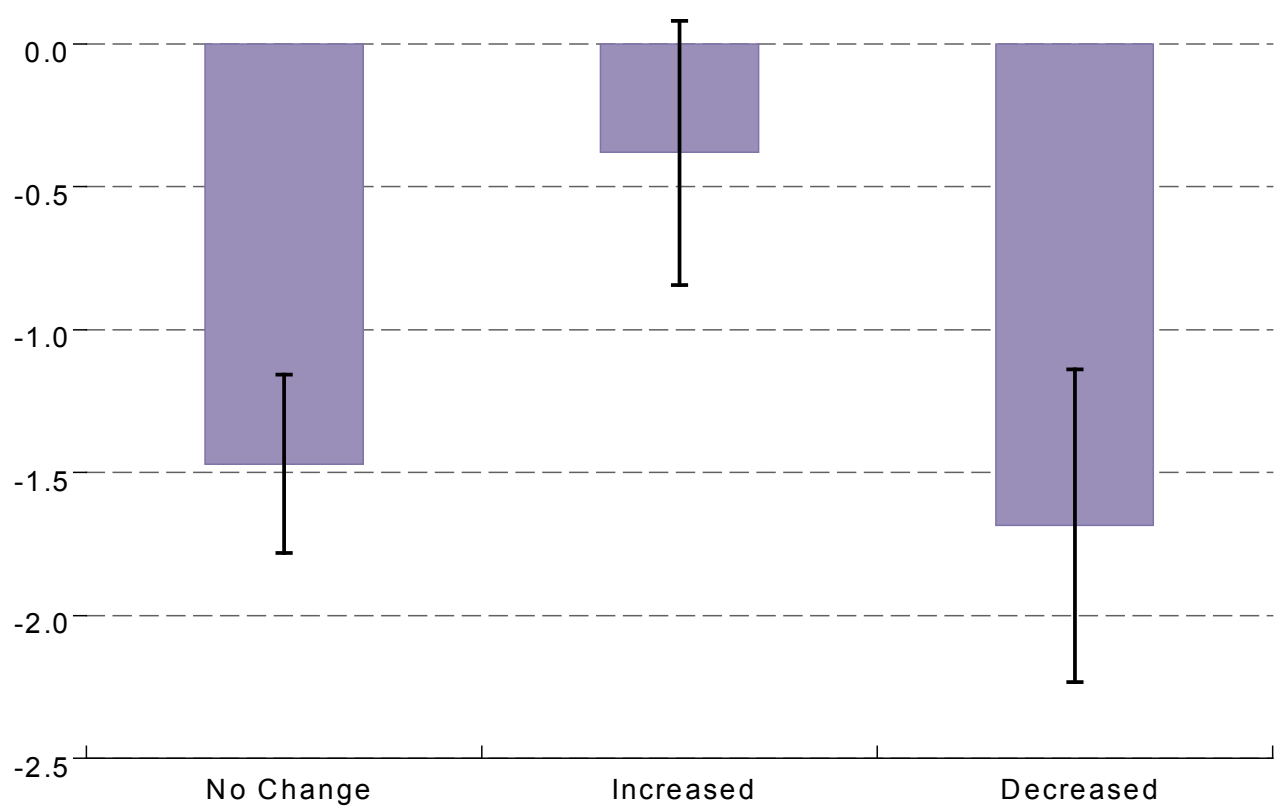

Note. $N=4271$; Missing obs $=152$; Error bars correspond to $95 \%$ confidence intervals

\subsection{Quality of life and caring}

Concern has been expressed about individuals who are caught in the middle between competing work, family and caring responsibilities (30). Previous research from ELSA suggests that providing care for parents and grandchildren is associated with higher quality of life (31). TILDA participants were asked about help given to children and parents, the type of help given, and the time allocated to these activities. Care given to parents includes help with basic personal activities such as dressing, eating and bathing, and help with other activities such as household chores, errands, shopping and transportation. Care given to adult children includes practical household help and taking care of grandchildren (see Appendix 6).

Overall, $10 \%$ of TILDA participants provided care to their parents in the past two years, $24 \%$ to their children and $35 \%$ looked after grandchildren. The type of help given varies by age, with $18 \%$ of participants aged $52-64$ years providing time support to their parents, compared to $3 \%$ in those aged $65-74$ years (see Figure 6.16). Just over a quarter of participants aged less than 75 cared for their children in the past two years, and this decreases to $13 \%$ among those aged 75 years or older. The percentage of participants providing care to grandchildren increases from $33 \%$ at $52-64$ years of age to $46 \%$ at 65 74 years of age, but declines sharply thereafter decreasing to $27 \%$ among those aged 75 
years or older.

Figure 6.16: Proportion providing care to parents and children at wave 2

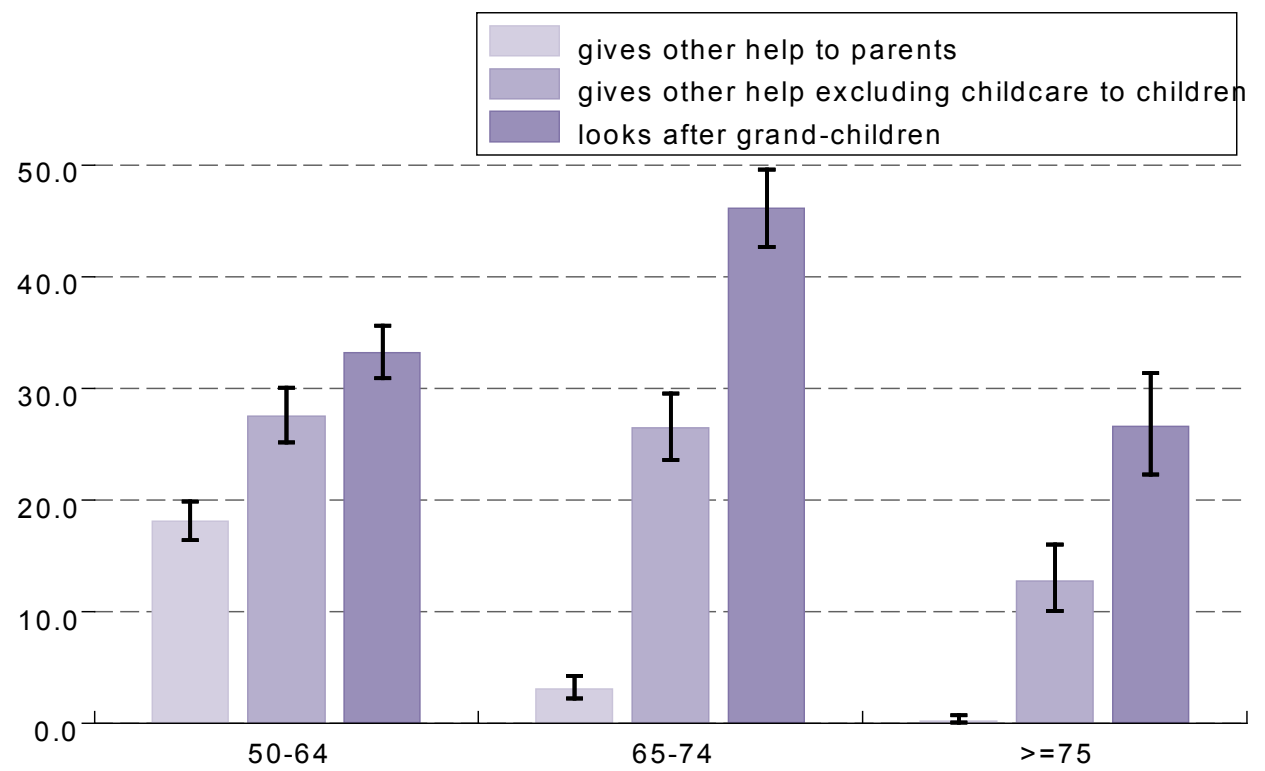

Note. $\mathrm{N}=4423$; Missing obs $=0$; Error bars correspond to $95 \%$ confidence intervals

Research suggests that quality of life varies by caring status (31). Table 6.10 summarises the mean score on the CASP-19 quality of life measure at wave 2 for carers and noncarers. While there is no difference in quality of life between those who do and do not provide care to their parents overall, quality of life is higher in participants aged over 75 who provided care to their parents. Providing care to children is associated with a higher mean quality of life score (mean $=43.7$ vs 42.2 ) and this difference is most marked among those aged 75 years and older. Similarly, analysis reveals that participants who are looking after grandchildren have a higher mean quality of life score (mean score $=43.5$ ) compared with those who do not (mean score $=42.0$ ).

Figures 6.17-6.19 show the mean change in quality of life score by age group between waves for those who (a) provide care to parents in wave 2 (b) provide care to their children in wave 2 and (c) provide care to grandchildren in wave 2. Figure 6.17 shows that caring for a parent is associated with an increase in quality of life between waves among those aged 75 years and older, although it should be acknowledged that these results are based on small numbers and statistically insignificant. Figures 6.18 and 6.19 show that there are no significant differences in the rate of decline in quality of life among those who cared for children and grandchildren compared with those who did not. 
Table 6.10: Mean CASP-19 quality of life score at wave 2 by caring status

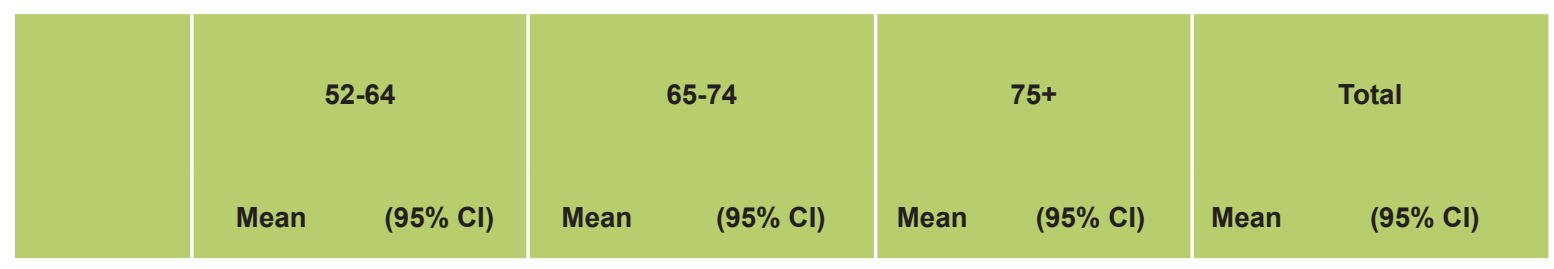

Providing care to parents

\begin{tabular}{|c|c|c|c|c|c|c|c|c|}
\hline No care & 42.8 & $(42.3,43.2)$ & 43.2 & $(42.5,43.9)$ & 41.1 & $(40.3,41.9)$ & 42.5 & $(42.2,42.9)$ \\
\hline $\begin{array}{l}\text { Care } \\
\text { given }\end{array}$ & 42.7 & $(41.8,43.5)$ & 45.0 & $(42.7,47.1)$ & 48.1 & $(42.3,54.0)$ & 42.9 & $(42.1,43.7)$ \\
\hline \multicolumn{9}{|c|}{ Providing care to children } \\
\hline No care & 42.5 & $(42.0,43.0)$ & 42.8 & $(42.0,43.6)$ & 40.8 & $(39.9,41.6)$ & 42.2 & $(41.8,42.6)$ \\
\hline $\begin{array}{l}\text { Care } \\
\text { given }\end{array}$ & 43.4 & $(42.6,44.1)$ & 44.6 & $(43.6,45.6)$ & 43.5 & $(40.9,46.0)$ & 43.7 & $(43.2,44.3)$ \\
\hline \multicolumn{9}{|c|}{ Looking after Grandchildren } \\
\hline No care & 42.6 & $(42.1,43.1)$ & 42.3 & $(41.2,43.3)$ & 40.5 & $(39.5,41.5)$ & 42.0 & $(41.6,42.4)$ \\
\hline $\begin{array}{l}\text { Care } \\
\text { given }\end{array}$ & 43.1 & $(42.4,43.8)$ & 44.4 & $(43.8,45.1)$ & 42.8 & $(41.6,44.0)$ & 43.5 & $(43.0,44.0)$ \\
\hline
\end{tabular}

Figure 6.17: Mean change in CASP-19 quality of life score by caring status at wave 2 (parents)

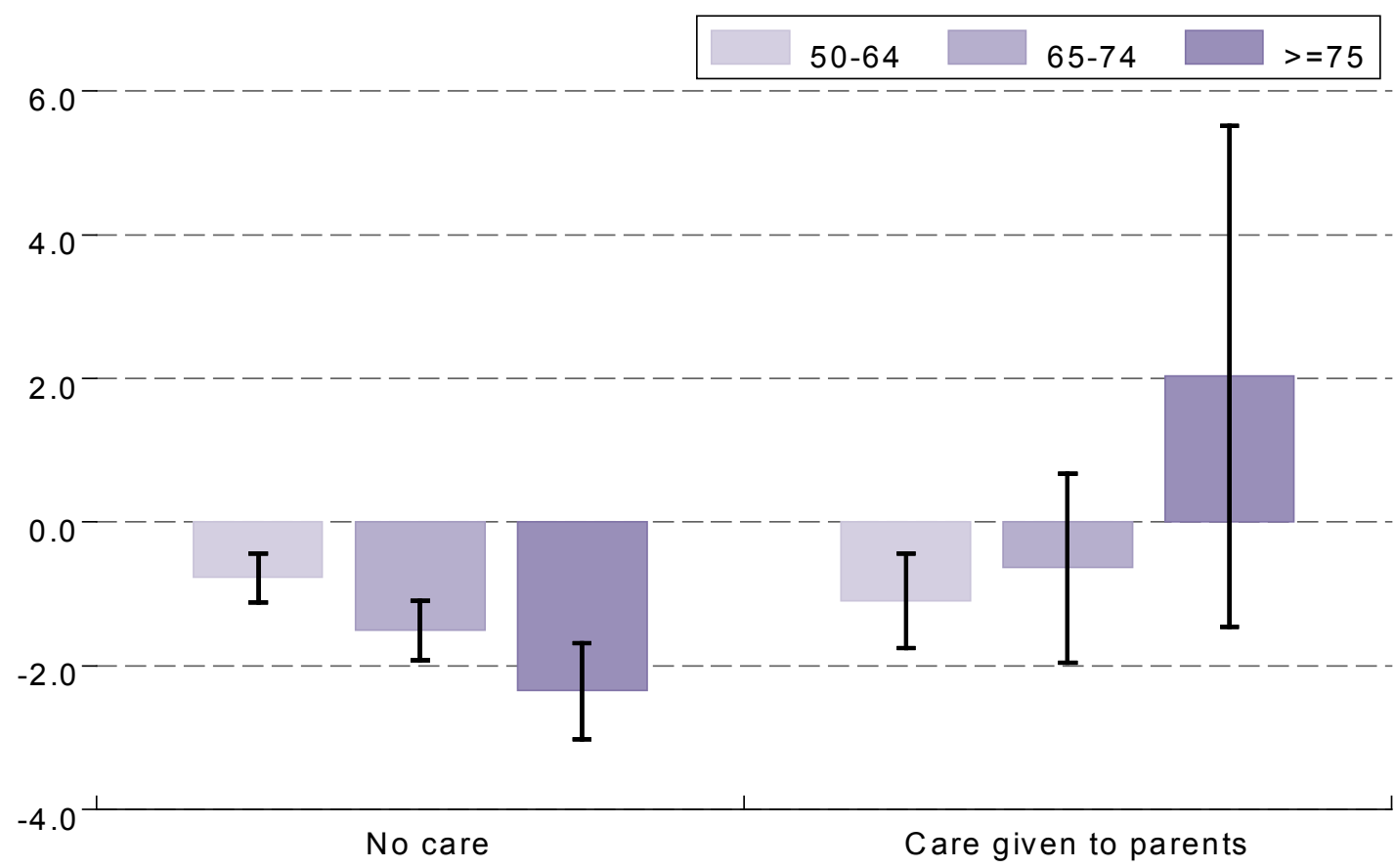

Note. $N=4423 ;$ Missing obs $=0$; Error bars correspond to $95 \%$ confidence intervals 
Figure 6.18: Mean change in CASP-19 quality of life score by caring status at wave 2 (children)

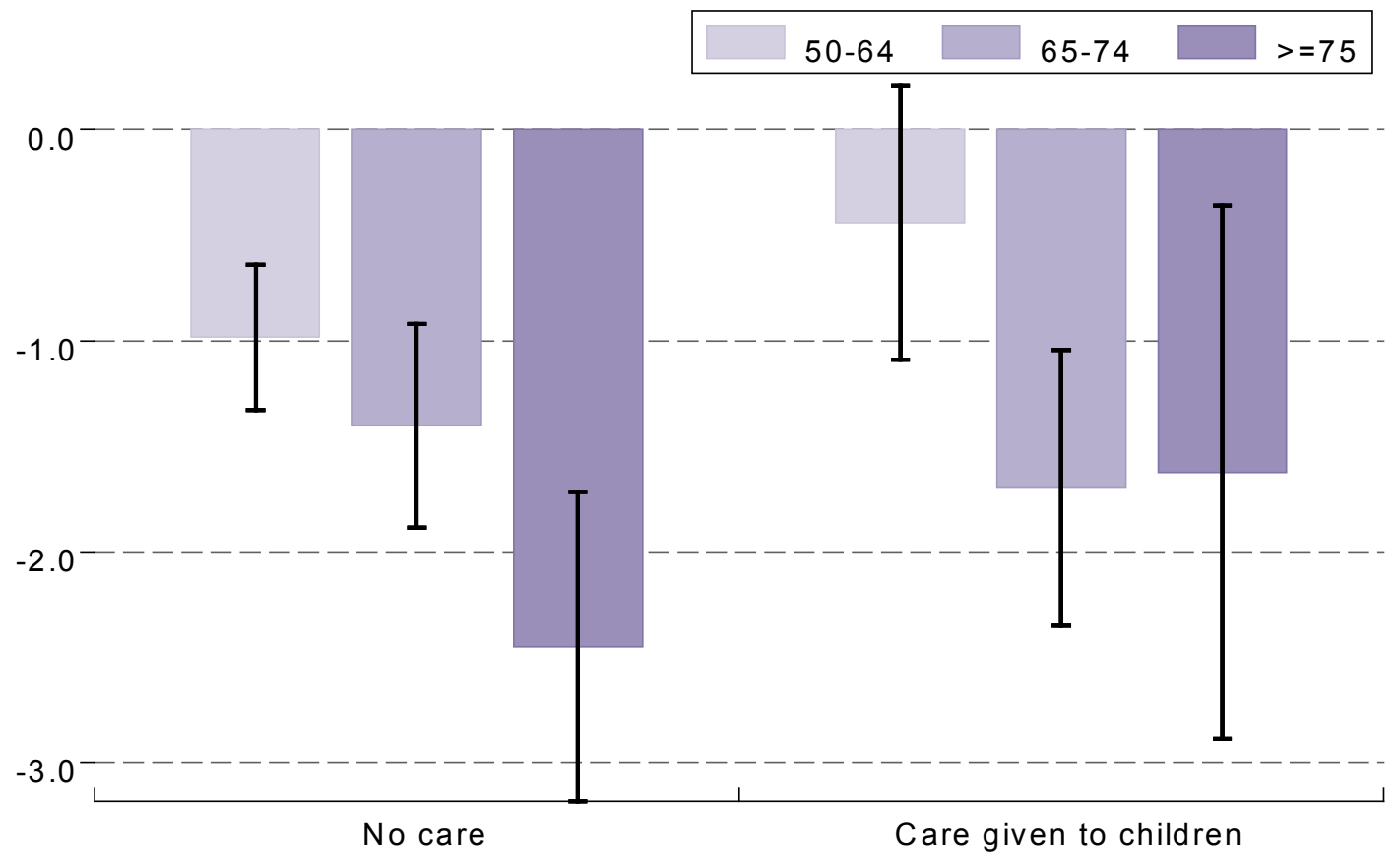

Note. $\mathrm{N}=4423$; Missing obs $=0$; Error bars correspond to $95 \%$ confidence intervals

Figure 6.19: Mean change in CASP-19 quality of life score by caring status at wave 2 (grandchildren)

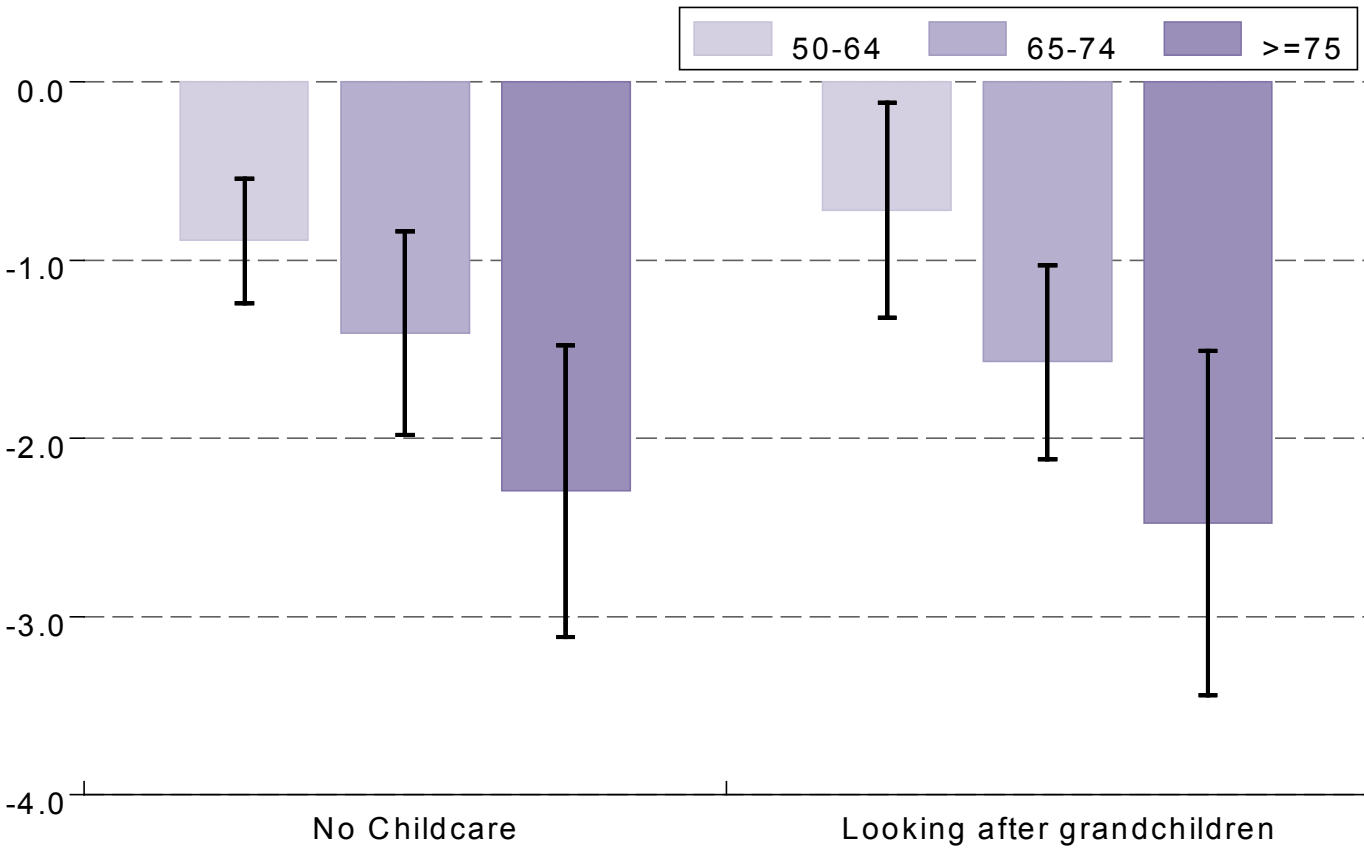

Note. $N=4423$; Missing obs $=0$; Error bars correspond to $95 \%$ confidence intervals 


\subsection{Conclusion}

This chapter has examined change in quality of life among the over 50s in Ireland over a two-year period and explored some of the factors associated with change. Although quality of life declined for the entire sample, the rate of deterioration was greatest for those aged 75 years and over, whose rate of decline was almost 3 times greater compared with those aged 52-64 years. Consistent with previous research in this field, there is a strong relationship between demographic factors such as age and marital status and quality of life. Specifically, participants who are married at both waves rate their quality of life as higher compared with those who were never married, divorced/separated or widowed in both waves. Similarly, participants who are in employment in both waves report higher quality of life than those who are unemployed in both waves.

There is also strong evidence that quality of life is responsive to changes in health and disability over time. For example, participants who indicated that their depressive symptoms had remitted between waves experienced a significant improvement in quality of life. Similarly, participants who report that they are no longer troubled by disability (in terms of ADLs) experienced a large improvement in quality of life relative to the average for the sample. These findings suggest that initiatives designed to deter functional decline and disability through, for example, the use of assistive technologies (e.g, mobility scooters) will ensure that quality of life can be sustained into later life.

This chapter also explored the extent to which quality of life is responsive to changes in social participation and social relationships among the older population. Persons with strong social networks, who engage in various types of social relationships and who volunteer regularly have a higher quality of life score than less socially active participants. Those aged 75 years or older are less socially integrated than those aged 65-74. Interestingly, the young old (aged 52-64) are engaged in intimate social relationships to a much lesser extent than the over 65s. Moreover, there was some evidence to suggest that caring for children and grandchildren is associated with higher self-rated quality of life.

It should be acknowledged that the factors that influence quality of life do not operate in isolation but interact over time to determine one's trajectory. For example, Blane et al found that the impact of health on quality of life was mediated via its effect on functional limitation (32). It is entirely possible that there are spill-over effects whereby a high quality of life in one sphere positively influences satisfaction in other domains. Moreover, it could be argued that quality of life varies not only as a function of one's demographic and personal circumstances (e.g. health, socio-economic status, social participation) but also 
involves a re-calibration of goals and aspirations to personal competencies and contextual constraints as people age (33). Future work employing multivariate statistical methods will allow for a more thorough analysis of the interplay between these different factors and an assessment of which of these impinge most heavily on quality of life within a longitudinal context.

\section{References}

1. WHO E. Strategy and action plan on healthy ageing for Europe, 2012-2020. Copenhagen: World Health Organisation, 2012.

2. O'Shea E. Healthy Ageing in Ireland: Policy, Practice and Evaluation. Dublin: National Council on Ageing and Older People, 2003.

3. Netuveli G, Blane D. Quality of life in older ages. British Medical Bulletin. 2008;85(1):113-26.

4. Fernández-Ballesteros R. Quality of life in old age: Problematic issues. Applied Research in Quality of Life. 2011;6(1):21-40.

5. Depp CA, Jeste DV. Definitions and predictors of successful aging: a comprehensive review of larger quantitative studies. FOCUS: The Journal of Lifelong Learning in Psychiatry. 2009;7(1):137-50.

6. Jivraj S, Nazroo J, Vanhoutte B, Chandola T. Age, ageing and subjective wellbeing in later life. The Cathie Marsh Centre for Census and Survey Research.

7. Netuveli G, Wiggins RD, Hildon Z, Montgomery SM, Blane D. Quality of life at older ages: evidence from the English longitudinal study of aging (wave 1). Journal of Epidemiology and Community Health. 2006;60(4):357-63.

8. Layte R, Sexton E, Savva G. Quality of life in older age: evidence from an Irish cohort study. J Am Geriatr Soc. 2013;61(2):12198.

9. Costanza R, Fisher B, Ali S, Beer C, Bond L, Boumans R, et al. Quality of life: An approach integrating opportunities, human needs, and subjective well-being. Ecological economics. 2007;61(2):267-76.

10. Diener E, Suh E. Measuring quality of life: Economic, social, and subjective indicators. Social indicators research. 1997;40(1-2):189-216.

11. Hyde M, Wiggins RD, Higgs $P$, Blane DB. A measure of quality of life in early old age: the theory, development and properties of a needs satisfaction model (CASP-19). 
Aging Ment Health. 2003;7(3):186-94.

12. Howel D. Interpreting and evaluating the CASP-19 quality of life measure in older people. Age and Ageing. 2012.

13. McGee H, Morgan K, Hickey A, Burke H, Savva G. Quality Of Life And Beliefs About Ageing. In: Barrett A, Savva G, Timonen V, Kenny RA, editors. Fifty Plus in Ireland 2011: The Irish Longitudinal Study on Ageing; 2011. p. 265-92.

14. Zaninotto P, Falaschetti E, Sacker A. Age trajectories of quality of life among older adults: results from the English Longitudinal Study of Ageing. Quality of Life Research. 2009;18(10):1301-9.

15. Myers DC. 19 Close Relationships and Quality of Life. Well-being: The foundations of hedonic psychology. 2003:374.

16. Kim JE, Moen P. Is retirement good or bad for subjective well-being? Current Directions in Psychological Science. 2001;10(3):83-6.

17. Freedman VA, Martin LG, Schoeni RF. Recent trends in disability and functioning among older adults in the united states: A systematic review. JAMA. 2002;288(24):3137-46.

18. WHO E. What are the main risk factors for disability in old age and how can disability be prevented? World Health Organisation, 2003.

19. Netuveli G, Wiggins RD, Hildon Z, Montgomery SM, Blane D. Functional limitation in long standing illness and quality of life: evidence from a national survey. BMJ. 2005;331(7529):1382-3.

20. Gaugler JE, Duval S, Anderson KA, Kane RL. Predicting nursing home admission in the US: a meta-analysis. BMC geriatrics. 2007;7(1):13.

21. Pyne JM, Patterson TL, Kaplan RM, Ho S, Gillin JC, Golshan S, et al. Preliminary longitudinal assessment of quality of life in patients with major depression.

Psychopharmacol Bull. 1997;33(1):23-9.

22. Rapaport MH, Clary C, Fayyad R, Endicott J. Quality-of-life impairment in depressive and anxiety disorders. American Journal of Psychiatry. 2005;162(6):1171-8.

23. Radloff LS. The CES-D Scale. Applied Psychological Measurement. 1977;1(3):385401.

24. Pinquart M, Sorensen S. Influences of Socioeconomic Status, Social Network, and 
Competence on Subjective Well-Being in Later Life- A Meta-Analysis. Psychology and Aging. 2000;15(2):187-224.

25. Netuveli G, Wiggins RD, Hildon Z, Montgomery SM, Blane D. Quality of life at older ages: evidence from the English longitudinal study of aging (wave 1). J Epidemiol Community Health 2006;60:357-63.

26. Berkman LF, Syme SL. Social netwroks, host resistance, and mortality: a nine-year follow-up study of Alameda County residents. Am J Epidemiol. 1979;109:186-204.

27. Siegrist J, Wahrendorf M. Participation in socially productive activities and quality of life in early old age: findings from SHARE. Journal of European Social Policy. 2009;19(4):317-26.

28. Ichida Y, Hirai H, Kondo K, Kazachi I, Takeda T, Endo H. Does social participation improve self-rated health in the older population? A quasi-experimental intervention study Social science \& Medicine. 2013;94:83-90.

29. House J, Robbins C, Metzner $\mathrm{H}$. The association of social relationships and activities with mortality: Prospective evidence from the Tecumseh Community Health Study. Am J Epidemiol. 1982;116:123-40.

30. Evandrou M, Glaser K, Henz U. Multiple role occupancy in midlife: Balancing work and family life in Britain. The Gerontologist. 2002;42(6):781-9.

31. Banks J, Breeze E, Crawford R, Demakakos P, Oliveira Cd GE, Green R, et al. Financial circumstances, health and well-being of the older population in England. The 2008 English Longitudinal Study of Ageing (Wave 4). 2010.

32. Blane D, Netuveli G, Montgomery SM. Quality of life, health and physiological status and change at older ages. Social science \& medicine. 2008;66(7):1579-87.

33. Baltes MM, Lang FR. Everyday functioning and successful aging: The impact of resources. Psychology and aging. 1997;12(3):433. 


\section{Appendix 6: Questions on caring for parents and children in TILDA}

Care given to parents was assessed with the following questions:

\section{Care given to parents in activities of daily living (ADL)}

"In the last two years, because of health problems, did you help your parents/father/ mother regularly with basic personal activities such as dressing, eating and bathing?"

"Roughly how many hours did you spend helping them/him/her in an average week?"

\section{Care given to parents in instrumental activities of daily living (IADL)}

"In the last two years, did you help your parents/father/mother regularly with other things such as household chores, errands, shopping, transportation etc?"

"Roughly how many hours did you spend helping them/him/her in an average week?"

Care given to adult children was assessed with the following questions:

\section{Non-financial help to children ${ }^{3}$}

"In the last 2 years, excluding childcare, have you spent at least 1 hour a week helping your adult children and/or grandchildren with things like:

1. Practical household help: help with home repairs, gardening, transportation, shopping, household chores

2. Help with paperwork, such as filling out forms, settling financial or legal matters"

"About how many hours per month on average did you provide such help to your children?"

\section{Taking care of grandchildren:}

"In the last two years, have you spent at least 1 hour a week taking care of grandchildren or great-grandchildren (who live outside your own household)?"

"About how many hours on average per month did you spend taking care of your grandchildren or great-grandchildren (who live outside your own household)?"

3. This refers only to help provided to children outside the household i.e. help provided to a coresident child was excluded. 


\section{Methodology}

\section{Cara Dooley}

\section{Contents}

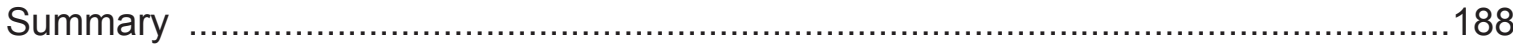

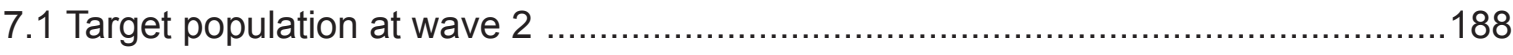

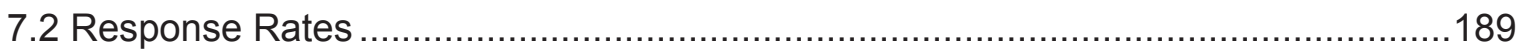

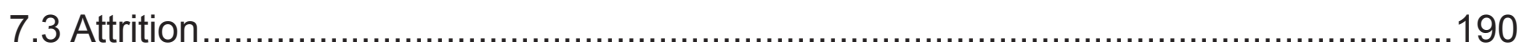

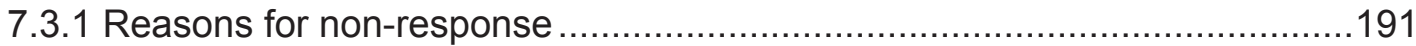

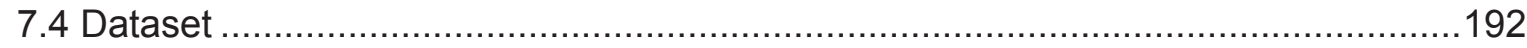

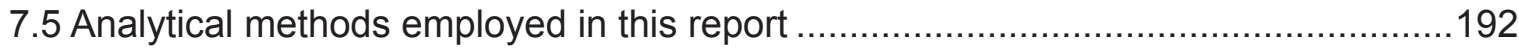

7.5.1 Confidence intervals and statistical significance .....................................192

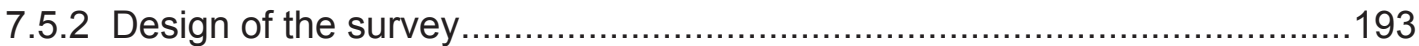

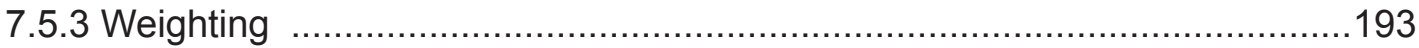

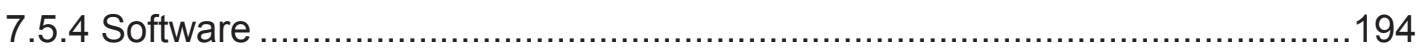

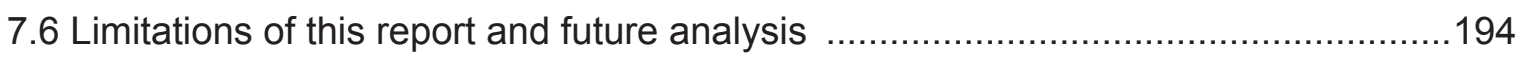

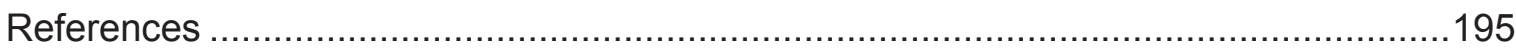




\section{Methodology}

\section{Summary}

- At wave 1, TILDA recruited a stratified clustered sample of 8178 individuals representative of the community dwelling Irish population aged 50 years and over. Younger spouses and partners were also invited to participate, primarily to provide information regarding family and financial circumstances.

- At wave 2, TILDA invited all living wave 1 respondents to undertake an extensive faceto-face computer-assisted personal interview (CAPI). Respondents were also invited to complete a self-completion questionnaire (SCQ).

- The overall response rate to wave 2 of the study was $86 \%$. Participants who had attended the health assessment at wave 1 and/or who had returned a self-completion questionnaire were more likely to participate in the second wave of the study

- Proxy, end-of-life and institutional interviews were introduced to the study at wave 2. In total, 155 end-of-life interviews, 80 proxy interviews and 22 institutional interviews were completed.

\subsection{Target population at wave 2}

The selection of the original wave 1 TILDA sample is described in detail elsewhere (1, 2). In March 2012, TILDA interviewers returned to each of the 6282 households that participated in the first wave of the study. Advance invite letters were sent to each of the original 8504 respondents (8175 eligible respondents and 329 younger partners) inviting them to take part in the next wave of the study. No active recruitment of new respondents was carried out; however, respondents who were eligible in wave 1 but had declined to participate were canvassed to join the study at wave 2. In addition, new spouses and partners of core respondents were invited to participate. This led to 170 new respondents at wave 2 .

Each respondent completed a computer-assisted personal interview (CAPI) in their own home which included detailed questions on health, social and economic circumstances. 
The questions were mainly a repeat of the questions asked in wave 1; however, wave 2 also included some new and amended questions. Where there was more than one respondent in a household, respondents were asked to nominate a financial and a family respondent. These 'types' of respondent represented members of the household who were most knowledgeable in financial and family matters and who agreed to answer questions in these domains on behalf of the household. The financial and family respondents may be the same individual.

At the end of the CAPI interview, each respondent was asked to fill in a self-completion questionnaire (SCQ) and return it by post (in a prepaid envelope) to the TILDA study. This questionnaire asked a range of potentially sensitive questions, including questions on quality of life, emotional well-being and health behaviours. Unlike wave 1 of the study, there was no health assessment at wave 2 .

Apart from the standard in-person CAPI interview, three new types of interview (proxy, end-of-life and institutional) were introduced at wave 2 . While every effort was made to achieve in-person interviews, those respondents who were deemed unable to participate in an interview due to a physical or cognitive impairment had a proxy interview. 80 proxy interviews were conducted in wave 2 and were found to be well received by family and carers of respondents. In addition, 155 end-of-life interview were undertaken with relatives, friends or carers of core TILDA members who had died since participating in wave 1 of the study. TILDA participants who had moved into a residential or nursing home by wave 2 were offered an institutional interview $(n=22)$.

\subsection{Response Rates}

Of the 8175 original wave 1 respondents, 6995 completed an interview at wave 2 . The wave 2 response rate is calculated as the percentage of wave 2 CAPI interviews that were successfully obtained from the original wave 1 respondents. This gives an individual response rate of $86 \%$. In addition, there were 170 interviews with new respondents. 150 of these new respondents met the age criteria for inclusion at wave 1 and 20 were younger partners and spouses who were now resident in the household. Response rates by age and sex are given in Table 7.1 below. While the response rates are similar for males and females, the over 75 s were less likely to complete an interview at wave 2 of the study. 
Table 7.1: Wave 2 response rates by age and sex

\begin{tabular}{|c|c|c|c|}
\hline \multicolumn{4}{|c|}{$\begin{array}{c}\text { wave } 2 \text { Response rate } \\
\%\end{array}$} \\
\hline & Male & Female & Total \\
\hline$<52$ & 94.4 & 87.4 & 88.1 \\
\hline $52-64$ & 87.7 & 87.3 & 87.5 \\
\hline $65-74$ & 85.9 & 87.9 & 86.9 \\
\hline $75+$ & 79.3 & 78.7 & 79 \\
\hline Total & 85.5 & 85.8 & 85.7 \\
\hline
\end{tabular}

\subsection{Attrition}

Table 7.2 examines how participation or attrition at wave 2 is influenced by study engagement at wave 1 and age.

Table 7.2 Wave 1 study engagement by wave 2 participation and age

\begin{tabular}{|c|c|c|c|c|c|c|c|c|}
\hline & $\begin{array}{c}\text { No health } \\
\text { assessment } \\
\%\end{array}$ & $\begin{array}{l}\text { Health } \\
\text { centre } \\
\text { record } \\
\%\end{array}$ & $\begin{array}{c}\text { Home } \\
\text { assessment } \\
\text { record } \\
\%\end{array}$ & Total & $\begin{array}{c}\text { No } \\
\text { Wave } 1 \\
\text { SCQ } \\
\%\end{array}$ & $\begin{array}{c}\text { Wave } 1 \\
\text { SCQ } \\
\%\end{array}$ & Total & $\begin{array}{l}\text { Number } \\
\text { in sample }\end{array}$ \\
\hline \multicolumn{9}{|l|}{$52-64$} \\
\hline Attriter & 56 & 35 & 9 & 100 & 31 & 69 & 100 & 516 \\
\hline $\begin{array}{l}\text { In Both } \\
\text { Waves }\end{array}$ & 20 & 74 & 6 & 100 & 13 & 87 & 100 & 3603 \\
\hline Total & 25 & 69 & 6 & 100 & 15 & 85 & 100 & 4119 \\
\hline \multicolumn{9}{|l|}{$65-74$} \\
\hline Attriter & 58 & 31 & 11 & 100 & 37 & 63 & 100 & 310 \\
\hline $\begin{array}{l}\text { In Both } \\
\text { Waves }\end{array}$ & 21 & 70 & 9 & 100 & 10 & 90 & 100 & 2063 \\
\hline Total & 26 & 65 & 9 & 100 & 13 & 87 & 100 & 2373 \\
\hline \multicolumn{9}{|l|}{$75+$} \\
\hline Attriter & 64 & 16 & 21 & 100 & 41 & 59 & 100 & 354 \\
\hline $\begin{array}{l}\text { In Both } \\
\text { Waves }\end{array}$ & 32 & 44 & 24 & 100 & 13 & 87 & 100 & 1329 \\
\hline Total & 39 & 38 & 23 & 100 & 19 & 81 & 100 & 1683 \\
\hline \multicolumn{9}{|l|}{ All } \\
\hline Attriter & 59 & 28 & 13 & 100 & 36 & 64 & 100 & 1180 \\
\hline $\begin{array}{l}\text { In Both } \\
\text { Waves }\end{array}$ & 23 & 67 & 10 & 100 & 12 & 88 & 100 & 6995 \\
\hline Total & 28 & 62 & 11 & 100 & 15 & 85 & 100 & 8175 \\
\hline
\end{tabular}


As part of the wave 1 interview, all respondents were invited to a health centre, in either Dublin or Cork, for a comprehensive health assessment. Participants who were unable or unwilling to attend a health centre were offered a modified assessment in their own home. As can be seen in Table 7.2, respondents who attrited from the study were less likely to have had a health assessment in wave $1(59 \%)$. Of those who took part in both waves of the study, $23 \%$ had not had a health assessment in wave 1 . The pattern is similar for those who returned an SCQ in wave 1.

The self-completion questionnaire was completed by $84 \%$ of the wave 2 respondents. The response rates were similar for the new respondents and those who responded to both waves of the study. No age or sex differences were observed for completion of the SCQ (see Table 7.3 below).

Table 7.3 Self Completion Questionnaire response rates by age and sex

\begin{tabular}{|c|c|c|c|}
\hline \multicolumn{4}{|c|}{$\begin{array}{c}\text { Self completion record present } \\
\qquad \%\end{array}$} \\
\hline & Male & Female & Total \\
\hline$<52$ & 75 & 86.1 & 84.8 \\
\hline $52-64$ & 82.8 & 86.2 & 84.7 \\
\hline $65-74$ & 85.9 & 88.9 & 87.5 \\
\hline $75+$ & 77.6 & 77.2 & 77.4 \\
\hline Total & 82.7 & 85.3 & 84.2 \\
\hline
\end{tabular}

\subsubsection{Reasons for non-response}

Table 7.4 summarizes reasons for non-response at wave 2. A total of 205 of the 1180 individuals who did not participate in wave 2 were deceased. An end-of-life interview was successfully completed in 155 cases $(76 \%)$. Those lost to follow-up $(n=166)$ were typically respondents who had moved outside of the island of Ireland, although occasionally the respondents had moved within Ireland and were untraceable. 
Table 7.4 Reasons for non-response

\begin{tabular}{|l|c|}
\hline Reason for Attrition & Number \\
\hline Deceased & 205 \\
\hline Lost to Follow-up & 166 \\
\hline Refusal & 809 \\
\hline Total & 1180 \\
\hline
\end{tabular}

\subsection{Dataset}

All of the results in this report are based on the TILDA dataset version 2.4.0. This dataset includes CAPI data from all 7455 TILDA wave 2 respondents (from 6266 households), of whom 7145 were aged 52 and over. These 7145 respondents form the base sample for this report. Various subsamples of this sample are used throughout the report, most notably the 6995 respondents who responded to both waves of the study. These subsamples are defined in the relevant chapters.

Data from the 310 younger respondents are incorporated where measures are taken at the level of the household or the couple. The dataset also includes the 6274 SCQ records for the wave 2 sample, 6011 for those aged 52 and over and 263 for the younger partners. The dataset will be archived in early 2014 in the Irish Social Science Data Archive at University College Dublin (UCD) (http://www.ucd.ie/issda/data/tilda/).

\subsection{Analytical methods employed in this report}

For estimates to be unbiased and for their uncertainty to be correctly determined, analyses used to generate the findings in this report incorporate the design of the study and the pattern of non-response (missing data). Statistical methods used to calculate the estimates presented in this report are described below.

\subsubsection{Confidence intervals and statistical significance}

The majority of the estimates in this report are the percentages (or proportions) of older people falling into various groups or averages (mean or median) of quantities.

Each estimate based on the TILDA sample is an estimate of the true value in the population. The TILDA sample is a random sample of the population of interest, so there 
is some uncertainty in these estimates due to the sampling process. For this reason, the majority of the estimates in this report are provided with a $95 \%$ confidence interval reflecting this uncertainty. The confidence intervals can be interpreted as the plausible range for the true value in the target population. Smaller confidence intervals indicate more precise estimates.

The formal interpretation of the $95 \%$ confidence interval is that in repeated sampling $95 \%$ of the confidence intervals calculated will include the true population parameter.

\subsubsection{Design of the survey}

The original design of TILDA used a RANSAM sampling plan and is described in detail in the TILDA design report (1). This used stratified sampling to select the 640 clusters used for recruitment to TILDA. This stratification ensured an efficient and population representative sample, by stratifying 3155 clusters by socio-economic status and geography (1). This stratification is incorporated into the estimation procedures in this report, and helps explain variability among individuals and can improve the precision of estimators.

The geographic clustering increased the efficiency of the data collection process, resulting in a lower fieldwork cost per interview. However, clustering also reduces the effective contribution of each individual taking part, since there is likely to be some correlation in the responses of individuals from the same cluster, due to their similar geographic and socioeconomic backgrounds. The effect of this is to reduce the precision of estimates, reflected by wider confidence intervals. The confidence intervals included in this report incorporate the effects of stratification and clustering on precision.

\subsubsection{Weighting}

Response rates to both wave 1 and wave 2 of the study are non-random, that is, the response rates to both waves of the study vary over certain subgroups of the population. This systematic difference in how certain sections of population respond to the survey can introduce bias into our estimates. For this reason, the analysis in this report is weighted to reduce the bias due to this systematic difference. This weighting ensures that subgroups in the sample are included proportionally, in the calculation of the estimates, to the number in that subgroup present in the population of Ireland.

Cross-sectionally, the dataset contains two main weights; a CAPI weight and an SCQ 
weight. Weights applied to the main (CAPI) sample were estimated by comparing the proportion of individuals in the sample across age, sex and highest level of education attained, with the proportion in the population with the same characteristics. The proportion in the population was estimated using the Quarterly National Household Survey (QNHS 2012).

The SCQ weight is then calculated by dividing the CAPI weight by the probability of the respondent filling in and returning the $S C Q$ in wave 2 . This probability is calculated using a logistic regression model. Factors in the model which were shown to affect the return of the SCQ included marital and employment status, mental health and whether the respondent lived in an urban or rural area.

Attrition (or longitudinal) weights were also calculated for longitudinal analysis of the data. These weights corrected for the systematic difference in attrition rates over subgroups and reduced the bias caused by this difference in attrition rates. These weights are calculated based on the reciprocal of the probability of a wave 1 respondent taking part in wave 2 . This probability is calculated using a logistic regression model. Factors in the model which were shown to affect attrition included measures of cognitive and behavioural health, marital status and several health measures.

The analyses for many sections of this report were based on subsamples of the overall TILDA sample. For these sections, a separate weight was calculated for each subsample. In the obesity chapter, for example, the analysis is based on a subsample of respondents who completed the wave 2 CAPI interview and the wave 1 health assessment (BMI measure).

A report explaining all of the TILDA weights used in this report will be available mid-2014 with the public dataset (Irish Social Science Data Archive) and thereafter on the TILDA website.

\subsubsection{Software}

All analysis presented in this report was conducted using Stata 12.0.

\subsection{Limitations of this report and future analysis}

The report has described the health, well-being and economic circumstances of over $52 \mathrm{~s}$ in Ireland. These analyses are preliminary and of a descriptive nature. Future analysis of 
the dataset, will allow for more complex statistical modelling, which will provide more in depth explorations that are outside the scope of this report.

Although the TILDA sample is representative of community dwelling adults aged over 52 in Ireland, it is not, as yet, fully representative of those who have moved to an institutional setting. TILDA initially recruited only those who were community dwelling; however, respondents who moved to an institutional setting were interviewed at wave 2 and will be interviewed at all subsequent waves of TILDA. As of wave 2, only 22 respondents had participated in an institutional interview. As the study continues, this number will increase, allowing for greater analysis of this important subsample of the older population.

TILDA has now collected two waves of data, presenting the first opportunity for longitudinal investigation of research questions. This is the first report to document longitudinal changes in the TILDA population. However, changes presented in this report are over just two years and for many measures and questions this is not nearly long enough to observe any substantive or robust change. As the number of data waves increases, this change will be measured more precisely and change over time will be better quantified. As the study matures, causal relationships can increasingly be examined and our understanding of the ageing process greatly enhanced.

\section{References}

1. Kenny R, Whelan B, Cronin H, Kamiya Y, Kearney P, O'Regan C, et al. The Design of the Irish Longitudinal Study on Ageing. Dublin: Trinity College Dublin; 2010.

2. Barrett A, Savva G, Timonen V, Kenny R. Fifty Plus in Ireland 2011. First results from the Irish Longitudinal Study on Ageing (TILDA). Dublin: The Irish Longitudinal Study on Ageing. 
